Florida International University

FIU Digital Commons

2-21-2019

\title{
The Validity and Reliability of an Adapted Problem-Solving Inventory (PSI): The Exploration of Paradoxical Problem-Solving as a Means to Manage Organizational Conflict
}

Salma A. Hadeed

Florida International University, smoha003@fiu.edu

Follow this and additional works at: https://digitalcommons.fiu.edu/etd

Part of the Adult and Continuing Education Commons, Educational Leadership Commons, and the Training and Development Commons

\section{Recommended Citation}

Hadeed, Salma A., "The Validity and Reliability of an Adapted Problem-Solving Inventory (PSI): The Exploration of Paradoxical Problem-Solving as a Means to Manage Organizational Conflict" (2019). FIU Electronic Theses and Dissertations. 4059.

https://digitalcommons.fiu.edu/etd/4059

This work is brought to you for free and open access by the University Graduate School at FIU Digital Commons. It has been accepted for inclusion in FIU Electronic Theses and Dissertations by an authorized administrator of FIU Digital Commons. For more information, please contact dcc@fiu.edu. 


\title{
FLORIDA INTERNATIONAL UNIVERSITY
}

\author{
Miami, Florida
}

\section{THE VALIDITY AND RELIABILITY OF AN ADAPTED PROBLEM-SOLVING INVENTORY (PSI): THE EXPLORATION OF PARADOXICAL PROBLEM- SOLVING AS A MEANS TO MANAGE ORGANIZATIONAL CONFLICT}

\author{
A dissertation submitted in partial fulfillment of \\ the requirements for the degree of \\ DOCTOR OF EDUCATION
}

in

ADULT EDUCATION AND HUMAN RESOURCE DEVELOPMENT

by

Salma A. Hadeed 
To: Dean Michael R. Heithaus

College of Arts, Sciences and Education

This dissertation, written by Salma A. Hadeed, and entitled The Validity and Reliability of an Adapted Problem-Solving Inventory (PSI): The Exploration of Paradoxical Problem-Solving as a Means to Manage Organizational Conflict, having been approved in respect to style and intellectual content, is referred to you for judgment.

We have read this dissertation and recommend that it be approved.

Teresa Lucas

Judith Bernier

Haiying Long, Co-Major Professor

Thomas Reio, Co-Major Professor

Date of Defense: February 21, 2019

The dissertation of Salma A. Hadeed is approved.

Dean Michael R. Heithaus

College of Arts, Sciences and Education

Andrés G. Gil

Vice President for Research and Economic Development and Dean of the University Graduate School

Florida International University, 2019 
(C) Copyright 2019 by Salma A. Hadeed

All rights reserved. 


\section{DEDICATION}

To my dad, Dr. Wahid Mohammed, who never stopped believing in me. To my late mother, Fazilla Mohammed, who inspired me to always achieve my goals. To my sisters, Nadia Mohammed and Seema Mohammed, you always made me want to reach for the stars.

I love you. 


\section{ACKNOWLEDGMENTS}

This dissertation could not have been possible without the help of God. I thank him for giving me the strength, courage and determination to survive these years with my research.

I would like to thank my committee, but most importantly my chair, Dr. Thomas Reio, thank you for all the support and mentoring along the way. I appreciate and will always be thankful for all of the mentoring that he provided. He has been a true leader in my journey and without his guidance, I would not have been able to create such a study. I would also like to thank my co-chair Dr. Long, for sitting with me almost every week to discuss my methods and findings. Her on-going support from the time I took her quantitative classes to the end of my journey will always be appreciated. Thanks to her, statistical analysis will forever be planted in my memory. Dr. Lucas, I will always appreciate your feedback and guidance with my qualitative research. Your perspectives

and attention to detail in qualitative research only strengthened my study. Lastly, I would like to thank Dr. Bernier. She was not only a committee member, but a mentor throughout my research. Our conversations in her office and during our walks after teaching her class, provided me with insightful ideas that added value to my research. I would always be thankful for her perspectives on conflict management and her suggestions that made me think outside the box. Thank you for always lending me books to increase my knowledge on conflict management. 
A special acknowledgement to my extended family, also known as \#coolcohort, Jonathan Abdullah and Jocelyn James. We started this journey together and with the support of these two, I would not have been able to accomplish my goals.

A special thanks to other colleagues who were with me along the way: my Comparative and International Education Society team (Dr. Hilary Landorf, Catherine Wadley, Sherrie Beeson, Ryan Blanton, Connie Penczak and Mariusz Galczynski), Gail Hansen, Michelle Osborne, Aisha Usher, Diana Santangelo, Ayanna Morgan and Rochelle Patten. Our conversations and small meetings/lunches/dinners will always be appreciated. I must also thank the individuals who participated in my research, during each phase.

Lastly, I would like to thank my family and Suzette. My mother, though she is not with us, always told me to follow my dreams. My father who always believed in me, provided on-going support during this journey. He and my sisters, Nadia Mohammed and Seema Mohammed, encouraged me and provided unconditional love. Suzette, without you by my side, with us literally writing together, this journey would not have been possible. 


\author{
ABSTRACT OF THE DISSERTATION \\ THE VALIDITY AND RELIABILITY OF AN ADAPTED PROBLEM-SOLVING \\ INVENTORY (PSI): THE EXPLORATION OF PARADOXICAL PROBLEM- \\ SOLVING AS A MEANS TO MANAGE ORGANIZATIONAL CONFLICT \\ by
}

Salma A. Hadeed

Florida International University, 2019

Miami, Florida

Professor Thomas Reio, Co-Major Professor

Professor Haiying Long, Co-Major Professor

The mixed methods research design was used to develop and validate an adapted survey that incorporates the paradoxical problem-solving concept under the context of social conflict theory, and to provide employees and employers more creative techniques to manage organizational conflict. One aspect of social conflict theory, problem-solving theory, focused on how individuals respond when confronted with unfamiliar tasks (Newell, Shaw \& Simon, 1958a).

A concurrent mixed methods design was used to determine validity and reliability evidence. The study included of four phases. Phase One was a qualitative phase that utilized 11 experts, examining for validity evidence of test content. Phase Two consisted of two stages (a) 3-person focus group pilot study which was qualitative, and (b) pilot study survey $(N=52)$ which was quantitative. The 3-person focus group pilot study examined validity evidence using response processes, and the pilot survey examined for 
reliability evidence and validity evidence using internal structure. Phase Three was a qualitative phase that utilized six persons and examined for validity evidence based on response processes. Phase Four was a quantitative phase that established validity evidence using internal structure and reliability evidence measured by Cronbach's alpha. Exploratory factor analysis was used on data gathered from 300 participants. Six factors were generated, with the first construct (Problem-Solving Confidence) loading strongly on the first and second factors; the second construct (Approach-Avoidance Style) loading on the fourth, fifth and sixth factors, and the third construct (Personal Control) loading strongly on the third factor. Cronbach's alpha was used to determine reliability evidence on the instrument; $\alpha=.849$. Reliability for each of the three constructs was examined using Cronbach's alpha: .845 for Problem-Solving Confidence (10 items), .789 for Approach-Avoidance Style (10 items), and .729 for Personal Control (5 items).

The instrument created in the study, the Paradoxical Problem-Solving Inventory, was developed to have organizations look at an alternative method instead of the traditional ADRs used. The instrument can provide human resource practitioners and researchers the tool that is necessary when managing organizational conflict, and the opportunity to transcend from problems into a learning-oriented approach. 


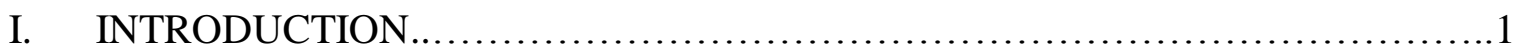

Background to the Problem....................................................

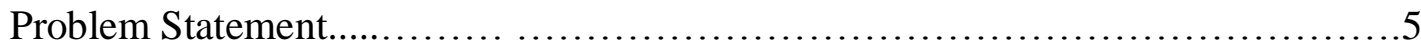

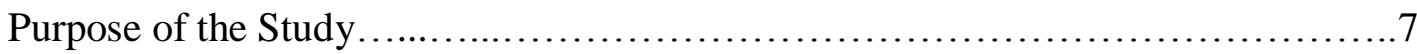

Research Question....................................................... 8

Theoretical Framework.......................................................... 8

Significance of the Study ................................................... 10

Definition of Key Terms.................................................. 11

Assumptions and Delimitations of the Study....................................13

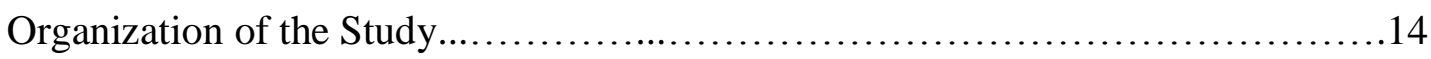

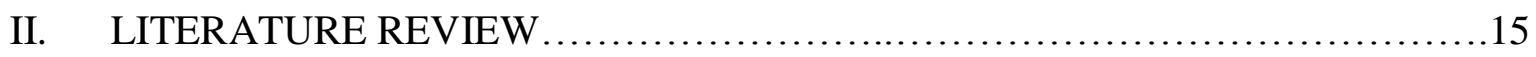

Managing Organizational Conflict..............................................

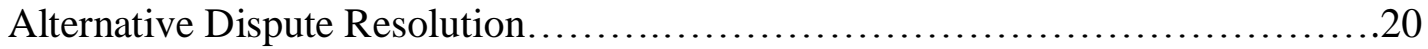

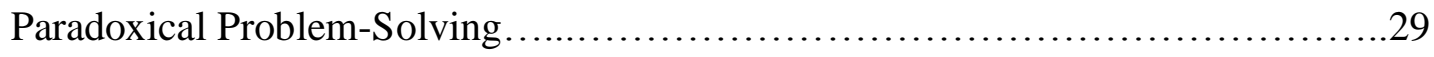

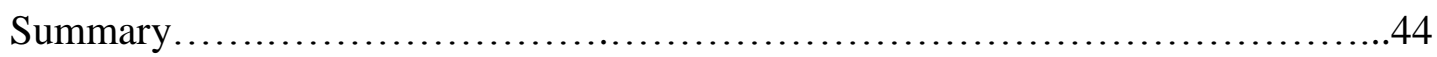

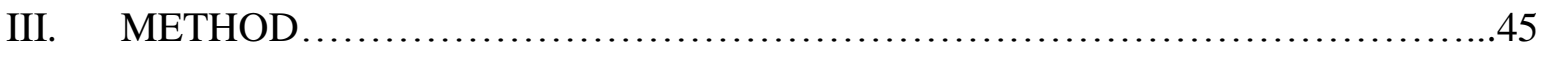

Research Question.........................................................

Concepts of Validity and Reliability ..........................................45

Development of the Constructs.............................................50

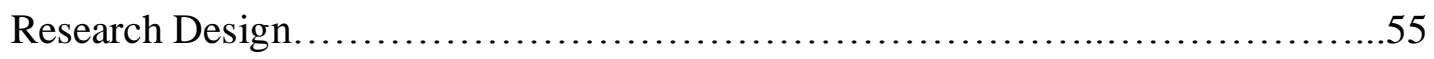

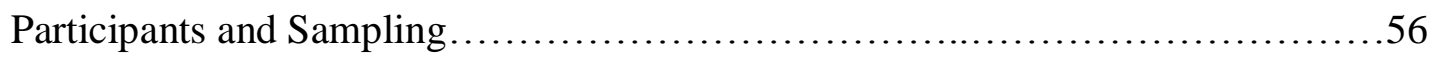

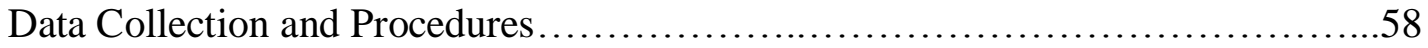

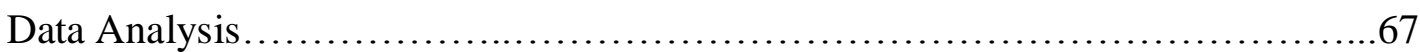

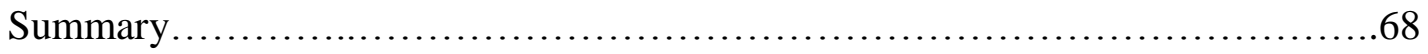




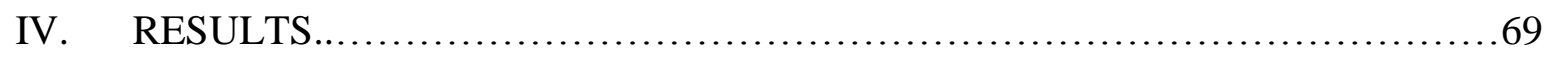

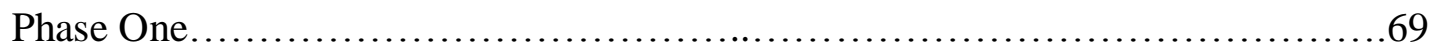

Phase Two............................................................... 78

Phase Three........................................................94

Phase Four............................................................. 104

Summary........................................................ 118

V. DISCUSSION ......................................................... 119

Analysis of Results......................................................... 119

Implications for Theory, Conflict Management, and Practice......................125

Limitations and Recommendations for Future Research.......................131

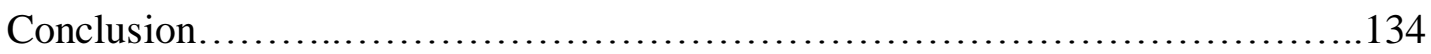

REFERENCES ............................................................ 135

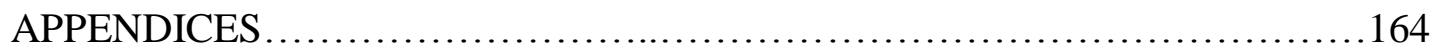

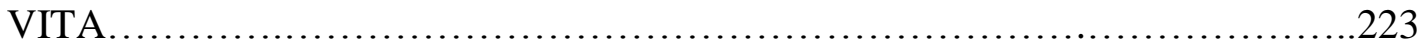




\section{LIST OF TABLES}

TABLE

PAGE

1. Role of Questioning in Disruptive Versus Integrative Negotiation................23

2. Mediation Techniques and Strategies.................................... 25

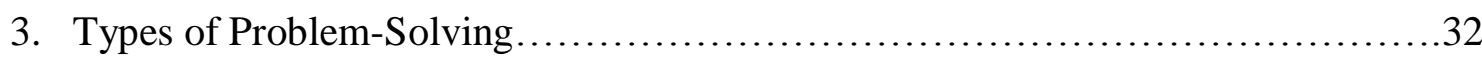

4. The Major Versions of Creative Problem-Solving $\ldots \ldots \ldots \ldots \ldots \ldots \ldots \ldots \ldots \ldots \ldots \ldots \ldots$

5. A Shift from Conflict to New Paradoxical Problem Thoughts........................................................... 40

6. Similarities and Differences of Paradoxical Problem-Solving and Creative Problem-Solving ................................................... 43

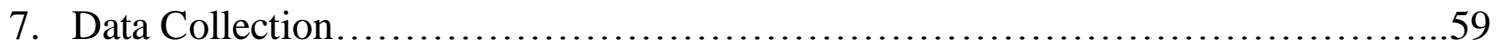

8. Research Design........................................................ 70

9. Statements that Needed Re-Wording Because of Inconsistencies..................72

10. Items that were Deleted.................................................. 84

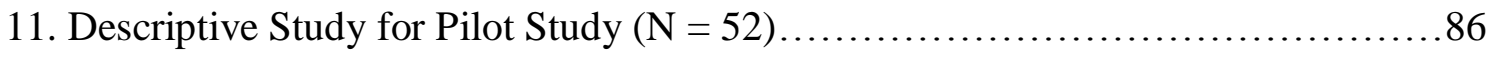

12. Summary of Exploratory Factor Analysis Results for Pilot Study $(\mathrm{N}=52) \ldots \ldots . . .90$

13. Frequency Table of Demographic Variables.................................107

14. Summary of Exploratory Factor Analysis for Hadeed Adapted Paradoxical

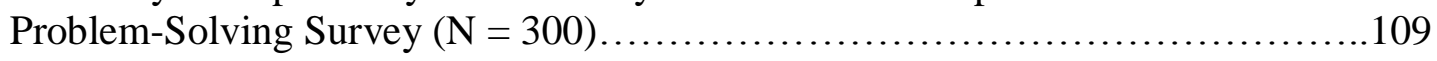

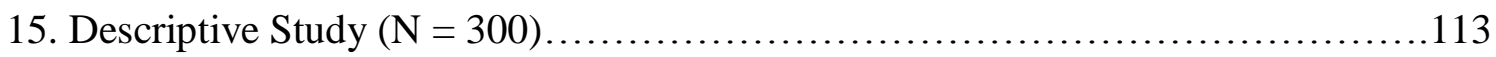

16. Hadeed Four Phases and Summary of The Findings .........................115

17. Reio and Werner's Four Stages of Mixed Methods Research (2017).............127 


\section{LIST OF FIGURES}

FIGURE

PAGE

1. Conflict Management Choices for a Collaborative Manager.....................18

2. Four Strategies Proposed for the Mediator Based on the Amount of Common Ground ................................................................. 28

3. The Four Strategies of the Creative Process ..................................... 37 


\section{LIST OF ABBREVIATIONS AND ACRONYMS}

ADR Alternative Dispute Resolution

AERA American Educational Research Association

APA American Psychological Association

ATD Association of Talent Development

BATNA Best Alternative To a Negotiated Agreement

CIES Comparative and International Education Society

CPS Creative Problem-Solving

NCME National Council on Measurement in Education

PPSI Paradoxical Problem-Solving Inventory

PSI Problem-Solving Inventory

SIG Special Interest Group 


\section{CHAPTER I \\ INTRODUCTION}

Human resource development scholars, researchers and organizational professionals support the implementation and development of conflict management systems that combine interest, position, and rights into one approach (Constantino \& Merchant 1996; Lipsky, Seeber, \& Fincher 2003; Ury, Brett, \& Goldberg 1988). The mixed methods research design study aims at developing and validating an adapted survey that incorporates the paradoxical problem-solving concept. The researcher adapted the survey. Chapter I will discuss the background of the problem, followed by the problem statement, purpose statement, and research questions. Additionally, the theoretical framework, significance of the study, definition of key terms, assumptions, and delimitations will be discussed.

\section{Background to the Problem}

Organizational conflict occurs when employees engage in activities that are incompatible with other individuals or groups in their network who share organizational resources (Roloff, 1987). Jehn (1997) identified two types of organizational conflict: cognitive and affective. Cognitive conflict occurs when team members discuss and deliberate on challenges about their tasks; affective conflict occurs when employees engage in conversations and debate on issues of a personal nature (Mooney, Holahan \& Amason, 1997). Organizational conflict is managed through formal intervention. Formal intervention for employees and management requires training (Wilmot \& Hocker, 2011). 
Subsequently, there are three common formal and voluntary intervention methods associated with managing organizational conflict: negotiation, mediation, and arbitration. An organizational intervention method is a problem-solving approach, rather than an adversarial one (Moore, 2003). Alternative dispute resolution (ADR) is the central term for negotiation, mediation, and arbitration. Alternative dispute resolution provides options to solving disputes (Moore, 2003). A more detailed overview of negotiation, mediation, arbitration and paradoxical problem-solving will be discussed.

\section{Negotiation}

Negotiation is a formal and voluntary problem-solving method where two or more persons discuss differences in an attempt to reach a mutual agreement (Moore, 2003). The most common way to reach a mutually acceptable agreement is through negotiation (Fisher \& Ury, 1981; Shell, 1999; Thompson, 2001). Negotiation is a process by which two or more parties voluntarily discuss their differences to receive what they think is viable (Walton \& McKersie, 1965). During negotiations, individuals engage in formal discussion that enable them to come to an agreement. Three forms of negotiation are hard, soft, and principled or interest-focused. During "hard" negotiation, the assumption is the opponent is the enemy; while "soft" negotiation is just the opposite; the relationship with the opponent is so close that one would usually concede easily. "Principled" or "interest-based" negotiations involve five steps: (1) separating people from the problem;

(2) negotiating about interests; (3) inventing options for mutual gain; (4) insisting on objective decision criteria; and (5) knowing your BATNA (best alternative to a negotiated agreement) (Fisher \& Ury, 2012). Some believe that negotiations typically 
involve "creating" and "claiming" value, where value is created (having more options) and then claimed (dividing the options) (Lax \& Sebenius, 1986). However, Fisher, Ury, and Patton (1991) argue that any dispute can be solved using principled or interest-based negotiations, but it will not result in a "win-win" situation for all parties involved. The controversial term "win-win" is often used with the term compromise, where managers create a "win-win" situation for their employees (Miller 1989). McNary (2003) states that during negotiations, there cannot be a "win-win" situation because in the bigger picture, the stakeholders may be the ones losing. If negotiations become challenging, and the parties have reached an impasse, the parties may have to seek advice from a third party through mediation.

\section{Mediation}

Mediation is an approach similar to negotiation, but structured and moderated by a neutral third party, who assists those persons involved in the conflict to reach an agreement acceptable by everyone involved (Mackie, Miles \& Marsh, 1995). Mediation is centered on position as opposed to interests. Mediation takes place when a third member is involved as the mediator, and the mediator has limited or no authoritative decision-making power (Moore, 2003). Mediation is entirely voluntary for the parties involved and would involve an impartial third party to mediate the discussion. An impartial third party is important in the process as the mediator cannot be involved or linked to the parties in conflict because of biases which can affect the mediator's responses. The mediator would also assist with giving new perspectives and ideas on matters that were causing the conflict, which can lead to a more amicable problem- 
solving relationship. Another formal method, paradoxical problem-solving, defined as solving problems creatively (Cloke \& Goldsmith, 2011) has commonalities with both negotiation and mediation. In later years, the authors, Cloke and Goldsmith (2011) argue that paradoxical problem-solving highlights a win-win process for both parties.

\section{Arbitration}

Arbitration is another form of formal intervention that also requires a third party, but differs from mediation, in that the third party views the evidence from all parties, asks the necessary questions and then makes a decision that is legally binding and enforceable in court (Sullivan \& Sheffrin, 2003). The third party is trained in formal intervention and acts as a private judge in disputes (Raines, 2012). Using arbitration has its advantages such as third-party intervention that is private and voluntary and is readily available when there is a breakdown in communication leading to an impasse (Wilmot \& Hocker, 2011). The literature is limited on the topic of arbitration, and the information found speaks to arbitration from a legal point of view. Because of the legal points of view found in the literature, the subject of arbitration will not be explored in Chapter II of the study.

\section{Paradoxical problem-solving}

The term paradox was defined as "something" that is constructed by individuals when oppositional propensities are brought into familiar proximity through reflection or communication (Ford \& Backoff, 1988). A paradoxical approach is defined as one that 'endorses two apparently contradictory views at the same time but produces a solution that aligns with both views' (Chan, 2014, p. 38). Paradoxical problem-solving is determined by interest and learning outcomes rather than position. An example that 
authors Cloke and Goldsmith (2011) used to explain paradoxical problem-solving is the answer to the question why fix a bike? Some suggest that the bike should be fixed because something is broken, others suggest that maybe something is faulty. If using paradoxical problem-solving, other suggestions to the question why fix a bike, would be to improve the bike, and why not explore ways to learn from improving the bike.

Paradoxical problem-solving occurs when there are many solutions to a problem, and where the key component is being able to learn from each problem and the application of a solution which can minimize the occurrence of the conflict arising in the future (Cloke \& Goldsmith, 2011). Paradoxical problem-solving can therefore be a longterm conflict management style. There are five steps involved with paradoxical problemsolving: (a) admit there is a problem; (b) jointly define the problem; (c) jointly investigate, analyze, categorize and prioritize the problem; (d) invent solutions that satisfy everyone; and (e) jointly act, evaluate the results, recognize efforts (Cloke \& Goldsmith, 2011). Throughout each step of paradoxical problem-solving, all parties involved in the conflict must be involved, which is a critical and necessary facet for it to work. The most important aspect of paradoxical problem-solving involves learning from the problem and transcending it (Cloke \& Goldsmith, 2011).

\section{Problem Statement}

The use of negotiation and mediation has significant limitations. Lax and Sebenius, (1985), claimed a predetermined negotiation decision before a meeting cause the negotiation intentions to be invalid. Subsequently, mediation is expensive, timeconsuming, and could escalate trust issues (Rounds \& Rounds, 2012). Arbitration also 
has its drawbacks. It generates expensive court fees, is content-based, and gives the impression that employees cannot manage their conflict without the intervention of a third party (Wilmot \& Hocker, 2007). Consequently, literature on arbitration is limited. According to the Financial Industry Regulatory Authority (2015), 4,392 arbitration cases were filed, and only 1,486 were closed. In 2016, the number of arbitrations cases increased to 4,647 and only 1,463 cases closed. From January to June 2017, 4,413 arbitration cases were opened, and only 1,668 closed. Additionally, the turnaround time for arbitration cases was approximately seventeen months (Financial Industry Regulatory Authority). According to Dabdoud and Cox (2012), arbitration fees averaged \$78,924 per case in outside council fees with increased costs up to $\$ 102,338.02$, which includes expenditure costs. Because of a lack of empirical research on organizational conflict and arbitration and the goals of this research, this topic is not covered in the current study.

Organizations can develop different methods to settle disputes. Paradoxical problem-solving is a method that can resolve and reduce the number of future conflicts. Notably, paradoxical problem-solving has not been explored empirically (Cloke \& Goldsmith, 2011). Subsequently, while paradoxical problem-solving has not been empirically tested, it shares similarities with creative problem-solving, such as the implementation of divergent and critical thinking skills, generation of ideas, and finding solutions (Cloke \& Goldsmith, 2011; Dellas \& Gaier, 1970; Eysenck, 1997; Feldhusen, 1995; Gough, 1979; Guilford, 1962; Torrance, 1986). Though close in nature, there are differences that exists between paradoxical problem-solving and creative problemsolving, such as paradoxical problem-solving engages learning from the conflict, it 
engages everyone who is affected by the conflict to find a solution, and it places emphasis on strategic thinking and the evaluation of different solutions. Creative problem-solving is linked positively to the creation of new ideas, critical thinking skills, and divergent thinking (Cloke \& Goldsmith, 2011).

Paradoxical problem-solving can benefit all parties and produce a win-win situation in resolving conflicts. Paradoxical problem-solving is an alternative method to negotiation, mediation and arbitration conflict management approaches. Paradoxical problem-solving may lead organizations to experience long-term benefits and increased leader effectiveness. Paradoxical problem-solving takes into account the interests of all parties and not just the organization's needs and wants. Organizations are familiar with the term 'paradox' rather than the combined use of 'paradox' and "problem-solving.' Subsequently, "paradox problem-solving" is an uncommon term to use when constructively managing organizational conflict; therefore, there is little, if any, use of the combined phrase paradoxical problem-solving.

The term conflict management or managing conflict is used in this study and not conflict resolution. Conflict resolution implies the removal, decrease, or dissolution of conflict (Robbins, 1978). Conflict management involves designing macro-level strategies that reduce the purposes of conflict and increase or improve positive functions of conflict that will boost learning in an organization (Rahim, 2002).

\section{Purpose of the Study}

The purpose of the mixed methods research is to develop and validate an adapted survey that incorporates the paradoxical problem-solving concept under the context of 
social conflict theory to provide employees and employers more creative techniques to manage organizational conflict

\section{Research Questions}

The primary research question of this study is: What are the psychometric properties of the Problem-Solving Inventory (PSI) incorporating a paradoxical problemsolving conceptual framework that is used in the workplace? Two secondary research questions will be used to guide this study:

1. What is the validity evidence of the adapted PSI inventory?

2. What is the reliability evidence of the adapted PSI inventory?

\section{Theoretical Framework}

Social conflict theory was proposed by Marx and Engel (1848) and states that social order or social inequality occurs because of domination and power, and not because of conformity and consensus. In classic sociology, social conflict theory focuses on power imbalance and the difference between classes. Coser (1967) defined social conflict theory as the conflict of group's intentions to gain desired values, offset and eliminate rivals, and the struggle over values or privileges to status, power, and limited resources. Social conflict theory encompasses a wide range of social phenomenon, which includes: class, religion, racial, strikes, communal conflicts, demonstrations, to name a few.

One aspect of social conflict theory is problem-solving. Cox (1981) stated problem-solving theory is accepting the world, the social struggles, and power relationships and using the institutions as a framework for which it is organized. He 
continues by stating that the aim of problem-solving is to make relationships and institutions work effectively with the sources of conflict (Cox, 1981). Krulik and Rudnick (1987) defined problem-solving as an unfamiliar situation that uses previously acquired knowledge, skills, and understanding to solve problems. Newell and Simon (1972), argued that in most cases, problem-solvers utilize a means-end analysis where the end or ultimate goal is envisioned to determine the best strategy to resolve the problem. Larkin et al. (1980) replaced this concept with forward chaining that leads directly to the goal. The problem-solving theory is research that initially focused on how individuals respond when confronted with unfamiliar tasks (Newell, Shaw \& Simon, 1958a). Problem-solving behaviors are often embedded with learning (Kahney, 1986), thinking (Bourne, Ekstrand \& Dominowski, 1971; Mayer, 1983), decision making (Abelson \& Levi, 1985; Tallman \& Gray, 1990), coping (Lazarus \& Folkman, 1984; Pearlin \& Schooler, 1978), task performance (Kelley \& Thibaut, 1969; Steiner, 1972), communication styles, networks, and patterns (Gottman, 1979; Leavitt, 1951; Tallman \& Miller, 1974), and information processing (Mayer, 1983; Simon, 1978).

One of the most basic claims of problem-solving theory involved the mental inspection and manipulation of list structures (Langley \& Rogers, 2005). Problemsolving theory consists of three categories: (a) the process of coping (Lazarus \& Folkman, 1984), (b) analysis of interpersonal and intergroup dynamics (Tallman, Leik, Gray \& Stafford, 1993); and (c) the act of critically investigating a problem (Kahney, 1986; Mayer, 1992). Kahney (1986) claims that the most important aspect of this theory 
is "to explain the interactions between problem situations and the people who are confronted by the problem" (p. 15).

The use of paradoxical problem-solving in the management of organizational conflict requires all parties to apply critical thinking skills. Dewey (1933) defines critical thinking as the number of ideas and thoughts that enter our minds uncontrollably. Paradoxical problem-solving utilizes the behaviors and attributes of learning, decisionmaking, coping, task performance, communication styles, and information processing in the five stages when resolving a conflict. In the first stage, communication styles are identified. The second and third stages, communication styles, decision-making, and task performance are used. The fourth and fifth stage, learning, decision making, coping, task performance, communication styles, and information processing is used. The five stages will be discussed in Chapter II.

\section{Significance of the Study}

Problem-solving has been visible in the literature for over 80 years (Dewey, 1933). Conversely, the combination of "paradox" and "problem-solving" is uncommon in literature and has never been studied together. Additionally, there is no empirical information on the link between conflict management and effective organizational learning (Rahim, 2002). The current study will contribute to the literature by developing and validating an adapted survey that incorporates the paradoxical problem-solving concept. The information will contribute to the professional field through: (a) theoretical enrichment to scholars and researchers with literature on problem-solving or conflict management theories, (b) empirical research contributions to researchers and scholars 
who would use the findings to guide new research, and, (c) practical information that would help bridge the gap in the literature between paradox and problem-solving, and (d) and provide insight into how paradoxical problem-solving could be used by Human Research Development (HRD) professionals to manage organizational conflict.

\section{Definition of Key Terms}

Affective conflict. This phrase refers to when employees engage in conversations and debate on issues that are of a personal nature (Mooney et al., 1997).

Arbitration. This term refers to the process where the third party views the evidence from all parties, asks the necessary questions and then makes a decision that is legally binding and enforceable in court (Sullivan \& Sheffrin, 2003).

Cognitive conflict. This term refers to when team members discuss and deliberate on challenges about their tasks (Mooney et al., 1997).

Exploratory Factor Analysis. A statistical method used to uncover the underlying structure of a relatively large set of variables. EFA is a technique within factor analysis whose overarching goal is to identify the underlying relationships between measured variables.

Mediation. This term refers to "a process of negotiation, but structured and influenced by the intervention of a neutral third party who seeks to assist the parties to reach an agreement that is acceptable to them" (Mackie et al., 1995, p. 9).

Negotiation. This term refers to a formal and voluntary problem-solving method in which two or more persons willingly discuss their differences and try to reach an understanding of their concerns (Moore, 2003). The most common way to reach a 
mutually acceptable agreement is through negotiation (Fisher \& Ury, 1981; Shell, 1999; Thompson, 2001). It is a process by which two or more parties voluntarily discuss their differences in order to receive what they think is viable (Walton \& McKersie, 1965). Organizational conflict. This term refers to when employees engage in activities that are incompatible with other individuals or groups, who are in their network and who utilize resources of the organization (Roloff, 1987).

Paradox. This term refers to "something that is constructed by individuals when oppositional tendencies are brought into recognizable proximity through reflection or interaction" (Ford \& Backoff, 1988).

Paradoxical approach. This phrase endorses two seemingly contradictory views at the same time, but nonetheless produces a solution that is aligned with both views (Chan, 2014, p. 38).

Problem. "A difficulty of theoretical or practical nature that causes an inquiring attitude of a subject and leads him/her to the enrichment of his/her knowledge" in Kupisiewicz (as cited in Dostal, 2015, p. 2799).

Reliability. "Refers to the accuracy or precision of a measurement procedure" (Thorndike \& Thorndike-Christ, 2010, p. 118).

Subject Matter Expert. A person who is an authority in a particular area or topic. Validity. The degree to which "evidence and theory support the interpretations of test scores for proposed uses of tests" (AERA, APA, \& NCME, 2014, p. 11). 
Validity evidence based on internal structure. indicates the relationships between the construct and the items on which the suggested test score interpretations are created (AERA, APA, \& NCME, 2014).

Validity evidence based on response processes. The evidence based on response processes of test takers "can provide evidence concerning the fit between the construct and the detailed nature of the performance or response actually engaged in by test takers" (p. 15).

Validity evidence based on test content. The "relationship between the content of the test and the constructs it is intended to measure" (AERA, APA, \& NCME, 2014, p. 14).

\section{Assumptions and Delimitations of the Study}

There were several assumptions and delimitations in this study.

\section{Assumptions}

The study's assumptions include: (a) participants in the survey will answer honestly and with integrity; (b) participants in the cognitive focus groups will answer the survey items truthfully; (c) management will be open to the use of alternative methods of the formal conflict management method; and (d) conflict management is present in organizations.

\section{Delimitations}

Given that although it would be ideal to investigate this research in a wide range of organizations to increase the generalizability (external validity) of the findings, the scope of this study is limited. The study will utilize the skills from individuals who are (a) employed in the human resource department and are either managers or supervisors; 
(b) academia who are experts in the topics of human resource development and conflict management; and (c) people employed in organizations who problem-solve as part of their routine.

\section{Organization of the Study}

Chapter I included the background to the study, the problem statement, purpose and theoretical framework. The significance of the study, definition of key terms, and assumptions and delimitations were discussed immediately after. Chapter II will provide a review of the literature that supports this dissertation. Chapter III will discuss the

method that will be used to examine this study. Chapter IV will discuss the findings of the study, and Chapter V will conclude with a discussion of the results and implications for theory, research and practice. 


\section{CHAPTER II}

\section{LITERATURE REVIEW}

This chapter examines four major sections. The first section is an introduction to managing organizational conflict. The second part focuses on alternative dispute resolution. The third examines literature on formal and voluntary intervention methods.

The fourth section reviews how the literature use the terms "problem solving" and "paradox." Additionally, the phrase "paradoxical problem-solving" is explored. The chapter concludes with a summary and overview of the next chapters.

\section{Managing Organizational Conflict}

Early conflict researchers, especially social psychologists, contributed to the efforts of defining conflict and its primary causes (Fink, 1968). Mack and Snyder (1957) described conflict as mutually exclusive or incompatible values derived from parties through a unique form of social interaction. More precisely, organizational conflict occurs when employees engage in activities that are inconsistent with a group or with other individuals in their network who share organizational resources (Roloff, 1987). Organizational conflict occurs at all levels of the organization (Hovtepo, Assokere, Abdul-Azeez, \& Ajemunighbohun, 2010). Studies show that organizational conflict focuses on the components of a disagreement at different hierarchal levels (Xin \& Pelled, 2003). The hierarchal level includes: conflict among managers (Ensley et al., 2000; Floyd \& Lane, 2000; Massey \& Dawes, 2007; Mohr \& Puck, 2007); between employees (Tjosvold et al., 2003); or between the manager and employee (Schaubroeck et al., 1993; Xin \& Pelled, 2003). Literature offers various types of organizational conflicts, its 
effects, and the strategies employed to manage conflict (Jehn et al., 2010; Lee \& Yu, 2004; Lewis et al., 1997; Thatcher et al., 2003; Wallace et al., 1999). Studies also indicate that organizational conflict is associated with low self-esteem, inadequate compensation, abuse of power, unclear expectations, unclear lines of communication, and cultural differences (Arops \& Beye, 1997; Hovtepo et al. 2010). Baron (1989) believed that personality characteristics were the cause of conflict at the interpersonal level.

Research on managerial theories of organization that pre-date the 1950's ignored internal conflicts in organizations and focused on finding optimal strategies to maximize efficiency (Barnard, 1938; Fayol, 1949). Contrarily, two managerial theory groups challenged this concept. The first group believed that organizational conflict was minimized through collaborative cooperation with those involved in the conflict (Blake \& Mouton, 1964; Likert, 1961). The second group assumed that organizational conflict was natural, with positive and negative consequences (Cyert \& March, 1963; March \& Simon, 1958).

According to Lewicki, Weiss, and Lewis (2016), organizational conflict comprised of three approaches: micro, macro, and economic analysis. The micro-level, or psychological approach, examined conflict between human beings. The micro-level approach focused on interpersonal, intrapersonal, and small group behavior characteristics that affected sources, dynamics, and results (Nye, 1973). The macro-level, or sociological approach, concentrated on understanding the conflict dynamics of groups, departments, or entire organizations (March \& Simon, 1958; Pondy, 1967). Economic 
analysis examined individual decision-making and complex social behaviors through the application of models or economic rationality (Luce \& Raiffa, 1957; Shubik, 1964).

Consequently, organizational managers spend a significant share of the working day dealing with conflict (Mintzberg, 1973; Thomas \& Schmidt, 1976; Watson \& Hoffman, 1996). Watson and Hoffman (1996) indicated that approximately $42 \%$ of a manager's workday is allocated to managing conflict. According to a survey conducted by Accountemps (2011), managers spend $18 \%$ of their time managing disputes, which equates to over seven hours each week. Managing disputes requires a significant amount of time. Literature on organizational conflict examined various conflict strategies used (Elangovan, 1995; Lewicki \& Sheppard, 1985; Sheppard, 1983, 1984) and diverse management styles (Filley, 1975; Pruitt, 1983; Putnam \& Wilson, 1982; Rahim, 1983; Thomas \& Kilmann, 1974). Kotter (1985) examined the indirect ways leaders managed conflict, which created a balanced atmosphere between effective teamwork and creative decisions.

Thomas, Bliese, and Jex (2005), and Meyer (2004) believed organizational conflict produced a negative impact on job performance, productivity and commitment. Argyris $(1976,1980)$ and Argyris and Schon (1978) argued for the promotion of doubleloop learning rather than single-loop learning as a way to reduce organizational conflict. Single-loop learning occurs when an error is found and corrected in the organization, but there is no change in policies, objectives and expectations; double-loop learning occurs 
when an error is detected and corrected and requires a change in policies, objectives and expectations (Argyris, 1980).

Rahim (1985) discovered double-loop learning was consistent with conflict management styles. Researchers showed a positive relationship between the various styles of managing interpersonal conflict of employees and the effects of conflict solution. Interpersonal conflict is the state of incompatible behaviors (Shantz, 1987), differences (Garvey, 1984), and obstruction (Hay, 1984), which produce organizational conflict as a result of incompatibility (Roloff, 1987).

Literature revealed interpersonal conflicts are handled by concern for self or concern for others (Blake \& Mouton, 1964; Thomas, 1976). The first approach examined the degree (high or low) to which a person fulfills oneself. The second method recognized the degree to which a person is concerned about satisfying others (Rahim, 1985). According to Blake and Mouton (1964), the two approaches of management styles have five distinct categories: integration, obligation, domination, avoidance, and compromise.

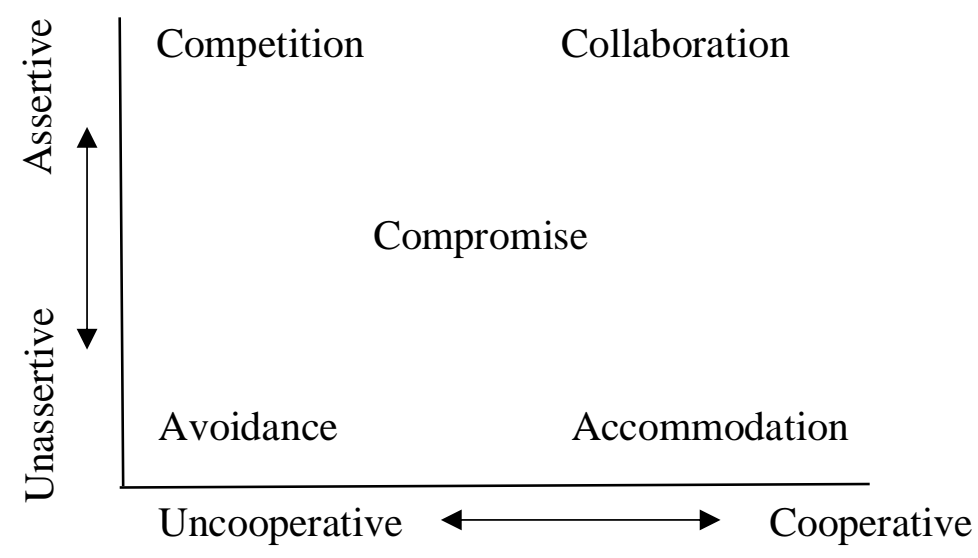

Figure 1. Conflict Management Choices for a Collaborative Manager 
Thomas (1976) revised the classifications into the following groups:

collaboration, competition, accommodation, avoidance, and compromise, with cooperation and assertiveness organized as a measure (Figure 1). Thomas (1976), believed cooperation satisfied the concerns of others, while assertiveness satisfied the concerns of oneself.

Accommodation has a low concern for self and a high concern for others. Individuals under this style often minimize their goals to adjust to the needs of others (Thomas, 1986). On the contrary, avoidance has low concern for self and others. Some view this style as disengaging to employees (Rahim \& Magner, 1995). Compromise management style comprises of a moderate concern for oneself and the other party involved (Rahim \& Magner, 1995). Competition, on the other hand, focuses on a high level of concern for oneself and low level is concern for others and is used when quick decisions are necessary, or there is no time for meetings or discussions (Thomas, 1986).

Rahim (1985) identified collaboration as a problem-solving style. Collaboration examines every part of a problem in an attempt to find all possible solutions (Altmae \& Turk, 2009). Trudel and Reio (2011), believed it was indicative of high concern for the objectives of oneself and others. Empirical evidence outlined by Thomas (as cited in Thomas, 1998) indicated that collaboration produces positive results when organizations manage conflict for individuals (e.g. increase in self-esteem and satisfaction); for relationships (confidence, respect and caring); and for organizational decision-making (more communication). This concept aligns with problem-solvers and problem-solving theory, which uses a means-end analysis strategy (Newell \& Simon, 1972) and yields a 
“win-win” outcome (Van de Vliert, Nauta, Euwama \& Jannsen, 1997). As a result, management envisions the end or ultimate goal to determine the best solution for everyone involved in the conflict.

Different conflict management styles exist with each having its priorities. The problem-solving or collaboration management styles are best when there is a need for a long-term solution (Altmae \& Turk, 2009). The examination of different conflict management styles reflects the diverse perceptions or mindsets developed toward conflict (Folger et al., 2005; Putnam, 2006). These conflict management styles emphasize conflicts between superiors and subordinates (Nicotera \& Dorsey, 2006). The scholarly research in this review of literature was developed to help direct the research questions outlined in this study. The following sections will discuss alternative dispute resolution, problem-solving, and paradoxical problem-solving.

\section{Alternative Dispute Resolution}

Organizational conflict occurs when employees utilize a company's resources but engage in activities that are incompatible with another individual or group (Roloff, 1987). Literature indicates that employees are unable to manage conflict on their own and must be told how to do so positively (Cloke \& Goldsmith, 2000; Eisaguirre, 2002; Hiam, 1997; Thomas, 1992; Weiss \& Hughes, 2005). Organizations manage conflict through use of formal intervention (Wilmot \& Hocker, 2011), also known as alternative dispute resolution (ADR). Negotiation, mediation, and arbitration are the three common formal and voluntary intervention methods used to manage organizational conflict. Formal 
interventions are used as a problem-solving approach to organizational conflict rather than an adversarial one (Moore, 2003). The first approach is negotiation.

\section{Negotiation}

Negotiation as a problem-solving method has been of interest for more than a few decades (Rubin and Brown 1975; Druckman 1977). According to Schelling (1960), in a negotiation the parties involved try to cooperate and compete with the best solution to a disagreement. There are five aspects to a negotiation: (a) people believe there are conflicting interests, (b) communication is achievable, (c) solutions and compromises exist, (d) each party can make offers and counter-offers, and (e) offers and proposals do not constitute the end until accepted by both parties (Chertkoff \& Esser, 1976; Cross, 1965; Schelling, 1960). Negotiation may involve some creativity toward finding a solution to more than one concern. In such cases, it becomes a matter of claiming value (Urlacher, 2014) where the negotiator chooses between the competitive (hard) or cooperation (soft) approach. The soft approach can lead to less value for the negotiator; while the hard approach is unwilling to compromise and risks the results of no settlement (Urlacher, 2014).

Negotiation is successful in most organizations, which leads to positive outcomes, economic wealth, and personal development (Rubin, Pruitt, \& Kim, 1994).

Subsequently, some scholars believe that negotiation is one-sided and that party seeks the best alternative for itself (Craver, 2005; Druckman, 1977; Gulliver, 1979; Haydock 1984; Hogue, Levashina, \& Hang, 2013; Karrass, 1970; Lewicki, Saunders, \& Minton 1997; Murray, Rau, \& Sherman 1996; Nelken, 2001, 2007; Pruitt 1981; Raiffa 1982; Rubin \& 
Brown 1975; Strauss, 1978; Thompson, 2011; Young, 1975;). The perspective of onesided behavior is known as "instrumental rationality" or instrumentalism (Fowers, 2010). In social sciences, instrumentalism is essential to motivation, human behavior, and relationships (Ingerson, DeTienne, \& Liljenquist, 2015).

A plethora of literature exists on the assumption of instrumentalism and its influence on motivation, human behavior, and relationships between the negotiator and the negotiation process in the organization (Cialdini, 1993; Craver 2005; Druckman, 1977; Gulliver, 1979; Haydock, 1984; Karrass, 1970; Lewicki, Saunders, \& Minton 1997; Murray, Rau, \& Sherman 1996; Nelken, 2001, 2007; Nierenberg, 1973; Pruitt, 1981; Raiffa, 1982; Rubin \& Brown 1975; Strauss, 1978; Thompson, 2011; Young, 1975). The negotiation process asks the question, What's in it for me (or us)? The question forces a means-end rationality by negotiators, which, in turn, reduces the actions to selfish motives (Fowers, 2010). Lewicki, Saunders and Barry (2010) believed that selfish motives could be reduced by knowing the right questions to ask during negotiations. Asking strategic questions in negotiation helps to gain insight into the other party's thinking (Weingart, Hyder, \& Prietula, 1996; Hyder, Prietula, \& Weingart, 2000). In organizations, strategic questioning aids with disruptive negotiations (learning information to refute the other party's argument), and integrative negotiation (learning information to better assist with coming to an agreement) (Lewicki, Saunders, \& Barry, 2010; Thompson, 2011). Disruptive negotiations are categorized as zero-sum where one party's gain is another party's loss, and vice versa. Subsequently, in disruptive negotiations there is usually no existing or future relationship gained (Miles, 2013). 
Table 1

Role of Questioning in Disruptive Versus Integrative Negotiation

Disruptive Negotiation

Purpose of Questioning:

- Learn information in order to assist substantiation

- Question (challenge) counterpart's substantiation

Purpose of Information:

- Substantiate position

Challenge counterpart's position

- State or imply strength (e.g. desirable BATNA)

- Justify requested concessions

- Anchor ambitiously

- Gain advantageous proportion of the resources available

Key Risk in Answering Questions:

- Sharing information that undermines negotiator's position or substantiation

BATNA: best alternative to negotiated agreement.
Purpose of Questioning:

- Understand interests and priorities of counterpart

- Discover potential trade-offs

- Identify trade-off issues, zerosum issues, and compatible issues

- Identify and Pareto inefficiency remaining in tentative agreement

Purpose of Information:

- Discover potential trade-offs

- Make interests and priorities known so that they are more likely to be considered in the agreement

- Gain information

- Test understanding

- Meet interests of both parties

- Attempt to move closer to Pareto optimal frontier

Key Risk in Answering Questions:

- Missing opportunity to discover beneficial trade-offs 
According to Hyder, Prietula, and Weingart (2000) disruptive negotiation is substantiation: or the creation of arguments to support a suggested negotiation solution. Integrative negotiations are not zero-sum. Integrative negotiations attempt to identify plausible agreements that can benefit both parties and allocate resources of lesser value for a higher value (Thompson, 1990). This is also known as Pareto-optimal, no other optimal trade, grants an advantage to one party over the other. Table 1 depicts the comparison of the questioning role.

In integrative negotiations, the primary purpose is different to disruptive negotiations (Thompson, 1990, 2012; Weingart, Hyder \& Prietula, 1996), in that insight is gained on the other party's interests. Thompson (1991) recognized that a negotiator who asked strategic questions about the other party's interests was more likely to gain insight into a solution than a negotiator who asked questions purely for disruptive purposes. Integrative agreements are considered to be steadier, can increase relationships between parties and increase the welfare of the organization (Pruitt, 1983a).

As discussed in the framework of this study, negotiators would need to utilize the necessary skills and behaviors to conduct successful integrative negotiations. These include learning about other parties' interests, thinking about what each party would like to achieve in the process, and communication styles to effectively communicate with others. Social conflict theory is reflected in the negotiation stage, that is, the power and domination of one party over the other. More specifically, problem-solving theory focuses on the power relationships and social struggles. The aim of this theory is to make 
the relationships and institutions work effectively with the sources of conflict (Cox, 1981), which is reflected in the negotiation approach.

Table 2

Mediation Techniques and Strategies

Techniques

Clarify situation

Establish protocol

Make parties aware of relevant information

Delineate forthcoming agenda

Rehearse each part in appropriate behavior

Separate parties

Clarify what parties intend to communicate

Pick up hints of what each party might concede

Strike a power balance

Provide direction and act as a spokesman for weaker side

Tender agreement points to parties

Help a party to undo a commitment

Contrive a "prominent" position

Arrange informal conferences

Reduce tension

Summarize the agreement

Guarantee compliance to an agreement

Reward parties' concessions

Act as sounding board for positions and tactics

Claim authorship for party's proposal

Strategies

Reflexive

Substantive

Substantive pressing

Substantive suggesting

Substantive face-saving

Contextual 


\section{Mediation}

Mediation is an approach similar to negotiation, but structured and moderated by a neutral third party, who assists those persons involved in the conflict to reach an agreement acceptable by everyone involved (Mackie, Miles, \& Marsh, 1995, p. 9). Mediation is similar to negotiation in the bargaining process. A third party who is not directly involved in the conflict helps resolve differences without invoking the authority of the law (Bercovitch \& Jackson, 2001). Third parties are more effective if they are impartial and are not representing the interests of their proxy (Fisher, 1995).

Mediators intervene in several ways and, are successful as an impartial third party (Young, 1967). Several conditions are necessary for mediation to take place: long and drawn out disputes (Bercovitch, 1992), when conflict management efforts reach a stalemate and a decision is not agreed (Bercovitch, 1992; Kleiboer \& t'Hart, 1995) or, when antagonism prevents decision-making to solve the dispute (Stephens, 1988).

In addition, other conditions that are necessary are when a prerequisite includes a mediator willing to intervene when conversations lose focus (Gulliver, 1979), and when the opportunity for the mediator to intervene is prevalent (Rubin, 1992). And, finally, when there is an impasse. The mediator can help by making a decision on behalf of the parties (Bercovitch, 1992; Kleiboer, 1996; Zartman \& Touval, 1996). Organizations use mediators when the mediator's expertise will benefit the company (Rogers, 1991) or when the solution seems superior to other alternatives. Over the decades, mediation is useful to resolving a variety of disputes. Mediation is used to aid in labor-management 
negotiations, international relations, and community disputes (Kressel \& Pruitt, 1989; Hiltrop, 1985; Mika, 1987; Wall \& Blum, 1991).

Mediation is present in conflict resolution, sexual harassment cases, public policy disputes, and consumer disputes (Gadlin, 1991; Orenstein \& Grant, 1989; Sussking, 1985). According to Wall (1981), mediators apply over one hundred interaction techniques between various parties (Table 2).

Mediators can strike a power balance through the dictation of agreement ideas (Conlon \& Fasolo, 1990). Occasionally, mediators may separate the parties to provide ease and to allow each side to discover and explore creative ideas (Bienenfeld, 1985). Mediators help reframe problems (Sheppard, Blumenfeld-Jones \& Roth, 1989; Mather \& Ynuesson, 1981). Mediators can determine what areas are negotiable and help shape the process to fit the negotiation (Carnevale \& Pehnetter, 1985; Gerhart \& Drotning, 1980; Hiltrop, 1985, Mayer, 1985).

Taxonomies or strategies help categorize the mediators' techniques. Contrarily, Silbey and Merry (1986) believed the taxonomies were judgmental. Zartmen and Touval (1985) argued that they were empirically-based. Kressel and Pruitt $(1985,1989)$ revised the most common taxonomies, reflexive, substantive, and contextual.

Reflexive strategies provide a setting for mediators to have discussions and mediations at a later period; substantive strategies deal directly with dispute; contextual strategies help the parties find agreeable solutions (Wall \& Lynn, 1988). Lim and Carnevale (1990) and McLaughlin, Carnevale, and Lim (1991) identified three subgroups of substantive strategies. The first is substantive pressing, which uses coercive tactics to 
move a party from a position. The second, substantive suggesting moves a party to a new position. The third, substantive face-saving helps the parties keep a positive image. Moore (1986) proposed a twelve-stage model that conceptualized what happens before the mediation process. According to Moore (1986), stages one through five are: making contact, selecting a strategy, collecting and analyzing background information, formulating a thorough plan, and building confidence and collaboration. Stages six through twelve are: beginning the session, defining issues and setting an agenda, uncovering hidden interests, finding options for dispute, assessing the options, final bargaining, and confirming the final agreement (Moore, 1986). Each stage incorporates the behaviors and attributes outlined in the problem-solving theory.

Carnevale (1986a/b) proposed four strategies based on the perceived amount of common ground and value of disputants' achieving their goal when faced with internal organizational conflict (Figure 2).

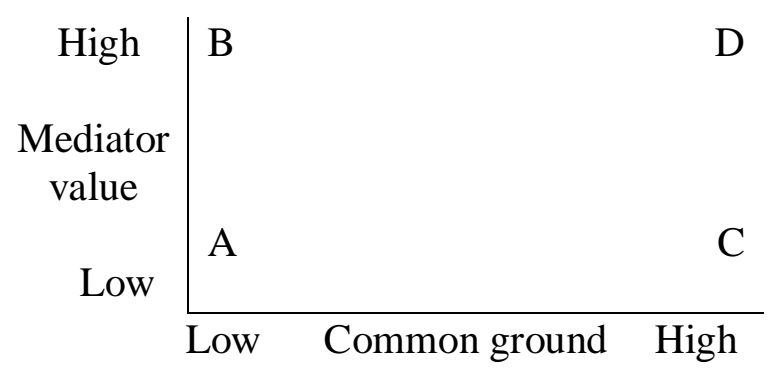

Figure 2. Four Strategies Proposed for the Mediator Based on the Amount of Common Ground

The strategies proposed by Carnevale (1986a/b) were: getting the parties to be less forceful (low common ground/low mediator value; rewarding them based on compromise (low common ground/high mediator value); remaining unengaging (high 
common ground/low mediator value); and, proposing agreements that both parties are comfortable with (high common ground/ high mediator value). The mediation approach when managing conflict is not guided by social conflict theory, in that the mediator does not focus on domination and power, or social inequality. The mediator's role encourages a power balance between parties, and in some cases, separates the parties to explore creative solutions.

\section{Paradoxical Problem-Solving}

According to Basadur (1994), problem-solving involves more than applying a method to identify an ideal solution to a defined problem. The word "problem" is defined as "a difficulty of theoretical or practical nature that causes an inquiring attitude of a subject and leads him/her to the enrichment of his/her knowledge" in Kupisiewicz (as cited in Dostal, 2015, p. 2799).

A problem is an inconsistency that exists between the desired goal and the existing state (Pounds, 1969; Daft, 2014). According to Kinicki \& Williams (2013), a problem hinders from achieving a goal. Agre (1982), Bourne et al. (1971), Hattiangadi (1978), Klein and Hill (1979), Newell and Simon (1972), and Tallmann (1988) determined the definition of problem includes barrier, uncertainty and risk. Tallman, Leik, Gray and Stafford (1993), identified a barrier as any condition that prevents the goal from being accomplished. Uncertainty is risk taken when the subject is unsure if the outcome is achievable. Risk is the probability of attaining a negative or positive outcome. Problems arise when a situation or condition takes place, and an individual has a challenge overcoming it (Duncker, 1945). Subsequently, a problematic relation is not 
based on a situation or condition. Problematic relations are determined by difficulties and inner uncertainties where the individual is aware of the struggles and takes the necessary precautions to remove the doubts causing the feeling (Dostál, 2015).

The problem defined by the relation between the subject matter and the environment consists of two natures, as stated in Linhart's study (as cited in Dostal, 2015). First, perceived inconsistency occurs when two parties have opposing ideas and alternatives (Dostal). Second, when inconsistency arises, there is disorder that causes a rise in tension (Dostal). According to Linhart's study (as cited in Dostal, 2015), conditions permit problematic situations. This is defined as all the situations that form the specifics of the problem (Dostal). Lerner (1986) further defined a problematic situation as a barrier that exists that the subjects are aware of and, by overcoming it, new knowledge, ways and creative activities are required. In some cases, problems exist without being perceived as such, and problem-solving requires knowledge of the conditions that are around a problem (Tallman \& Stafford, 1993). Krulik and Rudnick (1980) define problem-solving as:

The means by which an individual uses previously acquired knowledge, skills, and understanding to satisfy the demands of an unfamiliar situation. The person must synthesize what he or she has learned and apply it to a new and different situation. (p. 4)

In Matyushkin's study (as cited in Dostal, 2015), problem-solving involves a thought process that engages individuals and generates knowledge with conflicting ideas and opinions. Problem-solving identifies gaps between reality and ways to resolve the 
problem (Shermerhorn, 2013). Problem-solving is an action used to achieve an outcome through use of critical thinking skills, problem-based learning, creative thinking skills and decision-making skills (Carson, 2007). These problem-solving competencies are necessary for management because they are desired employment skills and essential in organizations (Buchanan \& O'Connel, 2006; Knight \& Yorke, 2004; Mintzberg, 2013; Yates, 2003). Over the last 30 years, Kerns (2016) discovered an increase in the development of problem-solving and organizational leaders.

Effective problem-solving includes the ability to:

- ask the right questions (Rausch, 2003)

- focus on what is important and what constitutes the problem (Kerns, 2008)

- balance obstacles with resources and well-being (Bakker, Demerouti \& Sanz-Vergel, 2014; Dodge, Daly, Huyton \& Sanders, 2012; Sheard \& Kakabadse, 2007; Swenson, Rhoads \& Whitlark, 2014)

- convert knowledge-based plans to action plans in a timely manner (Donate \& Sanchez de Pablo, 2015; Kownatzki, Walter, Floyd \& Lechner, 2013)

- find ways for stakeholder agreement (Stacey, 1996)

- actively engage others (Labovitz \& Rosansky, 2012; Kerns, 2013; Kerns, 2014), and,

- evaluate the results and look for solution successes or drawbacks (Kerns, 2015; Kaplan \& Kaiser, 2006; Worley, Williams \& Lawler, 2014).

Dewey (1933), Polya (1988); Krulik and Rudnick (1980) identified various types of problem-solving and the requirements for a heuristic approach (Table 3). Dewey 
(1933) modified the problem-solving steps. He concentrated on thinking and reflection.

Polya (1988) focused on solving mathematical problems. Krulik and Rudnick (1980)

addressed another explanation of a step-by-step approach to the problem-solving process.

Krulik and Rudnick (1980) documented five steps to problem-solving: (a) read, (b)

explore, (c) select a strategy, (d) solve, and (e) review and extend.

The first step, read, occurred when the problem is identified with keywords and by gaining clarity if the problem is not easily understood. The second step, explore, looked for patterns to discover the root the problem. The third step, select a strategy, determined a solution for the problem through the application of steps one and two.

Table 3

Types of Problem-Solving

\begin{tabular}{llc}
\multicolumn{3}{c}{ Problem Solving Steps } \\
\hline John Dewey (1933) George & $\begin{array}{c}\text { George Polya (1988) } \\
\text { Steps }\end{array}$ & $\begin{array}{c}\text { Stephen Krulik and } \\
\text { Jesse Rudnick } \\
(\mathbf{1 9 8 0})\end{array}$ \\
\hline Confront problem & Understand the problem & Read \\
Diagnose or define problem & Devise a plan & Explore \\
Inventory several solutions & Carry out the plan & Select a Strategy \\
Conjecture consequences of & Look back & Solve \\
solutions & & Review and Extend \\
\hline Test consequences & & \\
\hline
\end{tabular}


The fourth step, solve the problem, required finding a solution based on the results derived in step three. The fifth step, review and extend, both the problem and solution are reviewed. Literature indicates that problem-solving, and coping can be confused (Lazarus \& Folkman, 1984; Klein, 1983; Stone \& Neal, 1984). Similarities exist between coping and problem-solving. Coping refers to physical and mental changes that range from finding ways to reduce elements that constitute the problem, to seeking practices and procedures for managing internal and external factors that influence the conflict (Lazarus \& Folkman, 1984; Moos \& Schaefer 1986; Pearlin \& Schooler 1978). Creative problem-solving is essential in organizations (Trilling \& Fadel, 2009).

\section{Creative Problem-Solving}

Guilford (1977), Rugg (1963), and Runco (2007) examined conceptual and operational distinctions and relationships between creativity and problem-solving. According to Newell, Shaw and Simon (1962), "Creative activity appears ... Simply to be a special class of problem-solving activity characterized by novelty, unconventionality, persistence, and difficulty in problem formulation" (p. 63). Creative problem-solving originated with the seminal works of Osborn $(1952,1953)$ and further developed through continuous research (Isaksen \& Treffinger, 2004; Treffinger \& Isaksen, 2005) (Table 4). The first major version honed on the need to define the creative process, and the latest version narrowed in on using the evaluation results to design a new process. Creative problem-solving involves the relationship between problem-solving and creative critical thinking skills (Kirton, 2003). 
Norris and Ennis (1989) defined critical thinking skills as the ability to decide what to do or believe based on rational, reflective thinking skills. Critical thinking skills are "active, persistent and careful consideration of a belief or supposed form of knowledge in the light of the grounds which support it and the further conclusions to which it tends" (Dewey, 1909, p. 9).

Table 4

The Major Versions of Creative Problem-Solving

Major Version 1942-1967

1963-1988

$1981-1986$

1987-1992

1990-1994

1994-Present

\section{Issue or Need}

The need for an explicit or defined creative process

The need for a validated instructional program to deliberately develop creative talents The need to address individual differences and situational issues when learning and applying CPS The need to respond to key learnings from impact research

The respond to developments in cognitive science and stylistic differences in viewing CPS The need for a systemic way to take the results from appraising a task, and then designing an approach to process.

The attributes associated with creative thinking are: independent thinking, openness, and divergent thinking (Dellas \& Gaier, 1970; Eysenck, 1997; Feldhusen, 1995; Gough, 1979; Guilford, 1962; Torrance, 1986). In the creative thinking and problem-solving process researchers view divergent thinking as a critical component (Guilford, 1967; Meadow, Parnes \& Reese, 1959; Parnes \& Meadow, 1959, 1960). Divergent thinking is one of the oldest and largest areas of creativity (Guilford, 1950; Weisberg, 2006). 
Divergent thinking is evaluated based on divergent thinking tasks, in which there is a generation of ideas based on verbal or figural prompts (Kim, 2006; Michael \& Wright, 1989; Wallach \& Kogan, 1965). There are various models that can enhance and maintain the creativity in organizations (Amabile \& Gryskiewicz, 1989; Rickards \& Jones, 1991). Osborn (1952, 1953), a pioneer known for his research on brainstorming presented a seven-stage model. The seven stages are: finding the problem; preparation or gathering relevant and necessary information; analysis or dissecting the problem; hypothesis or obtaining solutions by generating ideas; incubation or shedding light on the solutions; synthesis or bringing the pieces together; and evaluating the results (Osborn, $1952,1953)$.

The model created by Osborn $(1952,1953)$ was later developed by several researchers (Buisine, Besacier, Aoussat, \& Vernier, 2012; Chant, Moes, \& Ross, 2009; Kuo, Chen, \& Hwang, 2014). Creative problem-solving focuses on the development of creative thinking, improving problem-solving abilities, and the enhancement of divergent thinking (Treffinger et al., 2003, Tseng et al., 2013; Vidal, 2010; Chen \& Cheng, 2009). The latest model consists of four main components and eight minor stages. The four sections are: (a) understand the challenge by data exploration, locating opportunities, and outlining the problem; (b) idea generating; (c) action preparation and solutions; and (d) approach planning and evaluate the tasks and design process (Treffinger et al., 2003). Each stage is critical toward understanding the importance of the problem (Treffinger et al., 2003) and this model was further developed. 
Basadur (1982) developed the simplex creative solving process. Basadur (1974, 1983) argued that the creative process is circular where the first two quadrants are the elements of problem finding, generation and conceptualization, shown in Figure 3. The second two quadrants are problem-solving (optimization), and solution implementation. The creative solving process involves gathering unlikely material in a useful, unfamiliar, and rational way to current conceptualizations (Koestler, 1964; Mednick, 1962). The first phase in the creative solving process is the generation of ideas. In this phase, problem-sensing and fact-finding are grouped together (Basadur, Graen \& Wakabayashi, 1990). In conceptualization, the problem is identified, intellectualized and structured. The second phase is problem structuring. Problem structuring identifies different variables in the problem and the relationships among them (Pitz et al., 1977). The third phase is optimization or problem-solving. The third phase consists of the solution development. The fourth phase consists of the implementation plans. Implementation involves both solutions and plans (Figure 3).

Researchers agree that problem identification, construction of ideas, identification of relevant information, generation of new ideas, and evaluation of these ideas are core processes necessary for creative problem-solving (Finke et al., 1992; Mumford et al., 1991). Some researchers argued that finding useful problems to solve is more important than the discovery of suitable solutions (Mackworth, 1965; Getzels, 1975), however Parnes et al. (1977) argued that the implementation of solutions is more important to creative problem-solving. 
Cloke \& Goldsmith (2011), believed problem-solving would appear premature and ineffective based on the natural tendency to view opponents as the problem and one's interests as the only possible solution. This belief produces a one-sided superficial assessment to the opponents. The ability to logically and practically calculate what needs to be realistically accomplished can lead to the beginning of the end of conflicts.

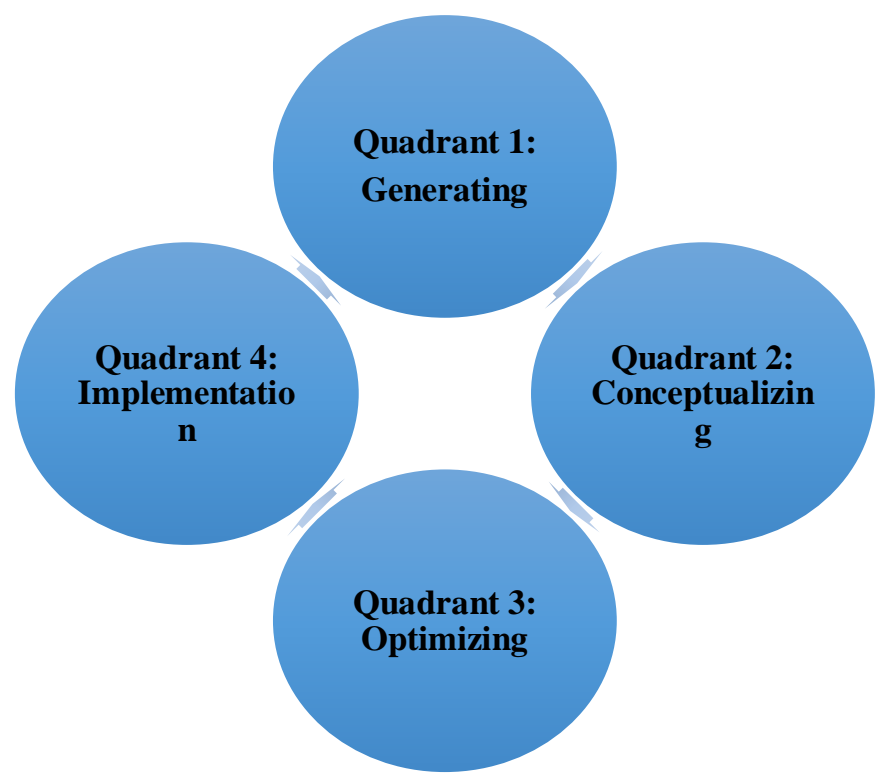

Figure 3. The Four Stages of the Creative Process

Moving from a period of emotional processing to a period of solving problems creatively and putting aside the assumption that our solution is the only, can lead to another problem-solving alternative solution, also known as paradoxical problem-solving (Cloke \& Goldsmith, 2011).

\section{Paradoxes}

Organizational studies researchers have defined paradoxes as inconsistencies rooted in a statement, human emotions or organizational practices (Eisenhardt \& 
Westcott, 1988; Murninghan \& Conlon, 1991; Vince \& Broussine, 1996). Paradoxes occur when an individual is living concurrently with alternate and opposing realities. This is important for persons employed in team-based organizations where the environment is complex and open to learning (Cloke \& Goldsmith, 2011). Through reflection and interaction, paradox is created by oppositional tendencies that are brought into recognizable proximity and is constructed by individuals as a thing (Ford \& Backoff, 1988). Ford and Backoff (1988) identified three central characteristics of a paradox: (a) the thing, which represents entwined components, such as feelings, demands, interests, or practices, (b) inconsistencies created, and (c) self or social reflection or interaction. Paradoxes became apparent and revealed as absurd or irrational due to polar opposites. According to Lewis (2000), the ability to understand a paradox requires more than defining the characteristics. The need to pay attention to paradoxical tensions, reinforcing cycles, and management is required (Argyris, 1993; Cameron \& Quinn, 1988; Smith \& Berg, 1987). Lewis (2000) believed paradoxical tensions were intuitive, and incompatible truths were masked by cognitive or socially constructed polarities, as in two sides of the same coin. A strange loop (Hofstadter, 1979) is created when one side of a polarity is suppressed, and there are pressure increases from another. This occurs when regression or splits are interpreted as two opposing thoughts or ideas. Eisengardt \& Westcott (1988), believed the power to generate creative insight and change is the result of the contribution of paradoxes from management thinking. Poole and Van deVen (1989), assumed management could transform theories and ways of thinking in a way that leads to paradoxical problem-solving. 
Cloke and Goldsmith (2011), suggested the adoption of a learning-oriented approach as an alternate method. A learning-oriented approach involves everyone impacted by the conflict to become a part of the problem-solving process. Paradoxical problem-solving has various truths that shape and inform the problem (Cloke \& Goldsmith, 2011). Paradoxical problem solving engages critical thinking and intellect as a way to unveil truths and new ideas. Problems transform into evolutionary ideas, and opportunities become new paradigms (Cloke \& Goldsmith). The most inspiring aspect of paradoxical problem-solving is not finding the solutions but discovering ways to learn and transcend them (Cloke \& Goldsmith). Table 5 shows that employees adopt paradoxical problem-solving when conflicts are approached differently through profound and far-reaching paradigm shifts (Cloke \& Goldsmith, 2011).

Some examples of paradigm shifts identified by Cloke and Goldsmith (2011) are a shift from problem elimination to discovering it; a shift from solving problems to learning from them; a shift from knowing the right answer to having the right questions to ask; a shift from confrontational to collaborative problem-solving; and a shift from following models to creating pilot projects.

Organizations can adopt and implement a learning-oriented approach to problemsolving. A learning-oriented approach requires a shift from the traditional way of solving conflicts to providing options to transform thoughts that satisfy both parties (Cloke \& Goldsmith, 2011). Five steps included in paradoxical problem-solving: 1) admit there is a problem by recognizing that it exists and that it needs a resolution; 2) collaboratively define the problem, by refining the elements and nature of the problem; 3) all parties 
should jointly investigate, analyze, categorize, and prioritize the problem; 4) develop solutions that avoids one solution and satisfies all parties and, 5) act, evaluate, recognize others efforts, and celebrate success collaboratively.

Table 5

A Shift from Conflict to New Paradoxical Problem Thoughts Conflict Shift To

Eliminate problems

Avoid and address problems

Solve problems

Blame, cynicism, reactivity, and passivity

Adversarial

Single, uniform solutions

Force or impose solutions

Know the right answer

Disempowerment and infantilization

Hierarchical solutions

Autocratically imposing solutions

Manage and direct

Follow models

Conform to past practices

Rule-driven values
Discovering them

Inviting and including them

Learning from them

Responsibility, optimism, proactivity, and prevention Collaborative problem-solving processes

Multiple, diverse options

Elicit or invite them

Ask the right question

Ownership and responsibility

Heterarchical ones (nonbureaucratic processes to innovation and teamwork)

Democratically selecting them

Lead and coach

Create pilot projects

Experiment and innovate

Value-driven rules 
Cloke and Goldsmith (2011) believed the first step to problem-solving paradoxically was recognition. Organizations should accept responsibility and seek to banish employee denial of a problem. This includes recognition that the problem is not solely with the opponent, identifying short- and long-term costs of not solving the problem, time commitment, energy, and resource commitment (Cloke \& Goldsmith, 2011). The second step defines the problem collaboratively and refines the elements and nature of the problem. This involves working together as a team on different ways to approach the problem strategically (Cloke \& Goldsmith, 2011). Cloke and Goldsmith (2011) believed information should be gathered before meeting employees or opponents, so that there is a clear understanding of the problem. After this phase, the problem should be restated incorporating the elements of their definition and then jointly identifying barriers that need to be overcome, identifying the possible solutions and redefining the problem again (Cloke \& Goldsmith, 2011).

In the third step, parties mutually investigate, analyze, categorize and prioritize the problem. Cloke and Goldsmith (2011) state that this stage addresses the problem by reducing it to sub-groups to examine the true essence of the problem. Cloke and Goldsmith (2011), suggests the optimal solution should be analyzed through the historical examination of the problem and its evolution over time. The third step consists of looking for inconsistencies, cultural myths, unexamined stereotypes, and environmental sources of the problem (Cloke \& Goldsmith, 2011).

In the fourth step, Cloke \& Goldsmith (2011) indicates the need to invent solutions that satisfy diverse interests without becoming attached to any particular 
solution. In this step, through brainstorming, creative solutions are produced to determine costs, consequences, impact, and merits of each while soliciting advice from coaches or experts (Cloke \& Goldsmith). The problem is reassessed for solutions through a pilot project with the intent to agree on the solutions based on the results (Cloke \& Goldsmith).

In the fifth step, a collective evaluation and feedback of the results, recognition of group efforts, and celebration is implemented. (Cloke \& Goldsmith, 2011). An action plan and set of goals with a timeline for resolving the problem is identified and implemented (Cloke \& Goldsmith, 2011). Feedback should be discussed to identify the areas that work and those that do not. Proposal of alternative solutions are identified, if not everyone agrees on a solution, which helps with the evaluation of the process (Cloke \& Goldsmith, 2011). Group input, shared experiences, knowledge, and solutions for improving the problem-solving process is implemented (Cloke \& Goldsmith, 2011).

Organizations face a number of obstacles when a conflict or problem requires a solution (Cloke \& Goldsmith, 2011). Bolman and Deal (1991) identified some of these obstructions as: the employees' inability to define the problem, employees unsure of the situation due to incomplete information or what they want, or insufficient resources. In the paradoxical problem-solving process, Cloke and Goldsmith (2011) stated obstacles could be overcome by identifying the problem and brainstorming for solutions. Additionally, through observation of historical data and trends, identifying roadblocks generated by organizational culture, and the assessment of what worked, what did not, and why can be learned. 
Collaboration is a problem-solving management style most suitable when the solution to a problem is long-term (Altmae \& Turk, 2009). An important attribute to paradoxical problem-solving involves learning and transcending from the problem (Cloke \& Goldsmith, 2011). The achievement of long-term learning is important when collaborative investigation, analyzing, and evaluation becomes a part of the solution.

Paradoxical problem-solving is related to creative problem-solving (CPS) as shown in Table 6. Paradoxical problem-solving and CPS integrate critical and divergent thinking. Each attempt to understand the problem, generate ideas, find solutions, and plan an approach. Parnes et al. (1977) argue that implementation of a solution is the most important aspect of creative problem-solving. Paradoxical problem-solving is vital when one is able to learn from the problem (Cloke \& Goldsmith, 2011).

Table 6

Similarities and Differences of Paradoxical Problem-Solving and Creative ProblemSolving

\begin{tabular}{ll}
\multicolumn{1}{c}{ Similarities } & \multicolumn{1}{c}{ Differences } \\
\hline $\begin{array}{l}\text { Implementation of critical and divergent } \\
\text { thinking skills }\end{array}$ & $\begin{array}{l}\text { The important aspects in paradoxical } \\
\text { problem-solving is learning and transcending }\end{array}$ \\
Understanding the problem & $\begin{array}{l}\text { Paradoxical problem-solving engages } \\
\text { everyone to find a solution }\end{array}$ \\
Generation of ideas & $\begin{array}{l}\text { Paradoxical problem-solving places } \\
\text { emphasis on strategic thinking and the } \\
\text { evaluation of different solutions }\end{array}$ \\
Finding solutions & \\
Planning an approach & \\
\hline
\end{tabular}


Paradoxical problem-solving involves all parties in finding a solution to the problem. On the other hand, no evidence indicates that CPS includes all parties in finding a solution to the problem.

\section{Summary}

Chapter II examined the literature encompassing management styles, current alternative dispute resolution methods used in organizations, and problem-solving. Literature also focused on the evolution of creative problem-solving processes and the introduction of the term paradoxical-problem-solving. Chapter III will explore the method in this study. Chapter IV presents the findings and Chapter V concludes with a discussion of the results, theory and implications for research and practice. 


\section{CHAPTER III}

\section{METHOD}

This chapter begins by restating the research questions that were identified in Chapter I. The research design, population and sampling, instrumentation, data collection and procedures, and data analysis will follow, concluding with a summary of the pertinent points.

\section{Research Questions}

The primary research question of this study is: What are the psychometric properties of the Problem-Solving Inventory (PSI) incorporating a paradoxical problemsolving conceptual framew ork that is used in the workplace? Two secondary research questions will be used to guide this study:

1. What is the validity evidence of the adapted PSI inventory?

2. What is the reliability evidence of the adapted PSI inventory?

\section{Concepts of Validity and Reliability}

The concepts of validity and reliability used in this study refer to the most updated Standards for Educational and Psychological Testing (Standards thereafter) published in 2014 by a joint committee from American Educational Research Association (AERA), American Psychological Association (APA), and National Council on Measurement in Education (NCME). Validity is defined as the degree to which "evidence and theory support the interpretations of test scores for proposed uses of tests" (AERA, APA, \& NCME, 2014, p. 11). These authors state that the test itself is not being evaluated for validity, but the interpretation of the test scores (AERA, APA, \& NCME, 2014). The 
meaning and conclusion of the test scores, and how it can be used for future research is what leads to validity (Cronbach, 1971).

The Standards (2014) lists five aspects of validity evidence: (a) evidence based on content; (b) evidence based on response process; (c) evidence based on internal structure; (d) evidence based on relations to other variables; and (e) evidence based on validity and consequences of testing.

\section{Evidence Based on Test Content}

Evidence derived from test content is the first aspect of validity evidence that is outlined in the Standards (2014). The evidence studies the "relationship between the content of the test and the constructs it is intended to measure" (p. 14). The use of expert judgment is crucial in examining the adapted PSI for evidence concerning test content. The Standards (2014) states that experts can assist with determining the relationship between the test and the construct. Expert judgment is also used to determine the representativeness of the items on the survey. The authors also stated that definitions of the constructs should be provided if necessary (AERA, APA, \& NCME, 2014).

To assess evidence using on test content, the edited survey will be distributed to experts who will examine the PSI for relationships between the test content and the constructs. According to the literature provided by O'Neil, Patry, and Penrod (2004) and Penfield and Miller (2004), at least 10 subject matter experts (SMEs) can be used to

provide evidence based on content. Following the guidelines in the Standards (2014), the researcher presented the experts with a clear definition of paradoxical problem solving and each construct. Then the researcher placed each item under the construct being 
examined so that each item was represented under the correct content domain. The experts take notes on the wording and appropriateness of the items and construct, and the relationship between the test and the construct. The survey items were revised using the feedback from the experts. There were three rounds of expert review. Revisions will follow feedback from experts and an updated draft will be sent to them for review. The last round will follow additional further feedback from the experts. The experts will have two weeks to revise each round.

\section{Evidence Taken from Response Processes}

In the Standards (2014), evidence derived from response processes of test takers "can provide evidence concerning the fit between the construct and the detailed nature of the performance or response actually engaged in by test takers" (p. 15). If the responses by the test takers are part of the argument for validity, then theoretical or empirical evidence should be provided. Empirical evidence is provided in the following section to support the cognitive processes in other fields of study where the PSI was examined.

Cognitive interviews entail overseeing draft survey questions to individuals and getting verbal feedback about the survey responses which is then used to determine if the survey is producing the information needed for research (Beatty, 2003). Recording other evidence, such as body language and response time is important information that would assist with determining evidence based on response processes. A sample question asked during the cognitive interview is: What was your thought process when answering the items in the first construct? Evidence based on response processes is in fact examining if the adapted PSI is actually measuring the constructs it is intended to measure. 
To provide evidence using response processes, I asked a sample of participants via think-aloud about the thought processes when they are completing the survey, and how the answers were determined. I also asked about participants' strategies or responses to specific questions.

\section{Evidence Using Internal Structure}

Evidence derived from internal structure indicates the relationships between the construct and the items on which the suggested test score interpretations are created (AERA, APA, \& NCME, 2014). The authors state that "if the rationale for a test score interpretation for a given use depends on premises about the relationships among test items or among parts of the test is being examined, then internal structure should be tested" (AERA, APA, \& NCME, 2014, p. 27). In the Standards (2014), the authors discuss the use of multivariate statistical analysis, such as factor analysis, to assist with supporting claims of a test being unidimensional.

The researcher used SPSS to determine evidence using internal structure, exploratory factor analysis using principal axis factoring for the extraction, and Direct Oblimin for the rotation. Direct Oblimin rotation is being used because the items are highly correlated. Exploratory factor analysis will focus on how the statements in the edited PSI will respond to the latent variables. Latent variables are not directly observed, but rather deduced from other observable variables (Bollen \& Lennox, 1991). The overarching goals of exploratory factor analysis is to understand the measured variables and their relationships. 
In examining evidence using internal structure, the researcher is expecting each statement in the instrument to load on to different factors, also known as the constructs. As a rule of thumb, Tabachnick and Fidell (2001) indicated that a 10\% overlapping variance can occur with other factors resulting in cross-loadings. Cross-loading of an item, "is an item that loads .32 on two or more factors/constructs" (Costello \& Osborne, 2005, p. 4).

\section{Evidence Based on relations to Other Variables}

Evidence using relations to other variables refers to "traditional forms of criterion related evidence for validity such as correlations with external criteria relevant to the attributes measures (e.g., other test scores, grades, supervisor ratings" (Sireci \& Parker, 2006, p. 28). Some concepts of evidence based on relations to other variables are convergent and discriminant evidence, test-criterion relationships, and validity generalization (The Standards, 2014).

\section{Evidence for Validity and Consequences of Testing}

The Standards (2014) states that evidence using validity and consequences of testing "involves gathering evidence to evaluate the soundness of the proposed interpretations for their intended uses" (p. 19). Some examples of considerations of consequences of testing are interpretation and uses of test scores intended by test developers, claims made about test use that are not directly derived from test score interpretations, and consequences that are unintended (The Standards, 2014). For the purpose of this study, the first three standards will be examined and estimated. 


\section{Reliability}

The Standards (2014) indicates that reliability is used in two ways:

reliability/precision and reliability coefficient. Reliability/precision is the consistency of scores in the more general sense "across replications of a testing procedure" (p. 33) and reliability coefficient is the "correlation between the scores on two equivalent forms of the test" (p. 33). Reliability/ precision of the scores of the adapted PSI depends on how the scores vary when replicated; and the analyses of reliability/precision depend on the inconsistencies permitted in the replications (for example, raters, or contexts) (AERA, APA, \& NCME, 2014). Reliability/precisions uses the generalizability theory as a framework that seeks to assess the factors that contribute to the different sources of error (AERA, APA, \& NCME, 2014). Reliability coefficients aim to quantify the consistency amongst the replicated tests on a scale from 0 to 1 . Coefficient alpha, also known as Cronbach alpha, is the most used reliability coefficient.

Cronbach alpha was developed (Cronbach, 1951) to measure the internal consistency of an instrument or scale and is expressed as a number between 0 and 1 . Internal consistency is the estimation of reliability based on internal items of the test and the correlation amongst them. To test Cronbach alpha, a single test is administered using information from the relationship among test items.

\section{Development of the Constructs}

Two prominent instruments were developed in earlier years to measure the problemsolving process. One was Platt and Spivack's (1975) Means-End Problem-Solving Procedure (MEPS), which focused on the personal aspects of the problem-solving 
process. The instrument consisted of 10 items that aim to understand a person's ability to find the means to reach an achievable solution (Platt \& Spivack, 1975). The second instrument, Problem-Solving Inventory (PSI), consists of 32 items measured on a 6-point Likert scale (Heppner \& Petersen, 1982). The instrument was designed to measure a person's problem-solving abilities, competences, behaviors, and attitudes toward problem-solving (Heppner \& Baker, 1997) using three constructs or factors: ProblemSolving Confidence (11 items), Approach-Avoidance Style (16 items), and Personal Control (5 items), which is shown in Appendix A. In this study, the PSI used a paradoxical problem-solving conceptual framework to closely examine human resource professionals' perceptions on problem-solving abilities.

\section{Problem-Solving Confidence}

Heppner and Baker (1997) defined problem-solving confidence as the belief in one's problem-solving abilities while engaging in problem-solving tasks. A sample statement is, "I trust my ability to solve new and difficult problems." Problem-Solving Confidence factor is measured by looking at one's own attitude and behavior against problem-solving confidence. Problem-solving confidence is positively associated with coping efforts and behavioral outcomes (Heppner et al., 1995).

\section{Approach-Avoidance Style}

Approach-avoidance style is defined as the penchant for either approaching or avoiding problem-solving tasks (Heppner \& Baker, 1997). A sample statement from this construct is, "I have a systematic method for comparing alternatives and making decisions." The previous statement is an example of the "approach" aspect of the 
construct. A sample of the "avoidance" aspect is, "When a solution to a problem is unsuccessful, I do not examine why it did not work." Approach-avoidance style is associated to rational decision-making style, coping, curiosity, and successful use of helping resources (Heppner et al., 1995).

\section{Personal Control}

The personal control construct was defined as the belief that one has control over their behavior or attitude when faced with problem-solving tasks (Heppner \& Baker, 1997). A sample statement is, "When my first efforts to solve a problem fail, I become uneasy about my ability to handle the situation." Personal control construct has been examined for over 30 years (e.g., Lefcourt, 1996; Rotter, 1966) and is positively associated with personal activity and negatively associated with anxiety, anger, distress (Heppner et al., 1995).

In the adapted PSI edited by the researcher, the second factor (approachavoidance style), 13 statements were modified for the purpose of the current study. The three statements that were not edited remained in their original form so that the researcher can examine how the individual responds to the approach-avoidance style from a personal view. The statements in the personal control construct were also kept so that the individual taking the PSI can reflect on his/her problem-solving skills and abilities. Another reason the statements were kept in their original form in the personal control construct, is that paradoxical problem-solving focuses on the learning-oriented approach (Cloke \& Goldsmith, 2011) and the evolution of not only finding solutions but learning from them. 
The three PSI factors have been replicated across many studies, cultures and samples. Some of these included cross-cultural researches among American and European college students (Neville, Heppner \& Wang, 1997), African American college students (Harrison, 1994; Neville et al., 1997), and Turkish college students (Sahin, Sahin \& Heppner, 1993), just to name a few. In later years, Nota, Heppner, Soresi and Heppner (2009), examined cultural validity on Italian students who completed the PSI and the Myer-Briggs Type Indicator, focusing on focusing on the (a) the psychometrics estimates of the PSI and the differences associated with gender, study motivation, use of learning strategies, intelligence, and (b) the relationships between the PSI and personality characteristics. A year later, a study was conducted on undergraduate students in Australia examining the relationship between the PSI and its subscales with positive and negative affect, depression and anxiety (Beccaria \& Machin, 2010). Previous studies using the PSI include: depressions (35 studies); hopelessness and suicidal behavior (12 studies); eating disorders (3 studies); general psychological and social adjustment (24 studies); anxiety (12 studies); gender-related variables (5 studies); alcohol use/abuse (5 studies); parental associations (6 studies); and childhood traumas (4 studies) (Heppner, Witty \& Dixon, 2004). However, the research is limited to the fields of adult education and human resource development, and conflict management.

Over 100 studies have been conducted (Heppner, Witty \& Dixon, 2004) and all support the convergent, construct and discriminant evidence of validity of the PSI. Also, research across a number of samples and cultures provide strong empirical evidence of relatively high internal consistency of the PSI, with alpha coefficients of .90 for total 
inventory, .85 for problem-solving confidence, .84 for approach-avoidance style, and .72 for personal control (Heppner et al., 1997). Previous studies have shown that the testretest reliability coefficients over a three-week period for each factor were .89 for problem-solving confidence, .85 for approach-avoidance style, and .83 for personal control respectively (Heppner, 1988).

The adapted PSI is used to measure the three factors, problem-solving confidence, approach-avoidance style, and personal control on an individualistic level. The adapted PSI used the paradoxical problem-solving concept to understand the perception of persons who are employed in organizations and problem-solve, and human resource professionals' perception of problem-solving ability in an organization.

\section{PSI Likert Scale}

The instrument in this study used a 6-point Likert scale: (1) strongly disagree, (2) disagree, (3) slightly disagree, (4) slightly agree (5) agree, and (6) strongly agree. A 6point Likert scale was used instead of a traditional 5 or 7-point Likert scale because the responses "neutral" or "prefer not to respond" was not an option for this adapted PSI. Furthermore, using either 5 or 7 - point Likert scale would not have provided the data that was necessary to develop and validate the adapted PSI. The Likert scale (Likert, 1932) is most frequently used in social sciences to measure attitudes, opinions, personalities and such. With the use of a Likert scale, the responses would be (a) concise and to the point; (b) easy and quick to answer; (c) easy to compare with other responses; and (d) less costly to analyze (Spector, 1992). 


\section{Research Design}

The study used a concurrent mixed methods design, in which the quantitative and qualitative data were collected independently and at the same time (Onwuegbuzie \& Collins, 2007). In the using test content. The second step included a pilot study with two stages: (a) a focus group cognitive interview that used validity evidence on response processes, and (b) the examination of the survey using validity evidence on internal structure and reliability. Following the validation, the researcher conducted a focus group cognitive interview with a sample of participants and distributed the PSI to HRD professionals to examine evidence using the response processes. Lastly, the researcher examined the adapted survey for evidence considering the internal structure. Cronbach's alpha was used to measure the internal consistency of the PSI.

A concurrent triangulation design (Creswell, Plano Clark, Gutmann \& Hanson, 2003) was used in the study to directly compare the quantitative results with the qualitative conclusions. Examining the integration of quantitative and qualitative results using a concurrent triangulation helps with "obtaining different but complementary data on the same topic" (Morris, 1991, p. 122).

According to Tashakkori and Creswell's (2007) study (as cited in Reio \& Werner, 2017), they offered a broad definition of mixed methods:

As an effort to be as inclusive as possible, we have broadly defined mixed methods here as research in which the investigator collects and analyzes data, integrates the findings, and draws inferences using both qualitative and quantitative approaches or methods in a single study or a program of 
inquiry. A key concept in this definition is integration. (p. 4)

There are two main strengths of using a mixed method design. First, it allows the researcher to use many approaches in order to answer the research questions. Second, it enables the researcher to take an eclectic approach to method selection and is not confined to one method or approach (Johnson \& Onwuegbuzie, 2004).

\section{Participants and Sampling}

The population for the study consisted of managers or supervisors who are employed in the human resources (HR) department as well as individuals who are employed and problem-solve as part of their routine. The targeted group belonged to various industries, such as hospitality, technology, academia, energy, advertising or travel. Professionals in the HR field were recruited from the Association of Talent Development (ATD), Florida International University, Nova Southeastern University and the Comparative and International Education Society's (CIES) Education: Conflict and Emergencies Special Interest Group (SIG). These associations and universities were chosen because of access to the diverse communities within the groups. The researcher is a member of the associations and society and is a student at FIU. The researcher also had connections at Nova Southeastern University in several departments such as Career Services, and College of Arts, Humanities and Social Sciences.

Criterion and convenience purposive sampling methods were used to recruit participants. Criterion sampling refers to the selection of participants who have met a predetermined criterion of importance to this study (Patton, 1990). In the study, all participants met the following criteria: (a) their position in the organization was either a 
supervisor or manager or equivalent, (b) they were employed in the human resources department, and (c) they were employed in an organization that required problemsolving. Convenience purposive sampling involves drawing samples that are willing to participate in the study and easily available based on specific purposes associated with answering the research questions in this study (Teddlie \& Yu, 2007).

\section{Phase One}

To examine the adapted survey for validity evidence using test content, the researcher emailed experts in HRD and/or conflict management and sought permission to examine the survey for: word appropriateness of the construct, wording of the survey, and the consistency between the construct and the items (see Appendix B). These experts consisted of academia and or practitioners from Florida International University and Nova Southeastern University and were contacted via an introductory email describing the study, purpose, and outcome of the study.

\section{Phase Two}

To examine the adapted survey for validity evidence using response processes in the pilot study, the researcher emailed two colleagues who are members of the Society for Human Resource Management (SHRM) and sort permission for them to participate in a focus group cognitive interview, shown in Appendix C. A third participant was recruited via purposive sampling using her occupation as a Group Training Manager. The emailed sent to participants described the study, purpose and the significance. To examine for validity evidence of the internal structure, a pilot study for survey distribution was conducted. In order to invite persons to participate, an email was sent to 
colleagues describing the study, the purpose and significance (see Appendix D).

Reliability evidence was also examined.

\section{Phase Three}

In the third phase, the researcher contacted the president and president-elect of ATD South Florida Chapter to seek permission to access a sample of participants, who are employed within the HR department, and to conduct focus group cognitive interviews. The request for permission was sent to the president and vice-president via email and phone. After the researcher received permission and access, an introductory letter was sent to potential participants outlining the purpose, goals and the significance of the study (see Appendix E).

\section{Phase Four}

To examine the adapted survey for validity considering internal structure, the researcher emailed colleagues several listservs within Florida International University and Nova Southeastern University (shown in Appendix F). The survey was opened for three weeks, and a reminder to participate was emailed to the same persons after the first and second week.

\section{Data Collection and Procedures}

In this section, the data collection procedure for each will be examined, in addition to the strengths and weakness of evidence based on test content, and validity based on response processes. 


\section{Data Collection Methods}

Web-based surveys were used to collect data to examine validity evidence using internal structure. To obtain a group of participants, the survey was administered via the web using Qualtrics (see Appendices D and E).

Table 7

Data Collection

\begin{tabular}{lll}
\hline $\begin{array}{c}\text { Sources of Validity } \\
\text { Evidence }\end{array}$ & \multicolumn{1}{c}{ Data Collection } & Type of Data \\
\hline Test Content & Experts: 5 Academia; 5 Professional & \\
& (O'Neil et al., 2004; Penfield \& Miller, & \\
& 2004) & \\
Pesponse Process & Pilot Study: Focus group Cognitive & QUALITATIVE \\
& Interviews: 3 persons. \\
& Focus group Cognitive Interviews: 6-9 & \\
& participants (Krueger, 2000). \\
& Therefore 6 participants will be used \\
& for each focus group interview \\
& Exploratory Factor Analysis: \\
& 320 individuals (Yong \& Pearce, \\
&
\end{tabular}




\section{Strengths and Weaknesses of Web-Based Survey}

Using online surveys to administer survey research can be a powerful and advantageous for researchers. Web-based online surveys are growing in reputation (Couper, 2000; Couper, Traugott, \& Lamias, 2001) and are being used by many researchers on various topics (Kypri, Stephenson, \& Langley, 2004). The main strength of using online surveys is the potential to contact and engage more participants. Webbased surveys are also more cost effective than using mail or phone surveys (Parks, Pardi, $\&$ Bradizza, 2006). Even if the respondents are given incentives to complete the online survey, the cost per response is often less than administering a mail or phone survey. Another main advantage of using web-based internet surveys is being able to access populations with diverse backgrounds (Garton, Haythornthwaite, \& Wellman, 1999). Tapping into virtual communities where you can access individuals with specific backgrounds, education, and attitudes helps researchers who are looking at cost-effective ways in distributing surveys. Researchers also use this method of distributing surveys because it saves time when looking for individuals with specific criteria to complete surveys. Other advantages include shorter communication times, more design options, and less time spent on inputting data (Fan \& Yan, 2010).

Despite the many advantages of using online surveys, there are also concerns with distributing web-based surveys to participants. A high non-response rate can jeopardize the quality of the survey. The reasons for non-response rates could include the nature or wording of the question (Smyth, Dillman, Christian, \& Stern, 2006) and the type of question and the answer format (Denscombe, 2008) (Couper, 2000; Crawford, Couper, \& 
Lamias, 2001; Dommeyer \& Moriarty, 2000). Another limitation of web-based surveys is the non-standardization of email address (Dillman, 2000). In some cases, respondents may have several email addresses, and some may not be checked regularly.

To reduce non-response rate, the researcher ensured that the survey questions or statements were written in a language that was easy to understand (Umbach, 2005). The researcher contacted the participants multiple times to increase response rates (Umbach, 2005). In addition, the researcher also kept the survey short and to the point in order to decrease non-response.

\section{Strengths and Weakness of Focus Group Cognitive Interview}

A focus-group interview is used to collect data for validity evidence using response processes. Focus group interviews are small group interviews where individuals are asked questions that explore their perceptions or ideas on a particular topic (Morgan, 1997) and are guided by a moderator. Conducting a focus group cognitive interview has its strengths and weaknesses. A main strength for conducting focus group interviews is that participants encourage each other to talk and ideas evolve during the conversations. Another strength of the focus group interview is that it allows the researcher to tap into participants' attitudes and beliefs within a specified timeframe (Kitzinger, 1995).

Conducting focus groups is also cost-effective when having participants gather in a room as opposed to one-on-one interviews that would involve expense.

However, there are some concerns when conducting focus group interviews, such as the lack of articulation when participants gather in a room (Kitzinger, 1995) and the interview setting. In some cases, participants are not able to speak fluently with other 
participants in the room because of shyness. Some participants may talk less if others talk more. In these cases, participants might not fully articulate what they are thinking and the information they want to convey may get lost. Another problem of using focus group interviews is the unnatural setting in which it is conducted (Morgan, 1984). Participants may not feel comfortable talking when the interviews are conducted in locations that the participants are not familiar with.

\section{Procedures}

Permission was requested from Florida International University's Graduate School and Institutional Review Board before the study was conducted (IRB-18-0136).

\section{Phase One}

To provide validity evidence based on test content, the researcher described the purpose of the study in an email and send it to the 10 experts in the field (practitioners and academia) for their review of the test contents (shown in Appendices A and G). The

contents of the items were reviewed on wording, relevance, appropriateness, and domain representation (Sireci \& Faulkner-Bond, 2014). In the email, the researcher presented the experts with a clear definition of paradoxical problem-solving and each of the constructs. The researcher requested that the experts examine each statement under each construct for relevance. The time-frame from the letter of invitation to SMEs to completion of this step was six weeks. There were three rounds of communication between the researcher and the reviewers, with two weeks for each review. 


\section{Phase Two}

This phase included two stages: (a) a pilot study focus group cognitive interview with three persons to examine for validity evidence based on response processes, and (b) a pilot study survey distribution to 52 individuals to examine for validity evidence based on internal structure, and reliability evidence. In the first stage, only three persons were used for the pilot study focus group cognitive interview because there were three constructs and one individual to represent each. At the beginning of the interview (see Appendix $\mathrm{H}$ ), the researcher described the study, purpose and significance to the participants. The researcher also reviewed the definition of paradoxical problem-solving and the purpose of this approach. The researcher allowed five minutes for the participants to review each construct and then think-aloud. Probing questions were asked at the end of the survey to capture more information about their thoughts on the survey. The researcher video-recorded the interview to capture any positive or negative body language. The time frame for the focus group cognitive interview was 1 day during a 30minute period. In the second phase, the survey was distributed to colleagues within the researcher's network. The emailed (see Appendix F) included the definition of paradoxical problem-solving, the purpose, and significance of the study. After five days, a reminder email was sent to colleagues requesting for them to participate if they did not and to invite them to email the survey to other persons. Time for completion for each participant was estimated to be 10-15 minutes. Exploratory factor analysis was used to determine validity using internal structure. The extraction approach used in this study is principal axis factoring. The rotation approach being used in this study is Direct Oblimin 
because the items are highly correlated. Cronbach's alpha was used to examine the survey for reliability evidence. The time frame for the distribution was ten days.

\section{Phase Three}

To provide evidence based on response processes, two focus group cognitive interviews were conducted, within an interval of three weeks. According to Krueger (2000), six to nine participants are necessary when conducting cognitive interviews. The researcher used six participants for each focus group interview session. The sample of participants were selected from Broward County, Florida for ease of location for participants. The goal was to have a diverse group of individuals from different ethnicities, age groups, and gender. The focus group interviews were held at Florida International University I-75 campus in a private study room. The rooms accommodated up to 10 persons and were quiet and confidential. Both focus group interviews were video-recorded and voice-recorded to capture body language and input from participants. The researcher acted as the moderator and note taker during both focus group interviews. The moderator has experience in mediation which allowed for ease of communication from each participant without having a dominant participant. A hard copy of the survey was given to the participants at the beginning of each focus group interview.

There are two methods for conducting cognitive interviews: think aloud and probing (Beatty \& Willis, 2007). Although think aloud is the more dominant form of conducting cognitive interviews (Bercini 1992; Forsyth \& Lessler 1991; Royston 1989), other researchers suggest that probing has its benefits as well (Royston \& Bercini 1987; Willis, Royston, \& Bercini, 1991). Think-aloud interviews can be guided by the 
interviewer and are based on the individual's perceptions (Beatty \& Willis, 2007). According to Willis (as cited in Beatty \& Willis, 2007), an emphasis is placed more on probing than think-aloud, as it makes the latter more problematic for the participants who are not sure what they should say. A mix of both probing and think aloud may be used depending on the feedback and communication from participants.

\section{Strengths and Weakness of Think-Aloud and Probing}

Think-aloud and probing methods both have advantages and disadvantages when conducting focus group interviews. Think-aloud reduces the researcher's biases and in some situations, the researcher does not need to be knowledgeable on the survey design or the specific questions (Bolton \& Bronkhorst, 1996). Another advantage to using think-aloud is that the researcher does not direct the flow of thoughts (Conrad, Blair \& Tracy, 2000). A third advantage of using think-aloud is that data are collected during the interview as opposed to probing which occurs after the interview (Forsyth \& Lessler, 1991; van der Veer, Hak \& Jansen, 2000). However, think-aloud is considered an obstruction when conducting focus group cognitive interviews, stating that self-reporting is taken from short-term memory (Ericcson \& Simon, 1980), and that participants thinkaloud poorly (Willis, 2005). Other researchers believe that probing has its advantages. Willis $(1994,2005)$ indicates that probing brings the interview back to focus, stating that participants tend to diverge onto irrelevant matters. Using this method, the interviewer is able to tap into short term-memory to retrieve responses that the participant might have forgotten about or ignored (Willis, 1994). 
The researcher used both probing questions and think-aloud during the 60-minute focus group cognitive interview in the current study. A sample of probing questions (see Appendix I) include: (a) I am interested in what you were thinking when you were completing this survey, could you tell me more about it? and (b) what were the thoughts going through your mind when you completed this survey? The time-frame for this step would be approximately six weeks.

\section{Phase Four}

Before examining the adapted survey for validity evidence based on internal structure, the survey was revised on the basis of feedback given in Phase Three. The adapted survey was uploaded into Qualtrics and was distributed via email (see Appendix J). The participants represented the final sample using the 10:1 ratio (10 persons per item) (Yong \& Pearce, 2013). The survey has a total of 27 items and data was collected from 300 HR managers or supervisors, and problem-solvers employed in organizations. To increase response rate, participants were told that their responses to the survey would contribute to future research of an adapted PSI. Exploratory factor analysis was used to determine validity of the internal structure. The extraction approach used in this study was principal axis factoring extraction. Using principal axis factoring extraction assumes that there is one factor for every variable, but that factor does not affect other variables (Ngure, Kihoro, \& Waititu, 2015). The rotation approach used in this study was Direct Oblimin, which is oblique rotation that aims to "simplify the structure and the mathematics of the output" (Yong \& Pearce, 2013, p. 84). Direct Oblimin was also used because the factors being used are highly correlated. Time for completion for each 
participant was approximately 10-15 minutes. The time-frame for this step was three weeks with three rounds of emails to achieve the number of participants.

\section{Data Analysis}

\section{Qualitative Data}

Validity evidence of test content and response processes was analyzed using content analysis, which is an independent qualitative descriptive approach identifying, reporting, and qualifying patterns (Vaismoradi, Turunen, \& Bondas, 2013). Content analysis is a general term to describe the different ways in which data are analyzed (Powers \& Knapp, 2006). The researcher analyzed the data when the experts returned the surveys. To analyze the data from both focus group cognitive interviews, the researcher first transcribed the recorded interviews. The researcher then reviewed the transcriptions several times noting initial ideas. The researcher searched for developing patterns and trends with words used by the participants, and the frequency of words (Mayring, 2000). The researcher examined the patterns, trends and frequency of words for developing categories. In the organizing stage of content analysis, the researcher conducted open coding, placing these codes into main categories.

\section{Quantitative Data}

The survey responses were entered in the SPSS database and analyzed by using the command of exploratory factor analysis (Williams, Onsman \& Brown, 2010). The aim of exploratory factor analysis is to discover multifaceted patterns by examining datasets and testing the anticipated results (Yong \& Pearce, 2013). In using exploratory factor analysis, the researcher was able to determine from the results the number of 
factors, the number of items that load on a factor and the factor loadings for all items. The researcher used rotation and extraction at the same time.

To examine the instrument for reliability evidence, the score of each scale was entered into SPSS and examined using Cronbach's alpha.

\section{Summary}

Chapter III focused on the research process which includes the concepts of validity and reliability, research design, population and sampling, data collection and data analysis in this study. Chapter IV presents the detailed findings and is followed by chapter 5. Chapter V includes a discussion of the results, theory and implications for research and practice. 


\section{CHAPTER IV}

\section{RESULTS}

The purpose of the mixed methods study was to develop and validate an adapted survey that incorporates the paradoxical problem-solving concept under the context of social conflict theory to provide employees and employers with more creative techniques to manage organizational conflict. Data were collected and analyzed to answer the study's main research question: What are the psychometric properties of the ProblemSolving Inventory (PSI) incorporating a paradoxical problem-solving conceptual framework that is used in the workplace? It was also guided by two secondary research questions:

1. What is the validity evidence of the adapted PSI?

2. What is the reliability evidence of the adapted PSI?

The study used a concurrent mixed methods design where the quantitative and qualitative data were collected independently and at the same time (Onwuegbuzie \& Collins, 2007). The report of the results is organized according to the four phases of research conducted: (a) validity based on test content, (b) validity based on response processes, (c) validity based on internal structure, and (d) reliability (AERA, APA, \& NCME, 2014), shown in Table 8.

\section{Phase One}

Phase One used a qualitative approach to preliminarily establish the validity using test content, which studies the "relationship between the content of the test and the 
constructs it is intended to measure" (AERA, APA, \& NCME, 2014, p. 14). The use of expert judgment is crucial in examining the adapted PSI for evidence gathered on test content. The Standards (2014) states that experts can assist with determining the relationship between the test and the construct.

Table 8

Research Design

\begin{tabular}{|c|c|c|c|c|c|}
\hline Phases & Validity & Reliability & $\begin{array}{l}\text { Date } \\
\text { Collection }\end{array}$ & $\begin{array}{l}\text { Type of } \\
\text { Data }\end{array}$ & Duration \\
\hline Phase 1 & $\begin{array}{l}\text { Evidence Based } \\
\text { on Test Content }\end{array}$ & & $\begin{array}{l}5 \\
\text { practitioners, } \\
6 \text { academia }\end{array}$ & Qualitative & 3 weeks \\
\hline \multirow[t]{3}{*}{$\begin{array}{l}\text { Phase } \\
\text { 2: } \\
\text { Pilot } \\
\text { Study }\end{array}$} & $\begin{array}{l}\text { Evidence } \\
\text { Based on } \\
\text { Response } \\
\text { Processes }\end{array}$ & & 3 participants & Qualitative & 1 day \\
\hline & $\begin{array}{l}\text { b. Evidence- } \\
\text { based on } \\
\text { Internal } \\
\text { Structure }\end{array}$ & & $\begin{array}{l}\text { Exploratory } \\
\text { Factor } \\
\text { Analysis: } \mathrm{N}= \\
52\end{array}$ & Quantitative & 10 days \\
\hline & & $\begin{array}{l}\text { Cronbach's } \\
\text { Alpha }\end{array}$ & $N=52$ & Quantitative & 10 days \\
\hline Phase 3 & $\begin{array}{l}\text { Evidence Based } \\
\text { on Response } \\
\text { Processes }\end{array}$ & & 6 participants & Qualitative & 2 weeks \\
\hline \multirow[t]{2}{*}{ Phase 4} & $\begin{array}{l}\text { Evidence-based } \\
\text { on Internal } \\
\text { Structure }\end{array}$ & & $\begin{array}{l}\text { Exploratory } \\
\text { Factor } \\
\text { Analysis: } N= \\
300\end{array}$ & Quantitative & 3 weeks \\
\hline & & $\begin{array}{l}\text { Cronbach's } \\
\text { Alpha }\end{array}$ & $N=300$ & Quantitative & 3 weeks \\
\hline
\end{tabular}


Expert judgment is also used to determine the representativeness of the items on the survey. The 11 experts were emailed the adapted Paradoxical Problem-Solving Inventory (PSI) along with the guidelines for completing this phase (see Appendix K). These words represented the change in the original PSI (Heppner \& Petersen, 1982), adapting the paradoxical approach. The experts included five practitioners and six persons in academia with $27.2 \%$ being male and $72.3 \%$ female. The experts completed three stages of the phase within a two-week timeframe for each.

\section{Stage One}

\section{Problem-Solving Confidence Construct}

In the survey emailed to the experts, the first construct, Problem-Solving Confidence, consisted of 11 statements. The general comments consisted of, "too wordy," "needs re-wording because of grammar," and "are you using teams or in a group setting?" Many of the experts also agreed that the use of "teams," "in a group setting," and "working with others" was confusing. Two experts indicated that the first and second statements need to be separated because "it was too wordy and confusing." More specifically, some experts said that the first statement, "I am able to think up creative and effective alternatives to solve a problem when working in groups", should be edited to "I am able to develop creative and effective alternatives to solve a problem when working in groups." They indicated that the words "think up" is too general and misleading. The experts agreed that the fourth, fifth, sixth, ninth, tenth and eleventh statements were too wordy, and that grammar could be a contributor to the misunderstanding of the survey. Appendix $\mathrm{H}$ includes the PSI that was given to the 11 experts to review in stage one. 
Table 9

Statements That Needed Re-Wording Because of Inconsistencies

\# $\quad$ Statements

1 When a solution to a problem was unsuccessful, I do not work with others to examine why it didn't work.

2 When I am confronted with a complex problem, I do not work with others to develop a strategy to collect information so I can define exactly what the problem is.

4 After I have tried to solve a problem with a certain course of action, I take time and compare the actual outcome to what I thought should have happened with others.

5 When I have a problem, I work with others to think up as many possible ways to handle it as I can until I can't come up with any more ideas.

6 When confronted with a problem, I consistently examine my feelings to find out what is going on in a problem situation.

7 When confronted with a problem, I tend to work with others do the first thing that I can think of to solve it.

8 When deciding on an idea or possible solution to a problem with others, I do not take time to consider the chances of each alternative being successful.

9 When confronted with a problem, I work with others to stop and think about it before deciding on the next step.

10 I generally go to the first good idea that comes to my mind.

13 When trying to think up possible solutions to a problem, I do not come up with very many alternatives when working with others.

15 When working with others and confronted with a problem, I do not usually examine what sort of external things my environment may be contributing to my problem. 


\section{Approach-Avoidance Style Construct}

The second construct, Approach-Avoidance Style, consisted of 16 statements. The general comment on this construct was that the statements were "too wordy." More specifically, the experts indicated that statements one, two, four, five, six, seven, eight, nine, ten, thirteen, and fifteen, shown in Table 9, needed re-wording because of the inconsistencies with the construct and with grammar.

More specifically, one expert suggested that in statement seven, "come up with more creative solutions" be used instead of "...do the first thing I can think of to solve it." Some experts also asked to clarify the use of the words "stop and think" in statement nine. They indicated that the use of these words made the statement too wordy and can be replaced with a phrase that would be more effective for the survey. One expert questioned the statement on its redundancy. It was commented "When trying to think up possible solutions, I do not come up with many alternatives in a group setting."

\section{Personal Control Construct}

The third construct, Personal Control, consisted of five statements. The five statements were the original statements that were developed by Heppner and Petersen (1982). The experts indicated that statement two, "sometimes I do not stop and take time to deal with my problems, but just kind of muddle ahead" should be edited and the word "muddle" be deleted. The experts indicated that this word can be confusing, and though the meaning can be sought from the context of the sentence, it can still be misleading. The experts also indicated that statement three, "even though I work on a problem, sometimes I feel like I am groping or wandering, and am not getting down to the real 
issue" should be edited and the words "groping and wandering" should be omitted. They indicated that word appropriateness for this construct can be misleading and confusing to the reader.

\section{Demographic Section}

The experts also gave feedback on the demographic section of the adapted PSI. Some general comments on this section include: "ethnicity should be placed before race," "demographic should be changed to demographic information," "Native American and Alaskan Native should be included" and "the number of years in the current position should accommodate Millennials." One expert suggested that the definition of a manager and a director role be present, and another expert suggested combining race and ethnicity to match the forward thinking of the United States Consensus. One overall comment on the adapted survey is that for ease of reading the definitions and the statements, each definition should be placed just before each respective construct.

\section{Stage Two}

During stage two of establishing validity based on test content, the adapted survey was revised and analyzed (see Appendix L) with all of the feedback and recommendations from the experts from the first round. Their feedback from the first round focused on word appropriateness, the wording of the survey, and the consistency between the construct and the item. The adapted survey was emailed to them with specific guidelines for the second round. The experts were asked to review the entire adapted survey and closely review specific statements for redundancy and to decide if specific statements matched another construct using the definitions presented in the 
adapted PSI. The experts were also asked to look closely at the demographic information to determine the wording and demographic specific questions. The PSI that was given to the 11 experts for stage two is shown in Appendix L.

The first construct, Problem-Solving Confidence, based on previous feedback, consisted of 12 items. Two statements were highlighted, and the experts were asked to review them to decide if they should be in the third construct, Personal Control. In the first statement, "Many problems I face are too complex for me to solve by myself," five experts concluded that the statement should be moved to Personal Control construct, and five experts concluded that the statement be kept in Problem-Solving Confidence Construct. One expert did not respond to this statement. The definitions of both Problem-Solving Confidence construct and Personal Control construct were reviewed again by the researcher, and the statement was moved to the latter. The rationale for the change was due to the keywords in Personal Control, which was "belief that one has power over their behavior or attitude."

In the second statement under Problem-Solving Confidence construct, "When confronted with a problem, I am unsure of whether I can handle the situation independently," three experts concluded that the statement remains in Problem-Solving Confidence construct, and seven experts concluded that the item be moved to Personal Control construct. The definitions were again reviewed by the researcher, and the statement was moved to Personal Control construct because of the one's own behavior or attitude when faced with a problem-solving task. 
The third statement under Approach-Avoidance Style construct, "When trying to think up possible solutions, I do not come up with many alternatives in a group setting," was reviewed by the experts for redundancy. The question to this statement's redundancy was based on feedback from stage one. Five experts concluded that the item was not redundant, and five experts concluded that it was redundant. One expert did not respond to this statement. After reviewing the original PSI created by Heppner and Petersen (1982), it was determined by the researcher that the statement remains in the adapted PSI. The statement, while similar to others, was not capturing the same evidence as the other statements under this construct, and therefore was left in the ApproachAvoidance Style construct.

The experts gave feedback on the demographic information that was revised for the second stage. One expert indicated that "Non-Hispanic, Non-Latino or Non-Spanish" would lead to more than one response, especially with an option on the survey being "Hispanic, Latino or Spanish," and that typically, "Non-Hispanic" is followed by "White" (Non-White Hispanic). Another expert asked who constitutes as "Non-Hispanic, Non-Latino, Non-Spanish?" Ethnicity and Race section was revised and "Non-Hispanic, Non-Latino or Non-Spanish" was deleted from the survey for the third stage.

Experts also indicated that the question "Number of years in problem-solving" was too vague and needed to be revised, focusing more on specifically in the number of years of problem-solving within organizations. This statement was revised for the third stage to "Number of years of problem-solving in organizations that you were employed." 


\section{Stage Three}

In stage three of establishing validity based on test content, the experts were emailed the adapted survey with the revisions from stage two (see Appendix M). During the final stage of establishing validity evidence based on test content, the experts reviewed the revised adapted survey for the last time. This included the demographic information for word appropriateness, wording of the survey, and the consistency between the construct and the item. Three experts provided feedback on grammar and edited seven statements. One expert suggested the use of the word "team" instead of "group" in statements. The expert indicated that "team" suggests "the experience of working together." Five experts narrowed in the demographic information section and provided feedback on the question, "Number of years problem-solving in organizations that you were employed." They indicated that the statement should be revised for grammar. This statement was revised to "Number of years employed in organizations that require you to problem-solve." The experts also indicated that "Number of years in current position" might be too vague and should be revised to reflect the number of years in "current field" or "current level." This statement was revised to "Number of years in the field." One expert indicated that Hispanic should be in a separate section asking, "Are you Hispanic?" with the options of "Black Hispanic," "White Hispanic," and "Mixed." The survey distributed to the 11 experts during stage three is shown in Appendix J. 


\section{Phase Two}

Phase two consisted of two stages via a pilot study: stage one was a qualitative phase used to establish validity evidence based on responses processes, and stage two was a quantitative phase used to establish validity evidence based on the internal structure using factor analysis and reliability using Cronbach's alpha.

\section{Stage One: Qualitative Pilot Study}

In the first stage of establishing validity evidence based on responses processes via a pilot study, three test-takers were asked to participate in a 30-minute focus group cognitive interview. The participants were asked to review each construct at a time and allowed to participate in think-aloud and then answered probing questions by the researcher. This stage helped the researcher determine if the respondents are interpreting the items on the survey and evaluating them appropriately the way the designer intended (AERA, 2014; Groves et al., 2011; Messick, 1995). The researcher recorded body language and response time for each statement in the constructs. The three participants were all female, 1 African American, 1 Indian, and 1 Other (Caribbean). Two of the participants were practitioners and 1 was a full-time student in a doctoral program working part-time at a university.

\section{Problem-Solving Confidence Construct}

In the first construct, Problem-Solving Confidence, the participants were given a few minutes to review the statements and then asked to think-aloud about their respective thought processes when reviewing the statements and trying to respond to each. The first participant indicated that when reading the statements, it made them think initially "What 
is a group setting and what is working with others?" This participant also indicated that they interpreted the statements as everyone "belonging to a team and working with a group." The participant suggested that the statements were easy to respond to and "did not seem to be attacking or too intrusive, but simple and comfortable." The second participant indicated that the use of the words "teamwork" was effective because it helped to understand how you work with others. This participant also responded that the questions in this construct seemed collaborative, and though slightly different for an introvert, seemed like valid statements. The third participant agreed with the second participant, that the statements were collaborative, but asked the question, "How do I fit in a group?" This participant also suggested that the "synergy amongst the statements were in sync," reflecting what working in a group setting is in an organization. The participant also indicated that "the statements seemed relevant to the construct." All participants indicated that answering the statements under this construct was easy and was done so with no difficulty. The body language that was recorded was no different from the time that was spent talking about the statements. The participants facial expressions were the same throughout the reading process, there was no frowning present, and there was no shifting in their seats. There was no hesitation to respond to statements and the participants looked comfortable while reading and answering.

\section{Approach-Avoidance Style Construct}

In the second construct, Approach-Avoidance Style, the three participants were given five minutes to review the 16 statements and then provide feedback via think-aloud and probing questions. The first participant indicated that the approach-avoidance style 
statements, while working with a team seemed to be constructed well. The participant liked the "mix of negative and positive statements." The second participant questioned why "the first two statements were negative and thought that maybe these can influence the way a person responds." The participant indicated that they would answer negatively because of this. The participant further discussed that if the statements were in the middle of the 16 statements, they would have responded differently. The second participant also suggested that the approach and avoidance statements were "well conveyed while working with a group or team." The third participant thought that responding to the statements were not difficult because it was "forcing individuals to confront their weakness or strengths." The participant also indicated that the statement "When working with others, I have a systematic method for comparing alternatives and making decisions," was difficult to respond. The participant argued that the statement could be interpreted as "a person might not be waiting to work with others." The body language during this construct was different from the first construct. During the initial reading, two of the participants shifted in their seat and frowned. This indicated to the researcher that the statements that were being read may not have been too clear and that they may not have understood the statements.

\section{Personal Control Construct}

In the third construct, Personal Control, the participants were asked to review for a few minutes and then provide feedback via think-aloud and probing questions. The first participant liked how the statements were constructed and thought it easy to respond to each statement. The participant continued to say that the statement "I make snap 
judgments and later regret them," seemed like a very appropriate statement to be asked under this construct. The second participant thought the statements under this construct were very easy to respond to and liked how each statement targeted different areas of problem-solving tasks. The participant however questioned why the last two statements had italics "independently" and "by myself" if it were under the construct Personal Control. The third participant indicated that the statements were easy to respond to but suggested that it was "inviting scrutiny to oneself." Where this would be an "easy task" for some, others may find it difficult. The participant also liked how the statements were "turned toward the individual" and liked how "one can examine themselves." The body language that was observed during the reading of the statements in this construct indicated that the participants were comfortable with the statements. It was observed that the participants were able to read the statements with ease with the absence of frowning or shifting in seats.

\section{Demographic Information}

The participants provided feedback on the demographic information. All three participants indicated that the section titled "Hispanic, Latino, Spanish" should be revised and should be a "stand-alone" statement. One participant indicated that "Pacific Islander alone, Asian alone" should also be revised, omitting the word "alone." All three participants suggested a last checkbox in the Race and Ethnicity section stating, "Prefer not to respond." 


\section{General Comments}

The general comments from the first participant indicated the following: "the PSI can be an excellent tool in organizations and can be implemented by Human Resources;" "when you take the PSI, seems like you can take an inventory of yourself and learn from others at the same time, without being demanding;" "you can identify your strengths and weaknesses;" "you can identify different skills for problem-solving, for instance, communication, decision-making, listening etc.;" and, "the persons implementing the survey can identify those individuals who seem uncomfortable when working in groups and assistance can be given to them." The second participant denoted that: "this PSI is something I would like to implement at my job," "the PSI can be used for executive and leadership teams," and "the PSI helps you understand how well you can work with others." The third participant's general comments included: "interesting PSI for organizations and people who work in teams," "individuals are able to investigate their problem-solving preference or style when working with teams," and "it is a good inventory when working with teams."

\section{Stage Two: Quantitative Pilot Study}

Stage two of the research study consisted of piloting the instrument to determine the questionnaire format, item variance, reliability, and item-scale correlations and initial evidence of validity (Babbie, 1990; DeVellis, 2016). The pilot study was conducted three days after conducting the pilot focus group cognitive interview. The pilot study for the PSI consisted of 52 persons who fit one or more of the following criteria: (a) their position in the organization was either a supervisor or manager or equivalent, (b) they are 
employed in the human resources department, and (c) persons who engage in problemsolving in their department. The PSI was emailed to members of The National Association of Professional Women (NAPW), members of Association of Talent Development (ATD), students and faculty at Florida International University, students and faculty at Nova Southeastern University, and the Comparative and International Education Society's (CIES) Education: Conflict and Emergencies Special Interest Group (SIG). The pilot study was open for a period of 10 days. After the fifth day, the PSI was emailed to colleagues who would then distribute to individuals who are problem-solvers in their department. The researcher used a 1:1 ratio for items on survey and participants, that is, there were 27 items on the surveys and at least 27 participants were needed.

The following is a classification of the demographic background of the participants: Male (13.5\%), Female (51.9\%), Unknown (34.6\%); White only (13.4\%), Black or African American (19.2), Asian Alone (5.8\%), Latino or Spanish (3.8\%), Two or more races (5.8\%), Other (7.7\%), Prefer not to respond (9.7\%), and Unknown (34.6\%). Participants in the pilot study were employed in a variety of fields, which include Human Resources, Conflict Resolution, Higher Education, Adult Education, Psychology, Real Estate, Law, Government, Marketing, Policy Analysis, Marketing and Food and Beverage. The participants with the highest response rate were from the Education field (> 25\%). 
Table 10

Items that were Deleted

\begin{tabular}{lc}
\hline Item & $\begin{array}{c}\text { Cronbach's } \\
\text { Alpha if } \\
\text { Deleted }\end{array}$ \\
\hline $\begin{array}{l}\text { When I am confronted with a complex problem, I do not collaborate with } \\
\text { others to develop a strategy to collect information, to clearly define what } \\
\text { is the problem. }\end{array}$ & .35 \\
$\begin{array}{l}\text { After I have solved a problem with others, I do not analyze what went } \\
\text { right or what went wrong with them. }\end{array}$ & .46 \\
$\begin{array}{l}\text { When a solution to a problem was unsuccessful, I do not communicate } \\
\text { with others to examine why it did not work. }\end{array}$ & .55 \\
When working with a team/group and confronted with a problem, I do \\
not usually examine what sort of external things in my environment may \\
be contributing to the problem.
\end{tabular}

\section{Quantitative: Reliability Evidence}

Cronbach's alpha was estimated to test reliability on each construct. In the first construct, Problem-Solving Confidence, Cronbach's alpha was .87 with 10 items. The third construct, Personal Control, Cronbach's alpha was .71 with 7 items.

However, the second construct, Approach-Avoidance Style, Cronbach's alpha was only .25 with 16 items, which was very low. A low value of Cronbach's alpha could be a result of too few questions or poor inter-relatedness of items (Tavakol \& Dennick, 2011). 
The second construct consisted of 16 items, therefore, the low value may be due largely to poor inter-relatedness among the items. Each statement was then analyzed to determine whether Cronbach's alpha would increase if that item were deleted. Table 10 includes the items that were deleted to increase Cronbach's alpha. For example, when the following statement was deleted, the Cronbach's alpha was .35: "When I am confronted with a complex problem, I do not collaborate with others to develop a strategy to collect information, to clearly define what is the problem". When the next statement was deleted, the Cronbach's alpha was .46: "After I have solved a problem with others, I do not analyze what went right or what went wrong with them." A Cronbach's alpha of .7 or greater is considered adequate (Cortina, 1993).

When examining the overall adapted PSI, the two items that got the highest scores were: "I believe I trust my ability to solve new and difficult problems when working with others" with a mean of 5.16 and standard deviation of .65; and "I believe when I become aware of a problem, one of the first things I do is try to find out exactly what the problem is by communicating with my team" with a mean of 5.14 and a standard deviation of 92 . The item "When I am confronted with a complex problem, I do not collaborate with others to develop a strategy to collect information, to clearly define what the problem is," had the lowest score with a mean of .182 and standard deviation of 1.04 . 
Table 11

Descriptive Study for Pilot Study $(N=52)$

\begin{tabular}{|c|c|c|c|}
\hline Construct & Item & Mean & $S D$ \\
\hline \multirow{10}{*}{ 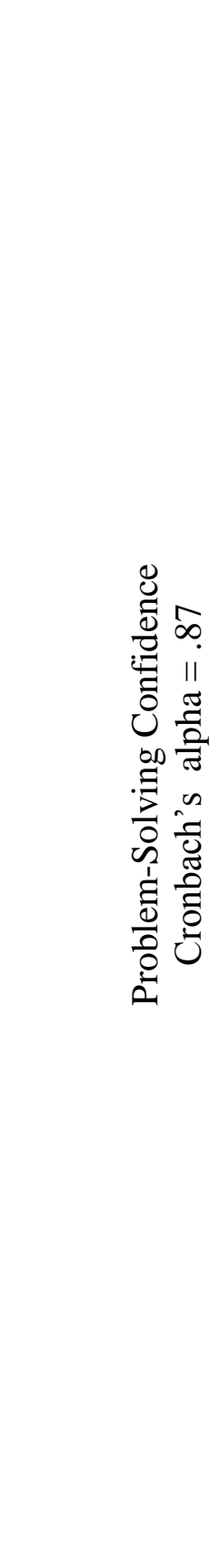 } & $\begin{array}{l}\text { I believe I am able to develop creative alternatives } \\
\text { to solve a problem when working with others. }\end{array}$ & 5.07 & .80 \\
\hline & $\begin{array}{l}\text { I believe I am able to develop effective } \\
\text { alternatives to solve a problem when working } \\
\text { with others. }\end{array}$ & 5.09 & .74 \\
\hline & $\begin{array}{l}\text { I believe I have the ability to solve most problems } \\
\text { in a group setting, even though initially no } \\
\text { solution is immediately apparent. }\end{array}$ & 4.89 & .72 \\
\hline & $\begin{array}{l}\text { I believe when making decisions as a group, I } \\
\text { trust the outcome. }\end{array}$ & 4.70 & .80 \\
\hline & $\begin{array}{l}\text { I believe when I make plans to solve a problem in } \\
\text { a group setting, I am almost certain that together } \\
\text { we can find solutions. }\end{array}$ & 5.00 & .87 \\
\hline & $\begin{array}{l}\text { I believe given enough time and effort, I believe I } \\
\text { can solve most problems I am confronted with } \\
\text { when collaborating with others. }\end{array}$ & 5.07 & .70 \\
\hline & $\begin{array}{l}\text { I believe when faced with a new situation, I have } \\
\text { confidence that I can handle problems that may } \\
\text { arise when working with teams. }\end{array}$ & 5.07 & .77 \\
\hline & $\begin{array}{l}\text { I believe I trust my ability to solve new and } \\
\text { difficult problems when working with others. }\end{array}$ & 5.16 & .65 \\
\hline & $\begin{array}{l}\text { I believe when I become aware of a problem, one } \\
\text { of the first things I do is try to find out exactly } \\
\text { what the problem is by communicating with my } \\
\text { team. }\end{array}$ & 5.14 & .92 \\
\hline & $\begin{array}{l}\text { I believe after making a decision with a group, the } \\
\text { actual outcomes usually matches what I expected. }\end{array}$ & 4.53 & .86 \\
\hline
\end{tabular}


When a solution to a problem was unsuccessful, I

$1.87 \quad .88$ do not communicate with others to examine why it did not work.

When I am confronted with a complex problem, I

1.82

1.04

do not collaborate with others to develop a

strategy to collect information, to clearly define

what is the problem.

After I have solved a problem with others, I do

not analyze what went right or what went wrong

with them.

After my group and I have found solutions, we take time and compare each alternative.

When I have a problem, I work with others to

create many ways to resolve it until I have

exhausted all alternative ideas.

When my team and I are confronted with a

problem, I consistently examine how I feel about the problem.

When confronted with a problem, I tend to work

with others to solve it, before considering the first solution that comes to mind.

When I decide on an idea or a possible solution to

a problem with a team, I do not take time to consider the possibility of each alternative being successful.

When confronted with a problem, I work with others to analyze it, before deciding on the next step.

When working with a team, I generally go to the first good idea that comes to my mind.

When making a decision, I work with others to weigh the consequences of each alternative and we compare them against each other. 
I try to work with others to predict the overall

result of carrying out a particular course of action.

When working with others, I have a systematic

$4.32 \quad 1.14$

method for comparing alternatives and making

decisions.

When working with a team/group and confronted

with a problem, I do not usually examine what sort of external things in my environment may be contributing to the problem.

When I am confused by a problem, one of the first things I do is work with others to survey the situation and consider all the relevant pieces of information.

When trying to think up possible solutions to a problem, I do not come up with very many alternatives in a group setting.

When my first efforts to solve a problem fail, I 3.22 1.27 become uneasy about my ability to handle the situation.

Sometimes I do not stop and take time to deal

with my problems.

₹. Even though I work on a problem, sometimes I feel like I am not getting to the real issue.

I make snap judgments and later regret them.

Sometimes I get so charged up emotionally that I my problems.

When confronted with a problem, I am unsure of whether I can handle the situation independently.

Many problems I face are too complex for me to solve by myself.

*Note: Items emboldened have the highest mean and standard deviation. Items italicized have the lowest mean and standard deviation. 
Another item that produced low score was "When a solution to a problem was unsuccessful, I do not communicate with others to examine why it did not work" with a mean score of 1.87 and standard deviation of .88. Table 11 shows the descriptive statistics for the pilot study.

\section{Quantitative: Validity Based on Internal Structure}

When exploratory factor analysis with principal axis factoring extraction and varimax rotation was conducted on 33-item pilot data, nine factors emerged. The first 10 items loaded on the first, second, third, fourth, fifth and sixth factors. The first factor loaded the strongest with factor-loadings of .40 to .92 . The second 16 items loaded on the first, second, third, fourth, fifth, sixth, seventh, eighth and ninth factor. The second factor loaded the strongest with factor-loadings of .31 to .72. The last seven items loaded on the fourth, sixth and ninth factor. The fourth factor loaded the strongest with factorloadings of .52 to .85 .

When the 6 items were deleted from the second construct based on the results of the reliability analysis, there were 8 factors. The first 10 statements loaded on the first, second, third, fourth, fifth, sixth and seventh factor. The first factor loaded the strongest with factor-loadings ranging from .52 to .92 . The second 10 statements loaded on first, second, third, fourth, fifth and eighth factors. The second factor loaded the strongest with factor-loadings ranging from .51 to .76 . The last 7 items loaded on the third, fifth and sixth factors. The third factor loaded the strongest with factor-loadings ranging from .54 to .85 . The second 10 items that were loaded on both second and third factors could be a result of a small sample size (Moore \& McCabe, 2002) and this provides valuable 
information for factor structure. No changes were made to the items based on the EFA results. The researcher examined the definitions after the EFA results and felt comfortable to keep the structure of the adapted survey at this stage. Table 12 shows the exploratory factor analysis results for the pilot study when the 6 items were deleted. The emboldened coefficients in Table 4 are those with the highest factor loadings.

Table 12

Summary of Exploratory Factor Analysis Results for Pilot Study $(N=52)$

\begin{tabular}{|c|c|c|c|c|c|c|c|c|}
\hline & \multicolumn{8}{|c|}{ Factor Loadings } \\
\hline & 1 & 2 & 3 & 4 & 5 & 6 & 7 & 8 \\
\hline $\begin{array}{l}\text { I believe I am able to } \\
\text { develop creative } \\
\text { alternatives to solve a } \\
\text { problem when working } \\
\text { with others. }\end{array}$ & .39 & & & & .74 & & & \\
\hline $\begin{array}{l}\text { I believe I am able to } \\
\text { develop effective } \\
\text { alternatives to solve a } \\
\text { problem when working } \\
\text { with others. }\end{array}$ & & & & & .83 & & & \\
\hline $\begin{array}{l}\text { I believe I have the } \\
\text { ability to solve most } \\
\text { problems in a group } \\
\text { setting, even though } \\
\text { initially no solution is } \\
\text { immediately apparent. }\end{array}$ & .54 & .46 & & & .34 & & .40 & \\
\hline $\begin{array}{l}\text { I believe when making } \\
\text { decisions as a group, I } \\
\text { trust the outcome. }\end{array}$ & .52 & .34 & & & & & & \\
\hline $\begin{array}{l}\text { I believe when I make } \\
\text { plans to solve a }\end{array}$ & .92 & & & & & & & \\
\hline
\end{tabular}


problem in a group

setting, I am almost

certain that together we

can find solutions.

I believe given enough

time and effort, I

believe I can solve

most problems I am

confronted with when

collaborating with

others.

I believe when faced

.62

with a new situation, I

have confidence that I

can handle problems

that may arise when

working with teams.

I believe I trust my

ability to solve new and

difficult problems

when working with

others.

I believe when I

become aware of a

problem, one of the

first things I do is try to

find out exactly what

the problem is by

communicating with

my team.

I believe after making a

decision with a group,

the actual outcomes

usually matches what I

expected.

After my group and I

have found solutions, 
we take time and

compare each

alternative.

When I have a

problem, I work with

others to create many

ways to resolve it until

I have exhausted all

alternative ideas.

When my team and I

are confronted with a

problem, I consistently

examine how I feel

about the problem.

When confronted with

.73

.49

a problem, I work with others to analyze it, before deciding on the next step.

When making a

decision, I work with

others to weigh the

consequences of each

alternative and we

compare them against

each other.

I try to work with

$\begin{array}{lll}.51 & -.52 & .35\end{array}$

others to predict the

overall result of

carrying out a

particular course of

action.

When working with

others, I have a

systematic method for

comparing alternatives

and making decisions. 


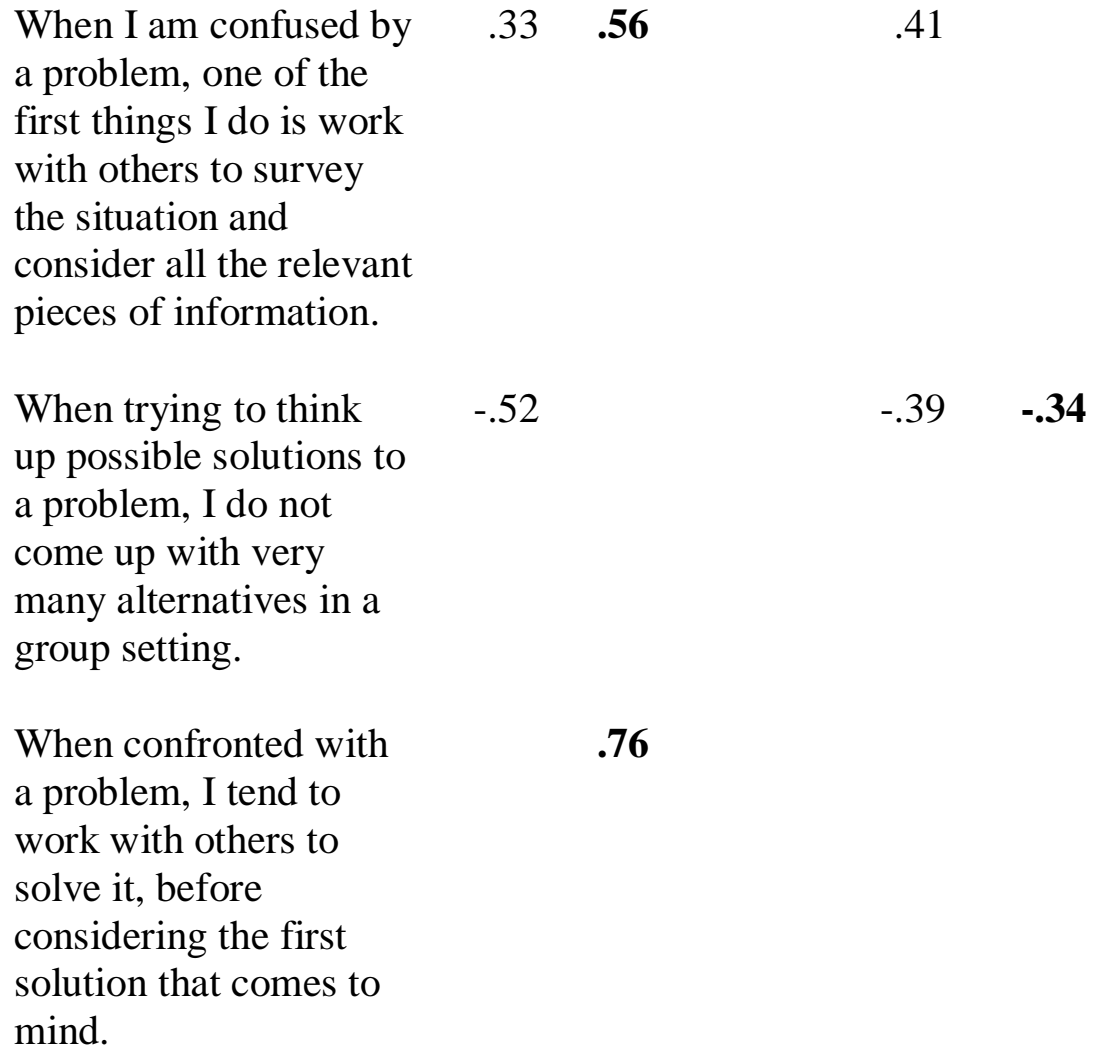

When my first efforts

to solve a problem fail, I become uneasy about my ability to handle the situation.

Sometimes I do not

stop and take time to deal with my problems.

Even though I work on

a problem, sometimes I feel like I am not

getting to the real issue.

I make snap judgments and later regret them. 
Sometimes I get so charged up emotionally

that I am unable to consider many ways of dealing with my

problems.

When confronted with a problem, I am unsure of whether I can handle the situation independently.

Many problems I face are too complex for me to solve by myself.
.85

.60

.82

Note: 1 . The emboldened coefficients have the highest factor loadings.

3. Factor loadings of $<.30$ are suppressed

\section{Phase Three}

In phase three of establishing evidence based on response processes, six professionals agreed to participate in two 60-minute focus group cognitive interviews. The difference between the pilot study focus group cognitive interview and the one conducted in Phase Three of this study, was that six persons were used in this study as opposed to three. Another difference was that the participants were allowed more time to review the statements and respond to the survey. Cognitive interviews entail overseeing draft survey questions to individuals and getting verbal feedback about the survey responses, which is then used to determine if the survey is producing the information needed for research (Beatty, 2003). The participants were given the 33 item-survey (see Appendix M) that was used during Phase 2. This was done to see if the items that were deleted would corroborate with the participants' responses. 
The demographic composition of the focus group were 4 females (2 Black or African American; 1 Hispanic, Latino or Spanish; 1 White only), and 2 males (1 White only; 1 Two or more races). The participants were employed in various fields, which include: 2 Higher Education, 1 Academia - University, 1 Software industry, 1 Instructional Design, and 1 Training and Development. The age range of the participants was from 22-to-49 years old.

\section{Round One}

At the beginning of the focus group cognitive interview, the participants were reminded of the purpose of the study and the definition of paradoxical problem-solving. The researcher reviewed the directions and instructions for the adapted PSI. The participants read each definition and the statements that followed within 5-10 minutes and then participated in think-aloud discussions. After the discussions of the three constructs, the demographic section was reviewed. The participants were told that there was no right or wrong answer and they would not be identified. They were also encouraged to give both positive and negative feedback.

\section{Problem-Solving Confidence Construct}

Participant A indicated that the first construct was partly easy to respond to except for two statements. Participant A indicated that in statement \#7, the words "new situation" was "troubling" and "situation" should be changed to "problem." Participants $\mathrm{B}, \mathrm{E}$, and F agreed that the use of "when working with teams" is a struggle when responding to statement \#7. They all asked, "is it a team or with different groups" and "do we have roles in the teams?" Participant A also indicated that in statement \#8, the 
words "ability to solve a new and difficult situation" can create a problem when taking the survey because "new and difficult" carry two separate meanings and suggested that this statement be split in two. Participant F also agreed with this participant, adding that the word "teams" is difficult. Participant E added that with this statement, it was questionable to "my ability, or collaboratively?"

Participant B said that in general, responding to this construct was fairly easy except for a few statements. This participant indicated that the definition was too vague and that "alternative verbiage" should be used suggested that the definition be more specific. The participant indicated that the word "effective" in statement \#2 should be revised because the word is too general. Participant E also agreed adding "what exactly is effective? Does it solve the problem?" Participant F also added that "effective" is not clear and this statement should be revised. Participant B suggested that in statement \#4, the words "I trust the outcome needs to be clarified: is the outcome positive or negative?" Participants D and F also agreed that trusting the outcome "as a group or as an individual?"

Participant C liked the adapted survey because one is able to "see how people react" and did not have any struggles to answer the statements in this construct.

Participant D indicated that the words "team," "group," and "working with others" should be revised and one word or phrase should be used to be consistent. All of the other participants agreed to this suggestion. They indicated that "it was confusing moving back and forth with the terms." The participant also suggested that statement \#5 
should be used to reflect a "we" standpoint instead of the "I" standpoint when trying to find solutions.

Participant E had difficulties when responding to the statements under this construct. The participant indicated that the term "creative alternatives" is confusing. Participant $\mathrm{F}$ agreed and both participants asked if creative meant unique. Participant $\mathrm{E}$ could not respond to statement \#3, asking if "I have the ability to solve most problems in a group setting" means "as a group or is it just me?" Participant F agreed with Participant E. Participant E indicated that in statement \#9, the phrase "find out exactly what the problem is" is confusing. The participant added that "how does one do this? Is it by consulting?"

Participant F suggested that in statement \#10, the statement needs to be revised. The phrase "the actual outcomes" is confusing and the participant asked if this meant "solutions or just the results."

\section{Approach-Avoidance Style Construct}

Participant A had some difficulties while responding to a few of the statements under this construct. One of the major challenges in this section was the interchanging of the words "I" and "we." It was suggested to be consistent and to be clear. This participant also added that the words in statement \#13 "what went right or what went wrong" was very confusing. The participant asked the questions "why would I analyze with others what went right or what went wrong if I have already solved the problem?" Participant F agreed with this question. Participant E agreed but added, "am I analyzing or am I doing it collaboratively?" The participant stated that statement \#24 needed to be consistent: 
"either use team or group, but not both." Participants C and D agreed with this suggestion. Participant also included that the phrase "external things in my environment" should be revised, asking "what are examples of external things?" Participant B had difficulties in answering some of the statements under this construct. Participant B said, "the use of negative statements at the beginning was overwhelming and this set the tone for the rest of the statements in this survey." Participant B also had questions on statement \#14, asking "why take time to compare each alternative after you have found a solution to a problem?" Participant F agreed with this suggestion, adding "is it collectively or individually comparing each alternative?" Participant B stated that the words "generally go to" in statement \#20 needed to be revised because it seemed confusing. Participants $\mathrm{E}$ and $\mathrm{F}$ agreed with this suggestion. The participant $\mathrm{B}$ also stated that the word "very" in statement \#26 was "unnecessary" and that "the statement can read well without the word."

Participant $\mathrm{C}$ asked if the definition of Approach-Avoidance Style could include a scenario that included a team setting. This participant suggested that statement \#12 be broken down into two sentences because there were two layers to the statement: "one part is to define what the problem is and the second is to develop a strategy to collect information.” Participants E and F agreed to this suggestion. The participant ended by stating that some of the statements seemed similar.

Participant $\mathrm{D}$ indicated that the use of italics was confusing when responding to the statements under this construct. They continued to say that statement \#25 was confusing: "do you have a choice and is it in a group setting?" 
Participant E had many challenges when responding to the statements under this construct. The general comment on the statements was "is it me or a group collaboratively?" This participant found the wording in statements\#11 and \#15 were confusing. The participant stated that the word "idea" in statement \#18 seemed vague and should be deleted. The participant also stated that \#26 was confusing, asking "is it a personal contribution or is it as a group?"

\section{Personal Control Construct}

All of the participants agreed that they had challenges when answering the statements under this construct. The major challenge for them was the use of the word "problem." They all asked if problems meant "professional problems or personal problems?" They all also agreed that the statements should be made positive instead of negative. Reading the negative statements were tiring for the participants and this showed in their body language. They also agreed that the negative statements "were encouraging you to fail." All participants agreed that statements \#30 and \#31 were great questions.

Participant A asked, "how do you know you failed and what comparison is there?" when they read statement \#27. Participant B agreed, adding if "this was a question on coping skills or ability?” Participants D and E, however, indicated that the statements seemed clear and that it seemed like a self-assessment of failure and confidence to problem-solve. Participant A added that the word "sometimes" in statement \#28 is too general and should be omitted. Participants B, D and E agreed to this 
suggestion. This participant was confused by statement \#32, asking "how else would you handle it?" Participant B agreed with Participant A.

Participant B found statements \#32 and \#33 were similar and should be reexamined to see if one should be omitted or if they can be combined. Participants $\mathrm{C}$ indicated that the italics in statements \#32 and \#33 were negatively viewed and there were challenges when reading those statements. Participant E indicated that the word "complex" in statement \#3 needed to be clarified.

\section{Demographic Information}

The participants provided feedback on demographic information. They all agreed that "Hispanic, Latino or Spanish" should be revised. A statement should be added asking “Are you Hispanic?” Another suggestion everyone agreed on was that under gender, the option of "prefer not to respond" should be added. They also agreed that the word "alone" under the different options under Race and Ethnicity Origin be omitted. The participants agreed that in organizations, baby boomers are still employed and another option of "70+" should be included under age. Lastly, the participants agreed that the options under "Level in organization" should be revised to "Entry, Supervisor, Manager etc." One additional suggestion by participant B was to change the wording of "Number of years in current position" to "number of years in current field."

\section{Round Two}

In preparation for round two, the feedback from round 1 was analyzed using formative assessment and revised (see Appendix N). Formative assessment refers to the assessment that is conducted continuously to produce results that can improve and 
facilitate learning (Sadler, 1998). At the beginning of the focus group cognitive interview, the same six participants were reminded of the purpose of the study and the definition of paradoxical problem-solving. They were also reminded to share their thoughts and that there was no right or wrong answer. The researcher added two questions to think about while they read the statements under each construct (a) how did it make you feel when you read each construct; and (b) tell me all of your thoughts while you read each construct. The participants were also told to tell the researcher what they were thinking when trying to respond to the statements in each construct. The participants also reviewed the demographic information and provided feedback.

General comments for the second round for the focus group cognitive interview included: (a) define team; (b) the first construct was very easy to respond to, and (c) one statements in the second construct should be split into two.

\section{Problem-Solving Confidence Construct}

Participant A indicated that responding to this construct was easy. The use of "team" throughout the first construct was an improvement from the first round. The word "team" suggests the roles within the groups and the responsibilities of each person. Participant B indicated that responding to this construct was easy and that overall left a good impression. The only concern was statement \#6 where the participant questioned the "problem to solve was with the team or was it an external problem?" Participant C indicated that responding to the statements were fine because they were clearer and more understandable. No changes should be made. Participant D indicated that even though responding to the statements was easier in round two than round one, there were still a lot 
of words per statement. This participant also showed a concern for the second statement, asking if "what successful alternatives meant and if that means there were many alternatives?" Participant E indicated that in the statement \#3, the word "immediately" should be deleted. This participant also suggested that the word "handle" in statement \#7 should be revised to "solved." Participant F questioned "my team" in statement \#9 and thought it better to revise it to "a team."

\section{Approach-Avoidance Style Construct}

Participant A experienced a little bit of difficulty when responding to this construct. The body language seemed uncomfortable and there was some frowning that occurred when reading the statements. The participant was confused about the "I versus team" in the statements, especially statement \#16. Participant E agreed with Participant

A. The participant also experienced difficulty with understanding statement \#25 with the phrase "what went right or what went wrong."

Participant B indicated that the statements under this construct were "overall clear and straightforward." There were a few concerns, some of which include: statements \#11 and \#27 needed re-wording so that it can be clear; revised the phrase "exhausted all alternative ideas," and does statement \#16 mean there is a team leader? Participant C also agreed with the re-wording of statement \#11, adding the statement seemed incomplete.

Participant $\mathrm{C}$ found the statements under this construct to be "clear and straightforward." No additional changes were recommended by the participant. Participant D found the main difficulty with responding to the statements under this 
construct, was the idea of "you are in a team, or do you prefer being on a team?"

Participant E agreed with Participant D. The body language of Participant D seemed uncomfortable; there was sighing and shifting in the seat when reading the statements. When asked about it, the participant responded that the compilation of positive statements and then negative statements were "tiring and overwhelming." Participant F also agreed with being overwhelmed by the negative statements at the end.

\section{Personal Control Construct}

All of the participants questioned the phrase "professional problem in the organization," asking "what is a professional problem?" They also questioned the phrase in statement \#28 "I pause and tackle" and asked if this can be re-worded. Participant A had no difficulty when responding to the statements under this construct. The participant added that they were not "confused and did not look at it from an analytical point of view like scholars would" and was "curious how non-scholars or random non-academia persons would respond to the survey."

\section{Demographic Information}

All of the participants indicated that "Are you Hispanic or Latino?" should be placed before Race and Ethnicity Origin and should have a "yes" or "no" checkbox. They all suggested that "Field or Industry and Job Title" should be two separate questions. Lastly, all six participants suggested that "Level in organization" should include "Mid-Level" to account for persons who are not entry or supervisor. The adapted 
PSI was revised reflecting the changes from the second round, in preparation for Phase 4 (see Appendix O).

\section{Integration of Using Mixed Methods}

During Phase 2 and Phase 3 of this research, the integration of quantitative and qualitative methods was used. The researcher used a concurrent triangulation design by integrating the quantitative results with the qualitative conclusions. In using a concurrent triangulation design, the researcher is merging the two sets of data, quantitative and qualitative, to interpret and transform the data during the analysis stage (Creswell, 2006). The researcher used the results from the first phase and used it to determine consistency during Phases 2 and 3. Phase 2 used a pilot study focus group cognitive interview with three participants and examined the adapted survey for reliability and validity evidence. Phase 3 of the research included a focus group with six participants. The researcher was able to determine two major similarities in the results including: (a) the six statements that had to be deleted when examining Cronbach's alpha in Phase 2 were consistent with the responses from the six participants in Phase 3, and (b) the statements that the six participants had trouble understanding produced low Cronbach alpha results and low exploratory factor loadings.

\section{Phase Four}

The final stage of this study was to determine evidence of reliability and validity based on internal structure with a large sample (AERA, 2014). Reliability evidence was examined using Cronbach's alpha on each individual construct as well as the overall instrument. In examining evidence based on internal structure, the same approach used 
in the pilot study, exploratory factor analysis was employed (Yong \& Pearce, 2013). The feedback from Phase three was analyzed and revised, resulting in the final survey in this phase (see Appendix P). The instrument was analyzed using SPSS with data gathered from a final sample size of 300 participants. A breakdown of the participants can be seen in Table 13. The adapted PSI was open for a period of three weeks. The adapted PSI was emailed to the members of the following two organizations: Association of Talent Development (ATD) and The National Association of Professional Women (NAPW). It was also emailed to the colleagues at FIU, which include professors and practitioners.

During the first week, over 100 responses were acquired. An email was sent at the beginning of the second week to individuals reminding them of participating in the survey. The PSI was also posted in a Global Learning Medallion newsletter to advertise the survey, inviting individuals who are employed and who are involved in problemsolving process to participate. The PSI was also emailed to students who are employed and who problem-solve as part of their responsibilities. By the end of the second week, 277 responses were received. At the beginning of the third week, a final email was sent to the prospective participants again to remind them. By the end of the third week, a total of 300 responses was achieved. The researcher used the 10:1 ratio rule (10 persons per item) (Yong \& Pearce, 2013) and accomplished the number of responses to examine for validity and reliability evidence. Therefore, for every 10 statements, the researcher was expecting 1 response.

The participants were employed in several industries including Education (Higher Education, Adult Education, Professor, and Academic Advisor), Hospitality (Food and 
Beverage, and Hotel), Conflict Resolution, Medical Practitioner, Engineering, Accounting, Law, Non-Profit, and Human Resource (Training and Development, Instructional Design). All of the participants met one or more of the following criteria (a) their position in the organization was either a supervisor or manager or equivalent, (b) they are employed in the human resources department, and (c) persons who engage in problem-solving in their department.

\section{Quantitative: Reliability Evidence}

Cronbach's alpha was used to test reliability on the overall instrument and each individual construct. When the overall instrument was examined, Cronbach's alpha was .85 , which indicated a high internal consistency. Each construct was then examined for internal consistency.

In the first construct, Problem-Solving Confidence, Cronbach's alpha was .85 on 10 items. In the second construct, Approach-Avoidance Style, Cronbach's alpha was .79 on 10 items. In the third construct, Personal Control, Cronbach's alpha was .31 on 7 items. Each item was then analyzed to determine, if deleted, would increase Cronbach's alpha. When analyzing in SPSS, if statement \# 25, "I got emotional when faced with professional problems within the organization" was deleted, Cronbach's alpha would increase to .47. When statement \#24, "I make quick judgments about professional problems and later regret them" was deleted, Cronbach's alpha increased to .73. These two statements were deleted from the adapted PSI. 
Table 13

Frequency Table of Demographic Variables

\begin{tabular}{|c|c|c|c|}
\hline Category & Variable & $f$ & Percent \\
\hline \multirow[t]{6}{*}{ Gender } & Male & 53 & 17.7 \\
\hline & Female & 164 & 54.7 \\
\hline & Other & 3 & 1.0 \\
\hline & Prefer not to respond & 2 & .7 \\
\hline & Total & 222 & 74 \\
\hline & Missing & 78 & 26 \\
\hline \multirow[t]{9}{*}{ Age } & $18-21$ & 50 & 16.7 \\
\hline & $22-29$ & 56 & 18.7 \\
\hline & $30-39$ & 41 & 13.7 \\
\hline & $40-49$ & 40 & 13.3 \\
\hline & $50-59$ & 22 & 7.3 \\
\hline & $60-69$ & 8 & 2.7 \\
\hline & $70+$ & 5 & 1.7 \\
\hline & Total & 222 & 74.0 \\
\hline & Missing & 78 & 26.0 \\
\hline \multirow[t]{8}{*}{ Race/Ethnicity } & White & 106 & 35.3 \\
\hline & Black/African American & 35 & 11.7 \\
\hline & Asian & 21 & 7.0 \\
\hline & Two or more races & 23 & 7.7 \\
\hline & Other & 24 & 8.0 \\
\hline & Prefer not to respond & 14 & 4.7 \\
\hline & Total & 223 & 74.3 \\
\hline & Missing & 77 & 25.7 \\
\hline \multirow{7}{*}{$\begin{array}{l}\text { Number of years } \\
\text { in field }\end{array}$} & Less than 1 year & 39 & 13.0 \\
\hline & $1-3$ years & 51 & 17.0 \\
\hline & $4-6$ years & 30 & 10.0 \\
\hline & $7-10$ years & 19 & 6.3 \\
\hline & $10+$ years & 73 & 24.3 \\
\hline & Total & 212 & 70.7 \\
\hline & Missing & 88 & 29.3 \\
\hline \multirow{5}{*}{$\begin{array}{l}\text { Title in } \\
\text { organization }\end{array}$} & Entry & 60 & 20.0 \\
\hline & Mid-Level & 49 & 16.3 \\
\hline & Supervisor & 25 & 8.3 \\
\hline & Manager & 30 & 10.0 \\
\hline & Other & 48 & 16.0 \\
\hline
\end{tabular}




\begin{tabular}{llrr}
\hline & Total & 212 & 70.7 \\
& Missing & 88 & 29.3 \\
\hline Number of years & Less than 1 year & 36 & 12.0 \\
employed in & $1-3$ years & 47 & 15.7 \\
organizations that & $4-9$ years & 46 & 15.3 \\
require you to & $10-10$ years & 30 & 10.0 \\
problem-solve & $16+$ years & 48 & 16.0 \\
& Total & 207 & 69.0 \\
& Missing & 93 & 31.0 \\
\hline
\end{tabular}

\section{Quantitative: Validity Based on Internal Structure}

When exploratory factor analysis (EFA) with principal axis factoring extraction and varimax rotation was conducted on the 27 -item instrument, seven factors emerged. The first 10 statements (first construct) double-loaded on the second and fourth factors; the second 10 items (second construct) double-loaded on the first and fifth factors; and the last 7 items (third construct) loaded strongly on the third factor. When statements \#24 and \#25 were deleted from the third construct, the results differed, with 6-factors, as presented in Table 14. The first 10 statements (Problem-Solving Confidence) doubleloaded on both the first and second factors; the second 10 statements (ApproachAvoidance Style) loaded on the fourth, fifth and sixth factors; and the last 5 statements (Personal Control) loaded strongly on the third factor. Double-loadings in EFA can be a result of a non-homogenous sample of participants or an overlap in construct definitions. Double-loadings occur when there are factor loadings on more than one factor. 
Table 14

Summary of Exploratory Factor Analysis for Hadeed Adapted Paradoxical ProblemSolving Survey $(N=300)$

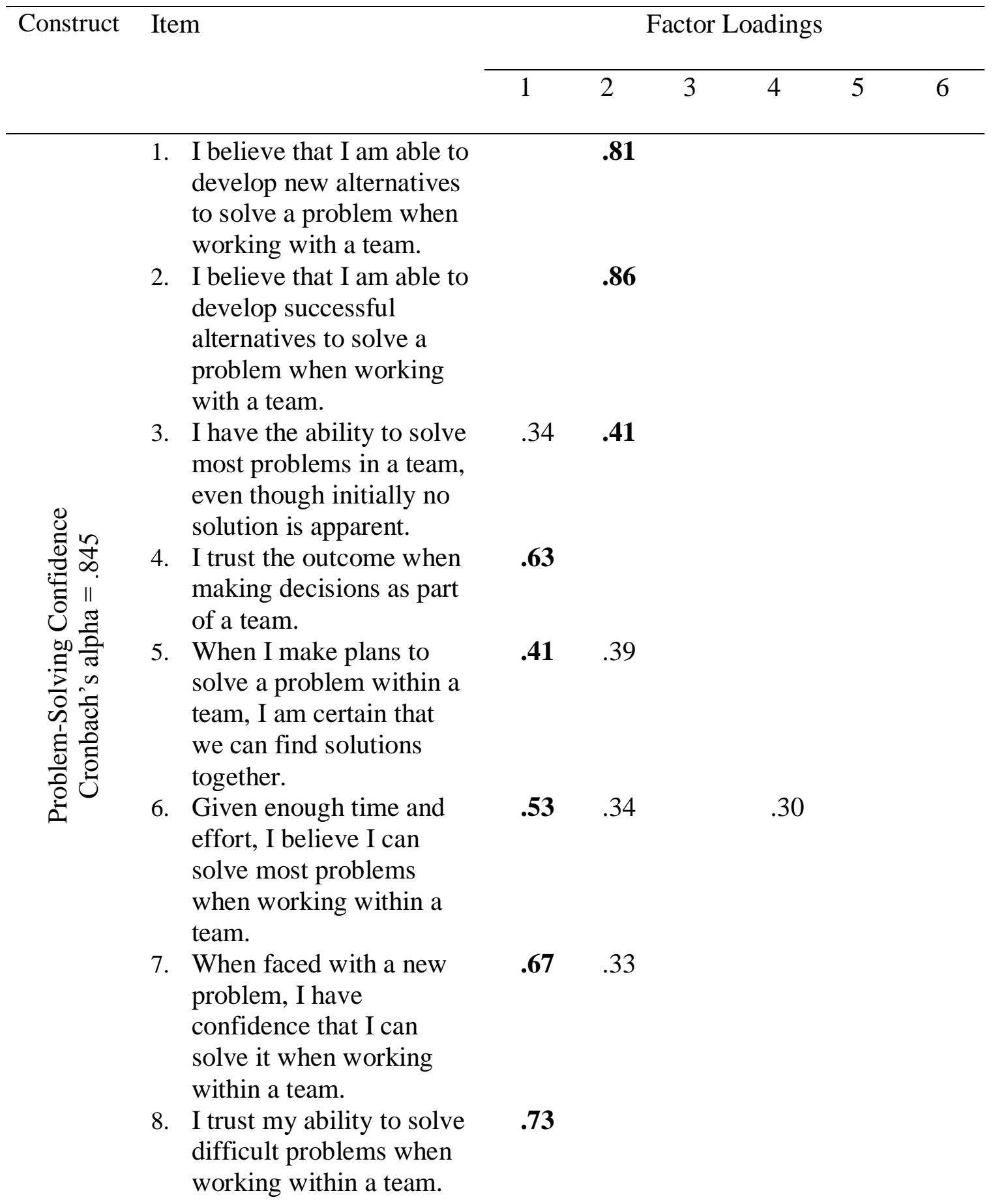


9. When I become aware of

a problem I first

communicate with a team

to find out the problem.

10. After making a decision

.49

.30

with a team, the actual

outcomes align with my

expectations.

11. After my team and I

.60

collectively find

alternative solutions to a

problem, we compare

each solution.

12. When I have a problem, I

work with a team to

create many possible

solutions until we have

exhausted all the ideas.

13. When my team and I

have a problem, we

examine how we feel

about that problem.

14. When confronted with a

$.53 \quad .38$

problem, I work with a

team to analyze it before

deciding on the next step.

15. When making a decision,

.67

I work with a team to weigh the consequences

of each alternative and compare them against each other.

16. I work with a team to

predict the overall result

of implementing a

particular action.

17. When working with a

team, I have a systematic

method for comparing

alternatives and making decisions.

18. When I am confused by a

problem, I first work 
with a team to understand

the situation and consider

all the relevant

information.

19. When confronted with a

problem, I work with a

team to solve it before

considering the first

solution that comes to

mind.

20. When thinking about

possible solutions to a

problem, I do not come

up with alternatives when

working with a team.

21. When my first efforts to

solve a problem fail, I

.53

pause and reassess the

situation.

22. I stop and take time to

.68

deal with professional

problems within the

organization.

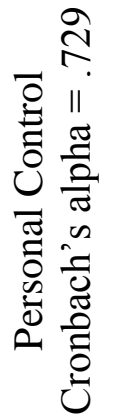

23. When I work on a

professional problem in

the organization, I am

getting to the root of the

problem.

24. When confronted with a

professional problem

within the organization, I

am confident that I can

handle the situation

independently.

25. I am able to think ok

.61

different ways of dealing

with my professional

problems within the

organization.

Note: 1 . The emboldened coefficients have the highest factor loadings. 2. Factor loadings of $<.30$ are suppressed 
On close examination of the first construct, Problem-Solving Confidence, the first 3 items loaded strongest (highest factor loadings) on the $2^{\text {nd }}$ factor, with factor loadings ranging from .41 to .86 . The $4^{\text {th }}$ to $8^{\text {th }}$ items and the $10^{\text {th }}$ item loaded strongest on the $1^{\text {st }}$ factor, with factor loadings ranging from .41 to .73 . The ninth item loaded strongly on the $5^{\text {th }}$ factor (.48), and even though it is higher than the factor loading in the first factor by .14, the loadings were quite close. In the second construct, Approach-Avoidance Style, the ten items loaded on the $4^{\text {th }}, 5^{\text {th }}$ and $6^{\text {th }}$ factors, with factor loadings ranging from .34 to .67 . The eleventh to thirteenth items loaded strongly on the $6^{\text {th }}$ factor, with factor loadings ranging from .54 to .60 . The fourteenth to sixteenth items loaded strongly on the $4^{\text {th }}$ factor, with factor loadings ranging from .53 to .67 . The seventeenth to twentieth items loaded strongly on the $5^{\text {th }}$ factor, with factor loadings ranging from .34 to .58. All items in the third construct, Personal Control, only loaded on the $3^{\text {rd }}$ factor, with factor loadings ranging from .48 to .68 .

The two items with the highest scores were statements \#21 and \#1. Statement \#21, "When my first efforts to solve a problem fail, I pause and reassess the situation" had a mean of 5.2 and a standard deviation of .76. Statement \#1, "I believe I am able to develop new alternatives to solve a problem when working with a team" with a mean of 5.15 and a standard deviation of .87 .

The two items with the lowest scores were statements \#24 and \#20. Statement \#24, "I make quick judgments about professional problems and later regret them" with a mean of 2.55 and a standard deviation of 1.26. Statement \#20, "When thinking about 
possible solutions to a problem, I do not come up with alternatives when working with a team" with a mean of 2.72 and a standard deviation of 1.45 as seen in Table 15.

Table 15

Descriptive Study $(N=300)$

\begin{tabular}{|c|c|c|c|}
\hline Construct & Item & Mean & $S D$ \\
\hline \multirow{10}{*}{ 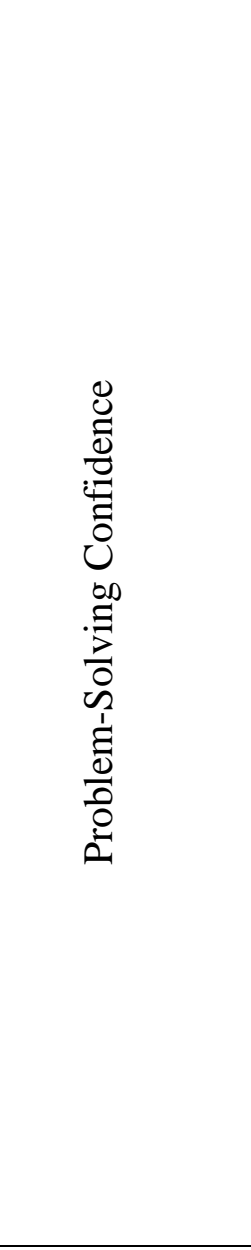 } & $\begin{array}{l}\text { 1. I believe that I am able to develop new } \\
\text { alternatives to solve a problem when working } \\
\text { with a team. }\end{array}$ & 5.15 & 0.87 \\
\hline & $\begin{array}{l}\text { 2. I believe that I am able to develop successful } \\
\text { alternatives to solve a problem when working } \\
\text { with a team. }\end{array}$ & 5.08 & 0.87 \\
\hline & $\begin{array}{l}\text { 3. I have the ability to solve most problems in a } \\
\text { team, even though initially no solution is } \\
\text { apparent. }\end{array}$ & 4.76 & 0.92 \\
\hline & $\begin{array}{l}\text { 4. I trust the outcome when making decisions as part } \\
\text { of a team. }\end{array}$ & 4.73 & 0.84 \\
\hline & $\begin{array}{l}\text { 5. When I make plans to solve a problem within a } \\
\text { team, I am certain that we can find solutions } \\
\text { together. }\end{array}$ & 4.99 & 0.87 \\
\hline & $\begin{array}{l}\text { 6. Given enough time and effort, I believe I can } \\
\text { solve most problems when working within a } \\
\text { team. }\end{array}$ & 5.09 & 0.82 \\
\hline & $\begin{array}{l}\text { 7. When faced with a new problem, I have } \\
\text { confidence that I can solve it when working } \\
\text { within a team. }\end{array}$ & 4.93 & 0.81 \\
\hline & $\begin{array}{l}\text { 8. I trust my ability to solve difficult problems when } \\
\text { working within a team. }\end{array}$ & 5.00 & 0.79 \\
\hline & $\begin{array}{l}\text { 9. When I become aware of a problem I first } \\
\text { communicate with a team to find out the problem. }\end{array}$ & 4.32 & 1.31 \\
\hline & $\begin{array}{l}\text { 10. After making a decision with a team, the actual } \\
\text { outcomes align with my expectations. }\end{array}$ & 4.45 & 0.85 \\
\hline \multirow{3}{*}{ 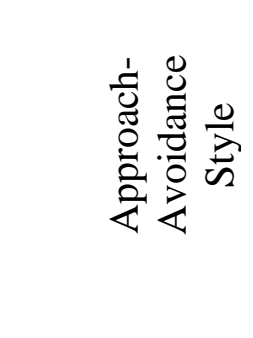 } & $\begin{array}{l}\text { 11. After my team and I collectively find alternative } \\
\text { solutions to a problem, we compare each solution. }\end{array}$ & 4.77 & 0.80 \\
\hline & $\begin{array}{l}\text { 12. When I have a problem, I work with a team to } \\
\text { create many possible solutions until we have } \\
\text { exhausted all the ideas. }\end{array}$ & 4.48 & 1.05 \\
\hline & $\begin{array}{l}\text { 13. When my team and I have a problem, we } \\
\text { examine how we feel about that problem. }\end{array}$ & 4.47 & 1.20 \\
\hline
\end{tabular}


14. When confronted with a problem, I work with a

$4.52 \quad 1.07$ team to analyze it before deciding on the next step.

15. When making a decision, I work with a team to

$4.64 \quad 0.95$ weigh the consequences of each alternative and compare them against each other.

16. I work with a team to predict the overall result of $\quad 4.62 \quad 0.86$ implementing a particular action.

17. When working with a team, I have a systematic method for comparing alternatives and making decisions.

18. When I am confused by a problem, I first work with a team to understand the situation and consider all the relevant information.

19. When confronted with a problem, I work with a $\quad 3.92 \quad 1.38$ team to solve it before considering the first solution that comes to mind.

20. When thinking about possible solutions to a problem, I do not come up with alternatives when working with a team.

21. When my first efforts to solve a problem fail, I pause and reassess the situation.

22. I stop and take time to deal with professional problems within the organization.

23. When I work on a professional problem in the organization, I am getting to the root of the problem.

24. I make quick judgments about professional problems and later regret them.

25. I get emotional when faced with professional problems within the organization.

$5.20 \quad 0.76$

$4.80 \quad 0.93$

$4.69 \quad 0.99$

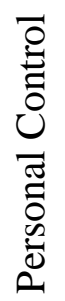

26. When confronted with a professional problem within the organization, I am confident that I can handle the situation independently.

27. I am able to think ok different ways of dealing with my professional problems within the organization.

This study used a concurrent mixed methods design which collects quantitative and qualitative data independently and at the same time (Onwuegbuzie \& Collins, 2007). The four phases and a summary of the findings can be seen in Table 16 . 
Table 16

Hadeed Four Phases and Summary of The Findings

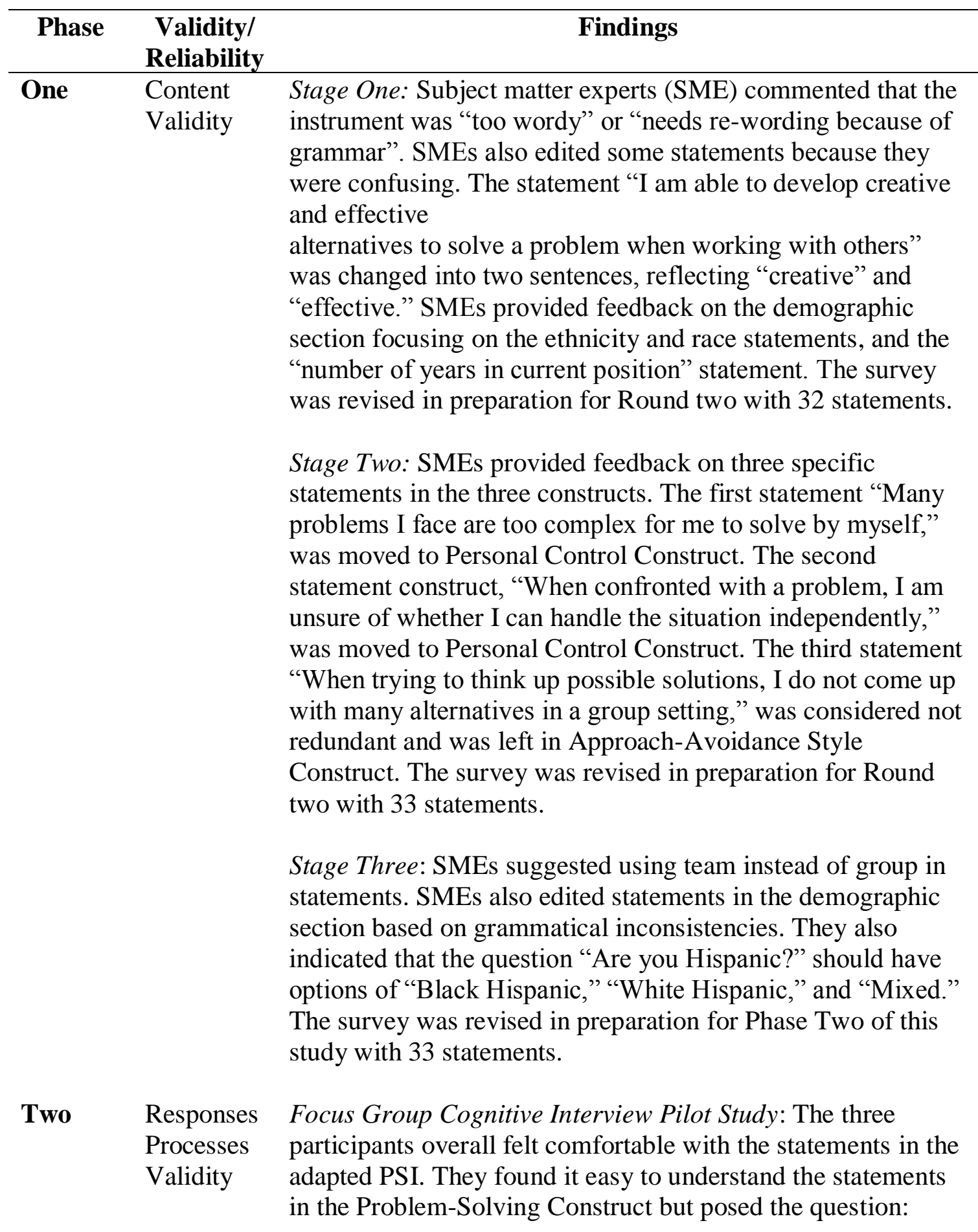


Reliability

"What is a group setting and what is working with others?" They also indicated that words such as "teamwork" was effective. They approved many of the Approach-Avoidance Style Construct statements and found it easy to respond to them. In the Personal Control Construct, they questioned why "independently" and "by myself" were in italics and this could have been a distraction. The body language was observed during the pilot study and participants seemed comfortable with the absence of frowning or shifting in their seats.

Quantitative Pilot Study: $(N=52)$. The first construct (10 items), Problem-Solving Confidence, Cronbach's alpha $=.87$. The second construct (16 items) Approach-Avoidance Style Construct, Cronbach's alpha $=.25$, The third construct $(7$ items), Personal Control Construct, Cronbach's alpha $=.71$. Six items were deleted from the second construct because of low Cronbach alpha values. When Cronbach's alpha was examined after deleting the 6 items, Approach-Avoidance Style Construct $\alpha=.745$.

Internal Quantitative Pilot Study: $(N=52)$. EFA with principal axis Structure factoring extraction and varimax rotation was conducted on Validity the pilot data, the results were as follows:

- Nine factors emerged

- First 10 items (Problem-Solving Confidence) strongly loaded on the first factor.

- The second 16 (Approach-Avoidance Style) items loaded on the second factor.

- The last seven items (Personal Control) strongly loaded on the fourth factor.

When 6 items were deleted from the second construct, the results were as follows:

- Eight factors emerged, first 10 (Problem-Solving Confidence) loading on the first factor.

- The second 10 (Approach-Avoidance Style) loading on a mix of the second and third factors.

- The last seven items (Personal Control) loaded on the third factor.

Three Responses Round One: Participants had difficulty with phrases such as Processes "new situation," "when working with teams," "external Validity things," and "creative alternatives." They questioned the use of the "team" and "group" simultaneously and suggested 
using only "team." They found some statements to be confusing and could not answer the survey to the best of their ability. Participants also provided feedback on the demographic section, for example having the questions "Are you Hispanic?" to be a separate statement before Race and Ethnicity section. Suggestions were made and 34 statements evolved. The survey was revised for Round Two.

Round Two: Participants felt more comfortable with the second round. There were a few suggestions, such as editing, re-wording and deleting a few statements. They also provided feedback on the demographic information with minor edits. The survey was revised with 10 statements in ProblemSolving Construct, 10 statements in Approach-Avoidance Style Construct, and 7 statements in Personal Control Construct, a total of 27 statements.

Four Reliability Quantitative $(N=300)$. Cronbach's alpha was calculated on the overall PPSI with $\alpha=.849$. Problem-Solving Confidence $\alpha$ $=.845$, Approach-Avoidance Style $\alpha=.789$, Personal Control $\alpha=.316$. Two items were deleted from the third construct because of low Cronbach alpha values. When Cronbach's alpha was calculated after this, $\alpha=.729$.

Internal Quantitative $(N=300)$. EFA with principal axis factoring Structure extraction and varimax rotation was conducted on the data and Validity the results are as follows:

- 7 factors emerged initially.

When the two statements were deleted from Personal Control Construct, the results are as follows:

- 6 factors emerged. The first 10 statements (ProblemSolving Confidence Construct) double-loaded on both the first and second factors.

- The second 10 statements (Approach-Avoidance Style Construct) loaded on the fourth, fifth and sixth factors.

- The last 5 statements (Personal Control Construct) loaded only on the third factor. 


\section{Summary}

Chapter IV presented an explanation of the results of each phase. It also presented both the qualitative and quantitative methods that were used in this concurrent mixed methods design. Phase One was a qualitative phase that utilized 11 experts, both academic and practitioners. During this phase, validity evidence of test content was determined. The results from this phase were given to the participants of phase two. Phase Two consisted of two stages (a) 3-person focus group pilot study which was qualitative, and (b) pilot study survey $(N=52)$ which was quantitative. The 3-person focus group pilot study examined validity evidence based on response processes, and the pilot survey examined for reliability evidence and validity evidence based on internal structure. Phase Three was a qualitative phase that utilized 6 persons and examined for validity evidence based on response processes. The results from this phase were used for the survey in phase four. The fourth and final phase was a quantitative phase that established validity evidence based on internal structure and reliability evidence with Cronbach's alpha. 


\section{CHAPTER V}

\section{DISCUSSION}

Chapter V begins with the analysis of the results as they relate to the existing literature and theoretical frameworks. The chapter concludes with the implications for theory, conflict management, and practice, and limitations and recommendations for future research.

\section{Analysis of Results}

This study aimed to develop and validate an adapted survey that incorporates the paradoxical problem-solving concept under the context of social conflict theory to provide employees and employers with more creative techniques to manage organizational conflict. The study addressed the main research question: What are the psychometric properties of the Problem-Solving Inventory (PSI) incorporating a paradoxical problem-solving conceptual framework that is used in the workplace? The study also addressed the following research questions:

1. What is the validity evidence of the adapted Problem-Solving Inventory (PSI)?

2. What is the reliability evidence of the adapted Problem-Solving Inventory (PSI)?

In this research, a new tool was developed to measure one's ability and confidence when working with teams so that individuals are able to find more creative techniques to manage organizational conflict using the paradoxical problem-solving concept. The validity and reliability of the tool were examined as the two most important 
psychometric properties. The combined results from all the four phases of this study provided evidence that the instrument yields valid and reliable conclusions about the management of the organizational conflict incorporating the paradoxical problem-solving theoretical framework.

Organizations that use the three current formal and voluntary methods, negotiation, mediation, and arbitration, can explore other techniques to manage organizational conflict. The adapted Problem-Solving Inventory, now being referred to as the Paradoxical Problem-Solving Inventory (PPSI), can assist employees, supervisors, or managers when faced with conflict in the organization. Using the PPSI will allow individuals to better understand their abilities or problem-solving style when working with teams, which can help them improve on weakness or improve on their own behavior or attitude when faced with problem-solving tasks (Heppner \& Baker, 1997). A timeline of how the adapted PSI was developed to its final stages (PPSI) can be seen in Appendix Q.

\section{Research Question 1:}

\section{What is the validity evidence of the adapted Problem-Solving Inventory} (PSI)?

Evidence supported the finding that the adapted Problem-Solving Inventory yielded valid conclusions about the three constructs, incorporating the paradoxical problem-solving concept. Validity evidence based on test content was established using 11 subject matter experts. Validity evidence based on response process was established through focus group cognitive interviews. Validity evidence based on the internal 
structure was established by conducting an exploratory factor analysis using principal axis factoring extraction and varimax rotation on data gathered from 300 participants. Problem Solving Confidence, the first construct, generated six factors and loaded strongest on the first and second factors. Approach-Avoidance Style, the second construct, loaded strongest on the fourth, fifth and sixth factors. Personal Control, the third construct, loaded only on the third factor.

On close examination of the Problem -Solving Confidence construct, the first three items loaded strongest on the second factor; whereas, the fourth and eighth items loaded strongest on the first factor. The ninth item loaded strongly on the $5^{\text {th }}$ factor, and even though it is higher that the factor loading in the first factor by .139, the loadings were quite close. The tenth item loading strong on the first factor. For the ApproachAvoidance Style construct, the ten items loaded on the fourth, fifth and sixth factors. The eleventh to thirteenth items loaded strongly on the $6^{\text {th }}$ factor, while the fourteenth to sixteenth items loaded strongly on the $4^{\text {th }}$ factor. The seventeenth to twentieth items loaded strongly on the fifth factor. All items in the Personal Control construct strongly loaded on the third factor.

The six factors that emerged from exploratory factor analysis can possibly be a result of using a diverse background of participants. Cross-loadings indicate that "an item's variance can be explained by multiple factors" (Beavers, Lounsbury, Richards, Huck, Skolits, \& Esquivel, 2013, p. 6). However, ross-loadings can be used for further analysis and research to examine the definitions of the two constructs. Using exploratory 
factor analysis in this research yielded similar results to previous studies. For example, the number of factors that emerged and strong structural validity.

Exploratory factor analysis and confirmatory factor analysis were used in several studies with samples of French-Canadian adults which resulted in an observed relation that supported concurrent validity (LaPorte, Sabourin, \& Wright, 1988); South African college students which resulted in validity estimates that provided strong support for generalizability of the PSI (Heppner, Pretorius, Wei, Lee, \& Wang, 2002); and Turkish college students, which resulted in a relationship between the PSI and anxiety and dysphoria resulting in 6 factors (Sahin, Sahin, \& Heppner, 1993). All of these studies produced factors that were replicated across a diverse demographic background of sample participants.

In later years, a study was conducted by Nota, Heppner and Ferrari (2009), where cultural validity was examined focusing on the (a) the psychometrics estimates of the PSI and the differences associated with gender, study motivation, use of learning strategies, intelligence, and (b) the relationships between the PSI and personality characteristics. Cultural validity refers to the "effectiveness with which science assessment addresses the sociocultural influence that shapes thinking" (Solano-Flores \& Nelson-Barber, 2000, p. 555). This study used 2,577 students from Italy who completed the PSI and the MyerBriggs Type Indicator. The results indicated that (a) the PSI factor structure was slightly different (e.g., the third factor was conceptualized as Emotional Control instead of being called Personal Control), (b) there was a difference in responses by gender, (c) the PSI accounted for $6 \%$ of the variance in intelligence indicating that a more positive problem- 
solving appraisal is related to a more developed level of intelligence , (d) approaching problems was steadily predictive, and (e) there were significant differences between the undecided and decided students of all three PSI factors.

Beccaria and Machin (2010) examined the structural validity using Confirmatory Factor Analysis (CFA) and the relationship between the PSI and its subscales with positive and negative affect, depression and anxiety. The PSI was administered to 556 undergraduate students enrolled at the University of Southern Queensland (USQ) in 2008 and 497 undergraduate students enrolled at USQ in 2009. The results indicated that the PSI and its subscales significantly correlated with both affect and mental health variables, with correlation coefficients between $r=.29$ for Approach-Avoidance Style and negative affect; and $r=.45$ for Problem-Solving Confidence and depression. These results indicate a good predictive validity and a strong structural validity for the PSI.

As mentioned in previous chapters, paradoxical problem-solving also has not been empirically examined. This study focused on understanding the psychometric properties of the PSI and incorporating the paradoxical problem-solving approach. In examining the PPSI to the PSI, there are a few similarities and differences. In a previous study, six factors emerged when examining the PSI using exploratory factor analysis. In another study, the suggested term for Personal Control Construct was Emotional Control because of the theme of "emotion of the situation." One major difference in this study was the cross-loadings of items. 


\section{Research Question 2:}

\section{What is the reliability evidence of the adapted Problem-Solving Inventory}

(PSI)?

Evidence supported the finding that the adapted Problem-Solving Inventory yielded reliable inferences about the three constructs (Problem-Solving Confidence, Approach-Avoidance Style, Personal Control), incorporating the paradoxical problemsolving approach (25 items; $\alpha=.849)$. This indicates that all of the items have a high covariance and measure the same underlying concept.

Though this research is the first to be empirically explored using the PPSI in an organization setting, the reliability evidence is consistent with previous studies that have explored the PSI with students. Reliability for each of the three constructs was examined using Cronbach's alpha: .845 for Problem-Solving Confidence (10 items), .789 for Approach-Avoidance Style (10 items), and .729 for Personal Control (5 items). In Sahin, Sahin, and Heppner's study (1993), 224 Turkish university students (153 women and 71 men) all enrolled in a psychology course were used as the sample to examine the psychometric properties of the PSI. This study yielded an internal consistency of .88 for the total inventory. The alpha coefficients were $.76, .78$, and .69 , respectively, for each of the three constructs. Other studies (Heppner et al., 1995) showed an alpha coefficient of .90 for the total inventory. In Heppner and Petersen's (1982) study of undergraduate students $(N=150)$ enrolled in an introductory psychology class, the alpha coefficients were comparable to this research, with their Problem-Solving Confidence $\alpha=.85$, Approach-Avoidance Style $\alpha=.84$, and Personal Control $\alpha=.72$. 
In a later study, Soliman (2014) examined the development of the factor structure based on data from 607 college Egyptian students enrolled at Tanta University. The internal consistency of the overall PSI resulted in $\alpha=.75$. The internal consistency of Problem-Solving Construct $=.88$; Approach-Avoidance Style Construct $=.82$; and Personal Control Construct $=.76$.

\section{Implications for Theory, Conflict Management, and Practice}

Organizations that currently manage conflict use one of the three Alternative Dispute Resolution (ADRs): negotiation, mediation, or arbitration. Cognitive and affective conflict among employees can be managed by embracing alternative techniques, such as paradoxical problem-solving, which does not require formal intervention and management training (Wilmot \& Hocker, 2011). The following sections examine the implications of this study to theory, conflict management and practice.

\section{Implications for Theory}

This study focused on developing and validating an adapted survey that incorporates the paradoxical problem-solving concept under the context of social conflict theory to provide employees and employers with more creative techniques to manage organizational conflict. The study derived its theoretical foundation from social conflict theory. Social conflict theory was defined as the conflict of group's intentions to gain desired values, offset and eliminate rivals, and the struggle over values or privileges to status, power, and limited resources (Coser, 1967). This study also used a branch of social conflict theory, problem-solving theory, to guide the approach and research methods. 
The problem-solving theory focuses on making relationships and ensuring that institutions work effectively with the sources of conflict (Cox, 1981). The PPSI that was developed as an alternative to the common ADRs being used in organizations, focused on the behaviors and attributes that are present in problem-solving theory: learning (Kahney, 1986), thinking (Bourne, Ekstrand \& Dominowski, 1971; Mayer, 1983), decision-making (Abelson \& Levi, 1985; Tallman \& Gray, 1990), coping (Lazarus \& Folkman, 1984; Pearlin \& Schooler, 1978), task performance (Kelley \& Thibaut, 1969; Steiner, 1972), communication styles, networks, and patterns (Gottman, 1979; Leavitt, 1951; Tallman \& Miller, 1974), and information processing (Mayer, 1983; Simon, 1978).

When managing organizational conflict, paradoxical problem-solving utilizes the behaviors and attributes of learning, decision-making, coping, task performance, communication styles, and information processing. In the first stage, communication styles are identified. The second and third stages, communication styles, decisionmaking, and task performance are used. The fourth and fifth stages, learning, decision making, coping, task performance, communication styles, and information processing are used. All of these behaviors and attributes guided the adaptation of the PSI by Heppner \& Petersen (1982).

The instrument that was developed in this study can be used to support the three categories of problem-solving theory: (a) the process of coping (Lazarus \& Folkman, 1984), (b) analysis of interpersonal and intergroup dynamics (Tallman, Leik, Gray \& Stafford, 1993), and (c) the act of critically investigating a problem (Kahney, 1986; Mayer, 1992). The first two constructs, Problem-Solving Confidence, and Approach- 
Avoidance Style focus on team dynamics, incorporating coping methods and the ability to critically investigate a problem. One of the key stages in using the paradoxical problem-solving approach is the ability for the team to jointly investigate the problem by defining what the problem is (Cloke \& Goldsmith, 2000). Personal control construct focuses on a self-examination using coping and critical thinking skills when faced with a problem.

In addition to the instrument supporting the three categories mentioned above, a closer examination of the problem-solving theory focusing on individualistic versus team-work problem-solving should be conducted.

Table 17

Reio and Werner's Four Stages of Mixed Methods Research (2017)

\begin{tabular}{ll}
\hline \multicolumn{1}{c}{ Stages } & \multicolumn{1}{c}{ Explanation } \\
\hline Formulate & $\begin{array}{l}\text { Determining the goal of the study. } \\
\text { Formulating research objectives, determining the } \\
\text { research/mixing rationale. } \\
\text { Determining the research/mixing purpose. } \\
\text { Determining the research question(s). }\end{array}$ \\
& $\begin{array}{l}\text { Selecting the sampling design. } \\
\text { Selecting the mixed methods design. }\end{array}$ \\
& Collecting data. \\
Plan & $\begin{array}{l}\text { Analyzing data. } \\
\text { Legitimating (e.g., validation, trustworthiness) data. }\end{array}$ \\
& Interpreting the data. \\
& Writing the research report. \\
Reformulating the research questions.
\end{tabular}


There is a shift in theory when examining one's feelings, abilities and behaviors as opposed to working in teams and the team dynamics that would be present.

\section{Integration of Mixed Methods}

According to Reio and Werner (2017), there are 13 research-based steps that exist (Onwuegbuzie \& Corrigan, 2014) that are valuable when reporting mixed methods research. The 13 steps were broken down into four stages by Reio and Werner (2017): formulate, plan, implement and disseminate (see Table 17).

In this study, the researcher included all four stages of Reio and Werner's (2017) mixed methods research when determining the psychometric properties of the adapted Problem-Solving Inventory (PSI). The researcher was able to formulate, plan, implement and disseminate the stages to add value to mixed methods research, conflict management studies, problem-solving studies, and to adult education and human resource development. Mixed-method science was also advanced in that this research demonstrated the necessity for and utility of using a mixed methods approach to design and test a new research instrument that yielded valid and reliable results.

\section{Implications for Conflict Management}

This study provided an alternative to using ADRs that are commonly used in organizations to manage conflict. Paradoxical problem-solving is a new innovative way introduced by Cloke and Goldsmith (2011). It is similar to creative problem-solving in that it utilizes critical and divergent thinking skills and that they both encompass understanding the problem and generating ideas. However, by using paradoxical problem-solving, one is able to learn and transcend, it engages everyone who is involved 
in the problem, and emphasis is placed heavily on strategic thinking and the evaluation of different possible solutions.

Paradoxical problem-solving is not limited to solely organizations. It can be used in any setting that requires solving problems, such as politics and international relations. Governments worldwide and nationwide can perhaps use the PPSI to understand their own behaviors and abilities when faced with a problem. By taking the PPSI, government officials and party representatives can understand the skills that they possess when working with teams to manage problems. This also extends to countries or government officials who are involved in international relations. Elected government officials who are involved in international relations can use paradoxical problem solving as a means to manage conflicts as a first-tier solution before using negotiation and mediation. Almost two decades ago, Castro and Nielsen (2001) conducted a study and found that some groups were not even aware of negotiation or mediation and the process that it entails. This may still be true today. These conflict resolution systems can be highly proceduralorientated and technique driven, operationalizing them can be a challenge or require training. However, paradoxical problem solving may prove to easier to understand and operationalize given its familiar cores of mutual strategizing and problem-solving. Government officials need to also consider cultural differences and the stressors associated with negotiation, mediation and management (Chapeskie, 1995). Government officials who choose to use the paradoxical problem-solving method can perhaps better understand the resources they have, the needs of the people, the needs of other countries, international policy perspectives, and socio-cultural needs. 


\section{Implications for Practice}

This study provides support for utilizing the PPSI in any setting that uses problem-solving because it examines team-work dynamics and one's feelings, abilities and behaviors. Organizations that are currently using one of the ADRs and not experiencing long-term results, can focus on utilizing the PPSI. This study resulted in an instrument that can be used as an alternative to the ADRs that are currently being used in organizations. The PSI (Heppner \& Petersen, 1982) has not been empirically examined and tested in an organization setting. The adapted PPSI can be used in organizations that want to explore new innovative methods for managing conflict. Human resource practitioners can utilize the PPSI to increase productivity through teamwork and decrease incivility and stressors at work. Human resource practitioners can increase creativity and adopt a learning-oriented approach (Cloke \& Goldsmith, 2011) by having employees engage in critical thinking that could unveil new creative ideas to address problems in the organization. Human resource practitioners can also examine the five stages of the paradoxical problem-solving approach and implement, design and develop new strategies that would positively impact employees' conflicts. By crafting new strategic paradigms in the organizations, human resource practitioners would be influencing management practices, job-design, and culture building (Joo \& Park, 2009).

Collaboration, the management style that Rahim (1985) identified as a problemsolving style, can be used in concert with the PPSI. The PPSI offers a tool that can assist management when managing organizational conflict. Managers who use the collaboration style can enhance their skills and expertise by utilizing the PPSI. This does 
not mean, however, that the other management style approaches, such as avoidance, accommodation, and compromise cannot utilize the PPSI. Management that utilizes the PPSI can self-reflect and learn more about teamwork dynamics that would include communication, coping, thinking, and decision-making.

\section{Limitations and Recommendations for Future Research}

The present study has limitations, as with all research. The first limitation was the use of a snowball sampling technique. This method can lead to potential sampling bias because of similar traits of the people being referred. Snowball sampling can be the lack of cooperation and motivation where even though people are being referred, they might refuse to participate. Using this sampling technique can lead to sampling error, sample bias, and response bias (Baltar \& Brunet, 2011). To reduce sampling error, the researcher sent frequent emails to many colleagues and individuals who would be able to benefit from the PPSI. In future studies, researchers can use cluster sampling as an approach when examining the PPSI for validity and reliability evidence. Cluster sampling occurs when a sample is used a group as opposed to an individual, for example, a school or hospital (Teddlie \& Yu, 2007). Researchers can use a mixed methods approach examining for validity evidence based on test content, response processes, and internal structure using exploratory factor analysis.

A second limitation of this study was the demographic characteristics of the study's focus group cognitive interview in Phase Three, using six participants. The participants were from a heterogeneous group and having this group could have been the reason for the 6-factor loading when examining for validity evidence based on internal 
structure. Future researchers can explore using a homogenous group; participants who belong to one industry, or where the participants' backgrounds are all common in nature. The same method of conducting a focus group cognitive interview can be examined to determine validity evidence based on response processes.

A third limitation of the study can be the participants who examined the adapted PSI for validity evidence based on test content. The participants were employed at Florida International University, Miami, Florida, and Nova Southeastern University, Davie, Florida. Having a group from other states in the United States could lend a different perspective on teamwork dynamics. Furthermore, subject matter experts from different countries may view content through a different lens and may contribute to future research. Future researchers can examine validity evidence based on test content by using ethnographic research. This type of study focuses on human society and culture, and how the data is interpreted (Merriam, 2002). By using this method, the researcher will be able to understand the cultures of the participants and how this can influence their feedback on an instrument.

Future recommendations for researchers can be to examine the lived experiences of those individuals who have been a party to negotiation, mediation or arbitration due to incivility or stress, or similar. Researchers can interview individuals and examine their experiences using semi-structured interviews. At the end of each interview, the researcher can present them with the PPSI to complete. After this, the researcher can conduct a short cognitive interview to understand how they feel about team dynamics and their self-examination when faced with problem-solving. Lastly, future researchers can 
open the scope for a larger sample size (> 1000) and examine the PPSI for validity evidence based on internal structure using confirmatory factor analysis. By using this method, the researcher is assuming the number of factors that will be encountered and which variables will load onto each factor.

According to the results of this study's exploratory factor analysis, ProblemSolving and Approach-Avoidance Style constructs overlapped conceptually. Overlapping of the first two constructs could indicate that the definitions of these two constructs should be further refined because of the similarity of words. A qualitative study such as phenomenology using structured interviews can be used to examine people's perceptions when defining the first two constructs.

The sample population that was used for this study was heterogeneous in nature. Researchers could focus on using a more homogenous sample group, such as only persons within the human resource industry, or college professors with a doctorate. For example, a researcher can use one organization and use that group to test the PPSI. By doing this, the researcher is using the employees of one organization and examining the coping, critical thinking and inter- and intra-group dynamics. An interesting study can also be conducted on college students and how they problem-solve within their groups for a class presentation or group activities. An insightful way to examine this would be a test-retest; that is, give the students the PPSI to complete, then have them work in groups, followed by them retaking the PPSI at the end of the semester. This future recommendation will be a continuing validation of the instrument because validation is an on-going process. 
An area that can also be examined when using the PPSI for research would be executives of Fortune 500 companies. As leaders of these companies, problem-solving would be an integral component of their job and examining how executives manage conflict using the paradoxical problem-solving approach would be interesting. This can be examined by using a case study method that would focus on the executives and their management styles and how it affects problem-solving.

\section{Conclusion}

As organizations look for new alternative methods to manage conflict, using the paradoxical problem-solving approach can be a useful method that yields long-term benefits (Cloke \& Goldsmith, 2011). Though this approach is new, it lends insight into teamwork dynamics and self-reflection when faced with organizational challenges. The instrument created in this study, the Paradoxical Problem-Solving Inventory, examines the psychometrics properties while incorporating the paradoxical problem-solving concept. The instrument can provide human resource practitioners and researchers the tool that is necessary when managing organizational conflict, and the opportunity to transcend from problems into a learning-oriented approach. The PPSI was developed to have organizations look at an alternative method instead of the traditional ADRs used. Participants who partake in PPSI will be able to better understand their coping, decisionmaking, critical thinking, and communication styles. These individuals would also be able to understand how they problem-solve with and without teamwork. This instrument can significantly contribute to the way that human resource practitioners manage organizational conflict. 


\section{REFERENCES}

Abelson, R. P., \& Levi, A. (1985). Decision making and decision theory. Handbook of Social Psychology, 1, 231-309.

Accountemps (2011). Keeping the peace. Retrieved from http://accountemps.rhi.mediaroom.com/StaffConflict

Agre, G. P. (1982). The concept of problem. Educational Studies, 13, 121-142.

Altmäe, S., \& Türk, K. (2009). Conflict management modes and leadership styles used by Estonian managers and specialists. EBS Review, 25, 61-73.

Amabile, T. M., \& Gryskiewicz, N. D. (1989). The creative environment scales: Work environment inventory. Creativity Research Journal, 2, 231-253.

American Educational Research Association, American Psychological Association, \& National Council on Measurement in Education. (2014). Standards for educational and psychological testing. Washington, DC: American Educational Research Association.

Argyris, C. (1976). Single-loop and double-loop models in research on decision making. Administrative Science Quarterly, 21, 363-375.

Argyris, C. (1980). Some limitations of the case method: Experiences in a management development program. Academy of Management Review, 5, 291-298.

Argyris, C. (1993). Knowledge for action: A guide to overcoming barriers to organizational change. San Francisco, CA: Jossey-Bass.

Argyris, C., \& Schön, D. A. (1978). A theory of action perspective. Boston, MA: Addison-Wesley Publishing Company.

Arops, V. N., \& G. Beye. (1997). Management of agricultural research: A training manual, Module 4: Leadership, motivation, building and conflict management. Rome, Italy: UN Food and Agricultural Organization.

Babbie, E. R. (1990). Survey research methods (2nd ed.). Belmont, CA: Wadsworth Publishing Company. 
Bakker, A. B., Demerouti, E., \& Sanz-Vergel, A. I. (2014). Burnout and work engagement: The JD-R approach. Annual Review of Organizational Psychology and Organizational Behavior, 1, 389- 411.

Baltar, F., \& Brunet, I. (2011). Social research 2.0: virtual snowball sampling method using Facebook. Internet Research, 22(1), 55-74.

Barnard, C. I. (1938). (1968). The functions of the executive. Cambridge, MA: Harvard University Press.

Baron, R. A. (1989). Personality and organizational conflict: Effects of the Type A behavior pattern and self-monitoring. Organizational Behavior and Human Decision Processes, 44, 281-296.

Basadur, M. (1997). Organizational development interventions for enhancing creativity in the workplace. The Journal of Creative Behavior, 31, 59-72.

Basadur, M. S. (1974). Think or sink. The Deliberate Methods Change Bulletin. Cincinnatti, OH: Procter \& Gamble Management Systems Division.

Basadur, M. S. (1982). Research in creative problem solving training in business and industry. In S. Gryskiewicz \& J. Shields (Eds.)., Proceedings: Creativity Week IV, 1981 (pp. 40-59). Greensboro, NC: Center for Creative Leadership.

Basadur, M. S. (1983). Employee involvement creative problem-solving workshop. In, Ford education and training catalog (p. 115). Greensboro, NC: Ford Education and Personnel Research Department.

Basadur, M. S., Ellspermann, S. J., \& Evans, G. W. (1994). A new methodology for formulating ill-structured problems. Omega, 22, 627-645.

Basadur M. S., Graen G. B., \& Wakabayashi, M. (1990). Identifying individual differences in creative problem solving style. Journal of Creative Behavior, 24, 111-131.

Beatty, P. (2004). The dynamics of cognitive interviewing. In S. Presser, J. Rothgeb, M. Couper, J. Lessler, E. Martin, J. Martin, E. Singer (Eds.), Methods for testing and evaluating survey questionnaires. New York, NY: Wiley.

Beatty, P. C. (2003). Answerable questions: Advances in the methods for identifying and resolving questionnaire problems in survey research. Dissertation Abstracts International: Section A. The Humanities and Social Sciences, 64(09): 3504A. 
Beatty, P. C., \& Willis, G. B. (2007). Research synthesis: The practice of cognitive interviewing. Public Opinion Quarterly, 71(2), 287-311.

https://doi.org/10.1093/poq/nfm006

Beccaria, G., \& Machin, M. A. (2010). Examining the validity of the problem-solving inventory in Australia. In Proceedings of the 27th International Congress of Applied Psychology (ICAP 2010) (pp. 477-477). Australian Psychological Society.

Bercini, D. H. (1992). Pretesting questionnaires in the laboratory: An alternative approach. Journal of Exposure Analysis and Environmental Epidemiology, 2(2), 241-248.

Bercovitch, J. (1992). The structure and diversity of mediation in international relations. In J. Bercovitch \& J. Z. Rubin (Eds.), Mediation in International Relations (pp. 129). Basingstoke, UK: Palgrave Macmillan.

Bercovitch, J., \& Jackson, R. (2001). Negotiation or mediation? An exploration of factors affecting the choice of conflict management in international conflict. Negotiation Journal, 17, 59-77.

Bercovitch, J., \& Lee, S. M. (2003). Mediating international conflicts: examining the effectiveness of directive strategies. International Journal of Peace Studies, 8, 117.

Blake, R. R., \& Mouton, J. S. (1964). The managerial grid. Houston, TX: Gulf.

Bogen, K. (1996). The effect of questionnaire length on response rates: A review of the literature. In Proceedings of the Section on Survey Research Methods (pp. 10201025). Washington, DC: American Statistical Association.

Bollen, K. A., \& Lennox, R. (1991). Conventional wisdom on measurement: A structural equation perspective. Psychological Bulletin, 110(2), 305-314. doi:10.1037/00332909.110.2.305

Bolman, L. G., \& Deal, T. E. (1991). Reframing organizations. San Francisco, CA: Jossey-Bass Publishers.

Bolton, R.N. \& Bronkhorst, T.M. (1996). Questionnaire pretesting: Computer assisted coding of concurrent protocols. In N. Schwarz \& S. Sudman (Eds.), In answering questions: Methodology for determining cognititve and communicative processes in survey research. San Francisco: Jossey-Bass. 
Bourne, L. E., Ekstrand, B. R., \& Dominowski, R. L. (1971). The psychology of thinking. Englewood Cliffs, NJ: Prentice-Hall.

Buchanan, L., \& O'Connell, A. (2006). A brief history of decision making. Harvard Business Review, 84, 32-41.

Buisine, S., Besacier, G., Aoussat, A., \& Vernier, F. (2012). How do interactive tabletop system influence collaboration? Computers in Human Behavior, 28, 49-59.

Cameron, K. S., \& Quinn, R. E. (1988). Organizational paradox and transformation. Pensacola, FL: Ballinger Publishing Co/Harper \& Row Publishers.

Castro, A. P., \& Nielsen, E. (2001). Indigenous people and co-management: implications for conflict management. Environmental Science \& Policy, 4(4-5), 229-239.

Carnevale, P. J. (1986). Strategic choice in mediation. Negotiation Journal, 2(1), 41-56.

Carson, J. (2007). A problem with problem solving: Teaching thinking without teaching knowledge. The Mathematics Educator, 17(2), 7-14.

Chan, D. (2014). A paradoxical approach to policymaking. Retrieved February 1, 2016 from http://www.straitstimes.com/opinion/a-paradoxical-approach-topolicymaking.

Chant, R. H., Moes, R., \& Ross, M. (2009). Curriculum construction and teacher empowerment: supporting invitational education with a creative problem solving model. Journal of Invitational Theory and Practice, 15, 55-67.

Chapeskie,A. (1995). Land, landscape, culturescape: aboriginal relation- ships to land and the co-management of natural resources. Quebec: The Government of Canada, Department of Indian and Northern Affairs.

Chen, Y. F., \& Cheng, K. W. (2009). Integrating computer-supported cooperative learning and creative problem solving into a single teaching strategy. Social Behavior and Personality, 37, 1283-1296.

Chertkoff, J. M., \& Esser, J. K. (1976). A review of experiments in explicit bargaining. Journal of Experimental Social Psychology, 12, 464-486.

Cialdini, R. (1993). The psychology of influence. New York, NY: William Morrow \& Co.

Cloke, K., \& Goldsmith, J. (2011). Resolving conflicts at work: eight strategies for everyone on the job. Hoboken, NJ: John Wiley \& Sons. 
Conlon, D. E., \& Fasolo, P. M. (1990). Influence of speed of third-party intervention and outcome on negotiator and constituent fairness judgments. Academy of Management Journal, 33, 833-846.

Conrad, F., Blair, J., \& Tracy, E. (2000). Verbal reports are data! A theoretical approach to cognitive interviews (Proceedings of the 1999 Federal Committee on Statistical Methodology Research Conference), Washington, D: Office of Management and Budget.

Cortina, L. M., Magley, V. J., Williams, J. H., \& Langhout, R. D. (2001). Incivility in the work-place: Incidence and impact. Journal of Occupational Health Psychology, 6, 64-80.

Coser, L. (1967). Continuities in the study of social conflict. New York: Free Press.

Costantino, C. A., \& Merchant, C. S. (1996). Designing conflict management systems: A guide to creating productive and healthy organizations. San Franisco, CA: Jossey-Bass.

Couper, M. P. (2000). Web surveys: A review of issues and approaches. Public Opinion Quarterly, 64(4), 464-494. https://doi.org/10.1086/318641

Couper, M. P., Traugott, M. W., \& Lamias, M. J. (2001). Web survey design and administration. Public Opinion Quarterly, 65(2), 230-253. doi:10.1086/322199

Cox, R. W. (1981). Social forces, states and world orders: Beyond international relations theory. Millennium, 10, 126-155.

Cranford, J. A., McCabe, S. E., Boyd, C. J., Slayden, J., Reed, M. B., Ketchie, J. M. \& Scott, M. S. (2008). Reasons for nonresponse in a web-based survey of alcohol involvement among first-year college students. Addictive Behaviors, 33, 206-210.

Crawford, S. D., Couper, M. P., \& Lamias, M. J. (2001). Web surveys: Perceptions of burden. Social Science Computer Review, 9(2), 146-162. doi:10.1177/089443930101900202

Craver, C. B. (2005). Effective legal negotiation and settlement (5th ed.). Danvers, MA: LexisNexis.

Craver, C. B. (2005). The Labor movement needs a twenty-first century committee for industrial organization. Hofstra Labor \& Employment Law Journal, 23(69), 1-57. 
Crawford, S.D., Couper, M.P., \& Lamias, M.J. (2001) Web surveys: Perceptions of burden. Social Science Computer Review, 19, 146-162.

Creswell, J. W. (1999). Mixed-method research: Introduction and application. In T. Cijek (Ed.), Handbook of Educational Policy (pp. 455-472). San Diego, CA: Academic Press.

Creswell, J.W. (2006). Research design: Qualitative, quantitative, and mixed method approaches $\left(3^{\text {rd }} \mathrm{ed}\right.$.) Thousand Oaks, CA: Sage.

Creswell, J. W., Fetters, M. D., \& Ivankova, N. V. (2004). Designing a mixed methods study in primary care. Annals of Family Medicine, 2, 7-12.

Creswell, J. W., Plano Clark, V. L., Gutmann, M. L., \& Hanson, W. E. (2003). Advanced mixed methods research designs. In A.Tashakkori \& C.Teddlie (Eds.), Handbook of mixed methods in social and behavioral research (pp. 209-240). Thousand Oaks, CA: Sage.

Cronbach, L. J. (1951). Coefficient alpha and the internal structure of tests. Psychometrika, 16(3), 297-334. doi:10.1007/BF02310555

Cronbach, L. J. (1971). Test validation. In R. L. Thorndike (Ed.), Educational measurement (2nd ed.) (pp. 443-507). Washington, DC: American Council on Education.

Cross, J. G. (1965). A theory of the bargaining process. The American Economic Review, $55(1 / 2), 67-94$.

Cyert, R. M., \& March, J. G. (1963). A behavioral theory of the firm. Englewood Cliffs, NJ: Prentice Hall.

Dabdoud, A., \& Cox, T. (2012). Which costs less: Arbitration or litigation? Retrieved from: http://web1.beta.insidecounsel.com/2012/12/06/which-costs-less-arbitration-orlitigation?slreturn $=1519513767$

Daft, R. L. (2014). The leadership experience. Boston, MA: Cengage Learning.

Dellas, M., \& Gaier, E. L. (1970). Identification of creativity: The individual. Psychological Bulletin, 73(1), 55-73. http://dx.doi.org/10.1037/h0028446 
Denscombe, M. (2008). The length of responses to open-ended questions: A comparison of online and paper questionnaires in terms of a mode effect. Social Science Computer Review, 26(3), 359-368. http://dx.doi.org/10.1177/0894439307309671

DeVellis, R. F. (2016). Scale development: Theory and application (Vol. 26). Newbury Park, CA: Sage.

Dewey, J. (1909). Moral principles in education. Boston, MA: Houghton Mifflin.

Dewey, J. (1933). How we think: A restatement of the relation of reflective thinking to the educational process. Lexington, MA: Heath.

Dillman, D. A. (2000). Mail and internet surveys: The tailored design method (2nd ed.). New York, NY: Wiley.

Dodge, R., Daly, A. P., Huyton, J., \& Sanders, L. D. (2012). The challenge of defining wellbeing. International Journal of Wellbeing, 2, 222-235.

Dommeyer, C. J., \& Moriarty, E. (2000). Increasing the response rate to E-mail surveys. Paper presented at The American Association for Public Opinion Research (AAPOR) 55th Annual Conference, Portland, OR. Retrieved from http://www.websm.org/index.php?fl=2\&lact=8\&vir=27

Donate, M. J., \& de Pablo, J. D. S. (2015). The role of knowledge-oriented leadership in knowledge management practices and innovation. Journal of Business Research, $68,360-370$.

Donovan, M. A., Drasgow, F., \& Munson, L. J. (1998). The perceptions of fair interpersonal treatment scale: Development and validation of a measure of interpersonal treatment in the workplace. Journal of Applied Psychology, 38, 683692.

Dostál, J. (2015). Theory of problem solving. Procedia-Social and Behavioral Sciences, $174,2798-2805$.

Druckman, D. (1977). Boundary role conflict: Negotiation as dual responsiveness. Journal of Conflict Resolution, 21, 639-662.

Druckman, D. (Ed.). (1977). Negotiations: Social-psychological perspectives. Beverly Hills, CA: Sage Publications.

Duncker, K., \& Lees, L. S. (1945). On problem-solving. Psychological Monographs, $58(5), \mathrm{i}-113$. 
Eisaguirre, L. (2002). The power of a good fight: How to embrace conflict to drive productivity, creativity, and innovation. New York, NY: Alpha Books.

Eisenhardt, K. M., \& Westcott, B. J. (1988). Paradoxical demands and the creation of excellence: The case of just-in-time manufacturing. In R. E. Quinn \& K. S. Cameron (Eds.), Paradox and transformation: Toward a theory of change in organization and management (pp. 19-54). Pensacola, FL: Ballinger Publishing.

Elangovan, A. R. (1995). Managerial third-party dispute intervention: A prescriptive model of strategy selection. Academy of Management Review, 20, 800-830.

Ensley, M.D., Pearson, A.W., \& Amason, A.C. (2000). Understanding the dynamics of new venture top management teams. Cohesion, conflict, and new venture performance. Journal of Business Venturing, 17, 365-386.

Eysenck, H. J. (1997). Creativity and personality. In M. A. Runco (Ed.), The creativity research handbook, Volume 1. Cresskill, NJ: Hampton Press.

Fan, W., \& Yan, Z. (2010). Factors affecting response rates of the web survey: A systematic review. Computers in Human Behavior, 26(2), 132-139. http://doi.org/10.1016/j.chb.2009.10.015

Fayol, H. (1949). Industrial and general management. London: Pitman.

Feldhusen, J. F. (1995). Creativity: A knowledge base, metacognitive skills, and personality factors. The Journal of Creative Behavior, 29, 255-268.

Filley, A. C. (1975). Interpersonal conflict resolution. Salt Lake City, UT: Scott, Foresman.

Fink, C. F. (1968). Some conceptual difficulties in the theory of social conflict. Journal of Conflict Resolution, 12, 412-460.

Finke, R. A., Ward, T. B., \& Smith, S. M. (1992). Creative cognition: Theory, research, and applications. Cambridge, MA: MIT Press.

Fisher, R., Ury, W., \& Patton, B. (1991). Getting to yes: Negotiating agreement without giving in. New York, NY: Penguin Books.

Fisher, R., Ury, W. L., \& Patton, B. (2011). Getting to yes: Negotiating agreement without giving in. New York, NY: Penguin. 
Floyd, S. W., \& Lane, P. J. (2000). Strategizing throughout the organization: Managing role conflict in strategic renewal. Academy of Management Review, 25, 154-177.

Folger, J. P., Poole, M. S., \& Stutman, R. K. (2005), Working through conflict: Strategies for relationships, groups, and organizations. Boston, MA: Pearson Education.

Ford, J. D., \& Backoff, R. W. (1988). Organizational change in and out of dualities and paradox. Ballinger Publishing Co/Harper \& Row Publishers.

Forsyth, B. H., \& Lessler, J. T. (1991). Cognitive laboratory methods: A taxonomy. In P. P. Biemer, R. M. Groves, L. E. Lyberg, N. A. Mathiowetz, \& S. Sudman (Eds.), Measurement errors in surveys (pp. 393-418). Hoboken, NJ: Wiley. doi:10.1002/9781118150382

Fowers, B. J. (2010). Instrumentalism and psychology beyond using and being used. Theory and Psychology, 20, 102-124.

Fricker, R. D., \& Schonlau, M. (2002). Advantages and disadvantages of Internet research surveys: Evidence from the literature. Field Methods, 14, 347-367.

Frone, M. R. (2000). Interpersonal conflict at work and psychological outcomes: Testing a model among young workers. Journal of Occupational Health Psychology, 5, 246-255.

Gadlin, H. (1991). Careful maneuvers: Mediating sexual harassment. Negotiation Journal, 7, 139-153.

Garton, L., Haythornthwaite, C., \& Wellman, B. (1997). Studying online social networks. Journal of Computer-Mediated Communication, 3(1). doi:10.1111/j.10836101.1997.tb00062.x

Garvey, C. (1984). Children's talk. Cambridge, MA: Harvard University Press.

Gerhart, P. F., \& Drotning, J. E. (1980). Dispute settlement and the intensity of mediation. Industrial Relations: A Journal of Economy and Society, 19, 352-359.

Getzels, J. W. (1979). Problem finding: A theoretical note. Cognitive science, 3(2), $167-$ 172.

Gottman, J. M. (2013). Marital interaction: Experimental investigations. New York, NY: Elsevier. 
Gough, H. G. (1979). A creative personality scale for the adjective check list. Journal of Personality and Social Psychology, 37(8), 1398-1405. http://dx.doi.org/10.1037/0022-3514.37.8.1398

Greene, J. C., Caracelli, V. J., \& Graham, W. F. (1989). Toward a conceptual framework for mixed-method evaluation designs. Educational Evaluation and Policy Analysis, 11, 255-274.

Groves, R. M. (1989). Survey errors and survey costs. New York: Wiley

Groves, R.M., Presser, S. \& Dipko, S. (2004). The role of topic interest in survey participation decisions. Public Opinion Quarterly, 44, 174-99.

Guilford, J. P. (1950). Creativity. American Psychologist, 5, 444-454.

Guilford, J. P. (1962). Creativity: Its measurement and development. In S. J. Parnes \& H. F. Harding (Eds.), A source book for creative thinking (pp. 151-167). New York, NY: Charles Scribner's Sons.

Guilford, J. P. (1967). Creativity: Yesterday, today and tomorrow. The Journal of Creative Behavior, 1, 3-14.

Guilford, J. P. (1977). Way beyond the IQ: Guide to improving intelligence and creativity. Scituate, MA: Creative Education Foundation.

Gulliver, P. H. (1979). Disputes and negotiations: A cross-cultural perspective. New York, NY: Academic Press.

Harrison, H. A. (1994). The relationship among Jungian psychological type preferences, problems experienced, and perceived problem-solving capabilities for African Americans holding graduate degrees. Unpublished doctoral dissertation, St. Louis University.

Hattiangadi, J. N. (1978). The structure of problems, (Part I). Philosophy of the Social Sciences, 8, 345-365.

Hay, D. F. (1984). Social conflict in early childhood. In G. Whitehurst (Ed.), Annals of Child Development, $l, 1-44$.

Haydock, R. S. (1984). Negotiation practice. New York, NY: John Wiley and Sons.

Heppner, P. P. (1988). The problem solving inventory: Manual. Palo Alto, CA: Consulting Psychologists Press. 
Heppner, P. P., \& Baker, C. E. (1997). Applications of the problem solving inventory. Measurement and Evaluation in Counseling and Development, 29(4), 229-241.

Heppner, P.P., Cook, S.W., Wright, D.M., \& Johnson, W.C., Jr. (1995). Progress in resolving problems: a problem-focused style of coping. Journal of Counseling Psychology, 42(3), 279-293.

Heppner, P. P., \& Petersen, C. H. (1982). The development and implications of a personal problem-solving inventory. Journal of Counseling Psychology, 29(1), 66-75. doi:10.1037/0022-0167.29.1.66

Heppner, P. P., Witty, T. E., \& Dixon, W. A. (2004). Problem-solving appraisal and human adjustment: A review of 20 years of research using the Problem Solving Inventory. The Counseling Psychologist, 32, 344-428.

Hiam, A. (1997). Assessing behavior in conflict. Taverny, FR: Trainer's Spectrum/E Pluribus Maximus.

Hiltrop, J. M. (1985). Mediator behavior and the settlement of collective bargaining disputes in Britain. Journal of Social Issues, 41, 83-99.

Hogue, M., Levashina, J., \& Hang, H. (2013). Will I fake it? The interplay of gender, Machiavellianism, and self-monitoring on strategies for honesty in job interviews. Journal of Business Ethics, 117, 399-411.

Hovtepo, O. M., Assokere, A., Abdul-Azeez, I., \& Ajemunighbohun, S. A. (2010). Empirical Study of Effects of Conflict on Organizational Performance in Nigeria. Business and Economics Journal, 2010(15), 1-9. http://www.insidecounsel.com/2012/12/06/which-costs-less-arbitration-orlitigation.

Hyder, E. B., Prietula, M. J., \& Weingart, L. R. (2000). Getting to best: Efficiency versus optimality in negotiation. Cognitive Science, 24, 169-204.

Ingerson, M., Detienne, K. B., \& Liljenquist, K. A. (2015). Beyond instrumentalism: A relational approach to negotiation. Negotiation Journal, 31, 31-46. http://doi.org/10.1111/nejo.12078

Isaksen, S. G., \& Treffinger, D. J. (2004). Celebrating 50 years of reflective practice: Versions of creative problem solving. Journal of Creative Behavior, 38, 75-101. 
Jehn, K. A. (1997). Affective and cognitive conflict in work groups: Increasing performance through value-based intragroup conflict. Using Conflict in Organizations, 87, 100-???..

Jehn, K. A., Rispens, S., \& Thatcher, S. M. (2010). The effects of conflict asymmetry on work group and individual outcomes. Academy of Management Journal, 53, 596616.

Jokipii, A. (2010). Determinants and consequences of internal control in firms: a contingency theory based analysis. Journal of Management \& Governance, 14, 115-144.

Joo, B. K., \& Park, S. (2010). Career satisfaction, organizational commitment, and turnover intention: The effects of goal orientation, organizational learning culture and developmental feedback. Leadership \& Organization Development Journal, 31(6), 482-500.

Kahney, H. (1986). Problem-solving: A cognitive approach. Milton Keynes, PA: Open University Press.

Kaplan, B., \& Kaiser, R. (2006). The versatile leader: Make the most of your strengths without overdoing it (Vol. 309). Hoboken, NJ: John Wiley \& Sons.

Karrass, C. L. (1970). The negotiating game. New York, NY: Thomas Y. Crowell.

Katz, N. H., Flynn, L. T. (2013). Understanding conflict management systems and strategies in the workplace: A pilot study. Conflict Resolution Quarterly, 30, 393410.

Kelley, H. H., \& Thibaut, J. W. (1969). Group problem-solving. The handbook of social psychology, 4, 1-101.

Kerns, C. D. (2008). The trybaby syndrome: Identifying and breaking out of this performance challenge. Graziadio Business Review, 11(2). Retrieved from https://gbr.pepperdine.edu/2010/08/the-trybaby-syndrome/

Kerns, C. D. (2013). Clarity of purpose and meaningfulness at work: Key leadership practice. International Leadership Journal, 5(1), 27-44.

Kerns, C. D. (2014). Fostering and managing engagement: A framework for managerial leaders. Journal of Leadership, Accountability, and Ethics, 11, 34-49. 
Kerns, C. D. (2015). Individual differences: A core leadership dimension. International Leadership Journal, 7, 54-77.

Kerns, C. D. (2016). Managing and negotiating conflict: A key managerial leadership practice. International Leadership Journal, 8, 73-98.

Kim Jean Lee, S., \& Yu, K. (2004). Corporate culture and organizational performance. Journal of Managerial Psychology, 19, 340-359.

Kim, K. H. (2006). Can we trust creativity tests? A review of the Torrance Tests of Creative Thinking (TTCT). Creativity Research Journal, 18(1-3), 3-14.

Kinicki, A. \& Williams, B. (2013). Management: A practical introduction (6th Ed.). Boston, MA: McGraw-Hill.

Kirton, M. J. (2003). Adaption-innovation in the context of diversity and change. London, UK: Routledge.

Kitzinger, J. (1995). Qualitative research: Introducing focus groups. BMJ, 311(7000), 299-302. http://doi.org/10.1136/bmj.311.7000.299

Kleiboer, M. (1996). Understanding success and failure of international mediation. Journal of Conflict Resolution, 40, 360-389.

Kleiboer, M., \& Hart, P. T. (1995). Time to talk?: Multiple perspectives on timing of international mediation. Cooperation and Conflict, 30(4), 307-348. doi:10.1177/0010836795030004001

Klein, D. M. (1983). Family problem solving and family stress. Marriage and Family Review, 6(1-2), 85-112.

Klein, D. M., \& Hill, R. (1979). Determinants of family problem-solving effectiveness. In W. R. Burr et al. (Ed.), Contemporary theories about the family: Research-based theories, Vol. 1 (pp. 493-548). New York, NY: Free Press.

Knight, P., \& Yorke, M. (2004). Learning, curriculum and employability in higher education. London, UK: RoutledgeFalmer.

Koestler, A. (1964). The act of creation. United Kingdom: Hutchinson.

Kotter, J. P. (1985). Power and influence. New York, NY: Free Press. 
Kownatzki, M., Walter, J., Floyd, S. W., \& Lechner, C. (2013). Corporate control and the speed of strategic business unit decision making. Academy of Management Journal, 56, 1295-1324.

Kressel, K., \& Pruitt, D. G. (1985). Themes in the mediation of social conflict. Journal of Social Issues, 41, 179-198.

Kressel, K., \& Pruitt, D. G. (1989). Conclusion: A research perspective on the mediation of social conflict. In K. Kressel \& D. G. Pruitt (Eds.), Mediation research: The process and effectiveness of third party intervention. San Francisco, CA: JosseyBass.

Krueger, R. A. (2000). Focus groups: A practical guide for applied research (3rd ed.). Thousand Oaks, CA: Sage.

Krulik, S., \& Rudnick, J. A. (1987). Problem solving: A handbook for teachers (2nd ed.). Boston, MA: Allyn and Bacon.

Krulik, S., \& Rudnick, J. A. (1994). Reflect... for better problem solving and reasoning. Arithmetic Teacher, 41, 334-339.

Kuo, F. R., Chen, N. S., \& Hwang, G. J. (2014). A creative thinking approach to enhancing the web-based problem solving performance of university students. Computers \& Education, 72, 220-230.

Kypri, K., Stephenson, S., \& Langley, J. (2004). Assessment of nonresponse bias in an internet survey of alcohol use. Alcoholism, Clinical and Experimental Research, 28(4), 630-634. doi:10.1097/01.ALC.0000121654.99277.26

Labovitz, G., \& Rosansky, V. (2012). Rapid realignment: How to quickly integrate people, processes, and strategy for unbeatable performance. New York, NY: McGraw Hill Professional.

Langley, P., \& Rogers, S. (2005). An extended theory of human problem-solving. In Proceedings of the Twenty-Seventh Annual Meeting of the Cognitive Science Society (pp. 1-6).

Larkin, J. H., McDermott, J., Simon, D. P., \& Simon, H. A. (1980). Models of competence in solving physics problems. Cognitive Science, 4, 317-345.

Larson, L. M., \& Heppner, P. P. (1989). Problem-solving appraisal in an alcoholic population. Journal of Counseling Psychology, 36(1), 73-78.

http://dx.doi.org/10.1037/0022-0167.36.1.73 
Lax, D. A., \& Sebenius, J. K. (1985). The power of alternatives or the limits to negotiation. Negotiation Journal, 1, 163-179.

Lax, D. A., \& Sebenius, J. K. (1986). Interests: The measure of negotiation. Negotiation Journal, 2, 73-92.

Lazarus, R. S., \& Folkman, S. (1984). Coping and adaptation. In W. D. Gentry (Ed.) The handbook of behavioral medicine (pp. 282-325). New York: Guilford.

Leavitt, H. J. (1951). Some effects of certain communication patterns on group performance. The Journal of Abnormal and Social Psychology, 46, 38-50.

Lefcourt, H. M. (1996). Perspective- taking humor and authoritarianism as predictors of anthropocentrism. Humor, 9(1), 57-71. https://doi.org/10.1515/humr.1996.9.1.57

Lewicki, R. J., Saunders, D. M. \& Minton, J. W. (1997). Essentials of negotiation. Chicago: Irwin.

Lewicki, R. J., Saunders, D. M., \& Barry, B. (2010). Negotiation. London, UK: Pearson.

Lewicki, R. J., \& Sheppard, B. H. (1985). Choosing how to intervene: Factors affecting the use of process and outcome control in third party dispute resolution. Journal of Organizational Behavior, 6, 49-64.

Lewicki, R. J., Weiss, S. E., \& Lewin, D. (2016). Models of conflict, negotiation and third party intervention: A review and synthesis. Journal of Organizational Behavior, 13, 209-252.

Lewis, D.S., French, E., \& Steane, P. (1997). A culture of conflict: Effects affective conflict within an organization. Leadership and Organization Development Journal, 18, 275-280.

Lewis, M. W. (2000). Exploring paradox: Toward a more comprehensive guide. Review, $25,760-776$.

Likert, R. (1932). A technique for the measurement of attitudes. Archives of Psychology, 22(140), 1-55.

Likert, R. (1961). New patterns of management. New York, NY: McGraw-Hill. 
Lim, R. G., \& Carnevale, P. J. (1990). Contingencies in the mediation of disputes. Journal of Personality and Social Psychology, 58(2), 259-272. doi:10.1037/00223514.58.2.259

Lipsky, D. B., Seeber, R. L., \& Fincher, R. D. (2003). Emerging systems for managing workplace conflict: Lessons from American corporations for managers and dispute resolution professionals. San Francisco, CA: Jossey-Bass.

Luce, R. D., \& Raiffa, H. (1957). Games and decisions: Introduction and critical surveys. New York, NY: Wiley.

Maccoby, M. (2004). Why people follow the leader: the power of transference. Harvard Business Review, 82(9), 76-85.

Mack, R. W., \& Snyder, R. C. (1957). The analysis of social conflict—toward an overview and synthesis. Conflict Resolution, 1, 212-248.

Mackie, K., Miles, D., \& Marsh, W. (1995). Commercial dispute resolution: An ADR practice guide. London: Butterworths.

Mackworth, N. H. (1965). Originality. American Psychologist, 20, 51-66.

March, J. G., \& Simon, H. A. (1958). Organizations. New York, NY: John Wiley \& Sons.

Marx, K. and Engel, F. (1848). Communist Manifesto. 1st ed. Moscow: Progress Publishers.

Massey, G. R., \& Dawes, P. L. (2007). Personal characteristics, trust, conflict, and effectiveness in marketing/sales working relationships. European Journal of Marketing, 41(9/10), 1117-1145.

Mayer, R. E. (1992). Thinking, problem-solving, cognition (2nd ed.). New York, NY: W.H. Freeman.

Mayring, Philipp (2000). Qualitative Content Analysis [28 paragraphs]. Forum Qualitative Sozialforschung / Forum: Qualitative Social Research, 1(2), Art. 20, http://nbn-resolving.de/urn:nbn:de:0114-fqs0002204.

McCann, B. S., Russo, J., \& Benjamin, G. A. H. (1997). Hostility, social support, and perceptions of work. Journal of Occupational Health Psychology, 2, 175-185. 
McLaughlin, M. E., Carnevale, P., \& Lim, R. G. (1991). Professional mediators' judgments of mediation tactics: Multidimensional scaling and cluster analyses. Journal of Applied Psychology, 76(3), 465-472. http://dx.doi.org/10.1037/00219010.76.3.465

Meadow, A., Parnes, S. J., \& Reese, H. (1959). Influence of brainstorming instructions and problem sequence on a creative problem solving test. Journal of Applied Psychology, 43(6), 413-416. http://dx.doi.org/10.1037/h0043917

Mednick, S. A. (1962). The associative basis of the creative process. Psychological Review, 69, 220-232.

Merriam, S. B. (2002). Qualitative research in practice: Examples for discussion and analysis. San Francisco, CA: Jossey-Bass Inc Pub.

Meyer, S. (2004). Organizational response to conflict: Future conflict and work outcomes. Social Work Research, 28, 183-190.

Michael, W. B., \& Wright, C. R. (1989). Psychometric issues in the assessment of creativity. In J. A. Glover, R. R. Ronning, \& C. R Reynolds (Eds.), Handbook of creativity (pp. 33-52). New York: Plenum Press.

Miles, E. W. (2013). In Practice - Developing strategies for asking questions in negotiation. Negotiation Journal, 29, 383-412. http://doi.org/10.1111/nejo.12034

Mintzberg, H. (1973). The nature of managerial work. Upper Saddle River, NJ: Prentice Hall College Division.

Mintzberg, H. (2013). Simply managing: What managers do-and can do better. Oakland, CA: Berrett-Koehler Publishers.

Mohr, A. T., \& Puck, J. F. (2007). Role conflict, general manager job satisfaction and stress and the performance of IJVs. European Management Journal, 25, 25-35.

Mooney, A. C., Holahan, P. J., \& Amason, A. C. (2007). Don't take it personally: Exploring cognitive conflict as a mediator of affective conflict. Journal of Management Studies, 44, 733-758.

Moore, C. W. (1986). The mediation process: Practical strategies for resolving conflict. San Francisco, CA: Jossey- Bass.

Moore, C. W. (1987). The Caucus: Private Meetings that Promote Settlement. Mediation Quarterly, 16, 87-101. 
Moore, C. W. (2003). The mediation process: Practical strategies for resolving conflict. San Francisco: Jossey-Bass.

Moos, R. H., \& Schaefer, J. A. (1986). Life transitions and crises. In R. H. Moos (Ed.), Coping with life crises (pp. 3-28). New York, NY: Springer US.

Morgan, D. L. (1997). Focus groups as qualitative research (2nd ed.). London, EN: Sage. http://dx.doi.org/10.4135/9781412984287

Morgan, D. L., \& Spanish, M. T. (1984). Focus groups: A new tool for qualitative research. Qualitative Sociology, 7(3), 253-270. doi:10.1007/BF00987314

Morse, J. M. (1991). Approaches to qualitative-quantitative methodological triangulation. Nursing Research, 40, 120-123.

Mumford, M. D., Mobley, M. I., Reiter-Palmon, R., Uhlman, C. E., \& Doares, L. M. (1991). Process analytic models of creative capacities. Creativity Research Journal, 4, 91-122.

Murnighan, J. K., \& Conlon, D. E. (1991). The dynamics of intense work groups: A study of British string quartets. Administrative Science Quarterly, 36, 165-186.

Murray, J. S., Rau, A. S., \& Sherman, E. F. (1996). Mediation and other non-binding ADR processes. London, UK: Foundation Pr.

Nelken, M. L. (2001). Understanding negotiation. Cincinnati, OH: Anderson Publishing Company.

Nelken, M. L. (2007). Negotiation: Theory and practice (2nd ed.) Danvers, MA: LexisNexis.

Neuman, J. H., \& Baron, R. A. (1998). Workplace violence and workplace aggression: Evidence concerning specific forms, potential causes, and preferred targets. Journal of Management, 24, 391-419.

Neville, H. A., Heppner, P. P., \& Wang, L. -F. (1997). Relations among racial identity attitudes, perceived stressors, and coping styles in African American college students. Journal of Counseling \& Development, 75(4), 303-311. doi:10.1002/j.1556-6676.1997.tb02345.x

Newell, A., Shaw, J. C., \& Simon, H. A. (1958). Elements of a theory of human problem solving. Psychological Review, 65, 151-166. 
Newell, A., Shaw, J. C., Simon, H.A. (1962). The process of creative thinking. Contemporary approaches to creative thinking, 63-119.

Newell, A., \& Simon, H. A. (1972). Human problem solving. Englewood Cliffs, NJ: Prentice-Hall.

Ngure, J. N., Kihoro, J. M., \& Waititu, A. (2015). Principal component and principal axis factoring of factors associated with high population in urban areas: A case study of Juja and Thika, Kenya. American Journal of Theoretical and Applied Statistics, 4(4), 258-263. doi:10.11648/j.ajtas.20150404.15

Nicotera, A. M., \& Dorsey, L. K. (2006). Individual and interactive processes in organizational conflict. In J. G. Oetzel \& S. Ting-Toomey (Eds.), The Sage handbook of conflict communication: Integrating theory, research, and practice (pp. 293-325). Thousand Oaks, CA: Sage.

Nierenberg, G. I. (1973). Fundamentals of negotiating. Broadway, NY: HarperCollins.

Norris, S. P., \& Ennis, R. H. (1989). What is critical thinking. In S. P. Norris \& R. H. Ennis (Eds.), The practitioner's guide to teaching thinking series: Evaluating critical thinking (pp. 1-26). Spirit Lake, IA: Midwest Publications.

Nota, L., Heppner, P.P., Soresi, S., Heppner, M.J. (2009). Examining cultural validity of the problem-solving inventory (PSI) in Italy. Journal of Career Assessment, 17(4), 478-494. doi: 10.1177/1069072709339490

Nye, R.D. (1973). Conflict among humans. New York, NY: Springer.

O'Neil, K. M., Patry, M. W., \& Penrod, S. D. (2004). Exploring the effects of attitudes toward the death penalty on capital sentencing verdicts. Psychology, Public Policy, and Law, 10(4), 443-470. http://dx.doi.org/10.1037/1076-8971.10.4.443

O'Sullivan, A., \& Sheffrin, S. M. (2003). Economics: Principles in action. Needham, MA: Prentice Hall.

Online Training Program on Intractable Conflict. (n.d.). Retrieved February 01, 2016, from http://www.colorado.edu/conflict/peace/

Onwuegbuzie, A. J., Bustamante, R. M., \& Nelson, J. A. (2010). Mixed research as a tool for developing quantitative instruments. Journal of Mixed Methods Research, 4, 56-78. 
Onwuegbuzie, A. J., \& Collins, K. M. T. (2007). A typology of mixed methods sampling designs in social science research. The Qualitative Report, 12(2), 281-316.

Onwuegbuzie , A. J. , \& Corrigan , J. A. ( 2014 ). Improving the quality of mixed research reports in the field of human resource development and beyond: A call for rigor as an ethical practice [Editorial] . Human Resource Development Quarterly , 25 , 273 - 299 . https://doi.org/10.1002/hrdq.21197

Orenstein, S. G., \& Grant, K. (1989). The face-to-face mediation program: A Massachusetts success story. Negotiation Journal, 5, 175-178.

Osborn, A. F. (1952). Wake up your mind: 101 ways to develop creativeness. New York, NY: Charles Scribner's Sons.

Osborn, A. F. (1953). Applied imagination: Principles and procedures of creative thinking. New York, NY: Charles Scribner's Sons.

Parks, K. A., Pardi, A. M., \& Bradizza, C. M. (2006). Collecting data on alcohol use and alcohol-related victimization: A comparison of telephone and Web-based survey methods. Journal of Studies on Alcohol, 67(2), 318-323. https://doi.org/10.15288/jsa.2006.67.318

Parnes, S. J., Noller, R. B., \& Biondi, A. M. (1977). Guide to creative action. New York: Charles Scribner's Sons.

Patton, M. Q. (1990). Qualitative evaluation and research methods. Thousand Oaks, CA: Sage

Pearlin, L. I., \& Schooler, C. (1978). The structure of coping. Journal of Health and Social Behavior, 19, 2-21.

Peers, I. (1996). Statistical analysis for education and psychology researchers. Bristol, PA: Falmer Press.

Penfield, R. D., \& Miller, J. M. (2004). Improving content validation studies using an asymmetric confidence interval for the mean of expert ratings. Applied Measurement in Education, 17(4), 359-370. https://doi.org/10.1207/s15324818ame1704_2

Platt, J. J., \& Spivack, G. (1975). Manual for the man-end problem-solving procedure (MEPS): A measure of interpersonal cognitive problem-solving skill. Philadelphia, PA: Hahnemann Community Mental Health/Mental Retardation Center, Hahnemann Medical College and Hospital. 
Polya, G. (1988). How to solve it: A new aspect of mathematical method (2nd ed.). Princeton, NJ: Princeton University Press.

Pondy, L. R. (1967). Organizational conflict: Concepts and models. Administrative Science Quarterly, 12, 296-320.

Poole, M. S., \& Van de Ven, A. H. (1989). Using paradox to build management and organization theories. Academy of Management Review, 14, 562-578.

Porter, S. R. (2004). Raising response rates: What works? New Directions for Institutional Research, 2004(121), 5-21. doi:10.1002/ir.97

Pounds, W. F. (1969). The process of problem finding. Industrial Management Review, 11(1), 1-19.

Powers, B. A., \& Knapp, T. R. (2010). Dictionary of nursing theory and research. New York, NY: Springer publishing company.

Pruitt, D. G. (1981). Negotiation behavior. New York, NY: Academic Press.

Pruitt, D. G. (1983). Strategic choice in negotiation. American Behavioral Scientist, 27, 167-194.

Putnam, L. L. (2006). Definitions and approaches to conflict and communication. In J. G. Oetzel \& S. Ting-Toomey (Eds.), The Sage handbook of conflict communication: Integrating theory, research, and practice. Thousand Oaks, CA: Sage.

Putnam, L. L., \& Wilson, C. E. (1982). Communicative strategies in organizational conflicts: Reliability and validity of a measurement scale. Annals of the International Communication Association, 6, 629-652.

Rahim, M. A. (1983). A measure of styles of handling interpersonal conflict. Academy of Management Journal, 26, 368-376.

Rahim, M. A. (1985). A strategy for managing conflict in complex organizations. Human Relations, 38, 81-89.

Rahim, M. A. (2002). Toward a theory of managing organizational conflict. The International Journal of Conflict Management, 13, 206-235.

Rahim, M. A., \& Magner, N. R. (1995). Confirmatory factor analysis of the styles of handling interpersonal conflict: First-order factor model and its invariance across 
groups. Journal of Applied Psychology, 80(1), 122-132.

http://dx.doi.org/10.1037/0021-9010.80.1.122

Raiffa, H. (1982). The art and science of negotiation. Cambridge, MA: Harvard University Press.

Raines, S. S. (2012). Conflict management for managers: Resolving workplace, client, and policy disputes. New Jersey, NJ: Wiley.

Rausch, E. (2003). Guidelines for management and leadership decision. Management Decision, 41, 979-988

Reio, T. G., Jr., \& Werner, J. M. (2017). Publishing mixed methods research: Thoughts and recommendations concerning rigor. Human Resource Development Quarterly, 28, 439-449.

Rickards, T., \& Jones, L. J. (1991). Towards the identification of situational barriers to creative behaviors: The development of a self-report inventory. Creativity Research Journal, 4, 303-315.

Robbins, S.P. (1978). "Conflict management" and "conflict resolution" are not synonymous terms. California Management Review, 21, 67-75.

Roloff, M. E. (1987). Communication and conflict. In C. R. Berger, M. E. Roloff \& D. Roskos-Ewoldsen (Eds.), Handbook of communication science. Newbury Park, CA: Sage.

Rotter, J. B. (1966). Generalized expectancies for internal versus external control of reinforcement. Psychological Monographs: General and Applied, 80, 1-28. http://dx.doi.org/10.1037/h0092976

Rounds, C. E., Jr., \& Rounds, C. E., III (2012). Loring and rounds: A trustee's handbook. New York, NY: Wolters Kluwer.

Royston, P. N. (1989). Using intensive interviews to evaluate questions. In F. J. Fowler, Jr. (Ed.), Conference Proceedings: Health Survey Research Methods (pp. 3-7). Washington, DC: US Department of Health and Human Services.

Royston, P., \& Bercini, D. (1987). Questionnaire design research in a laboratory setting: results of testing cancer risk factor questions. In 1987 Proceedings of the Section on Survey Research Methods (pp. 829-833). Alexandria, VA: American Statistical Association. 
Rubin, J. Z., Pruitt, D. G., \& Kim, S. H. (1994). Social conflict: Escalation, stalemate, and settlement. New York: McGraw-Hill Book Company.

Rubin, K. H., \& Brown, I. D. (1975). A life-span look at person perception and its relationship to communicative interaction. Journal of Gerontology, 30, 461-468.

Rugg, H. O. (1963). Imagination: An inquiry into the sources and conditions of creativity. New York, NY: Harper.

Runco, M. A. (2007). Achievement sometimes requires creativity. High Ability Studies, $18,75-77$.

Sahin, N., Sahin, N. H., \& Heppner, P. P. (1993). Psychometric properties of the problem solving inventory in a group of Turkish university students. Cognitive Therapy and Research, 17(4), 379-396. doi:10.1007/BF01177661

Schaubroeck, J., Ganster, D. C., Sime, W. E., \& Ditman, D. (1993). A field experiment testing supervisory role clarification. Personnel Psychology, 46, 1-25.

Schelling, T. C. (1960). The strategy of conflict. Cambridge, MA: Harvard University Press.

Schweiger, D.M., Sandberg, W. R., \& Ragan, J.W. (1986). Group approaches for improving strategic decision making: A comparative analysis of dialectical inquiry, devil's advocacy, and consensus approaches to strategic decision making. Academy of Management Journal, 29, 51-71.

Shantz, C. U. (1987). Conflicts between children. Child Development, 58, 283-305.

Sheard, A. G., \& Kakabadse, A. P. (2007). A role-based perspective on leadership as a network of relationships. Journal of Management Development, 26, 331-352.

Shell, G. R. (1999). Bargaining for advantage: Negotiation strategies for reasonable people. New York: Viking.

Shepard, R. N. (1984). Ecological constraints on internal representation: Resonant kinematics of perceiving, imagining, thinking, and dreaming. Psychological Review, 91(4), 417-447. http://dx.doi.org/10.1037/0033-295X.91.4.417

Sheppard, B., Blumenfeld-Jones, K., \& Roth, J. (1989). Informal thirdpartyship: A program of research on every day conflict intervention. In D. Pruitt \& K. Kressel (Eds.), Mediation research: The process and effectiveness of third-party intervention. San Francisco, CA: Jossey-Bass. 
Shermerhorn, J. R. (2013). Management (12th Ed.) Hoboken, NJ: John Wiley \& Sons.

Shubik, M. (1964). Game theory and related approaches to social behavior: Selections. New York, NY: Wiley.

Silbey, S. S., \& Merry, S. E. (1986). Mediator settlement strategies. Law \& Policy, 8, 732.

Simon, H. A. (1978). Information-processing theory of human problem solving. Handbook of learning and cognitive processes, 5, 271-295.

Sireci, S., \& Faulkner-Bond, M. (2014). Validity evidence based on test content. Psicothema, 26(1), 100-107. doi:10.7334/psicothema2013.256

Sireci, S. G. \& Parker, P. (2006) Validity on trial: Psychometric and legal conceptualizations of validity. Educational Measurement: Issues and Practice, 25(3), 27-34.

Smith, K. K., \& Berg, D. N. (1987). Paradoxes of group life. San Francisco, CA: JosseyBass.

Smyth, J. D., Dillman, D. A., Christian, L. M., \& Stern, M. J. (2006). Comparing checkall and forced-choice question formats in Web surveys. Public Opinion Quarterly, 70, 66-77. http://doi.org/10.1093/poq/nfj007

Solano-Flores, G., \& Nelson-Barber, S. (2000). Cultural validity of assessments and assessment development procedures. In annual meeting of the American Educational Research Association. New Orleans, LA, April.

Soliman, A.M. (2014). The problem-solving inventory: Appraisal of problem-solving in the Arab context, factor structure, and validation. International Perspectives in Psychology: Research, Practice, Consultation, 3, 252-267.

Spector, P. E. (1992). Summated rating scale construction. Newbury Park, CA: Sage.

Spector, P. E., \& Jex, S. M. (1998). Development of four self-report measures of job stressors and strain: Interpersonal conflict at work scale, organizational constraints scale, quantitative workload inventory, and physical symptoms inventory. Journal of Occupational Health Psychology, 3, 356-367.

Stacey, R. D. (1996). Complexity and creativity in organizations. Oakland, CA: BerrettKoehler Publishers. 
Steiner, I. D. (1972). Group processes and group productivity. New York: Academic.

Stone, A. A., \& Neale, V. M. (1984). New measure of daily coping: Development and preliminary results. Journal of Personality and Social Psychology, 46, 892-906.

Strauss, A. L. (1978). Negotiations: Varieties, contexts, processes, and social order. San Francisco, CA: Jossey-Bass.

Swenson, M. J., Rhoads, G. K., \& Whitlark, D. B. (2014). Startup marketing: Leveraging leverage. Journal of Applied Business \& Economics, 16(6), 56-62.

Tallman, I., \& Gray, L. N. (1990). Choices, decisions, and problem-solving. Annual Review of Sociology, 16, 405-433.

Tallman, I., \& Miller, G. (1974). Class differences in family problem solving: The effects of verbal ability, hierarchical structure, and role expectations. Sociometry, 37, 1337.

Tallman, I., Leik, R. K., Gray, L. N., \& Stafford, M. C. (1993). A theory of problemsolving behavior. Social Psychology Quarterly, 56, 157-177.

Teddlie, C., \& Yu, F. (2007). Mixed methods sampling: A typology with examples. Journal of Mixed Methods Research, 1, 77-100. http://doi.org/10.1177/2345678906292430

Thatcher, S. M., Jehn, K. A., \& Zanutto, E. (2003). Cracks in diversity research: The effects of diversity faultlines on conflict and performance. Group Decision and Negotiation, 12, 217-241.

Thomas, J. L., Bliese, P. D., \& Jex, S. M. (2005). Interpersonal conflict and organizational commitment: Examining two levels of supervisory support as multilevel moderators. Journal of Applied Social Psychology, 35, 2375-2398.

Thomas, K. W. (1974). Thomas-Kilmann conflict mode instrument. Tuxedo, NY: Xicom.

Thomas, K.W. (1976). Conflict and conflict management. In M. D. Dunnette (Ed.), Handbook of industrial and organizational psychology (pp. 889-935). Palo Alto, CA; Consulting Psychologists Press.

Thomas, K. W. (1986). Conflict and conflict management: Reflections and update. Journal of Organizational Behavior, 13, 265-274. 
Thomas, K.W. (1998). Conflict and negotiation processes. In M. D. Dunnette (Ed.), Handbook of industrial and organizational psychology. Chicago, IL: Rand McNally.

Thomas, K. W., \& Schmidt, W. H. (1976). A survey of managerial interests with respect to conflict. Academy of Management Journal, 19, 315-318.

Thompson, L. (1990). Negotiation behavior and outcomes: Empirical evidence and theoretical issues. Psychological Bulletin, 108, 515-532.

Thompson, L. L. (2001). The mind and heart of the negotiator. Upper Saddle River, NJ: Prentice Hall.

Thompson, L. L. (2011). The mind and heart of the negotiator. Upper Saddle River, NJ: Prentice-Hall.

Tjosvold, D., Hui, C., Ding, D. Z., \& Hu, J. (2003). Conflict values and team relationships: Conflict's contribution to team effectiveness and citizenship in China. Journal of Organizational Behavior, 24, 69-88.

Torrance, E. P. (1986). Teaching creative and gifted learners. In M. E. Wittrock (Ed.), Handbook of research on teaching (pp. 630-647). New York, NY: MacMillan.

Torres, V. (2004). The diversity amongst us: Puerto Ricans, Cuban Americans, Caribbean Americans, and Central and South Americans. New Directions for Student Services, 5, 5-16.

Treffinger, D. J., \& Isaksen, S. G. (2005). Creative problem solving: The history, development, and implications for gifted education and talent development. Gifted Child Quarterly, 49, 342-353.

Treffinger, D. J., Isaksen, S. G., \& Dorval, K. B. (2003). Creative problem solving: A contemporary framework for managing change. Sarasota, FL: Center for Creative Learning, Inc. and Creative Problem Solving Groups, Inc.

Trilling, B., \& Fadel, C. (2009). 21st century skills: Learning for life in our times. Hoboken, NJ: John Wiley \& Sons.

Trudel, J., \& Reio, T. G. (2011). Managing workplace incivility: The role of conflict management styles - antecedent or antidote? Human Resource Development Quarterly, 22, 395-423. 
Tseng, K. H., Chang, C. C., Lou, S. J., \& Hsu, P. S. (2013). Using creative problem solving to promote students' performance of concept mapping. International Journal of Technology and Design Education, 23, 1093-1109.

Umbach, P. D. (2005). Getting back to the basics of survey research. New Directions for Institutional Research, 2005(127), 91-100. http://doi.org/10.1002/ir.157

Urlacher, B. R. (2014). Groups, decision rules, and negotiation outcomes: Simulating the negotiator's dilemma. Negotiation Journal, 30, 5-22.

Ury, W. L., Brett, J. M., \& Goldberg, S. B. (1988). Getting disputes resolved: Designing systems to cut the costs of conflict. San Francisco, CA: Jossey-Bass.

Van der Veer, K. Hak, T., Jansen, H. (2002). The three-step test interview (TSTI): An observational instrument for pre-testing self-completion questionnaires. Paper presented at the Questionnaire Development, Evaluation, and Testing Conference, South Carolina.

Van de Vliert, E., Nauta, A., Euwama, M.C., \& Janssen, O. (1997). The effectiveness of mixing problem solving and forcing. Thousand Oaks, CA: Sage.

Vidal, R. V. V. (2010). Creative problem solving: an applied university course. Pesquisa Operacional, 30, 405-426.

Vaismoradi, M., Turunen, H., \& Bondas, T. (2013). Content analysis and thematic analysis: Implications for conducting a qualitative descriptive study. Nursing \&Health Sciences, 15(3), 398-405. http://doi.org/10.1111/nhs.12048

Vince, R., \& Broussine, M. (1996). Paradox, defense and attachment: Accessing and working with emotions and relations underlying organizational change. Organization Studies, 17, 1-21.

Wall, J. A., \& Blum, M. (1991). Community mediation in the People's Republic of China. Journal of Conflict Resolution, 35, 3-20.

Wall, J.A. (1981). Mediation: An analysis, review and proposed research. Journal of Conflict Resolution, 25, 157-183.

Wallace, J., Hunt, J., \& Richards, C. (1999). The relationship between organizational culture, organizational climate and managerial values. The International Journal of Public Sector Management, 12, 548-564. 
Wallach, M. A., \& Kogan, N. (1965). Modes of thinking in young children: A study of the creativity-intelligence distinction. New York, NY: Holt, Rinehart, and Wilson.

Walton, R. E., \& McKersie, R. B. (1965). A behavioral theory of labor negotiations: An analysis of a social interaction system. Ithaca, NY: Cornell University Press.

Watson, C., \& Hoffman, L. R. (1996). Managers as negotiators: A test of power versus gender as predictors of feelings, behavior, and outcomes. The Leadership Quarterly, 7, 63-85.

Weingart, L. R., Hyder, E. B., \& Prietula, M. J. (1996). Knowledge matters: The effect of tactical descriptions on negotiation behavior and outcome. Journal of Personality and Social Psychology, 70, 1205-1217.

Weisberg, R. W. (2006). Creativity: Understanding innovation in problem solving, science, invention, and the arts. Hoboken, NJ: John Wiley \& Sons.

Weiss, J., \& Hughes, J. (2005). Want collaboration. Harvard Business Review, 83, 93101.

Williams, B., Onsman, A., \& Brown, T. (1996). Exploratory factor analysis: A five-step guide for novices. Journal of Emergency Primary Health Care, 19, 42-50.

Willis, G. B. (1994). Cognitive interviewing and questionnaire design: A training manual. Hyattsville, MD: National Center for Health Statistics.

Willis, G.B. (2004). Cognitive interviewing revisited: A useful technique, in theory? In S. Presser, J. M. Rothberg, M. P. Couper, J. T. Lessler, E. Martin, J. Martin, \& E. Singer (Eds.), Methods for testing and evaluating survey questionnaires. Hoboken, NJ: John Wiley \& Sons.

Willis, G. B., Royston, P., \& Bercini, D. (1991). The use of verbal report methods in the development and testing of survey questionnaires. Applied Cognitive Psychology, 5, 251-267. doi:10.1002/acp.2350050307

Wilmot, W., and J. Hocker. 2007. Interpersonal conflict. New York: McGraw-Hill.

Worley, C. G., Williams, T. D., \& Lawler III, E. E. (2014). The agility factor: Building adaptable organizations for superior performance. Hoboken, NJ: John Wiley \& Sons.

Xin, K. R., \& Pelled, L. H. (2003). Supervisor-subordinate conflict and perceptions of leadership behavior: a field study. The Leadership Quarterly, 14, 25-40. 
Yammarino, F. J., Skinner, S. J., \& Childers, T. L. (1991). Understanding mail survey response behavior a meta-analysis. Public Opinion Quarterly, 55, 613-639. https://doi.org/10.1086/269284

Yates, J. F. (2003). Decision management. San Francisco, CA: Jossey-Bass.

Yong, A. G., \& Pearce, S. (2013). A beginner's guide to factor analysis: Focusing on exploratory factor analysis. Tutorials in Quantitative Methods for Psychology, 9(2), 79-94. http://doi.org/10.20982/tqmp.09.2.p079

Young, O. R. (1967). The intermediaries: Third parties in international crises. Princeton, N. J.: Princeton University Press.

Young, O. R. (1975). Bargaining: Formal theories of negotiation. Urbana-Champaign, IL: University of Illinois Press.

Zartman, I. W., \& Touval, S. (1996). International mediation in the post-cold war era. In C. A. Crocker, F. O. Hampson \& P. R. Aall (Eds.), Managing global chaos: Sources of and responses to international conflict (pp. 445-461). Washington, DC: United States Institute of Peace Press. 
APPENDICES 


\section{Appendix A}

\section{Problem-Solving Inventory}

Please indicate how much you agree with each of the following items by rating them on this scale: $1=$ strongly disagree; $2=$ disagree; $3=$ slightly disagree; $4=$ slightly agree; 5 $=$ agree; or $6=$ strongly agree. Please be sure to answer ALL of the questions.

Remember, there are no right or wrong answers.

Definitions:

1. Problem-solving confidence as the belief in one's problem-solving abilities while engaging in problem-solving tasks (Heppner \& Baker, 1997).

2. Approach-avoidance style is defined as the penchant for either approaching or avoiding problem-solving tasks (Heppner \& Baker, 1997).

3. Personal control construct was defined as the belief that one has control over their behavior or attitude when faced with problem-solving tasks (Heppner \& Baker, 1997)

\begin{tabular}{|c|c|c|c|c|c|c|}
\hline $\begin{array}{l}\text { Problem-Solving } \\
\text { Confidence }\end{array}$ & $\begin{array}{l}1 \\
\text { Strongly } \\
\text { Disagree }\end{array}$ & $\begin{array}{l}2 \\
\text { Disagree }\end{array}$ & $\begin{array}{l}3 \\
\text { Slightly } \\
\text { Disagree }\end{array}$ & $\begin{array}{l}4 \\
\text { Slightly } \\
\text { Agree }\end{array}$ & $\begin{array}{l}5 \\
\text { Agree }\end{array}$ & $\begin{array}{l}6 \\
\text { Strongly } \\
\text { Agree }\end{array}$ \\
\hline $\begin{array}{l}\text { I am usually able to think up } \\
\text { creative and effective } \\
\text { alternatives to solve a } \\
\text { problem when working in } \\
\text { groups. }\end{array}$ & & & & & & \\
\hline $\begin{array}{l}\text { I have the ability to solve } \\
\text { most problems with others } \\
\text { even though initially no } \\
\text { solution is immediately } \\
\text { apparent. }\end{array}$ & & & & & & \\
\hline $\begin{array}{l}\text { Many problems I face are } \\
\text { too complex for me to solve } \\
\text { by myself. }\end{array}$ & & & & & & \\
\hline $\begin{array}{l}\text { I make decisions with others } \\
\text { and am happy with them } \\
\text { later. }\end{array}$ & & & & & & \\
\hline $\begin{array}{l}\text { When I make plans to solve } \\
\text { a problem with others, I am } \\
\text { almost certain that we can } \\
\text { make them work. }\end{array}$ & & & & & & \\
\hline $\begin{array}{l}\text { Given enough time and } \\
\text { effort, I believe I can solve } \\
\text { most problems that confront }\end{array}$ & & & & & & \\
\hline
\end{tabular}




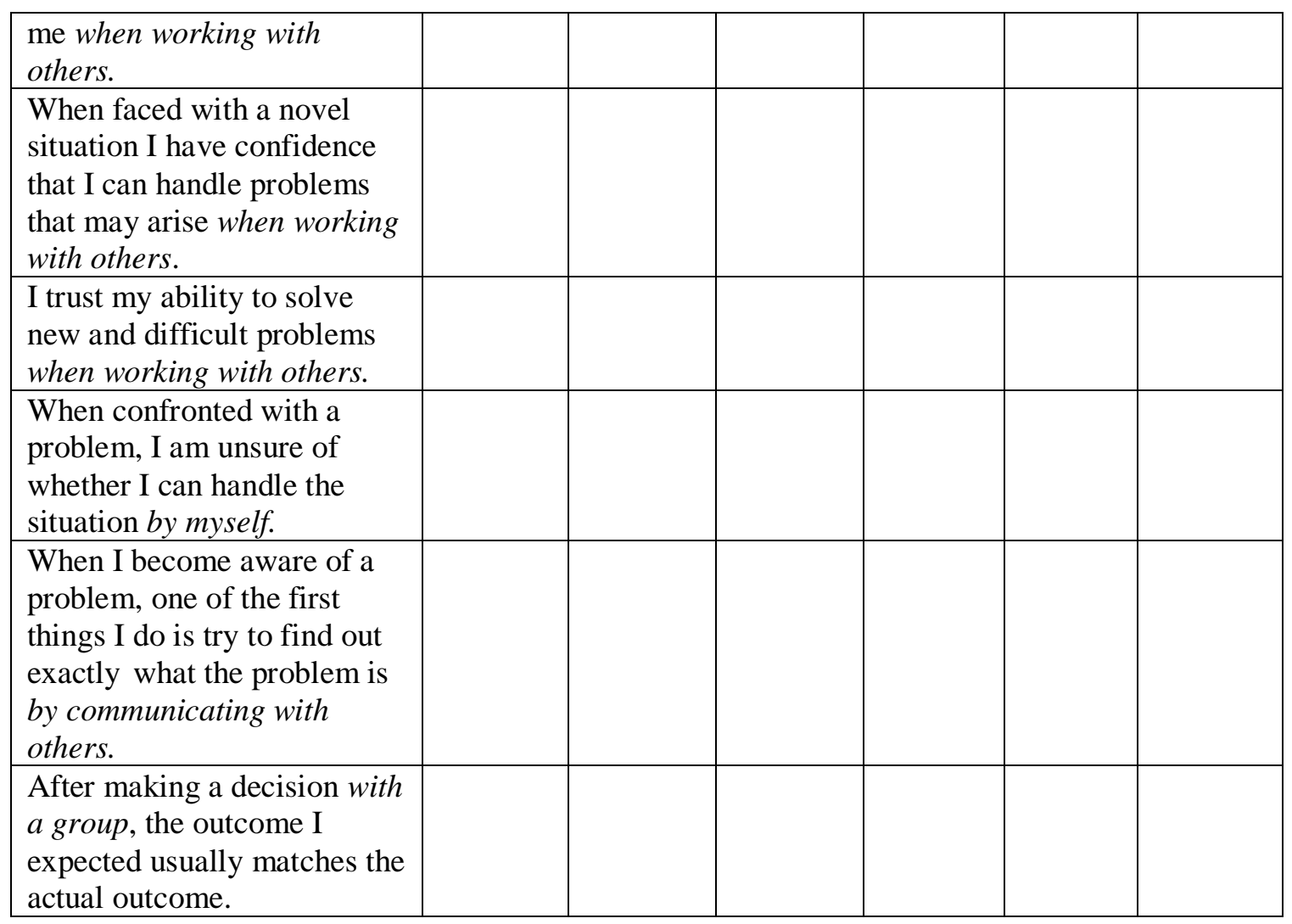

\begin{tabular}{|c|c|c|c|c|c|c|}
\hline Approach Avoidance Style & $\begin{array}{l}1 \\
\text { Strongly } \\
\text { Disagree }\end{array}$ & $\begin{array}{l}2 \\
\text { Disagree }\end{array}$ & $\begin{array}{l}3 \\
\text { Slightly } \\
\text { Disagree }\end{array}$ & $\begin{array}{l}4 \\
\text { Slightly } \\
\text { Agree }\end{array}$ & $\begin{array}{l}5 \\
\text { Agree }\end{array}$ & $\begin{array}{l}6 \\
\text { Strongly } \\
\text { Agree }\end{array}$ \\
\hline $\begin{array}{l}\text { When a solution to a } \\
\text { problem was unsuccessful, I } \\
\text { do not work with others to } \\
\text { examine why it didn't work. }\end{array}$ & & & & & & \\
\hline $\begin{array}{l}\text { When I am confronted with } \\
\text { a complex problem, I do not } \\
\text { work with others to develop } \\
\text { a strategy to collect } \\
\text { information so I can define } \\
\text { exactly what the problem is. }\end{array}$ & & & & & & \\
\hline $\begin{array}{l}\text { After I have solved a } \\
\text { problem, I do not work with } \\
\text { others to analyze what went } \\
\text { right or what went wrong. }\end{array}$ & & & & & & \\
\hline $\begin{array}{l}\text { After I have tried to solve a } \\
\text { problem with a certain } \\
\text { course of action, I take time }\end{array}$ & & & & & & \\
\hline
\end{tabular}




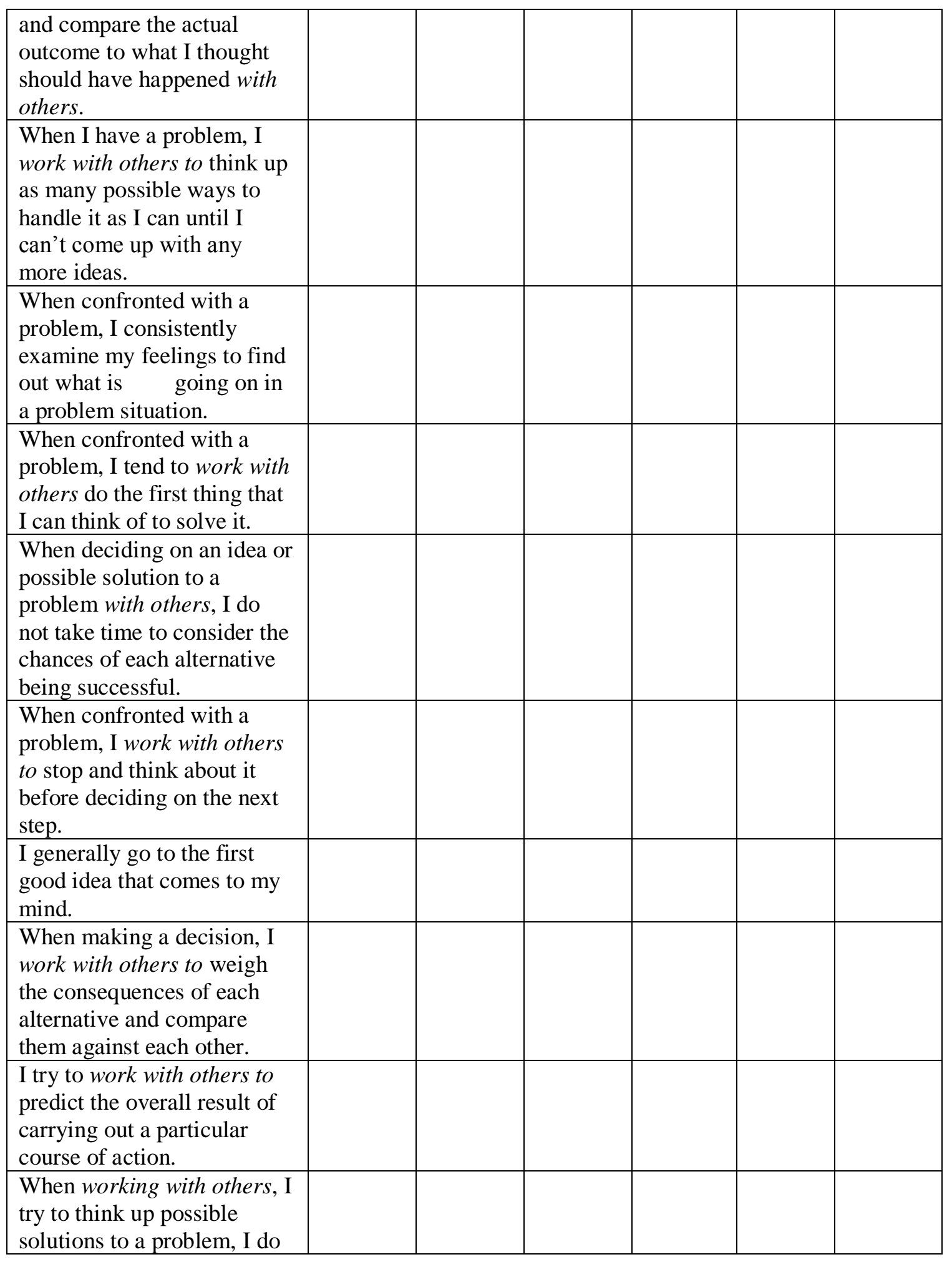




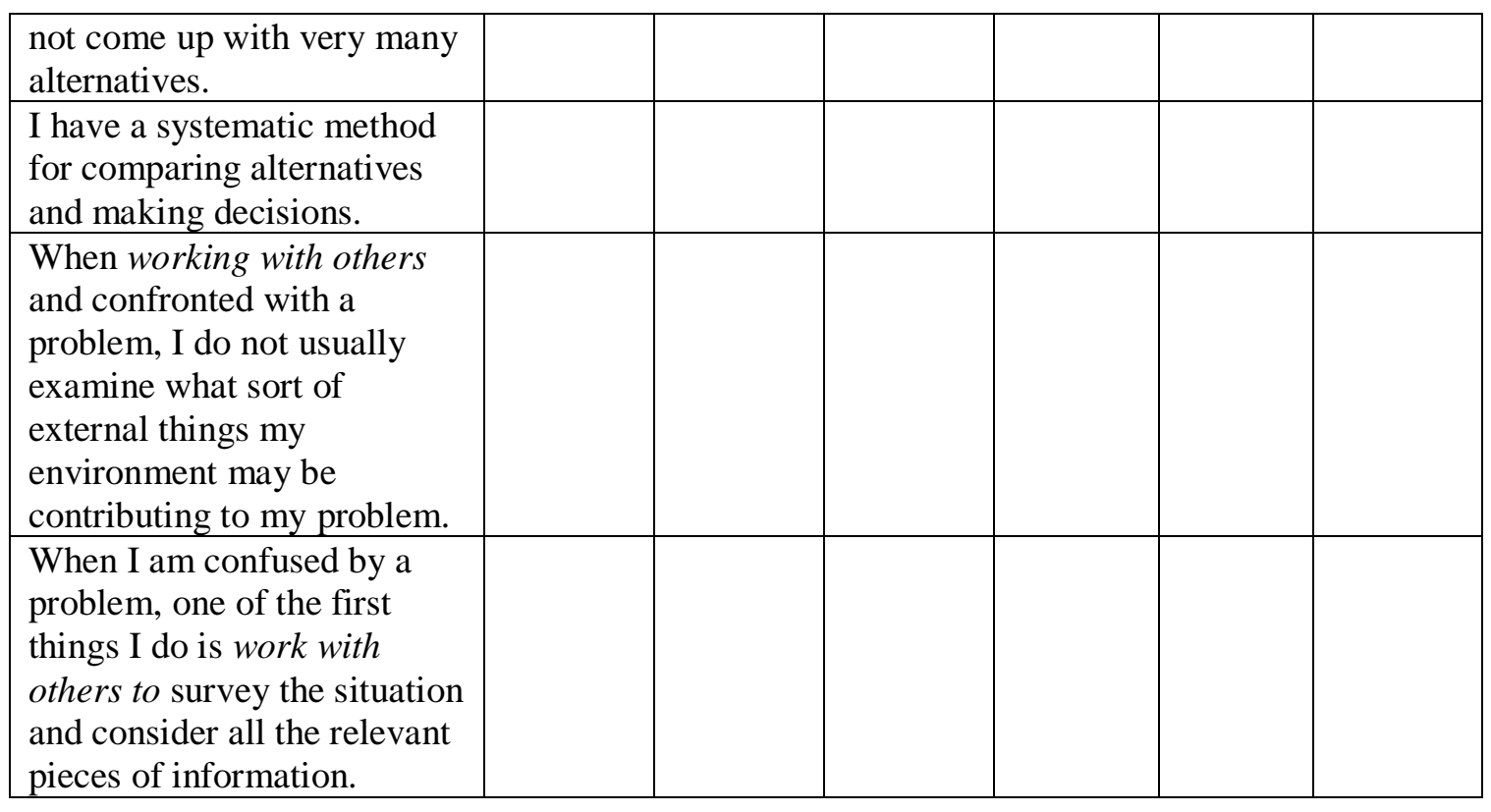

\begin{tabular}{|c|c|c|c|c|c|c|}
\hline Personal Control & $\begin{array}{l}1 \\
\text { Strongly } \\
\text { Disagree }\end{array}$ & $\begin{array}{l}2 \\
\text { Disagree }\end{array}$ & $\begin{array}{l}3 \\
\text { Slightly } \\
\text { Disagree }\end{array}$ & $\begin{array}{l}4 \\
\text { Slightly } \\
\text { Agree }\end{array}$ & $\begin{array}{l}5 \\
\text { Agree }\end{array}$ & $\begin{array}{l}6 \\
\text { Strongly } \\
\text { Agree }\end{array}$ \\
\hline $\begin{array}{l}\text { When my first efforts to } \\
\text { solve a problem fail, I } \\
\text { become uneasy about my } \\
\text { ability to handle the } \\
\text { situation. }\end{array}$ & & & & & & \\
\hline $\begin{array}{l}\text { Sometimes I do not stop and } \\
\text { take time to deal with my } \\
\text { problems, but just kind of } \\
\text { muddle ahead. }\end{array}$ & & & & & & \\
\hline $\begin{array}{l}\text { Even though I work on a } \\
\text { problem, sometimes I feel } \\
\text { like I am groping or } \\
\text { wandering, and am not } \\
\text { getting down to the real } \\
\text { issue. }\end{array}$ & & & & & & \\
\hline $\begin{array}{l}\text { I make snap judgments and } \\
\text { later regret them. }\end{array}$ & & & & & & \\
\hline $\begin{array}{l}\text { Sometimes I get so charged } \\
\text { up emotionally that I am } \\
\text { unable to consider many } \\
\text { ways of dealing with my } \\
\text { problems. }\end{array}$ & & & & & & \\
\hline
\end{tabular}




\section{DEMOGRAPHICS}

ID\#

(Please use your initials followed by your birth month and date. For example, Mary Brown born May $26^{\text {th }}$ is MB0526)

How do you identify? Male $\square \quad$ Female $\square$ Other

Age: $\quad 22-29 \square \quad 30-39 \square \quad 40-49 \square 50-59$

Race:

White

Black or African American

Asian (Asian Indian, Chinese Filipino, Japanese, Korean Vietnamese Other Asian

Native Hawaiian and Other Pacific Islander

Two or more Races

\section{Ethnicity}

Hispanic or Latino

Non-Hispanic or Latino

American Indian and Alaska Native alone

Caribbean

\section{Number of years in current position:}

$1-5$

6-10

10 or more

\section{Level in organization:}

Entry
Junior
Supervisor
Manager
Director
Executive
Other




\section{Appendix B}

\section{CONSENT TO PARTICIPATE IN EXAMINING THE ADAPTED PSI FOR EVIDENCE BASED ON TEST CONTENT}

\section{DISSERTATION TITLE:}

\section{The Exploration of Paradoxical Problem-Solving as a Means to Manage Organizational Conflict}

Dear Prospective Participant,

I would like to invite you to be 1 of 10 persons who are considered as a Subject Matter Expert (SME) in either human resource development or conflict management to review an adapted Problem-Solving Inventory (PSI) for validity evidence based on test content.

A definition of "paradoxical problem-solving" is that it endorses two seemingly contradictory views at the same time, but nonetheless produces a solution that is aligned with both views. It is based on interest and learning outcomes rather than position. Paradoxical problem-solving takes into account the interests of all parties and not just the organization's needs and wants.

The purpose of this mixed methods research is to develop and validate an adapted survey that incorporates the paradoxical problem-solving concept under the context of social conflict theory. The use of expert judgement is crucial in examining the adapted PSI for evidence based on test content. As a SME, you will be required to examine the adapted PSI for word appropriateness of the construct, wording of the survey, and the consistency between the construct and the items.

Your views will be used for (a) theoretical enrichment to scholars and researchers with literature on problem-solving or conflict management theories, (b) empirical research contributions to researchers and scholars who would use the findings to guide new research, and, (c) practical information that would help bridge the gap in the literature between paradox and problem-solving, and (d) and provide insight into how paradoxical problemsolving could be used by Human Research Development (HRD) professionals to manage organizational conflict.

Reviewing the adapted PSI should take no more than 30 minutes. You will be required to review the PSI 3 times, with 2 weeks given for each review. If you would like to be 1 of the 10 SMEs please let me know by contacting Salma Hadeed (786-354-6354) or e-mailing smoha003@fiu.edu. More background information on the constructs will be sent to those interested in being a subject matter expert in this study.

Yours faithfully,

Salma Hadeed 


\section{Appendix C}

\section{CONSENT TO PARTICIPATE IN A PILTO STUDY FOCUS GROUP COGNITIVE INTERVIEW}

\section{DISSERTATION TITLE: \\ The Exploration of Paradoxical Problem-Solving as a Means to Manage Organizational Conflict}

Dear Prospective Participant,

I would like to invite you to take part in a focus group interview (small discussion group) on XXX (Date), 2018. The purpose of my mixed methods research (The Exploration of Paradoxical Problem-Solving As a Means to Manage Organizational Conflict) is to develop and validate an adapted survey that incorporates the paradoxical problem-solving concept under the context of social conflict theory.

A definition of "paradoxical problem-solving" is that it endorses two seemingly contradictory views at the same time, but nonetheless produces a solution that is aligned with both views. It is based on interest and learning outcomes rather than position. Paradoxical problem-solving takes into account the interests of all parties and not just the organization's needs and wants.

The focus group will provide an opportunity for you to find out about paradoxical problemsolving as a means to manage organizational conflict as an alternative to mediation and negotiation. In particular, I would like to understand your cognitive process (the process of thinking) when reviewing an adapted survey that incorporates the paradoxical problemsolving concept.

Your views will be used for (a) theoretical enrichment to scholars and researchers with literature on problem-solving or conflict management theories, (b) empirical research contributions to researchers and scholars who would use the findings to guide new research, and, (c) practical information that would help bridge the gap in the literature between paradox and problem-solving, and (d) and provide insight into how paradoxical problemsolving could be used by Human Research Development (HRD) professionals to manage organizational conflict.

Being a participant requires you to be present for 1,30-minute focus group interviews. If you would like to take part in the focus group on XXX (date) please let me know by contacting Salma Hadeed (786-354-6354) or e-mailing smoha003@fiu.edu. More background information will be sent to those confirming attendance before the focus group.

Yours faithfully,

Salma Hadeed 


\section{Appendix D}

\section{CONSENT FOR PILOT STUDY: SURVEY DISTRIBUTION}

\section{Dear Everyone,}

I am a doctoral candidate at Florida International University, and I would like to invite you to take part in a research study that aims at examining the psychometric properties of the Problem-Solving Inventory (PSI), incorporating a paradoxical problem-solving conceptual framework that is used in the workplace. This inventory/survey will assist me with my research for my dissertation.

A definition of "paradoxical problem-solving" is that it endorses two seemingly contradictory views at the same time, but nonetheless produces a solution that is aligned with both views. It is based on interest and learning outcomes rather than position. Paradoxical 1 problem-solving takes into account the interests of all parties and not just the organization's needs and wants. The purpose of this mixed methods research is to develop and validate an adapted survey that incorporates the paradoxical problem-solving concept under the context of social conflict theory.

Your views will be used for (a) theoretical enrichment to scholars and researchers with literature on problem-solving or conflict management theories, (b) empirical research contributions to researchers and scholars who would use the findings to guide new research, and, (c) practical information that would help bridge the gap in the literature between paradox and problem-solving, and (d) and provide insight into how paradoxical problem-solving could be used by Human Research Development (HRD) professionals to manage organizational conflict.

The data collection for this adapted PSI will be used to establish validity based on internal structure and reliability evidence for this study. There are no risks involved with being a participant in this study. A potential benefit of being a participant in this study is examining oneself when faced with organizational conflict.

Being a participant in this survey will take no more than 20 minutes of your time. I thank you in advance for your willingness to participate in our research study and encourage you to send this information to anyone you think might be interested in also participating.

\section{https://fiu.qualtrics.com/jfe/form/SV doO1VUcbVFKdutv}

Sincerely,

Salma Hadeed 


\title{
Appendix E
}

\section{CONSENT TO PARTICIPATE IN A FOCUS GROUP COGNITIVE INTERVIEW}

\author{
DISSERTATION TITLE: \\ The Exploration of Paradoxical Problem-Solving as a Means to Manage Organizational \\ Conflict
}

Dear Prospective Participant,

I would like to invite you to take part in a focus group interview (small discussion group) on XXX (Date), 2018. The purpose of my mixed methods research (The Exploration of Paradoxical Problem-Solving As a Means to Manage Organizational Conflict) is to develop and validate an adapted survey that incorporates the paradoxical problem-solving concept under the context of social conflict theory.

A definition of "paradoxical problem-solving" is that it endorses two seemingly contradictory views at the same time, but nonetheless produces a solution that is aligned with both views. It is based on interest and learning outcomes rather than position. Paradoxical problem-solving takes into account the interests of all parties and not just the organization's needs and wants.

The focus group will provide an opportunity for you to find out about paradoxical problemsolving as a means to manage organizational conflict as an alternative to mediation and negotiation. In particular, I would like to understand your cognitive process (the process of thinking) when reviewing an adapted survey that incorporates the paradoxical problemsolving concept.

Your views will be used for (a) theoretical enrichment to scholars and researchers with literature on problem-solving or conflict management theories, (b) empirical research contributions to researchers and scholars who would use the findings to guide new research, and, (c) practical information that would help bridge the gap in the literature between paradox and problem-solving, and (d) and provide insight into how paradoxical problemsolving could be used by Human Research Development (HRD) professionals to manage organizational conflict.

Being a participant requires you to be present for 2 focus group interviews. This will take place during a six-week period. Each interview will last approximately one hour. If you would like to take part in the focus group on XXX (date) please let me know by contacting Salma Hadeed (786-354-6354) or e-mailing smoha003@fiu.edu. More background information will be sent to those confirming attendance before the focus group.

Yours faithfully, Salma Hadeed 


\section{Appendix F}

\section{CONSENT TO PARTICIPATE IN A RESEARCH STUDY}

\section{DISSERTATION TITLE: \\ The Exploration of Paradoxical Problem-Solving as a Means to Manage Organizational Conflict}

I would like to invite you to take part in a research study that aims at examining the psychometric properties of the Problem Solving Inventory (PSI) incorporating a paradoxical problem-solving conceptual framework that is used in the workplace. A definition of "paradoxical problem-solving" is that it endorses two seemingly contradictory views at the same time, but nonetheless produces a solution that is aligned with both views. It is based on interest and learning outcomes rather than position. Paradoxical 1 problem-solving takes into account the interests of all parties and not just the organization's needs and wants. The purpose of this mixed methods research is to develop and validate an adapted survey that incorporates the paradoxical problem-solving concept under the context of social conflict theory.

Your views will be used for (a) theoretical enrichment to scholars and researchers with literature on problem-solving or conflict management theories, (b) empirical research contributions to researchers and scholars who would use the findings to guide new research, and, (c) practical information that would help bridge the gap in the literature between paradox and problem-solving, and (d) and provide insight into how paradoxical problem-solving could be used by Human Research Development (HRD) professionals to manage organizational conflict.

The data collection for this adapted PSI will be used to establish validity based on internal structure and reliability evidence for this study. There are no risks involved with being a participant in this study. A potential benefit of being a participant in this study is examining oneself when faced with organizational conflict.

Being a participant in this survey will take no more than 20 minutes of your time. I thank you in advance for your willingness to participate in our research study and encourage you to send this information to anyone you think might be interested in also participating. 


\section{Appendix G}

\section{EMAIL TO EXPERTS, ROUND 1}

Dear All,

Thank you once again for being a part of my study and volunteering your time as SMEs in Human Resources/Conflict Management.

I am attaching the adapted Problem-Solving Inventory (PSI) for your perusal along with a guide on how you will be examining the PSI for validity based on test content. Please know you will not need to actually complete the survey. Two things to note:

1. Words in italics represent the adapted version of the PSI, reflecting the paradoxical problem-solving concept.

2. If there are statements with no italics, then the statement has not been modified.

Feel free to use track changes and email to me, or you can print a copy of the PSI, make notes and email it to me; the choice is yours. I will email you on Friday 11th May, reminding you that the feedback is due on Monday, 14 May.

Thanks again and look forward to this phase with all of you.

Sincerely,

Salma Hadeed 


\section{Appendix $\mathbf{H}$}

\section{PILOT STUDY: FOCUS GROUP COGNITIVE INTERVIEW QUESTIONS}

Introduction (Interviewer):

1. The topic

2. The definition of Paradoxical Problem-Solving

3. The purpose of the study

4. The significance of the study

Introduction (Interviewee)

1. Each person introduced themselves

Agenda:

1. Each participant reads only the construct definition and the statements below for 5 mins.

2. The participants were asked to think about what was going through their mind as they were reading and answering the statements.

3. Think-aloud and then probing questions for 5 mins.

4. Repeat for the 2 other constructs and demographic information. 


\section{APPENDIX I \\ FOCUS GROUP COGNITIVE INTERVIEW QUESTIONS}

Introduction (Interviewer):

1. The topic

2. The definition of Paradoxical Problem-Solving

3. The purpose of the study

4. The significance of the study

Introduction (Interviewee)

1. Each person introduced themselves

Agenda:

1. Each participant reads only the construct definition and the statements below for 7 mins.

2. The participants were asked to think about what was going through their mind as they were reading and answering the statements.

3. Think-aloud and then probing questions for 10 mins.

(a) I am interested in what you were thinking when you were completing this survey, could you tell me more about it? and

(b) what were the thoughts going through your mind when you completed this survey?

4. Repeat for the 2 other constructs and demographic information. 


\section{Appendix J}

\section{CONSENT: SURVEY DISTRIBUTION}

Good Morning Everyone,

I am a doctoral candidate at Florida International University, and I would like to invite you to take part in a research study that aims at examining the psychometric properties of the Problem-Solving Inventory (PSI), incorporating a paradoxical problem-solving conceptual framework that is used in the workplace. This inventory/survey will assist me with the final stages of my research for my dissertation.

A definition of "paradoxical problem-solving" is that it endorses two seemingly contradictory views at the same time, but nonetheless produces a solution that is aligned with both views. It is based on interest and learning outcomes rather than position. Paradoxical 1 problem-solving takes into account the interests of all parties and not just the organization's needs and wants. The purpose of this mixed methods research is to develop and validate an adapted survey that incorporates the paradoxical problem-solving concept under the context of social conflict theory.

Your views will be used for (a) theoretical enrichment to scholars and researchers with literature on problem-solving or conflict management theories, (b) empirical research contributions to researchers and scholars who would use the findings to guide new research, and, (c) practical information that would help bridge the gap in the literature between paradox and problem-solving, and (d) and provide insight into how paradoxical problem-solving could be used by Human Research Development (HRD) professionals to manage organizational conflict.

The data collection for this adapted PSI will be used to establish validity based on internal structure and reliability evidence for this study. There are no risks involved with being a participant in this study. A potential benefit of being a participant in this study is examining oneself when faced with organizational conflict.

Being a participant in this survey will take no more than 15 minutes of your time. I thank you in advance for your willingness to participate in our research study

and encourage you to send this information to anyone you think might be interested in also participating.

\section{https://fiu.qualtrics.com/jfe/form/SV 261hYHXF3pXUNVj}

Sincerely,

Salma Hadeed 
Appendix K

\section{PROBLEM-SOLVING INVENTORY: PHASE 1, STAGE 1}

\section{Problem-Solving Inventory}

Please indicate how much you agree with each of the following items by rating them on this scale: $1=$ strongly disagree; $2=$ disagree; $3=$ slightly disagree; $4=$ slightly agree; $5=$ agree; or $6=$ strongly agree. Please be sure to answer ALL of the questions. Remember, there are no right or wrong answers.

\section{Definitions:}

1. Problem-solving confidence as the belief in one's problem-solving abilities while engaging in problem-solving tasks (Heppner \& Baker, 1997).

2. Approach-avoidance style is defined as the penchant for either approaching or avoiding problem-solving tasks (Heppner \& Baker, 1997).

3. Personal control construct was defined as the belief that one has control over their behavior or attitude when faced with problem-solving tasks (Heppner \& Baker, 1997)

\section{Problem-Solving Confidence}

\begin{tabular}{|c|c|c|c|c|c|c|c|}
\hline Original PSI & $\begin{array}{l}\text { Adapted PSI } \\
\text { (Given to experts) }\end{array}$ & \begin{tabular}{|l|}
1 \\
Strongly \\
disagree
\end{tabular} & $\begin{array}{l}2 \\
\text { Disagree }\end{array}$ & $\begin{array}{l}3 \\
\text { Slightly } \\
\text { Disagree }\end{array}$ & $\begin{array}{l}4 \\
\text { Slightly } \\
\text { Agree }\end{array}$ & $\begin{array}{l}5 \\
\text { Agree }\end{array}$ & \begin{tabular}{|l|}
6 \\
Strongly \\
Agree
\end{tabular} \\
\hline $\begin{array}{l}\text { I am usually able to think up creative and } \\
\text { effective alternatives to solve a problem. }\end{array}$ & $\begin{array}{l}\text { I am able to think up creative } \\
\text { and effective alternatives to } \\
\text { solve a problem when working } \\
\text { in groups. }\end{array}$ & & & & & & \\
\hline
\end{tabular}




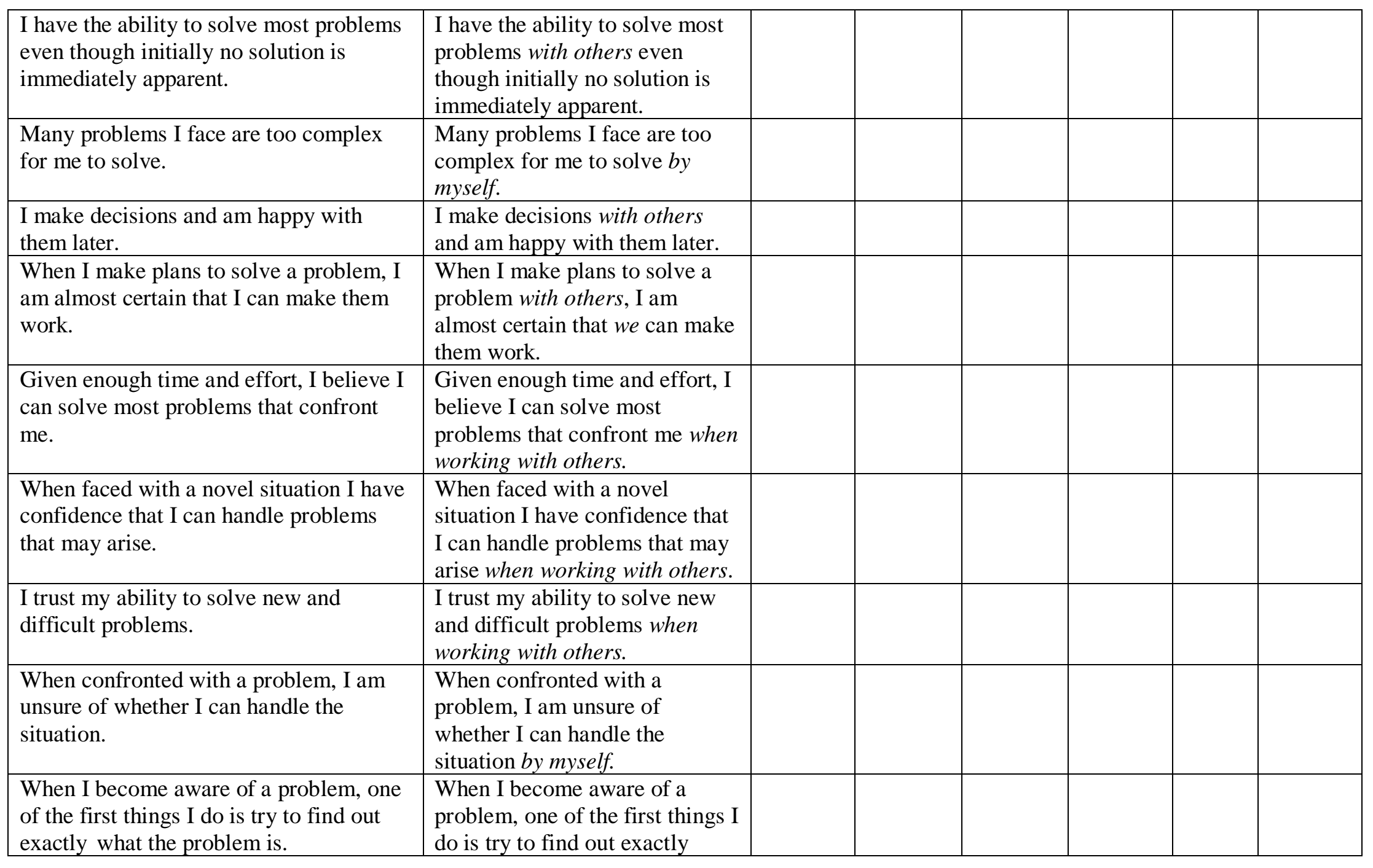




\begin{tabular}{|l|l|l|l|l|l|}
\hline & $\begin{array}{l}\text { what the problem is by } \\
\text { communicating with others. }\end{array}$ & & & & \\
\hline $\begin{array}{l}\text { After making a decision, the outcome I } \\
\text { expected usually matches the actual } \\
\text { outcome. }\end{array}$ & $\begin{array}{l}\text { After making a decision with a } \\
\text { group, the outcome I expected } \\
\text { usually matches the actual } \\
\text { outcome. }\end{array}$ & & & & \\
\hline
\end{tabular}

\section{Approach Avoidance Style}

\begin{tabular}{|c|c|c|c|c|c|c|c|}
\hline Original PSI & $\begin{array}{l}\text { Adapted PSI } \\
\text { (Given to experts) }\end{array}$ & $\begin{array}{l}1 \\
\text { Strongly } \\
\text { disagree }\end{array}$ & $\begin{array}{l}2 \\
\text { Disagree }\end{array}$ & $\begin{array}{l}3 \text { Slightly } \\
\text { Disagree }\end{array}$ & $\begin{array}{l}4 \\
\text { Slightly } \\
\text { Agree }\end{array}$ & $\begin{array}{l}5 \\
\text { Agree }\end{array}$ & $\begin{array}{l}6 \\
\text { Strongl } \\
\text { y Agree }\end{array}$ \\
\hline $\begin{array}{l}\text { When a solution to a problem was } \\
\text { unsuccessful, I do not examine why it } \\
\text { didn't work. }\end{array}$ & $\begin{array}{l}\text { When a solution to a problem } \\
\text { was unsuccessful, I do not work } \\
\text { with others to examine why it } \\
\text { didn't work. }\end{array}$ & & & & & & \\
\hline $\begin{array}{l}\text { When I am confronted with a complex } \\
\text { problem, I do not bother to develop a } \\
\text { strategy to collect information so I can } \\
\text { define exactly what the problem is. }\end{array}$ & $\begin{array}{l}\text { When I am confronted with a } \\
\text { complex problem, I do not work } \\
\text { with others to develop a strategy } \\
\text { to collect information so I can } \\
\text { define exactly what the problem } \\
\text { is. }\end{array}$ & & & & & & \\
\hline $\begin{array}{l}\text { After I have solved a problem, I do not } \\
\text { analyze what went right or what went } \\
\text { wrong. }\end{array}$ & $\begin{array}{l}\text { After I have solved a problem, I } \\
\text { do not work with others to } \\
\text { analyze what went right or what } \\
\text { went wrong. }\end{array}$ & & & & & & \\
\hline $\begin{array}{l}\text { After I have tried to solve a problem } \\
\text { with a certain course of action, I take } \\
\text { time and compare the actual outcome to } \\
\text { what I thought should have happened. }\end{array}$ & $\begin{array}{l}\text { After I have tried to solve a } \\
\text { problem with a certain course of } \\
\text { action, I take time and compare } \\
\text { the actual outcome to what I } \\
\text { thought should have happened } \\
\text { with others. }\end{array}$ & & & & & & \\
\hline
\end{tabular}




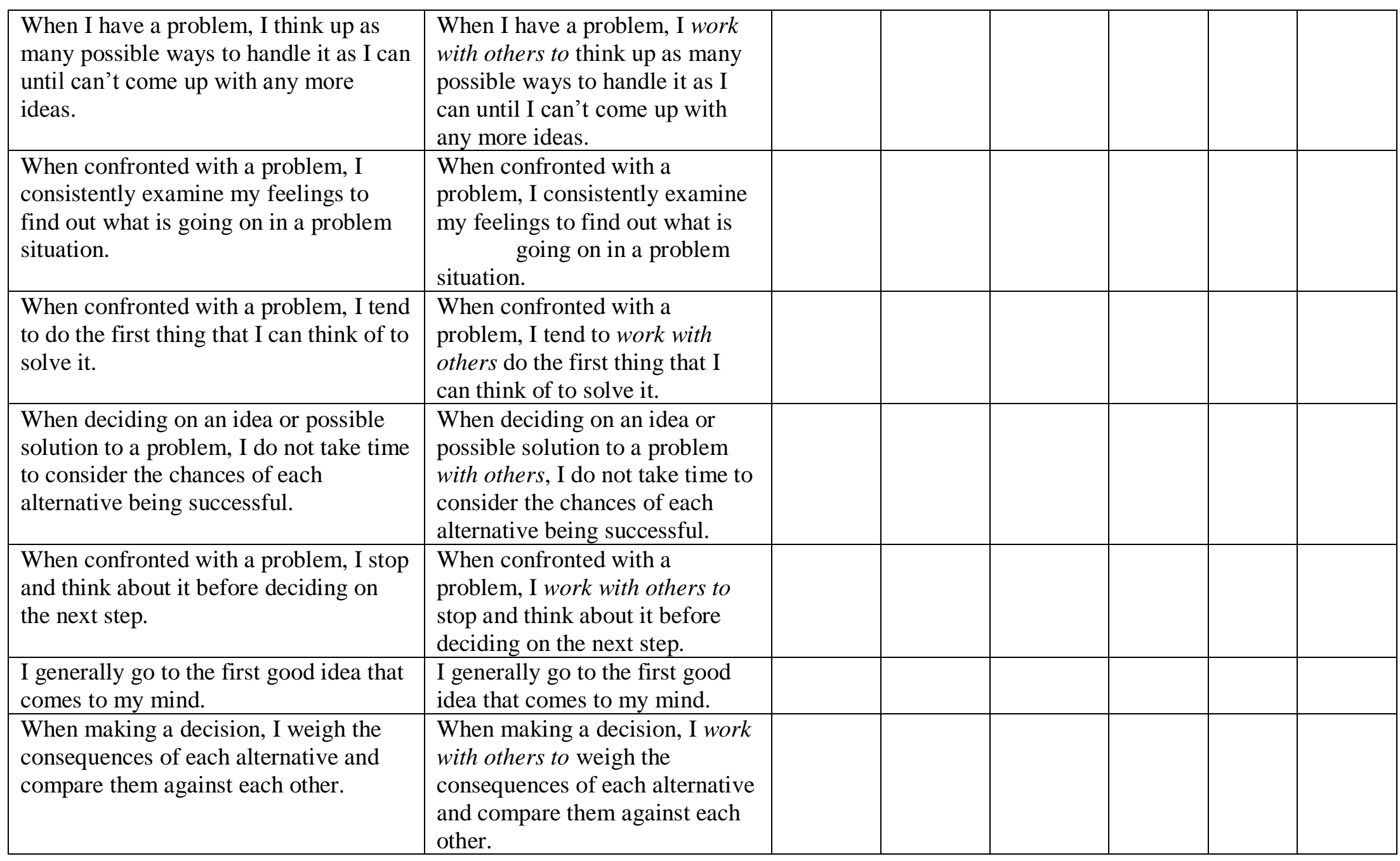




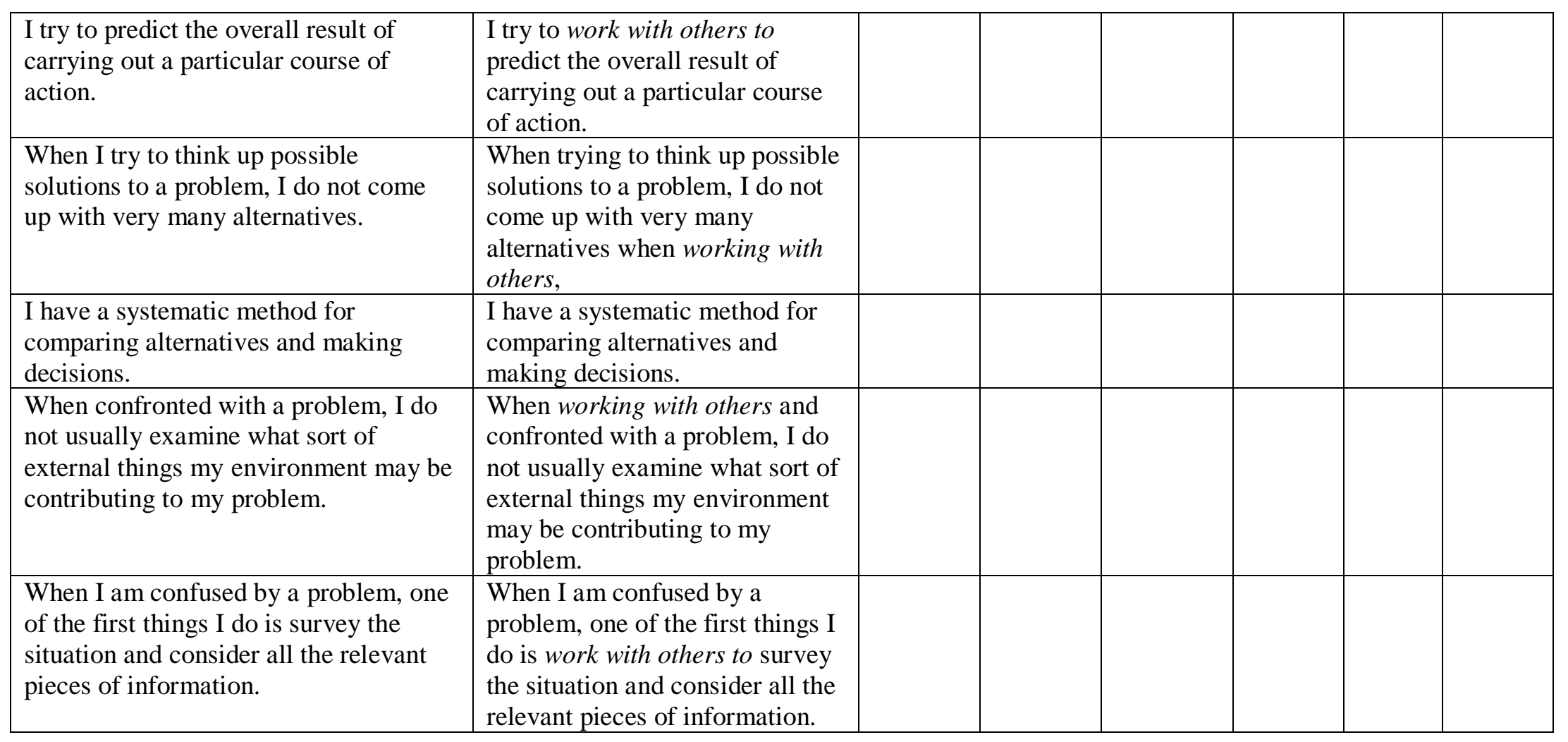




\section{Personal Control}

\begin{tabular}{|c|c|c|c|c|c|c|c|}
\hline Original PSI & $\begin{array}{l}\text { Adapted PSI } \\
\text { (no Changes with Personal } \\
\text { Control Construct) given to } \\
\text { experts }\end{array}$ & $\begin{array}{l}1 \\
\text { Strongly } \\
\text { disagree }\end{array}$ & $\begin{array}{l}2 \\
\text { Disagree }\end{array}$ & $\begin{array}{l}3 \\
\text { Slightly } \\
\text { Disagree }\end{array}$ & $\begin{array}{l}4 \\
\text { Slightly } \\
\text { Agree }\end{array}$ & $\begin{array}{l}5 \\
\text { Agree }\end{array}$ & $\begin{array}{l}6 \\
\text { Strongly } \\
\text { Agree }\end{array}$ \\
\hline $\begin{array}{l}\text { When my first efforts to solve a problem } \\
\text { fail, I become uneasy about my ability to } \\
\text { handle the situation. }\end{array}$ & $\begin{array}{l}\text { When my first efforts to } \\
\text { solve a problem fail, I } \\
\text { become uneasy about my } \\
\text { ability to handle the } \\
\text { situation. }\end{array}$ & & & & & & \\
\hline $\begin{array}{l}\text { Sometimes I do not stop and take time to } \\
\text { deal with my problems, but just kind of } \\
\text { muddle ahead. }\end{array}$ & $\begin{array}{l}\text { Sometimes I do not stop and } \\
\text { take time to deal with my } \\
\text { problems, but just kind of } \\
\text { muddle ahead. }\end{array}$ & & & & & & \\
\hline $\begin{array}{l}\text { Even though I work on a problem, } \\
\text { sometimes I feel like I am groping or } \\
\text { wandering, and am not getting down to } \\
\text { the real issue. }\end{array}$ & $\begin{array}{l}\text { Even though I work on a } \\
\text { problem, sometimes I feel } \\
\text { like I am groping or } \\
\text { wandering, and am not } \\
\text { getting down to the real } \\
\text { issue. }\end{array}$ & & & & & & \\
\hline $\begin{array}{l}\text { I make snap judgments and later regret } \\
\text { them. }\end{array}$ & $\begin{array}{l}\text { I make snap judgments and } \\
\text { later regret them. }\end{array}$ & & & & & & \\
\hline $\begin{array}{l}\text { Sometimes I get so charged up } \\
\text { emotionally that I am unable to consider } \\
\text { many ways of dealing with my problems. }\end{array}$ & $\begin{array}{l}\text { Sometimes I get so charged } \\
\text { up emotionally that I am } \\
\text { unable to consider many } \\
\text { ways of dealing with my } \\
\text { problems. }\end{array}$ & & & & & & \\
\hline
\end{tabular}




\section{DEMOGRAPHICS}

How do you identify?

Male $\square \quad$ Female $\square$ Other $\square$

Age: $18-21 \square$

Race:

White

Black or African American

Asian

Native Hawaiian and Other Pacific Islander

Two or more Races

Other

\section{Ethnicity}

Hispanic or Latino

Non-Hispanic or Latino

Other

\section{Field or Industry}

Number of years in current position:

$\begin{array}{ll}\text { Less than 1 year } & \square \\ 1-5 & \square \\ 6-10 & \square\end{array}$


$10+$

Level in organization:

Entry

Junior $\quad \square \quad$ Executive

Supervisor $\quad \square \quad$ Other

Manager

Number of Years Problem-Solving

Less than 1 year

$1-3$

4-9

$10-15$

$16+$

$\square$
$\square$
$\square$
$\square$
$\square$ 


\section{Appendix L}

PROBLEM-SOLVING INVENTORY: PHASE 1, STAGE 2

\section{Problem-Solving Inventory}

Please indicate how much you agree with each of the following items by rating them on this scale: 1 = strongly disagree; $2=$ disagree; $3=$ slightly disagree; $4=$ slightly agree; 5 $=$ agree; or $6=$ strongly agree. Please be sure to answer ALL of the questions.

Remember, there are no right or wrong answers.

For ease of reading, each definition will be placed under the respective construct (Problem-Solving Confidence, Approach-Avoidance Style, and Personal Control).

\section{Problem-Solving Confidence}

Definition: Problem-solving confidence is the belief in one's problem-solving abilities while engaging in problem-solving tasks (Heppner \& Baker, 1997).

\begin{tabular}{|c|c|c|c|c|c|c|}
\hline I believe... & $\begin{array}{l}1 \\
\text { Strongly } \\
\text { disagree }\end{array}$ & $\begin{array}{l}2 \\
\text { Disagree }\end{array}$ & $\begin{array}{l}3 \\
\text { Slightly } \\
\text { disagree }\end{array}$ & $\begin{array}{l}4 \\
\text { Slightly } \\
\text { agree }\end{array}$ & $\begin{array}{l}5 \\
\text { Agree }\end{array}$ & $\begin{array}{l}6 \\
\text { Strongly } \\
\text { agree }\end{array}$ \\
\hline $\begin{array}{l}\text { I am able to develop creative } \\
\text { alternatives to solve a } \\
\text { problem when working with } \\
\text { others. }\end{array}$ & & & & & & \\
\hline $\begin{array}{l}\text { I am able to develop effective } \\
\text { alternatives to solve a } \\
\text { problem when working with } \\
\text { others. }\end{array}$ & & & & & & \\
\hline $\begin{array}{l}\text { I have the ability to solve } \\
\text { most problems in a group } \\
\text { setting, even though initially } \\
\text { no solution is immediately } \\
\text { apparent. }\end{array}$ & & & & & & \\
\hline $\begin{array}{l}\text { Many problems I face are too } \\
\text { complex for me to solve by } \\
\text { myself. }\end{array}$ & \multicolumn{6}{|c|}{ Should this statement be moved to Personal Control } \\
\hline $\begin{array}{l}\text { When making decisions as a } \\
\text { group, I trust the outcome. }\end{array}$ & & & & & & \\
\hline $\begin{array}{l}\text { When I make plans to solve a } \\
\text { problem in a group setting, I } \\
\text { am almost certain that } \\
\text { together we can find } \\
\text { solutions. }\end{array}$ & & & & & & \\
\hline $\begin{array}{l}\text { Given enough time and } \\
\text { effort, I believe I can solve }\end{array}$ & & & & & & \\
\hline
\end{tabular}




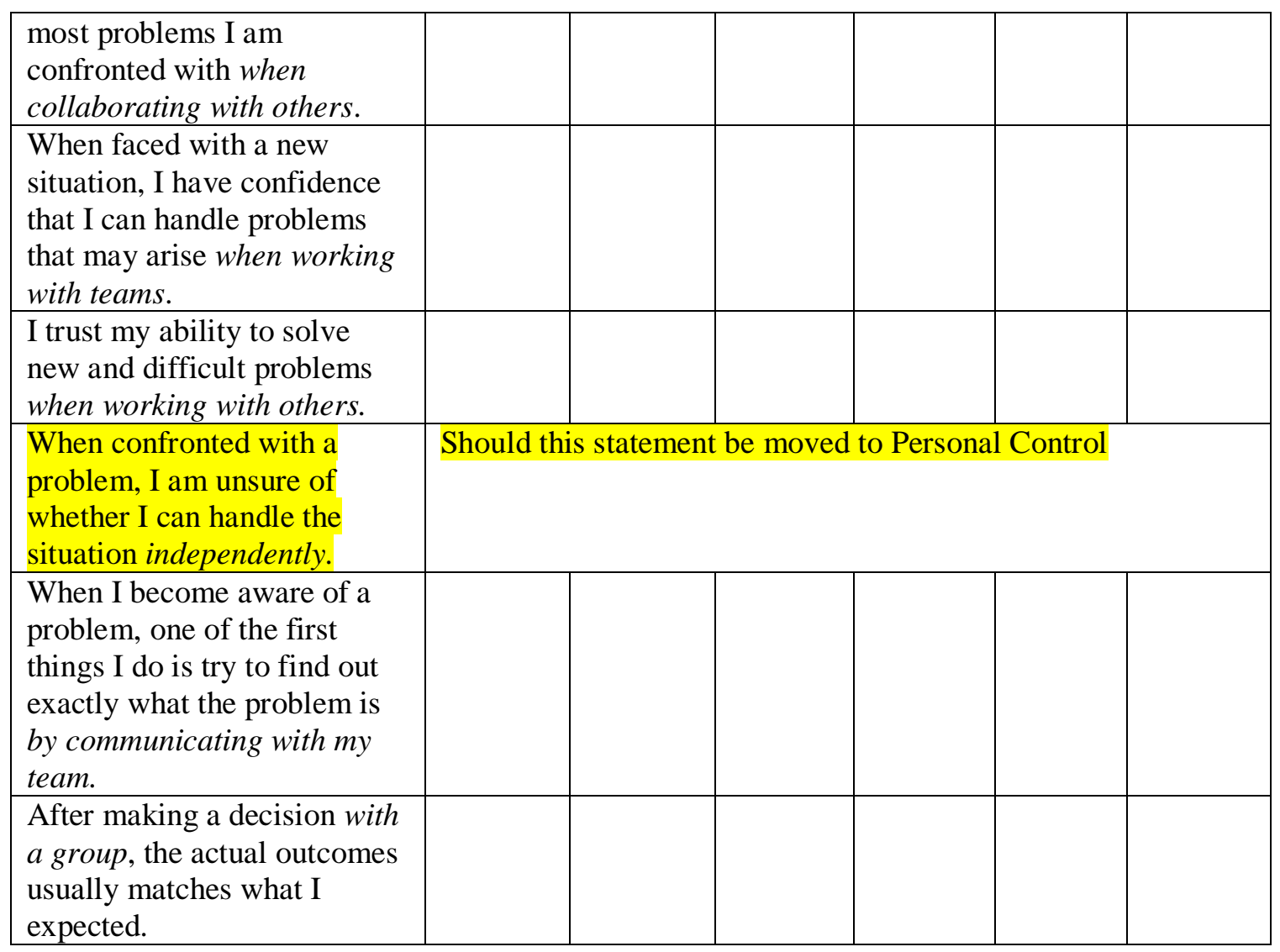

\section{Approach Avoidance Style}

Definition: Approach-avoidance style is defined as the preference for either approaching or avoiding problem-solving tasks (Heppner \& Baker, 1997).

\begin{tabular}{|l|l|l|l|l|l|l|}
\hline & $\begin{array}{l}1 \\
\text { Strongly } \\
\text { disagree }\end{array}$ & $\begin{array}{l}2 \\
\text { Disagree }\end{array}$ & $\begin{array}{l}3 \\
\text { Slightly } \\
\text { disagree }\end{array}$ & $\begin{array}{l}4 \\
\text { Slightly } \\
\text { agree }\end{array}$ & $\begin{array}{l}5 \\
\text { Agree }\end{array}$ & $\begin{array}{l}6 \\
\text { Strongly } \\
\text { agree }\end{array}$ \\
\hline $\begin{array}{l}\text { When a solution to a } \\
\text { problem was unsuccessful, I } \\
\text { do not communicate with } \\
\text { others to examine why it did } \\
\text { not work. }\end{array}$ & & & & & & \\
\hline $\begin{array}{l}\text { When I am confronted with a } \\
\text { complex problem, I do not } \\
\text { collaborate with others to } \\
\text { develop a strategy to collect } \\
\text { information, to clearly define } \\
\text { what is the problem. }\end{array}$ & & & & & & \\
\hline $\begin{array}{l}\text { After I have solved a } \\
\text { problem with others, I do not } \\
\text { analyze what went right or } \\
\text { what went wrong with them. }\end{array}$ & & & & & & \\
\hline
\end{tabular}




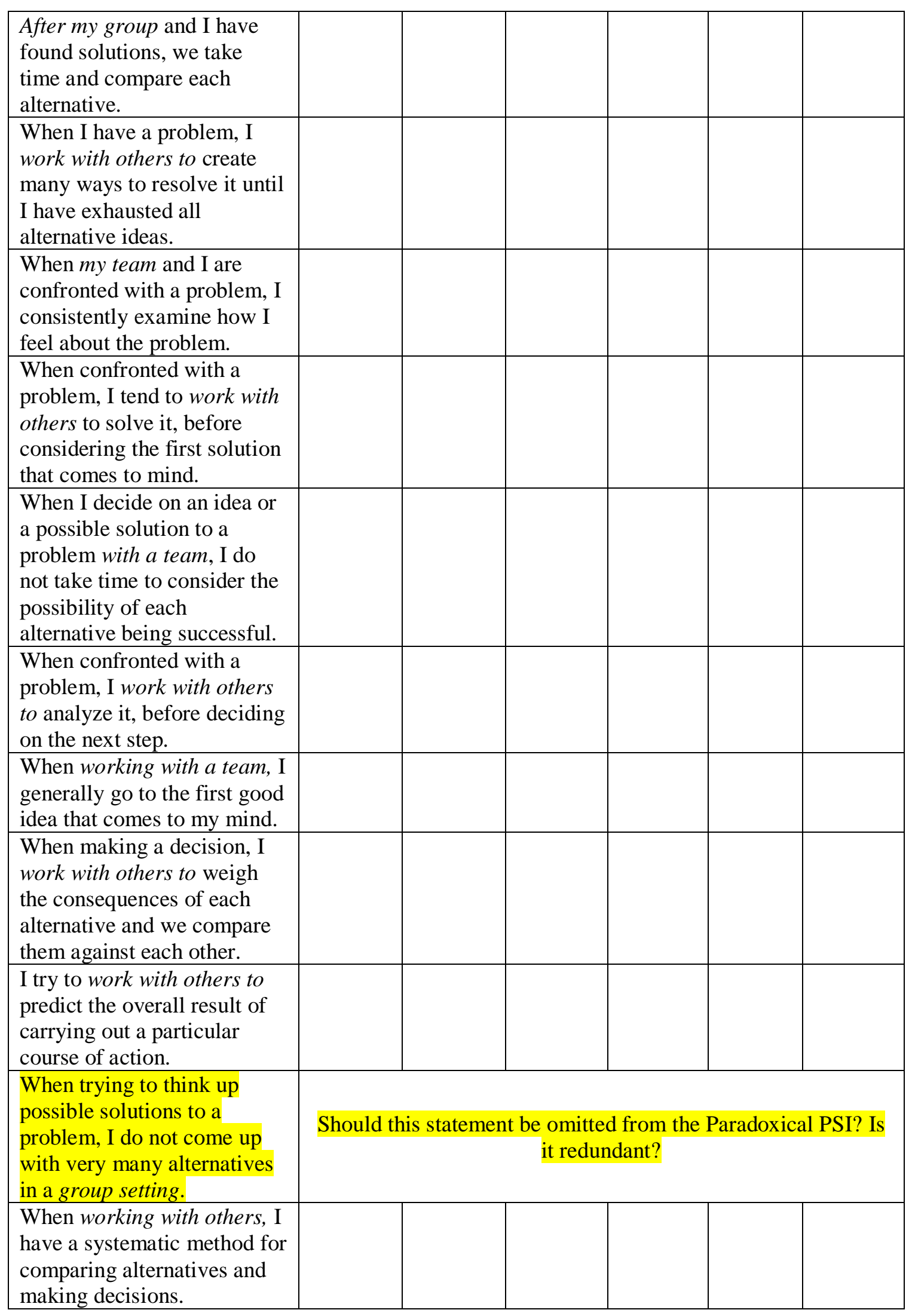




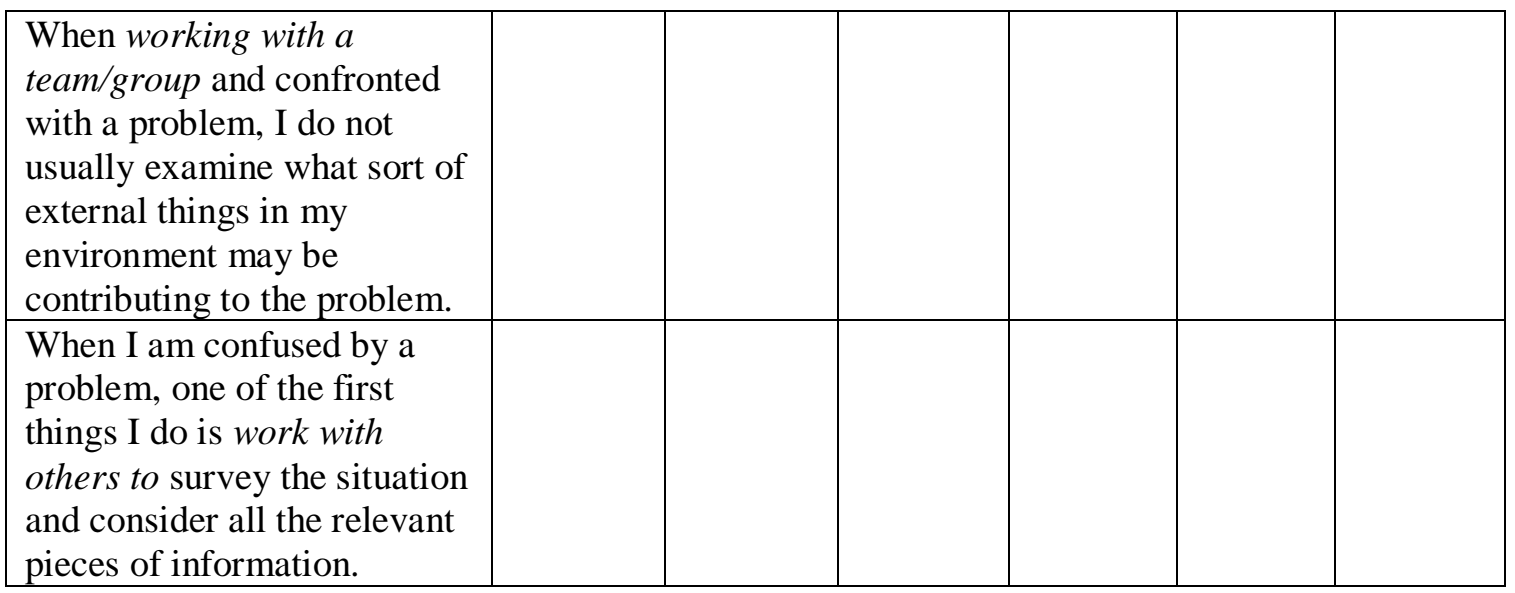

\section{Personal Control}

Definition: Personal control is defined as the belief that one has power over their behavior or attitude when faced with problem-solving tasks (Heppner \& Baker, 1997)

\begin{tabular}{|c|c|c|c|c|c|c|}
\hline & $\begin{array}{l}1 \\
\text { Strongly } \\
\text { disagree }\end{array}$ & $\begin{array}{l}2 \\
\text { Disagree }\end{array}$ & $\begin{array}{l}3 \\
\text { Slightly } \\
\text { disagree } \\
\end{array}$ & $\begin{array}{l}4 \\
\text { Slightly } \\
\text { agree }\end{array}$ & $\begin{array}{l}5 \\
\text { Agree }\end{array}$ & $\begin{array}{l}6 \\
\text { Strongly } \\
\text { agree }\end{array}$ \\
\hline $\begin{array}{l}\text { When my first efforts to } \\
\text { solve a problem fail, I } \\
\text { become uneasy about my } \\
\text { ability to handle the } \\
\text { situation. }\end{array}$ & & & & & & \\
\hline $\begin{array}{l}\text { Sometimes I do not stop anc } \\
\text { take time to deal with my } \\
\text { problems. }\end{array}$ & & & & & & \\
\hline $\begin{array}{l}\text { Even though I work on a } \\
\text { problem, sometimes I feel } \\
\text { like I am not getting to the } \\
\text { real issue. }\end{array}$ & & & & & & \\
\hline $\begin{array}{l}\text { I make snap judgments and } \\
\text { later regret them. }\end{array}$ & & & & & & \\
\hline $\begin{array}{l}\text { Sometimes I get so charged } \\
\text { up emotionally that I am } \\
\text { unable to consider many } \\
\text { ways of dealing with my } \\
\text { problems. }\end{array}$ & & & & & & \\
\hline
\end{tabular}




\section{DEMOGRAPHIC INFORMATION}

Gender identification $\quad$ Male $\square$ Female $\square$ Other

$\begin{array}{llllll}\text { Age: } \quad 18-21 \square & 22-29 \square \quad 30-39 \square & 40-49 & \square \quad 50-59\end{array} \quad 60+$

\section{Race/ Ethnic Origin}

White alone

Black or African American

Asian alone

Native Hawaiian and Other Pacific Islander alone

Native American and Alaska Native

Hispanic, Latino or Spanish

Two or more races

Non-Hispanic, Non-Latino or Non-Spanish

Other

\section{Field or Industry}

\section{Number of years in current position:}

Less than 1 year

1-3

7-10

$10+$

Title in organization:

Entry

Manager

Junior

Director

Assistant

Executive

Supervisor $\quad \square \quad$ Other

Number of Years Problem-Solving

Less than 1 year

$1-3$

$4-9$

$10-15$

$16+$ 


\section{Appendix M}

PROBLEM-SOLVING INVENTORY: PHASE 1, STAGE 3

\section{Problem-Solving Inventory}

Please indicate how much you agree with each of the following items by rating them on this scale: $1=$ strongly disagree; $2=$ disagree; $3=$ slightly disagree; $4=$ slightly agree; 5 $=$ agree; or $6=$ strongly agree. Please be sure to answer ALL of the questions. Remember, there are no right or wrong answers.

For ease of reading, each definition will be placed under the respective construct (Problem-Solving Confidence, Approach-Avoidance Style, and Personal Control).

\section{Problem-Solving Confidence}

Definition: Problem-solving confidence is the belief in one's problem-solving abilities while engaging in problem-solving tasks (Heppner \& Baker, 1997).

\begin{tabular}{|c|c|c|c|c|c|c|}
\hline I believe... & $\begin{array}{l}1 \\
\text { Strongly } \\
\text { disagree }\end{array}$ & $\begin{array}{l}2 \\
\text { Disagree }\end{array}$ & $\begin{array}{l}3 \\
\text { Slightly } \\
\text { disagree }\end{array}$ & $\begin{array}{l}4 \\
\text { Slightly } \\
\text { agree }\end{array}$ & $\begin{array}{l}5 \\
\text { Agree }\end{array}$ & $\begin{array}{l}6 \\
\text { Strongly } \\
\text { agree }\end{array}$ \\
\hline $\begin{array}{l}\text { 1. I am able to develop } \\
\text { creative alternatives to } \\
\text { solve a problem when } \\
\text { working with others. }\end{array}$ & & & & & & \\
\hline $\begin{array}{l}\text { 2. I am able to develop } \\
\text { effective alternatives to } \\
\text { solve a problem when } \\
\text { working with others. }\end{array}$ & & & & & & \\
\hline $\begin{array}{l}\text { 3. I have the ability to solve } \\
\text { most problems in a group } \\
\text { setting, even though } \\
\text { initially no solution is } \\
\text { immediately apparent. }\end{array}$ & & & & & & \\
\hline $\begin{array}{l}\text { 4. When making decisions } \\
\text { as part of a group, I trust } \\
\text { the outcome. }\end{array}$ & & & & & & \\
\hline $\begin{array}{l}\text { 5. When I make plans to } \\
\text { solve a problem in } a \\
\text { group setting, I am } \\
\text { almost certain that } \\
\text { together we can find } \\
\text { solutions. }\end{array}$ & & & & & & \\
\hline $\begin{array}{l}\text { 6. Given enough time and } \\
\text { effort, I believe I can } \\
\text { solve most problems I am } \\
\text { confronted with when }\end{array}$ & & & & & & \\
\hline
\end{tabular}




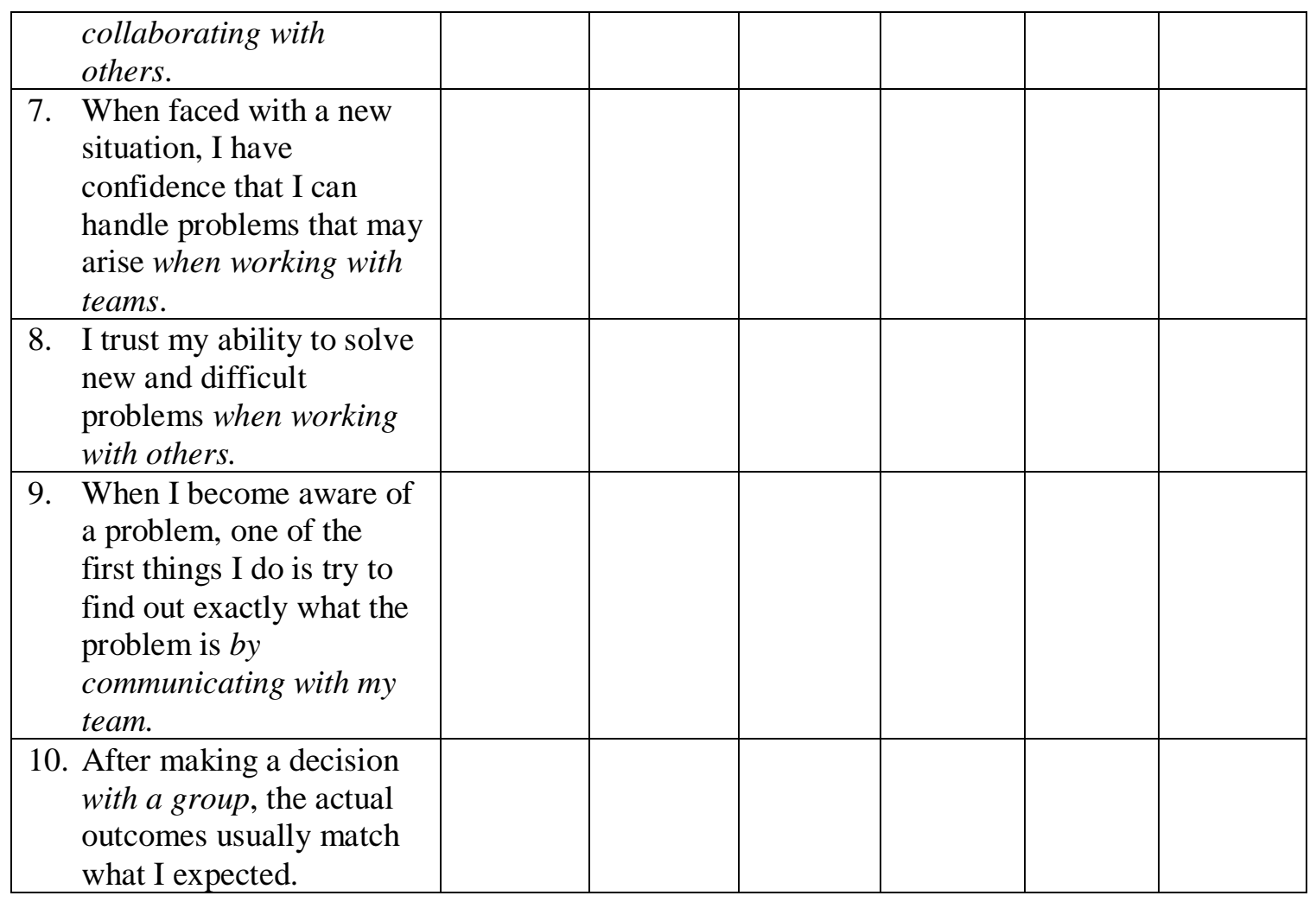

\section{Approach Avoidance Style}

Definition: Approach-avoidance style is defined as the preference for either approaching or avoiding problem-solving tasks (Heppner \& Baker, 1997).

\begin{tabular}{|c|c|c|c|c|c|c|}
\hline & $\begin{array}{l}1 \\
\text { Strongly } \\
\text { disagree }\end{array}$ & $\begin{array}{l}2 \\
\text { Disagree }\end{array}$ & $\begin{array}{l}3 \\
\text { Slightly } \\
\text { disagree }\end{array}$ & $\begin{array}{l}4 \\
\text { Slightly } \\
\text { agree }\end{array}$ & $\begin{array}{l}5 \\
\text { Agree }\end{array}$ & $\begin{array}{l}6 \\
\text { Strongly } \\
\text { agree }\end{array}$ \\
\hline $\begin{array}{l}\text { 11. When a solution to a } \\
\text { problem is unsuccessful, } \\
\text { I do not communicate } \\
\text { with others to examine } \\
\text { why it did not work. }\end{array}$ & & & & & & \\
\hline $\begin{array}{l}\text { 12. When I am confronted } \\
\text { with a complex problem, } \\
\text { I do not collaborate with } \\
\text { others to develop a } \\
\text { strategy to collect } \\
\text { information, to clearly } \\
\text { define what the problem } \\
\text { is. }\end{array}$ & & & & & & \\
\hline $\begin{array}{l}\text { 13. After I have solved a } \\
\text { problem with others, I do } \\
\text { not analyze with them } \\
\text { what went right or what } \\
\text { went wrong. }\end{array}$ & & & & & & \\
\hline
\end{tabular}




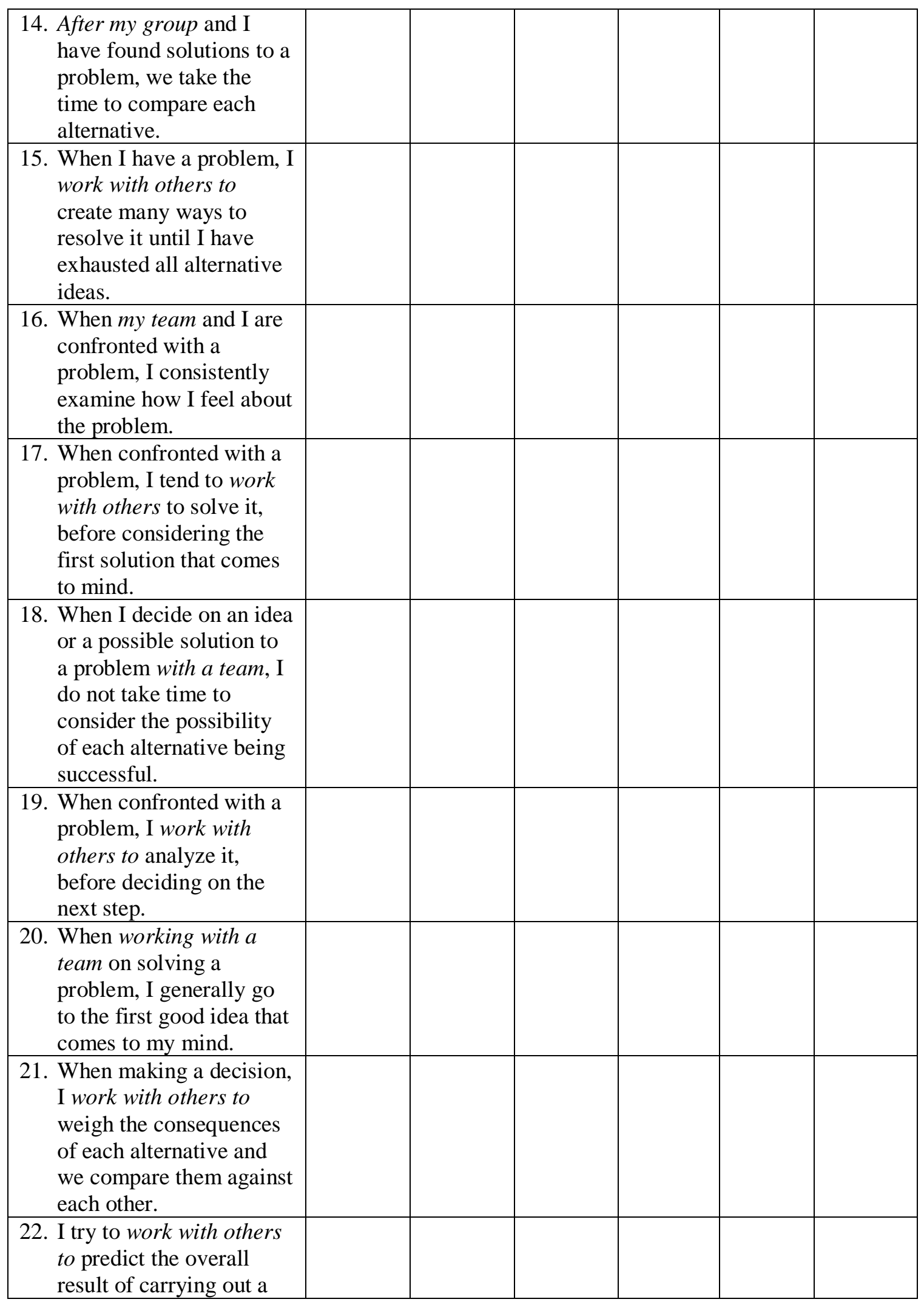




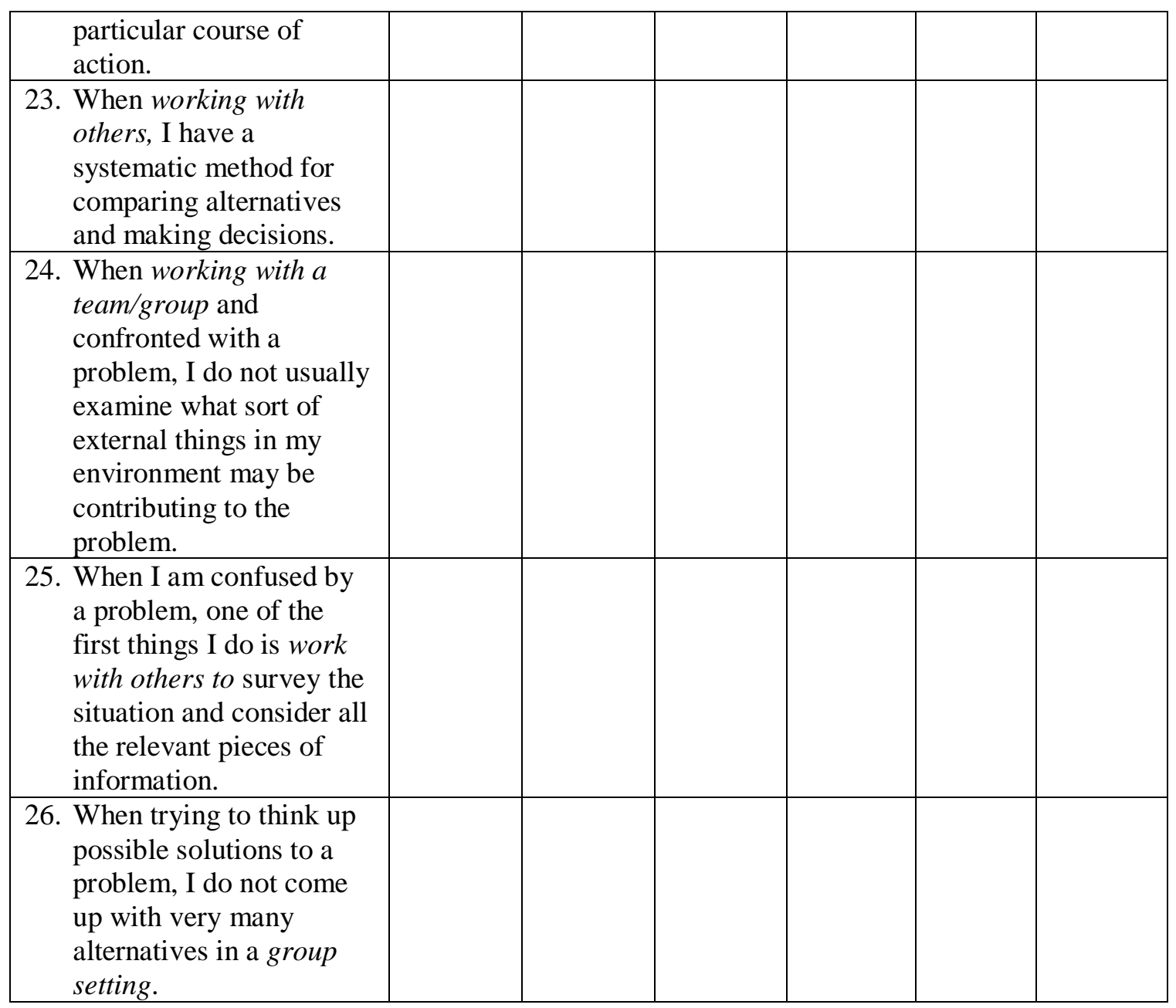

\section{Personal Control}

Definition: Personal control is defined as the belief that one has power over their behavior or attitude when faced with problem-solving tasks (Heppner \& Baker, 1997)

\begin{tabular}{|l|l|l|l|l|l|l|}
\hline & $\begin{array}{l}1 \\
\text { Strongly } \\
\text { disagree }\end{array}$ & $\begin{array}{l}2 \\
\text { Disagree }\end{array}$ & $\begin{array}{l}3 \\
\text { Slightly } \\
\text { disagree }\end{array}$ & $\begin{array}{l}4 \\
\text { Slightly } \\
\text { agree }\end{array}$ & $\begin{array}{l}5 \\
\text { Agree }\end{array}$ & $\begin{array}{l}6 \\
\text { Strongly } \\
\text { agree }\end{array}$ \\
\hline $\begin{array}{c}\text { 27. When my first efforts to } \\
\text { solve a problem fail, I } \\
\text { become uneasy about my } \\
\text { ability to handle the } \\
\text { situation. }\end{array}$ & & & & & & \\
\hline $\begin{array}{l}\text { 28. Sometimes I do not stop } \\
\text { and take time to deal } \\
\text { with my problems. }\end{array}$ & & & & & & \\
\hline $\begin{array}{l}\text { 29. Even though I work on a } \\
\text { problem, sometimes I }\end{array}$ & & & & & & \\
\hline
\end{tabular}




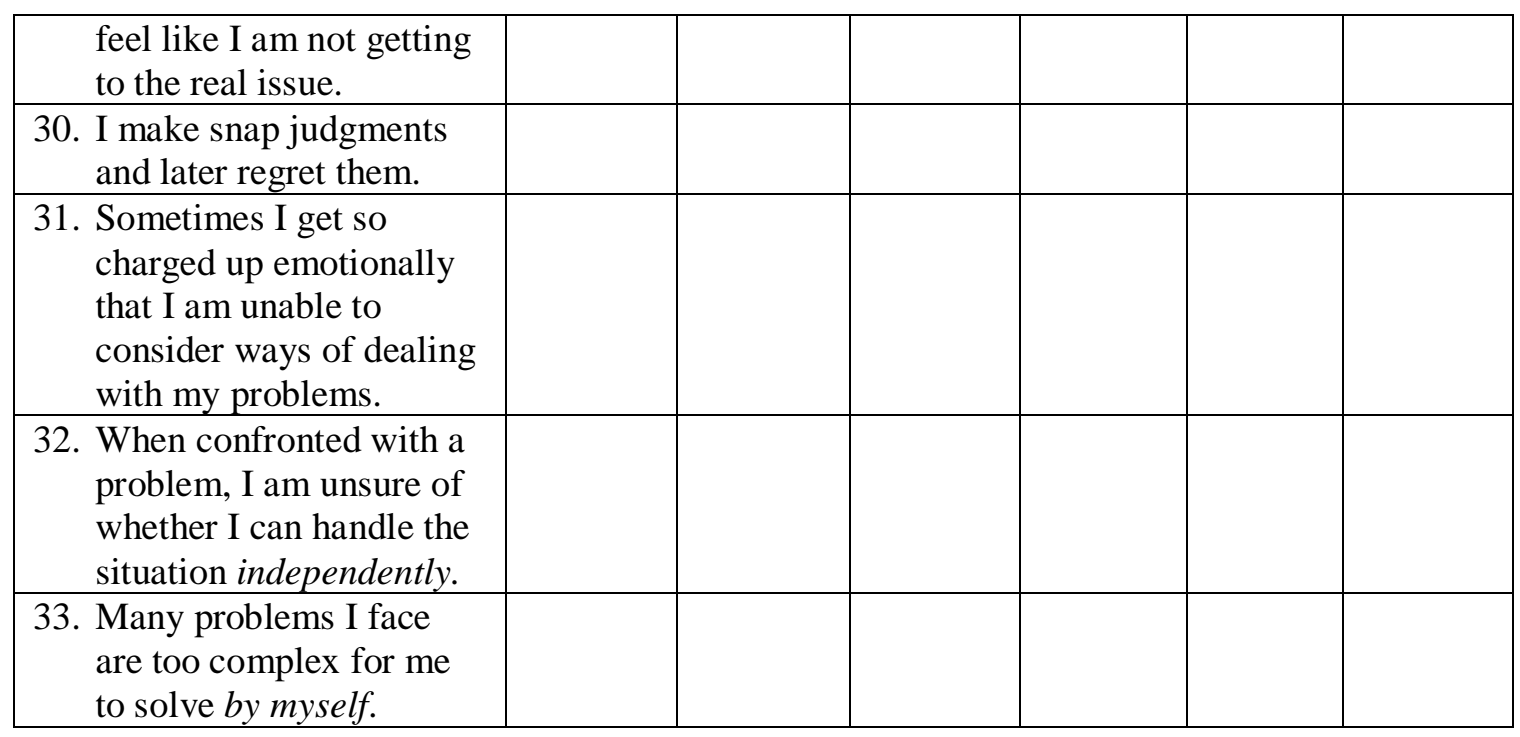

\section{DEMOGRAPHIC INFORMATION}

Gender identification

Other
Male $\square \quad$ Female $\square$ Prefer not to Respond

$22-29 \square \quad 30-39$

40-49

50-59

$60+$

\section{Race/ Ethnic Origin}

White only

Black or African American

Asian alone

Native Hawaiian and Other Pacific Islander alone

Native American and Alaska Native

Hispanic, Latino or Spanish

Two or more races

Other

\section{Field or Industry}

\section{Number of years in current position:}

Less than 1 year

$1-3$

4-6

7-10

$10+$ 
Level in organization:

Entry $\quad \square \quad$ Manager

Junior $\quad \square \quad$ Director

Assistant $\square \quad$ Executive

Supervisor $\square \quad$ Other

Number of years employed in organizations that required you to problem solve

Less than 1 year

$1-3$

4-9

$10-15$

$16+$ 


\section{Appendix N}

\section{REVISED PROBLEM-SOLVING INVENTORY FROM FOCUS GROUP}

\section{COGNITIVE INTERVIEW: ROUND 1}

\section{Paradoxical Problem-Solving Inventory}

Please indicate how much you agree with each of the following items by rating them on this scale: 1 = strongly disagree; $2=$ disagree; $3=$ slightly disagree; $4=$ slightly agree; 5 $=$ agree; or $6=$ strongly agree. Please be sure to answer ALL of the questions. Remember, there are no right or wrong answers.

For ease of reading, each definition will be placed under the respective construct (Problem-Solving Confidence, Approach-Avoidance Style, and Personal Control).

\section{Problem-Solving Confidence}

Definition: Problem-solving confidence is the belief in one's problem-solving abilities while engaging in problem-solving tasks (Heppner \& Baker, 1997).

\begin{tabular}{|c|c|c|c|c|c|c|}
\hline & $\begin{array}{l}1 \\
\text { Strongly } \\
\text { disagree }\end{array}$ & $\begin{array}{l}2 \\
\text { Disagree }\end{array}$ & $\begin{array}{l}3 \\
\text { Slightly } \\
\text { disagree }\end{array}$ & $\begin{array}{l}4 \\
\text { Slightly } \\
\text { agree }\end{array}$ & $\begin{array}{l}5 \\
\text { Agree }\end{array}$ & $\begin{array}{l}6 \\
\text { Strongly } \\
\text { agree }\end{array}$ \\
\hline $\begin{array}{l}\text { 1. I believe I am able to } \\
\text { develop creative or } \\
\text { unique alternatives to } \\
\text { solve a problem when } \\
\text { working with a team. }\end{array}$ & & & & & & \\
\hline $\begin{array}{l}\text { 2. I believe I am able to } \\
\text { develop successful } \\
\text { alternatives to solve a } \\
\text { problem when working } \\
\text { with a team. }\end{array}$ & & & & & & \\
\hline $\begin{array}{l}\text { 3. I have the ability to solve } \\
\text { most problems in a team, } \\
\text { even though initially no } \\
\text { solution is immediately } \\
\text { apparent. }\end{array}$ & & & & & & \\
\hline $\begin{array}{l}\text { 4. When making decisions } \\
\text { as part of a team, I trust } \\
\text { the outcome. }\end{array}$ & & & & & & \\
\hline $\begin{array}{l}\text { 5. When I make plans to } \\
\text { solve a problem within a } \\
\text { team, I am almost certain }\end{array}$ & & & & & & \\
\hline
\end{tabular}




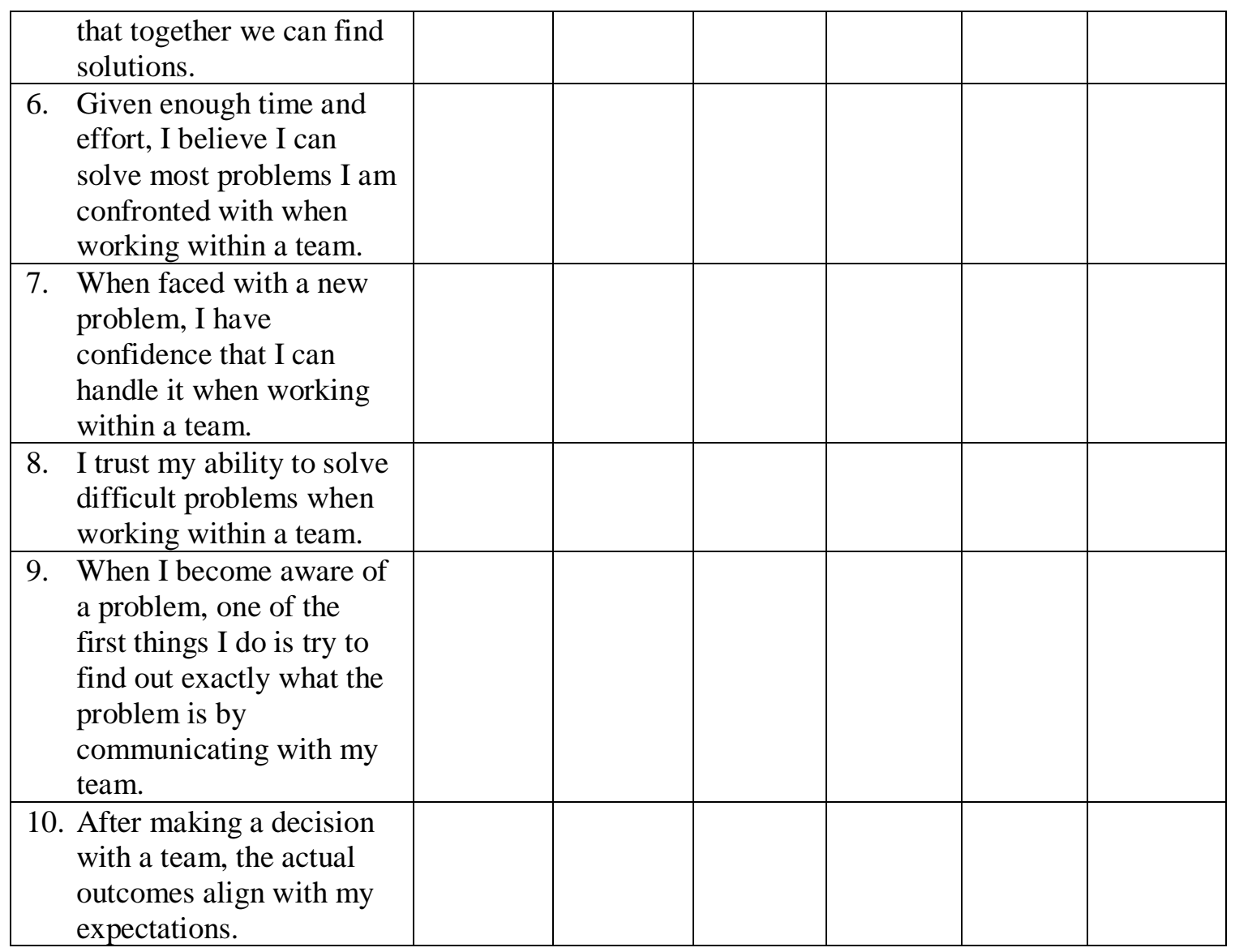

\section{Approach Avoidance Style}

Definition: Approach-avoidance style is defined as the preference for either approaching or avoiding problem-solving tasks (Heppner \& Baker, 1997).

\begin{tabular}{|c|c|c|c|c|c|c|}
\hline & $\begin{array}{l}1 \\
\text { Strongly } \\
\text { disagree }\end{array}$ & $\begin{array}{l}2 \\
\text { Disagree }\end{array}$ & $\begin{array}{l}3 \\
\text { Slightly } \\
\text { disagree }\end{array}$ & $\begin{array}{l}4 \\
\text { Slightly } \\
\text { agree }\end{array}$ & $\begin{array}{l}5 \\
\text { Agree }\end{array}$ & $\begin{array}{l}6 \\
\text { Strongly } \\
\text { agree }\end{array}$ \\
\hline $\begin{array}{l}\text { 11. After my team and I } \\
\text { have collectively found } \\
\text { alternative solutions to a } \\
\text { problem, I take the time } \\
\text { to compare each. }\end{array}$ & & & & & & \\
\hline $\begin{array}{l}\text { 12. When I have a problem, I } \\
\text { work with a team to } \\
\text { create many possible } \\
\text { solutions until I have } \\
\text { exhausted all alternative } \\
\text { ideas. }\end{array}$ & & & & & & \\
\hline $\begin{array}{l}\text { 13. When my team and I are } \\
\text { confronted with a }\end{array}$ & & & & & & \\
\hline
\end{tabular}




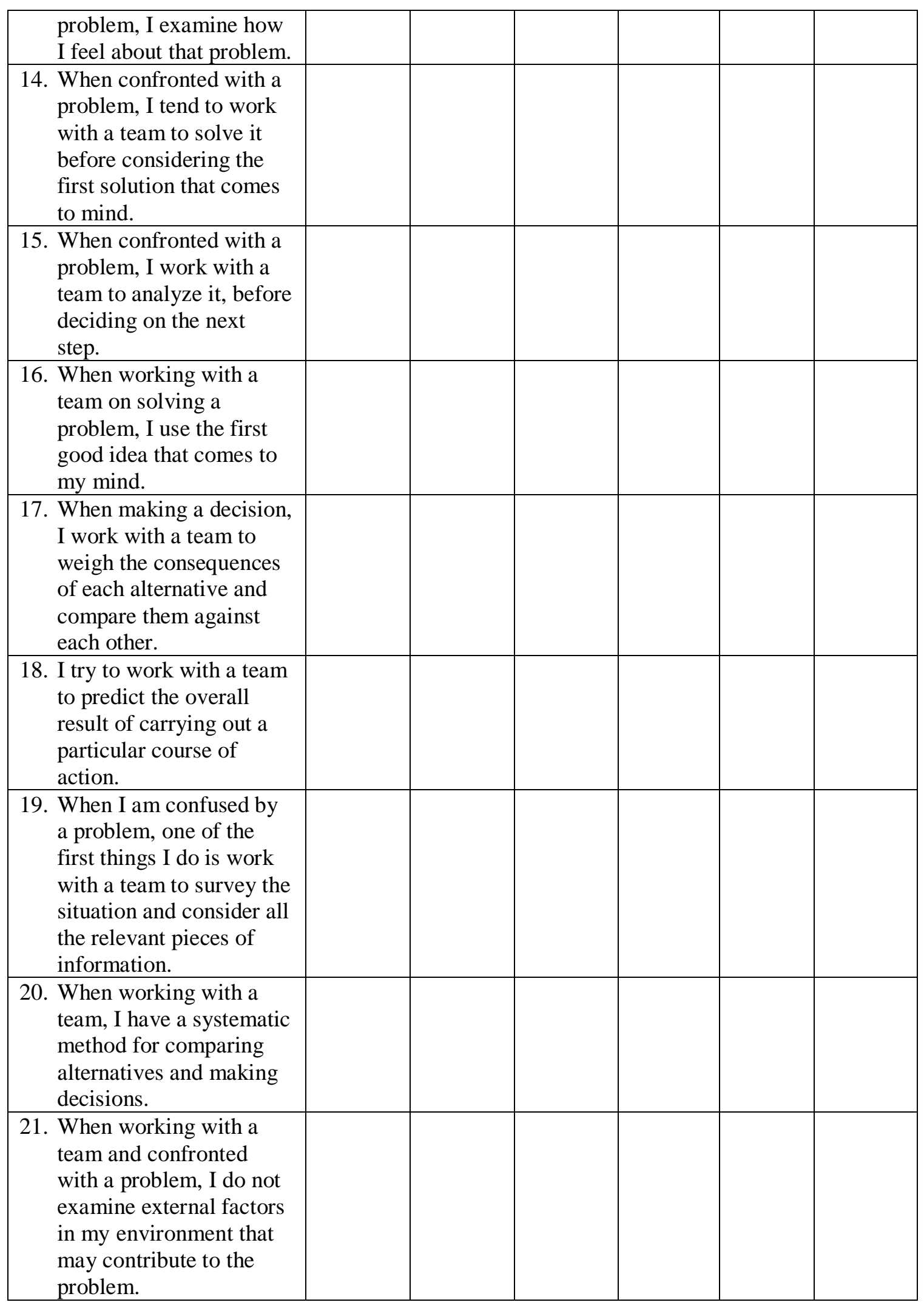




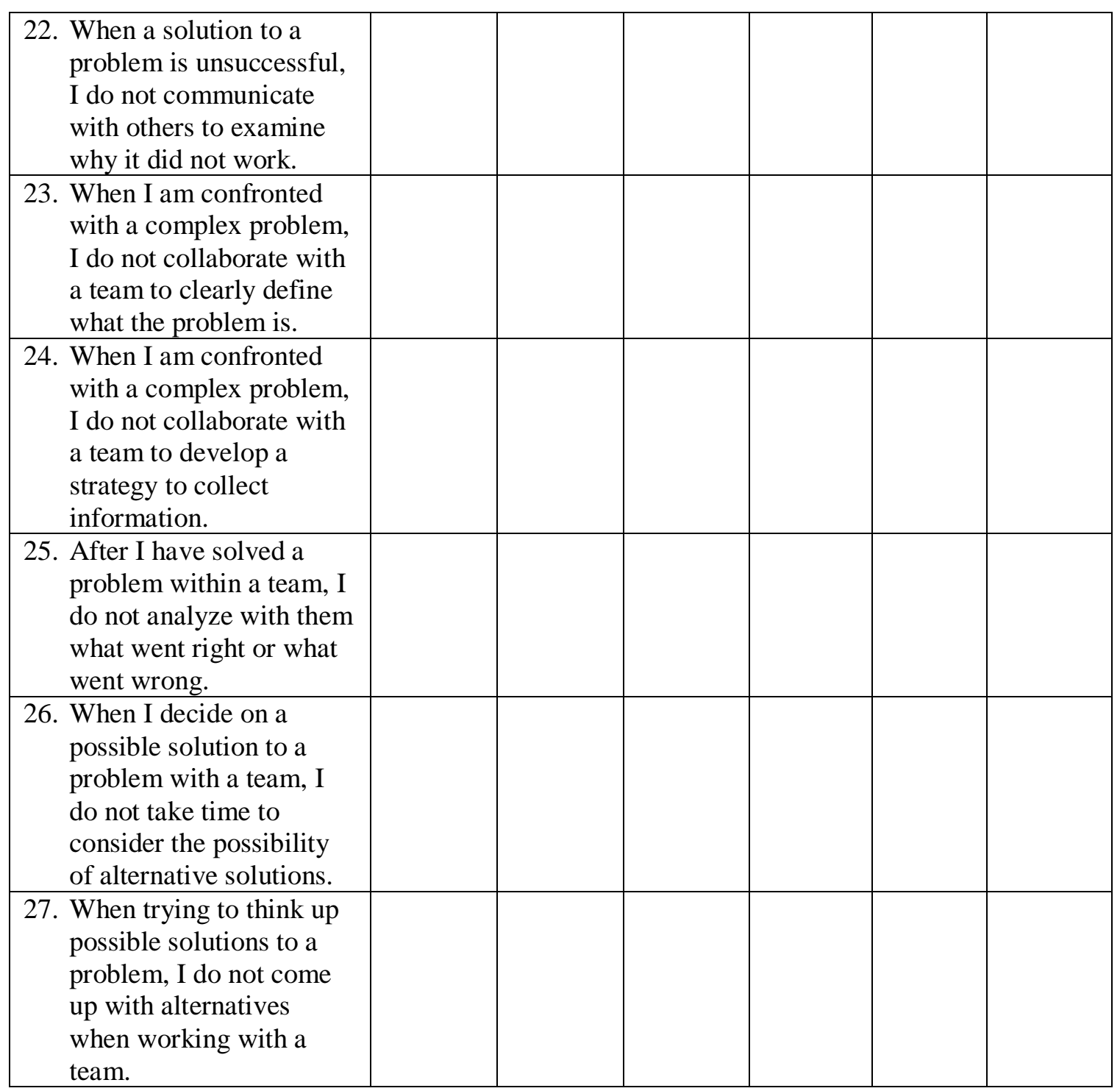

\section{Personal Control}

Definition: Personal control is defined as the belief that one has power over their behavior or attitude when faced with problem-solving tasks (Heppner \& Baker, 1997)

\begin{tabular}{|l|l|l|l|l|l|l|}
\hline & $\begin{array}{l}1 \\
\text { Strongly } \\
\text { disagree }\end{array}$ & $\begin{array}{l}2 \\
\text { Disagree }\end{array}$ & $\begin{array}{l}3 \\
\text { Slightly } \\
\text { disagree }\end{array}$ & $\begin{array}{l}4 \\
\text { Slightly } \\
\text { agree }\end{array}$ & $\begin{array}{l}5 \\
\text { Agree }\end{array}$ & $\begin{array}{l}6 \\
\text { Strongly } \\
\text { agree }\end{array}$ \\
\hline $\begin{array}{l}\text { 28. When my first efforts to } \\
\text { solve a problem fail, I } \\
\text { pause and tackle the } \\
\text { situation again. }\end{array}$ & & & & & & \\
\hline $\begin{array}{l}\text { 29. I stop and take time to } \\
\text { deal with my }\end{array}$ & & & & & & \\
\hline
\end{tabular}




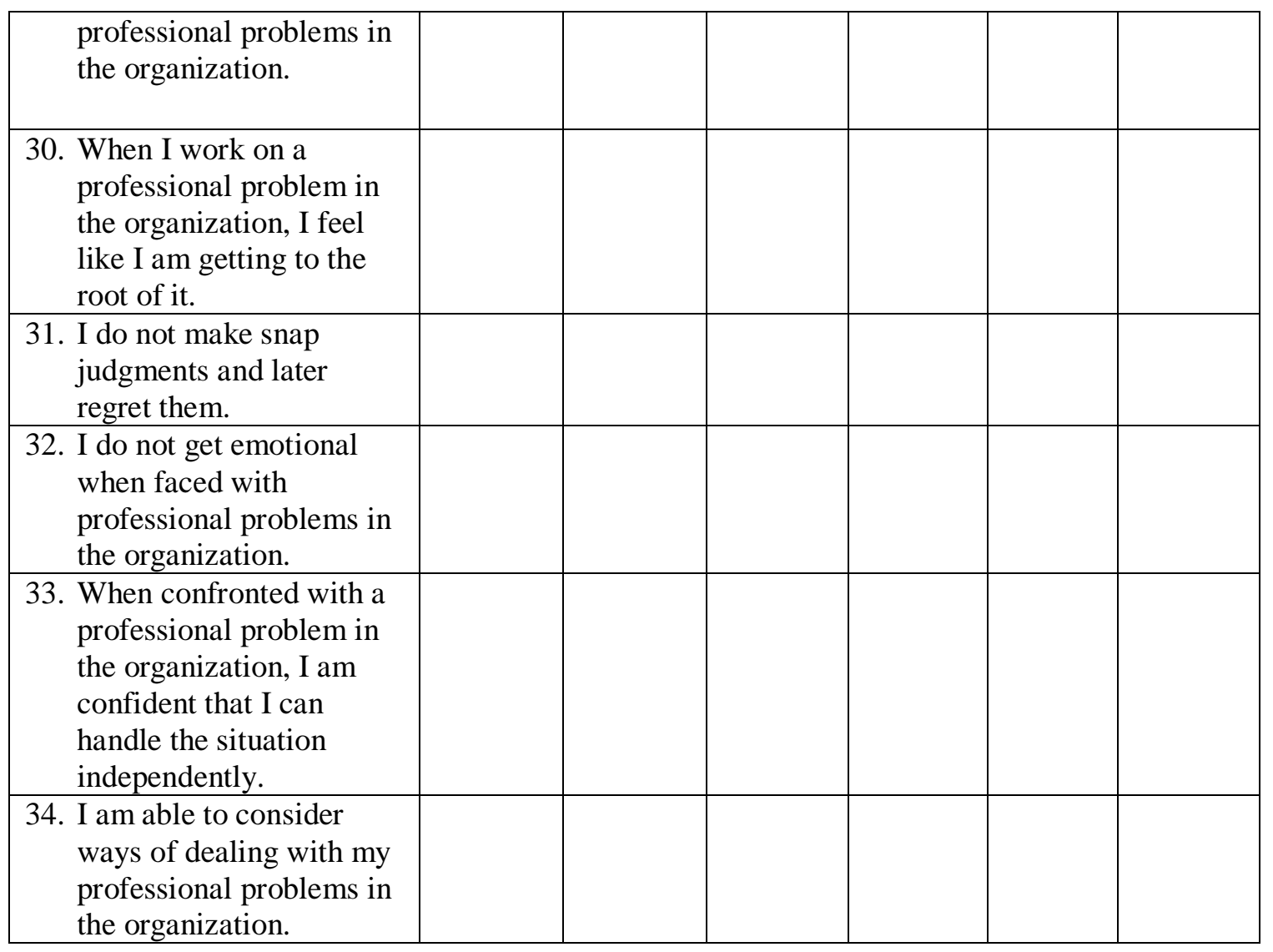

\section{DEMOGRAPHIC INFORMATION}

Gender identification

Prefer not to Respond
Male $\square \quad$ Female $\square \quad$ Other

22-29

30-39

40-49

$50-59$

60-69

$70+$

\section{Race/ Ethnic Origin}

White

Black or African American

Asian

Native American and Alaska Native

Native Hawaiian and Other Pacific Islander

Two or more races

Other

Prefer not to respond 
Are you Hispanic or Latino?

Black Hispanic or Latino

White Hispanic or Latino

Mixed

Prefer not to respond

Field or Industry \& Job Title

Number of years in field:

Level in organization:

Less than 1 year

Entry

$1-3$

Supervisor

4-6

Manager

7-10

$10+$

Number of years employed in organizations that required you to problem-solve

Less than 1 year

$1-3$

$4-9$

$10-15$

$16+$ 


\section{APPENDIX O}

\section{REVISED PROBLEM-SOLVING INVENTORY FROM FOCUS GROUP}

\section{COGNITIVE INTERVIEW: ROUND 2}

\section{Paradoxical Problem-Solving Inventory}

Please indicate how much you agree with each of the following items by rating them on this scale: 1 = strongly disagree; 2 = disagree; 3 = slightly disagree; $4=$ slightly agree; 5 $=$ agree; or $6=$ strongly agree. Please be sure to answer ALL of the questions. Remember, there are no right or wrong answers.

\section{Team Definition}

That combination of people whose coordinated inputs are necessary to accomplish a given task or set of tasks (Lawrence, 1969; Galbraith, 1973; Thompson, 1967).

For ease of reading, each definition will be placed under the respective construct (Problem-Solving Confidence, Approach-Avoidance Style, and Personal Control).

\section{Problem-Solving Confidence}

Definition: Problem-solving confidence is the belief in one's problem-solving abilities while engaging in problem-solving tasks (Heppner \& Baker, 1997).

\begin{tabular}{|c|c|c|c|c|c|c|}
\hline & $\begin{array}{l}1 \\
\text { Strongly } \\
\text { disagree }\end{array}$ & $\begin{array}{l}2 \\
\text { Disagree }\end{array}$ & $\begin{array}{l}3 \\
\text { Slightly } \\
\text { disagree }\end{array}$ & $\begin{array}{l}4 \\
\text { Slightly } \\
\text { agree }\end{array}$ & $\begin{array}{l}5 \\
\text { Agree }\end{array}$ & $\begin{array}{l}6 \\
\text { Strongly } \\
\text { agree }\end{array}$ \\
\hline $\begin{array}{l}\text { 1. I believe that I am able to } \\
\text { develop creative or } \\
\text { unique alternatives to } \\
\text { solve a problem when } \\
\text { working with a team. }\end{array}$ & & & & & & \\
\hline $\begin{array}{l}\text { 2. I believe that I am able to } \\
\text { develop successful } \\
\text { alternatives to solve a } \\
\text { problem when working } \\
\text { with a team. }\end{array}$ & & & & & & \\
\hline $\begin{array}{l}\text { 3. I have the ability to solve } \\
\text { most problems in a team, } \\
\text { even though initially no } \\
\text { solution is apparent. }\end{array}$ & & & & & & \\
\hline $\begin{array}{l}\text { 4. When making decisions } \\
\text { as part of a team, I trust } \\
\text { the outcome. }\end{array}$ & & & & & & \\
\hline
\end{tabular}




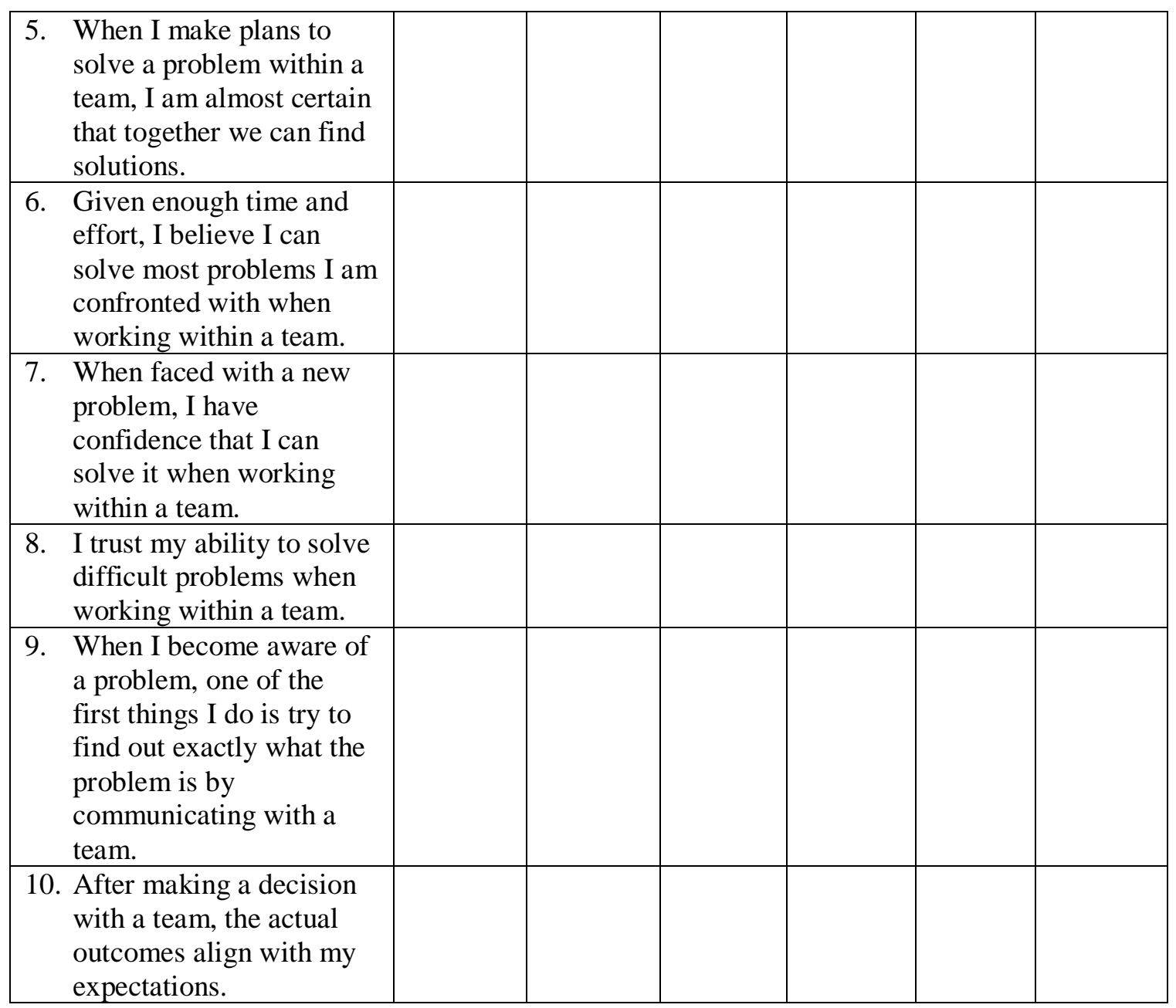

\section{Approach Avoidance Style}

Definition: Approach-avoidance style is defined as the preference for either approaching or avoiding problem-solving tasks (Heppner \& Baker, 1997).

\begin{tabular}{|c|c|c|c|c|c|c|}
\hline & $\begin{array}{l}1 \\
\text { Strongly } \\
\text { disagree }\end{array}$ & $\begin{array}{l}2 \\
\text { Disagree }\end{array}$ & $\begin{array}{l}3 \\
\text { Slightly } \\
\text { disagree }\end{array}$ & $\begin{array}{l}4 \\
\text { Slightly } \\
\text { agree }\end{array}$ & $\begin{array}{l}5 \\
\text { Agree }\end{array}$ & $\begin{array}{l}6 \\
\text { Strongly } \\
\text { agree }\end{array}$ \\
\hline $\begin{array}{l}\text { 11. After my team and I } \\
\text { have collectively found } \\
\text { alternative solutions to a } \\
\text { problem, we take the } \\
\text { time to compare each } \\
\text { solution. }\end{array}$ & & & & & & \\
\hline $\begin{array}{l}\text { 12. When I have a problem, I } \\
\text { work with a team to } \\
\text { create many possible } \\
\text { solutions until we have } \\
\text { exhausted all ideas. }\end{array}$ & & & & & & \\
\hline
\end{tabular}




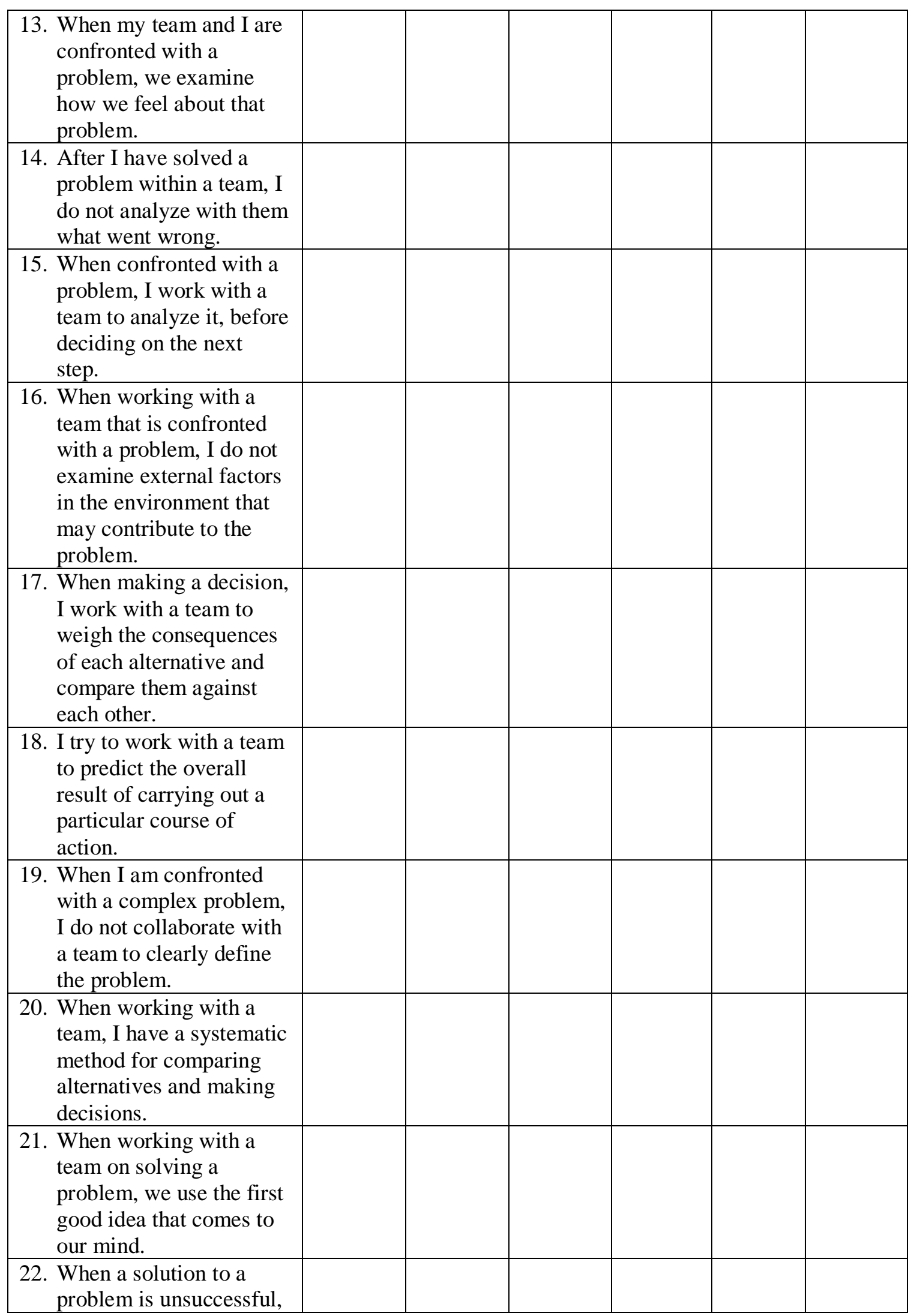




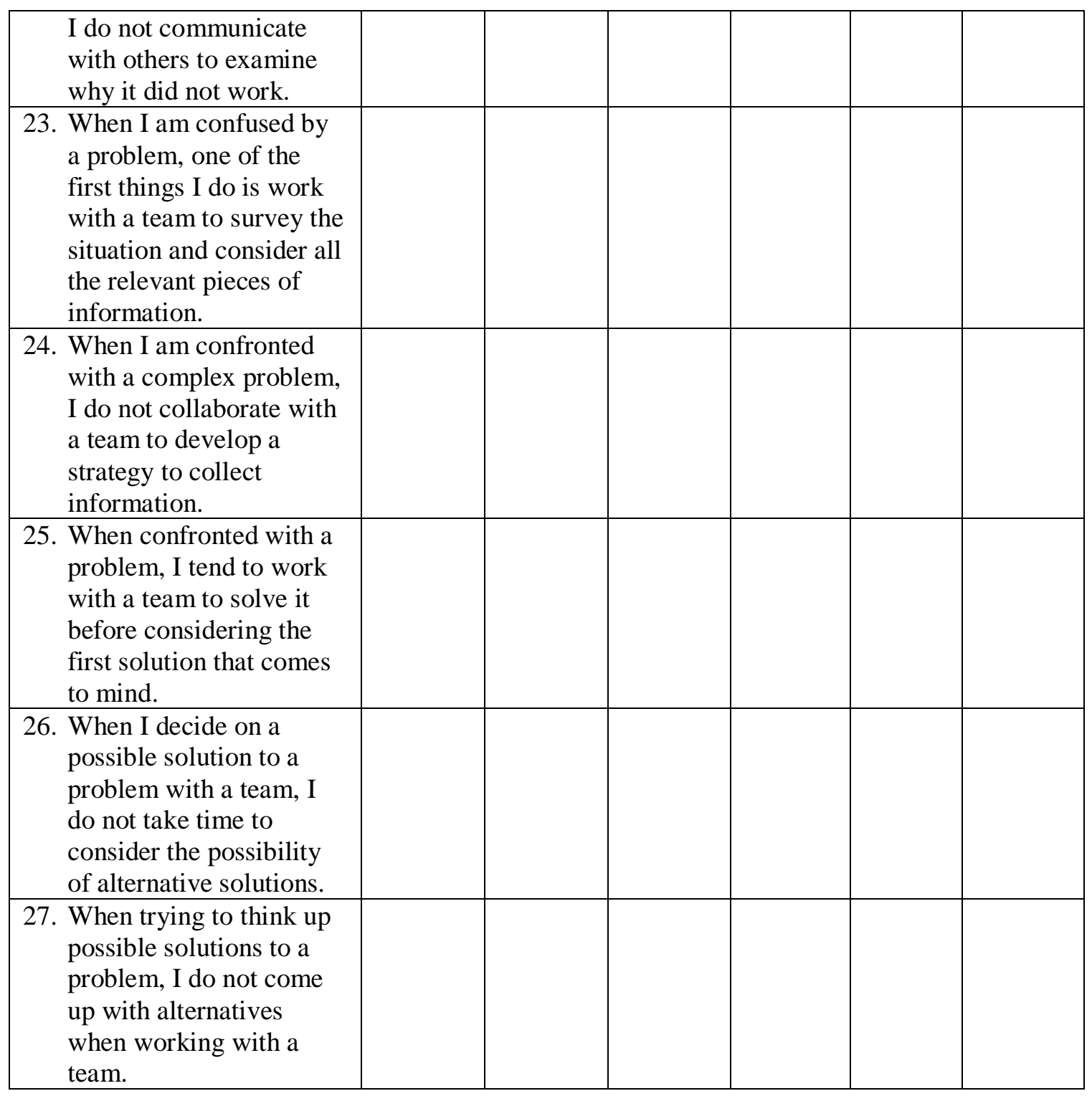

\section{Personal Control}

Definition: Personal control is defined as the belief that one has power over their behavior or attitude when faced with problem-solving tasks (Heppner \& Baker, 1997)

\begin{tabular}{|l|l|l|l|l|l|l|}
\hline & $\begin{array}{l}1 \\
\text { Strongly } \\
\text { disagree }\end{array}$ & $\begin{array}{l}2 \\
\text { Disagree }\end{array}$ & $\begin{array}{l}3 \\
\text { Slightly } \\
\text { disagree }\end{array}$ & $\begin{array}{l}4 \\
\text { Slightly } \\
\text { agree }\end{array}$ & $\begin{array}{l}5 \\
\text { Agree }\end{array}$ & $\begin{array}{l}6 \\
\text { Strongly } \\
\text { agree }\end{array}$ \\
\hline $\begin{array}{c}\text { 28. When my first efforts to } \\
\text { solve a problem fail, I } \\
\text { pause and reassess the } \\
\text { situation again. }\end{array}$ & & & & & & \\
\hline $\begin{array}{c}\text { 29. I stop and take time to } \\
\text { deal with professional }\end{array}$ & & & & & & \\
\hline
\end{tabular}




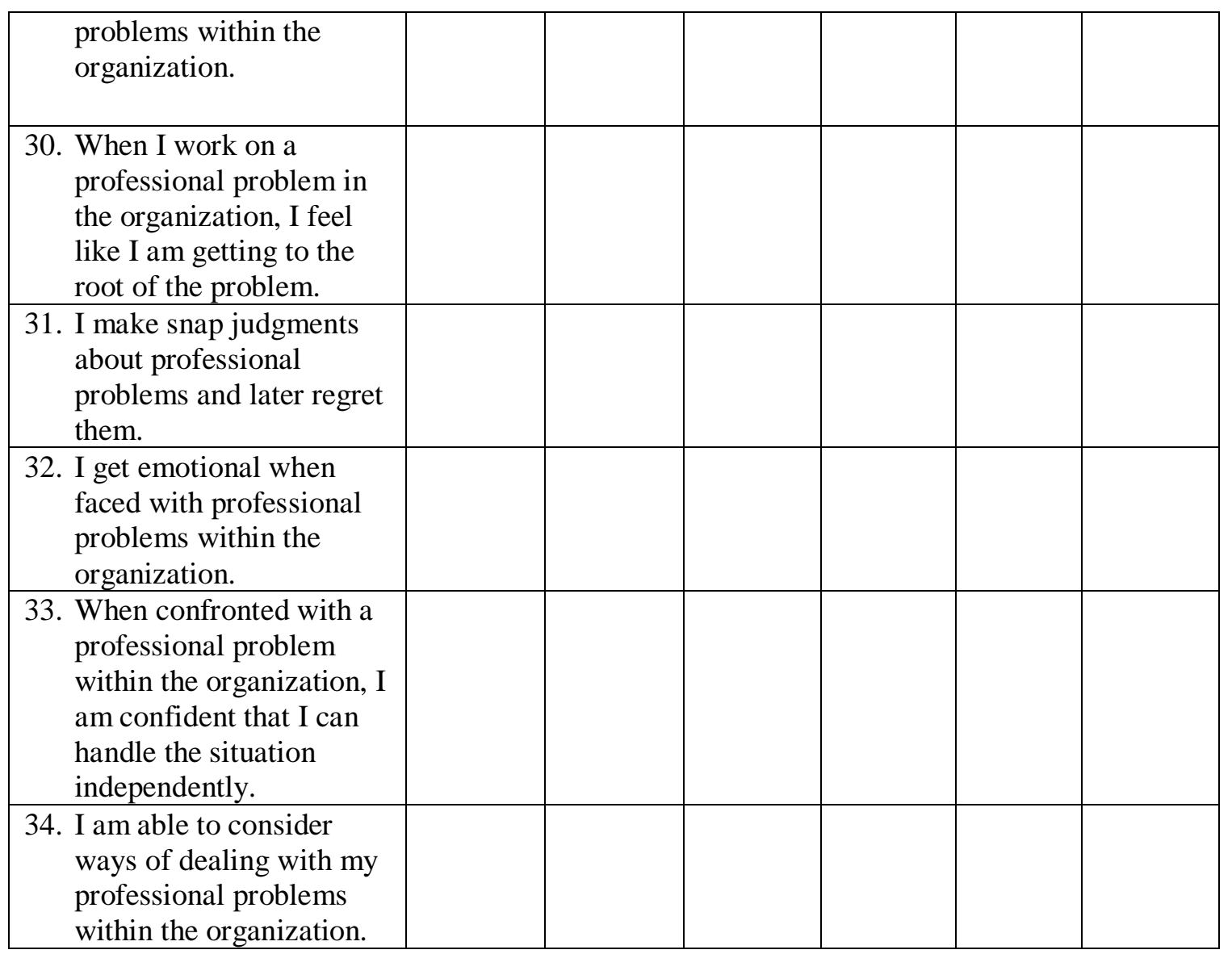

\section{DEMOGRAPHIC INFORMATION}

Gender identification

Male $\square \quad$ Female $\square \quad$ Other

Prefer not to Respond

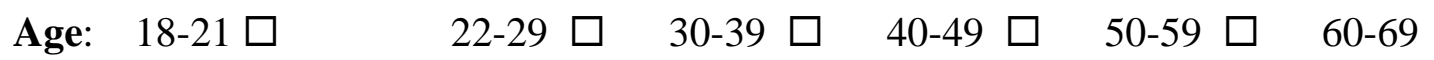

$70+\square$

Are you Hispanic or Latino?

Yes

No

\section{Race/ Ethnic Origin}

White

Black/ African American

Asian

Native American/ Alaska Native

Native Hawaiian/ Other Pacific Islander

Two or more races 
Other

Prefer not to respond

Field or Industry

Job Title

Number of years in field:

Level in organization:

Less than 1 year

Entry

$1-3$

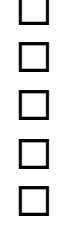

Mid-Level

Supervisor

4-6

Manager

$10+$

Other

Number of years employed in organizations that required you to problem-solve

Less than 1 year

1-3

4-9

10-15

$16+$ 


\section{APPENDIX P \\ FINAL PROBLEM-SOLVING INVENTORY: SURVEY DISTRIBUTION IN \\ QUALTRICS}

\section{Paradoxical Problem-Solving Inventory}

Please indicate how much you agree with each of the following items by rating them on this scale: $1=$ strongly disagree; $2=$ disagree; $3=$ slightly disagree; $4=$ slightly agree; 5 $=$ agree; or $6=$ strongly agree. Please be sure to answer ALL of the questions.

Remember, there are no right or wrong answers.

\section{Team Definition}

That combination of people whose coordinated inputs are necessary to accomplish a given task or set of tasks (Lawrence, 1969; Galbraith, 1973; Thompson, 1967).

For ease of reading, each definition will be placed under the respective construct (Problem-Solving Confidence, Approach-Avoidance Style, and Personal Control).

\section{Problem-Solving Confidence}

Definition: Problem-solving confidence is the belief in one's problem-solving abilities while engaging in problem-solving tasks (Heppner \& Baker, 1997).

\begin{tabular}{|c|c|c|c|c|c|c|}
\hline & $\begin{array}{l}1 \\
\text { Strongly } \\
\text { disagree }\end{array}$ & $\begin{array}{l}2 \\
\text { Disagree }\end{array}$ & $\begin{array}{l}3 \\
\text { Slightly } \\
\text { disagree }\end{array}$ & $\begin{array}{l}4 \\
\text { Slightly } \\
\text { agree }\end{array}$ & $\begin{array}{l}5 \\
\text { Agree }\end{array}$ & $\begin{array}{l}6 \\
\text { Strongly } \\
\text { agree }\end{array}$ \\
\hline 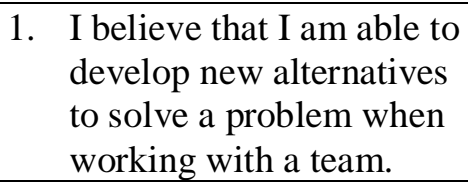 & & & & & & \\
\hline $\begin{array}{l}\text { 2. I believe that I am able to } \\
\text { develop successful } \\
\text { alternatives to solve a } \\
\text { problem when working } \\
\text { with a team. }\end{array}$ & & & & & & \\
\hline $\begin{array}{l}\text { 3. I have the ability to solve } \\
\text { most problems in a team, } \\
\text { even though initially no } \\
\text { solution is apparent. }\end{array}$ & & & & & & \\
\hline $\begin{array}{l}\text { 4. I trust the outcome when } \\
\text { making decisions as part } \\
\text { of a team. }\end{array}$ & & & & & & \\
\hline $\begin{array}{l}\text { 5. When I make plans to } \\
\text { solve a problem within a } \\
\text { team, I am certain that }\end{array}$ & & & & & & \\
\hline
\end{tabular}




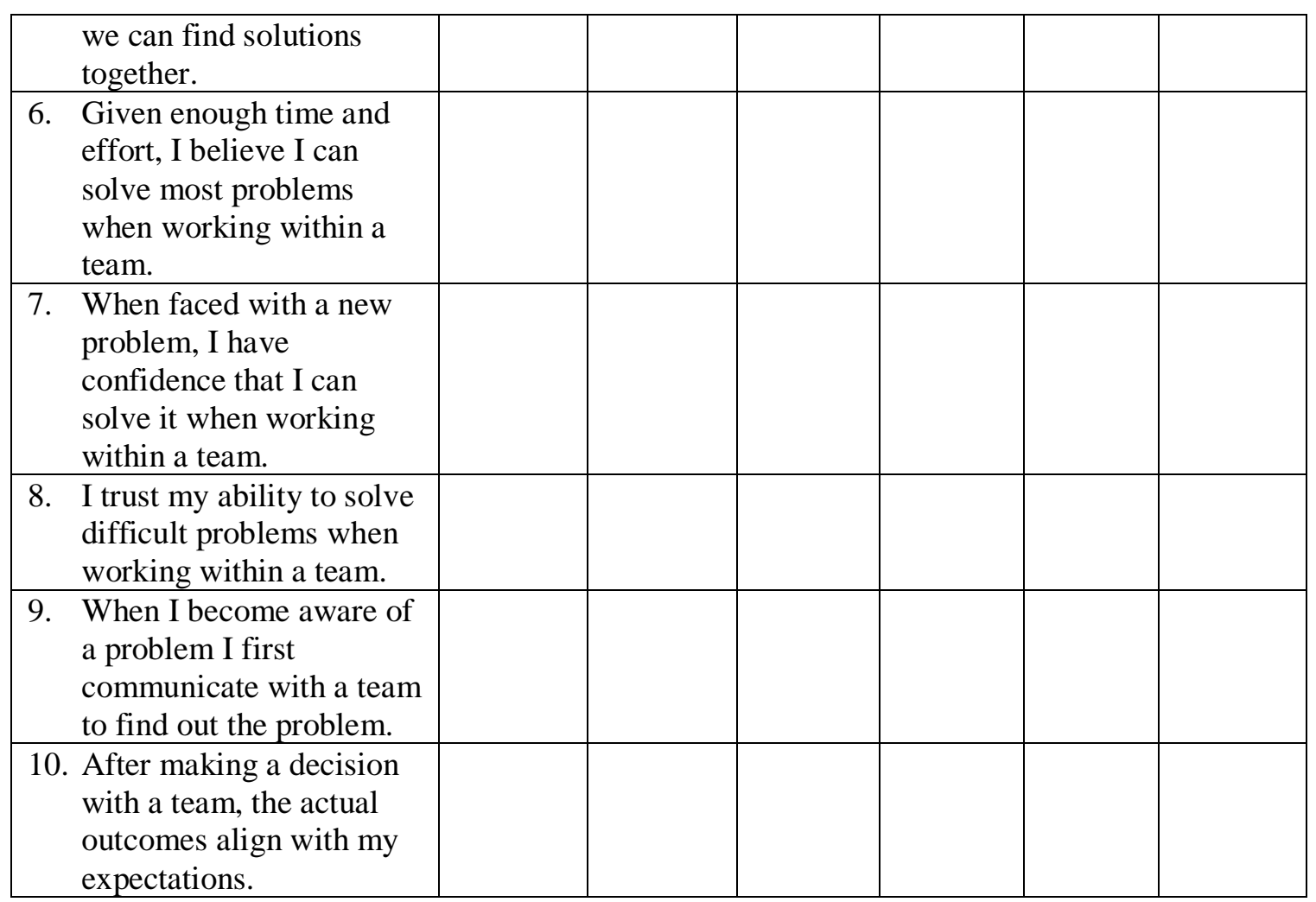

\section{Approach Avoidance Style}

Definition: Approach-avoidance style is defined as the preference for either approaching or avoiding problem-solving tasks (Heppner \& Baker, 1997).

\begin{tabular}{|l|l|l|l|l|l|l|}
\hline & $\begin{array}{l}\text { Strongly } \\
\text { disagree }\end{array}$ & $\begin{array}{l}2 \\
\text { Disagree }\end{array}$ & $\begin{array}{l}3 \\
\text { Slightly } \\
\text { disagree }\end{array}$ & $\begin{array}{l}4 \\
\text { Slightly } \\
\text { agree }\end{array}$ & $\begin{array}{l}5 \\
\text { Agree }\end{array}$ & $\begin{array}{l}6 \\
\text { Strongly } \\
\text { agree }\end{array}$ \\
\hline $\begin{array}{l}\text { 11. After my team and I } \\
\text { collectively find } \\
\text { alternative solutions to a } \\
\text { problem, we compare } \\
\text { each solution. }\end{array}$ & & & & & & \\
\hline $\begin{array}{l}\text { 12. When I have a problem, I } \\
\text { work with a team to } \\
\text { create many possible } \\
\text { solutions until we have } \\
\text { exhausted all the ideas. }\end{array}$ & & & & & & \\
\hline $\begin{array}{l}\text { 13. When my team and I } \\
\text { have a problem, we } \\
\text { examine how we feel } \\
\text { about that problem. }\end{array}$ & & & & & & \\
\hline $\begin{array}{l}\text { 14. When confronted with a } \\
\text { problem, I work with a } \\
\text { team to analyze it before }\end{array}$ & & & & & & \\
\hline
\end{tabular}




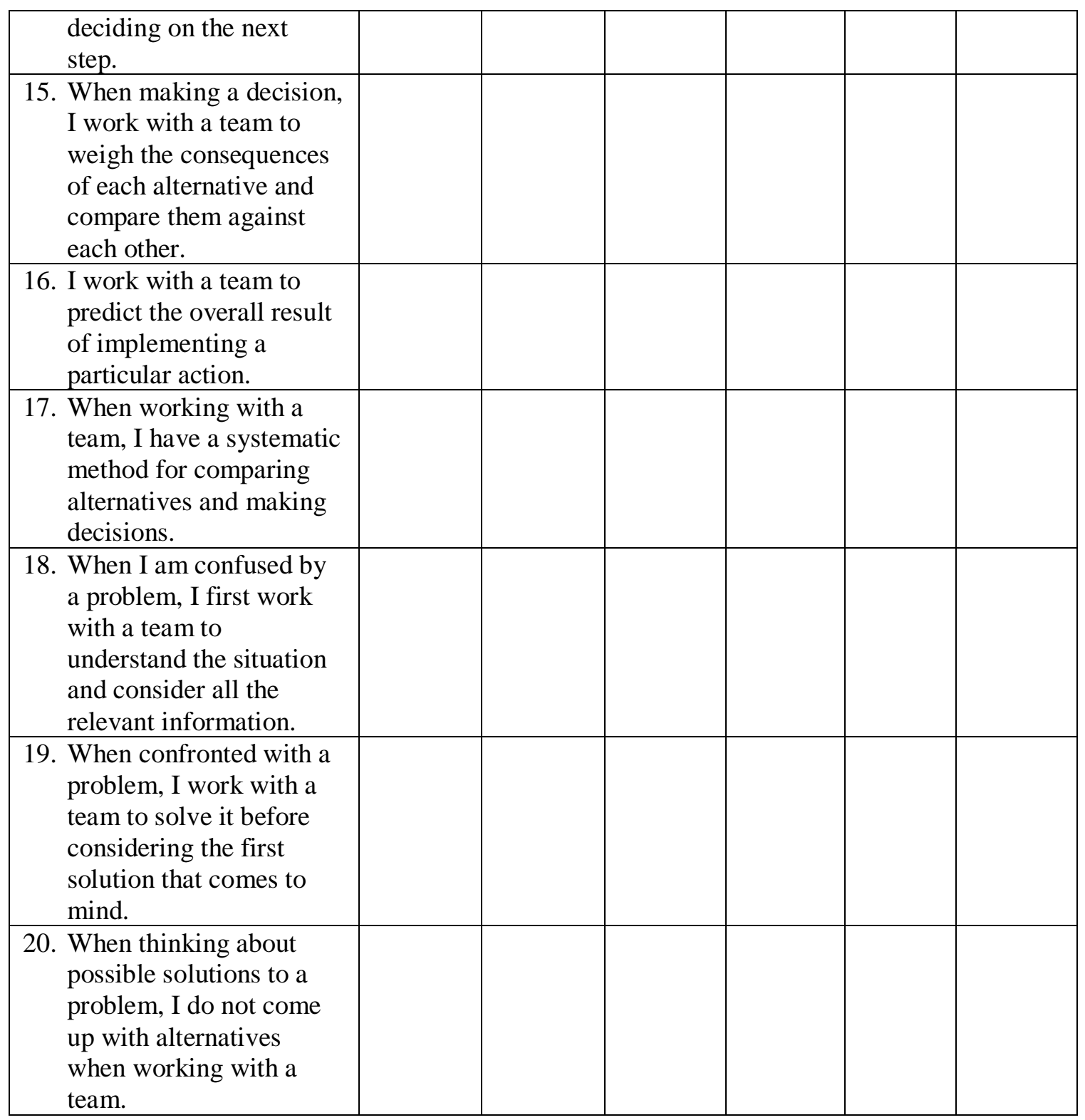

\section{Personal Control}

Definition: Personal control is defined as the belief that one has power over their behavior or attitude when faced with problem-solving tasks (Heppner \& Baker, 1997)

\begin{tabular}{|l|l|l|l|l|l|l|}
\hline & $\begin{array}{l}1 \\
\text { Strongly } \\
\text { disagree }\end{array}$ & $\begin{array}{l}2 \\
\text { Disagree }\end{array}$ & $\begin{array}{l}3 \\
\text { Slightly } \\
\text { disagree }\end{array}$ & $\begin{array}{l}4 \\
\text { Slightly } \\
\text { agree }\end{array}$ & $\begin{array}{l}5 \\
\text { Agree }\end{array}$ & $\begin{array}{l}6 \\
\text { Strongly } \\
\text { agree }\end{array}$ \\
\hline $\begin{array}{c}\text { 21. When my first efforts to } \\
\text { solve a problem fail, I } \\
\text { pause and reassess the } \\
\text { situation. }\end{array}$ & & & & & & \\
\hline
\end{tabular}




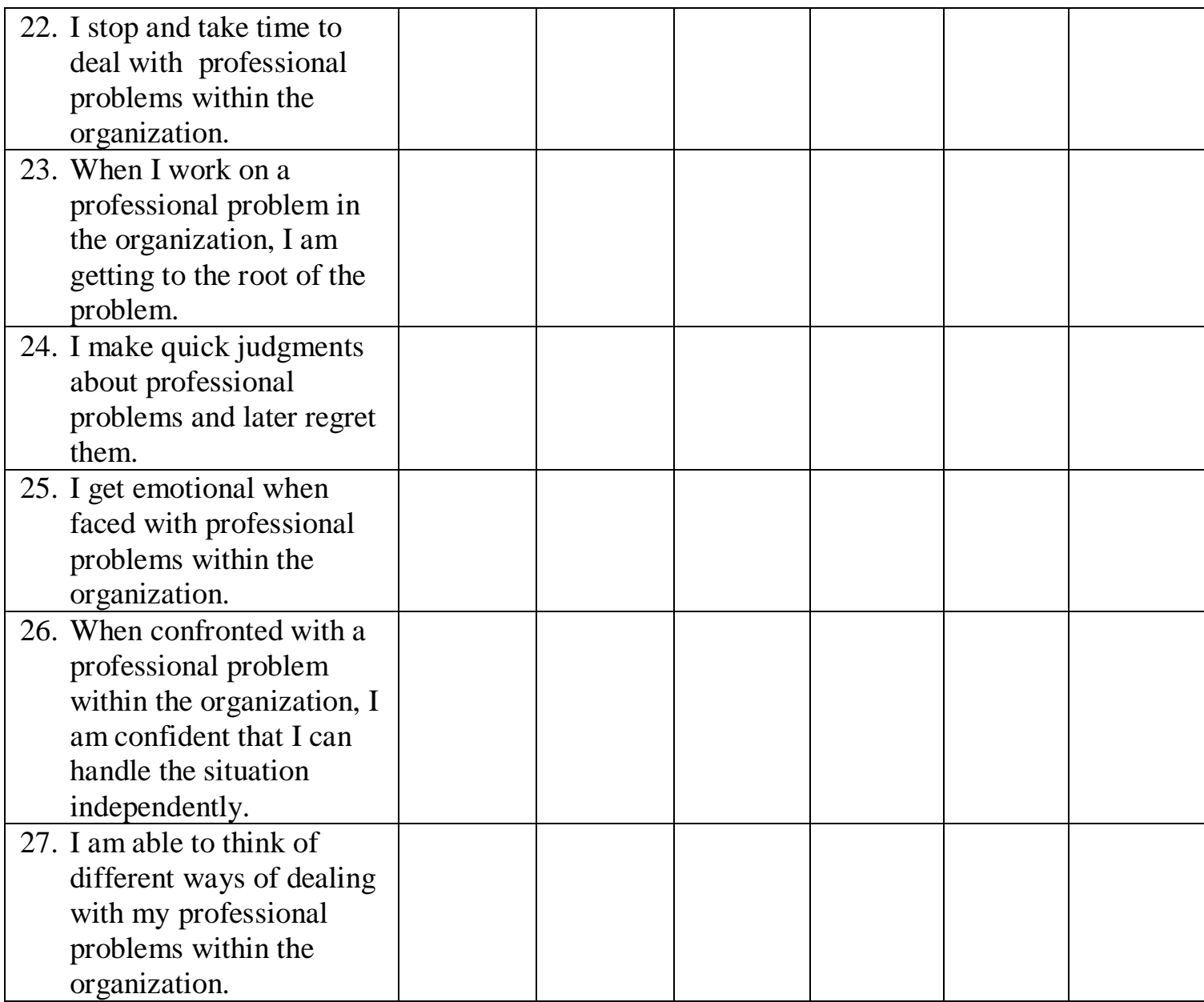

\section{DEMOGRAPHIC INFORMATION}
Gender identification
Male
Female
Other
Prefer not to Respond

Age: $18-21$

22-29

30-39

40-49

50-59

60-69

$70+$

Are you Hispanic or Latino?

Yes

No

\section{Race/ Ethnic Origin}

White

Black/ African American

Asian

Native American/ Alaska Native 
Native Hawaiian/ Other Pacific Islander

Two or more races

Other

Prefer not to respond

Field or Industry

Job Title

Number of years in field:

Level in organization:

Less than 1 year

Entry

$1-3$

Mid-Level

Supervisor

7-10

Manager

$10+$

Other

Number of years employed in organizations that required you to problem-solve

Less than 1 year

$1-3$

4-9

$10-15$

$16+$ 


\section{APPENDIX Q}

\section{PPSI TIMELINE: FROM THE ADAPTED PSI TO FINAL PPSI}

\begin{tabular}{|c|c|c|c|c|}
\hline Original PSI & $\begin{array}{c}\text { Adapted PSI } \\
\text { (Given to experts) }\end{array}$ & $\begin{array}{c}\text { Experts Feedback } \\
\text { I believe... }\end{array}$ & $\begin{array}{l}\text { Focus Group Cognitive } \\
\text { Interview Feedback }\end{array}$ & Final \\
\hline \multirow[t]{2}{*}{$\begin{array}{l}\text { I am usually able to think } \\
\text { up creative and effective } \\
\text { alternatives to solve a } \\
\text { problem. }\end{array}$} & \multirow[t]{2}{*}{$\begin{array}{l}\text { I am able to think up } \\
\text { creative and effective } \\
\text { alternatives to solve a } \\
\text { problem when working in } \\
\text { groups. }\end{array}$} & $\begin{array}{l}\text { I am able to develop } \\
\text { creative alternatives to } \\
\text { solve a problem when } \\
\text { working with others. }\end{array}$ & $\begin{array}{l}\text { I believe that I am able to } \\
\text { develop creative or unique } \\
\text { alternatives to solve a } \\
\text { problem when working } \\
\text { with a team. }\end{array}$ & $\begin{array}{l}\text { I believe that I am able } \\
\text { to develop new } \\
\text { alternatives to solve a } \\
\text { problem when working } \\
\text { with a team. }\end{array}$ \\
\hline & & $\begin{array}{l}\text { I am able to develop } \\
\text { effective alternatives } \\
\text { to solve a problem } \\
\text { when working with } \\
\text { others. }\end{array}$ & $\begin{array}{l}\text { I believe that I am able to } \\
\text { develop successful } \\
\text { alternatives to solve a } \\
\text { problem when working } \\
\text { with a team. }\end{array}$ & $\begin{array}{l}\text { I believe that I am able } \\
\text { to develop successful } \\
\text { alternatives to solve a } \\
\text { problem when working } \\
\text { with a team. }\end{array}$ \\
\hline $\begin{array}{l}\text { I have the ability to solve } \\
\text { most problems even } \\
\text { though initially no } \\
\text { solution is immediately } \\
\text { apparent. }\end{array}$ & $\begin{array}{l}\text { I have the ability to solve } \\
\text { most problems with others } \\
\text { even though initially no } \\
\text { solution is immediately } \\
\text { apparent. }\end{array}$ & $\begin{array}{l}\text { I have the ability to } \\
\text { solve most problems in } \\
\text { a group setting, even } \\
\text { though initially no } \\
\text { solution is } \\
\text { immediately apparent. }\end{array}$ & $\begin{array}{l}\text { I have the ability to solve } \\
\text { most problems in a team, } \\
\text { even though initially no } \\
\text { solution is apparent. }\end{array}$ & $\begin{array}{l}\text { I have the ability to } \\
\text { solve most problems in } \\
\text { a team, even though } \\
\text { initially no solution is } \\
\text { apparent. }\end{array}$ \\
\hline $\begin{array}{l}\text { Many problems I face are } \\
\text { too complex for me to } \\
\text { solve. }\end{array}$ & $\begin{array}{l}\text { Many problems I face are } \\
\text { too complex for me to } \\
\text { solve by myself. }\end{array}$ & MOVED TO PC & MOVED TO PC & MOVED TO PC \\
\hline $\begin{array}{l}\text { I make decisions and am } \\
\text { happy with them later. }\end{array}$ & $\begin{array}{l}\text { I make decisions with } \\
\text { others and am happy with } \\
\text { them later. }\end{array}$ & $\begin{array}{l}\text { When making } \\
\text { decisions as part of a } \\
\text { group, I trust the } \\
\text { outcome. }\end{array}$ & $\begin{array}{l}\text { When making decisions as } \\
\text { part of a team, I trust the } \\
\text { outcome. }\end{array}$ & $\begin{array}{l}\text { I trust the outcome } \\
\text { when making decisions } \\
\text { as part of a team. }\end{array}$ \\
\hline
\end{tabular}




\begin{tabular}{|c|c|c|c|c|}
\hline $\begin{array}{l}\text { When I make plans to } \\
\text { solve a problem, I am } \\
\text { almost certain that I can } \\
\text { make them work. }\end{array}$ & $\begin{array}{l}\text { When I make plans to } \\
\text { solve a problem with } \\
\text { others, I am almost certain } \\
\text { that we can make them } \\
\text { work. }\end{array}$ & $\begin{array}{l}\text { When I make plans to } \\
\text { solve a problem in a } \\
\text { group setting, I am } \\
\text { almost certain that } \\
\text { together we can find } \\
\text { solutions. }\end{array}$ & $\begin{array}{l}\text { When I make plans to solve } \\
\text { a problem within a team, I } \\
\text { am almost certain that } \\
\text { together we can find } \\
\text { solutions. }\end{array}$ & $\begin{array}{l}\text { When I make plans to } \\
\text { solve a problem within } \\
\text { a team, I am certain that } \\
\text { we can find solutions } \\
\text { together. }\end{array}$ \\
\hline $\begin{array}{l}\text { Given enough time and } \\
\text { effort, I believe I can } \\
\text { solve most problems that } \\
\text { confront me. }\end{array}$ & $\begin{array}{l}\text { Given enough time and } \\
\text { effort, I believe I can solve } \\
\text { most problems that } \\
\text { confront me when working } \\
\text { with others. }\end{array}$ & $\begin{array}{l}\text { Given enough time } \\
\text { and effort, I believe I } \\
\text { can solve most } \\
\text { problems I am } \\
\text { confronted with when } \\
\text { collaborating with } \\
\text { others. }\end{array}$ & $\begin{array}{l}\text { Given enough time and } \\
\text { effort, I believe I can solve } \\
\text { most problems I am } \\
\text { confronted with when } \\
\text { working within a team. }\end{array}$ & $\begin{array}{l}\text { Given enough time and } \\
\text { effort, I believe I can } \\
\text { solve most problems } \\
\text { when working within a } \\
\text { team. }\end{array}$ \\
\hline $\begin{array}{l}\text { When faced with a novel } \\
\text { situation I have } \\
\text { confidence that I can } \\
\text { handle problems that } \\
\text { may arise. }\end{array}$ & $\begin{array}{l}\text { When faced with a novel } \\
\text { situation I have confidence } \\
\text { that I can handle problems } \\
\text { that may arise when } \\
\text { working with others. }\end{array}$ & $\begin{array}{l}\text { When faced with a } \\
\text { new situation, I have } \\
\text { confidence that I can } \\
\text { handle problems that } \\
\text { may arise when } \\
\text { working with teams. }\end{array}$ & $\begin{array}{l}\text { When faced with a new } \\
\text { problem, I have confidence } \\
\text { that I can solve it when } \\
\text { working within a team. }\end{array}$ & $\begin{array}{l}\text { When faced with a new } \\
\text { problem, I have } \\
\text { confidence that I can } \\
\text { solve it when working } \\
\text { within a team. }\end{array}$ \\
\hline $\begin{array}{l}\text { I trust my ability to solve } \\
\text { new and difficult } \\
\text { problems. }\end{array}$ & $\begin{array}{l}\text { I trust my ability to solve } \\
\text { new and difficult problems } \\
\text { when working with others. }\end{array}$ & $\begin{array}{l}\text { I trust my ability to } \\
\text { solve new and difficult } \\
\text { problems when } \\
\text { working with others. }\end{array}$ & $\begin{array}{l}\text { I trust my ability to solve } \\
\text { difficult problems when } \\
\text { working within a team. }\end{array}$ & $\begin{array}{l}\text { I trust my ability to } \\
\text { solve difficult problems } \\
\text { when working within a } \\
\text { team. }\end{array}$ \\
\hline $\begin{array}{l}\text { When confronted with a } \\
\text { problem, I am unsure of } \\
\text { whether I can handle the } \\
\text { situation. }\end{array}$ & $\begin{array}{l}\text { When confronted with a } \\
\text { problem, I am unsure of } \\
\text { whether I can handle the } \\
\text { situation by myself. }\end{array}$ & MOVED TO PC & MOVED TO PC & MOVED TO PC \\
\hline $\begin{array}{l}\text { When I become aware of } \\
\text { a problem, one of the } \\
\text { first things I do is try to }\end{array}$ & $\begin{array}{l}\text { When I become aware of a } \\
\text { problem, one of the first } \\
\text { things I do is try to find } \\
\text { out exactly what the }\end{array}$ & $\begin{array}{l}\text { When I become aware } \\
\text { of a problem, one of } \\
\text { the first things I do is } \\
\text { try to find out exactly }\end{array}$ & $\begin{array}{l}\text { When I become aware of a } \\
\text { problem, one of the first } \\
\text { things I do is try to find out } \\
\text { exactly what the problem is }\end{array}$ & $\begin{array}{l}\text { When I become aware } \\
\text { of a problem I first } \\
\text { communicate with a }\end{array}$ \\
\hline
\end{tabular}




\begin{tabular}{|c|c|c|c|c|}
\hline $\begin{array}{l}\text { find out exactly what the } \\
\text { problem is. }\end{array}$ & $\begin{array}{l}\text { problem is by } \\
\text { communicating with } \\
\text { others. }\end{array}$ & $\begin{array}{l}\text { what the problem is by } \\
\text { communicating with } \\
\text { my team. }\end{array}$ & $\begin{array}{l}\text { by communicating with a } \\
\text { team. }\end{array}$ & $\begin{array}{l}\text { team to find out the } \\
\text { problem. }\end{array}$ \\
\hline $\begin{array}{l}\text { After making a decision, } \\
\text { the outcome I expected } \\
\text { usually matches the } \\
\text { actual outcome. }\end{array}$ & $\begin{array}{l}\text { After making a decision } \\
\text { with a group, the outcome } \\
\text { I expected usually matches } \\
\text { the actual outcome. }\end{array}$ & $\begin{array}{l}\text { After making a } \\
\text { decision with a group, } \\
\text { the actual outcomes } \\
\text { usually match what I } \\
\text { expected. }\end{array}$ & $\begin{array}{l}\text { After making a decision } \\
\text { with a team, the actual } \\
\text { outcomes align with my } \\
\text { expectations. }\end{array}$ & $\begin{array}{l}\text { After making a decision } \\
\text { with a team, the actual } \\
\text { outcomes align with my } \\
\text { expectations. }\end{array}$ \\
\hline
\end{tabular}

\section{Approach Avoidance Style}

\begin{tabular}{|c|c|c|c|c|}
\hline Original PSI & $\begin{array}{c}\text { Adapted PSI } \\
\text { (Given to experts) }\end{array}$ & Experts Feedback & $\begin{array}{l}\text { Focus Group Cognitive } \\
\text { Interview Feedback }\end{array}$ & Final \\
\hline $\begin{array}{l}\text { When a solution to a } \\
\text { problem was } \\
\text { unsuccessful, I do not } \\
\text { examine why it didn't } \\
\text { work. }\end{array}$ & $\begin{array}{l}\text { When a solution to a } \\
\text { problem was unsuccessful, } \\
\text { I do not work with others } \\
\text { to examine why it didn't } \\
\text { work. }\end{array}$ & $\begin{array}{l}\text { When a solution to a } \\
\text { problem is } \\
\text { unsuccessful, I do not } \\
\text { communicate with } \\
\text { others to examine why } \\
\text { it did not work. }\end{array}$ & $\begin{array}{l}\text { When a solution to a } \\
\text { problem is unsuccessful, I } \\
\text { do not communicate with } \\
\text { others to examine why it } \\
\text { did not work. }\end{array}$ & DELETED \\
\hline $\begin{array}{l}\text { When I am confronted } \\
\text { with a complex problem, } \\
\text { I do not bother to develop } \\
\text { a strategy to collect } \\
\text { information so I can } \\
\text { define exactly what the } \\
\text { problem is. }\end{array}$ & $\begin{array}{l}\text { When I am confronted } \\
\text { with a complex problem, I } \\
\text { do not work with others to } \\
\text { develop a strategy to } \\
\text { collect information so I } \\
\text { can define exactly what } \\
\text { the problem is. }\end{array}$ & $\begin{array}{l}\text { When I am confronted } \\
\text { with a complex } \\
\text { problem, I do not } \\
\text { collaborate with others } \\
\text { to develop a strategy to } \\
\text { collect information, to } \\
\text { clearly define what the } \\
\text { problem is. }\end{array}$ & $\begin{array}{l}\text { When I am confronted } \\
\text { with a complex problem, I } \\
\text { do not collaborate with a } \\
\text { team to clearly define the } \\
\text { problem. }\end{array}$ & DELETED \\
\hline $\begin{array}{l}\text { After I have solved a } \\
\text { problem, I do not analyze }\end{array}$ & $\begin{array}{l}\text { After I have solved a } \\
\text { problem, I do not work } \\
\text { with others to analyze }\end{array}$ & $\begin{array}{l}\text { After I have solved a } \\
\text { problem with others, I } \\
\text { do not analyze with }\end{array}$ & $\begin{array}{l}\text { After I have solved a } \\
\text { problem within a team, I }\end{array}$ & DELETED \\
\hline
\end{tabular}




\begin{tabular}{|c|c|c|c|c|}
\hline $\begin{array}{l}\text { what went right or what } \\
\text { went wrong. }\end{array}$ & $\begin{array}{l}\text { what went right or what } \\
\text { went wrong. }\end{array}$ & $\begin{array}{l}\text { them what went right or } \\
\text { what went wrong. }\end{array}$ & $\begin{array}{l}\text { do not analyze with them } \\
\text { what went wrong. }\end{array}$ & \\
\hline $\begin{array}{l}\text { After I have tried to solve } \\
\text { a problem with a certain } \\
\text { course of action, I take } \\
\text { time and compare the } \\
\text { actual outcome to what I } \\
\text { thought should have } \\
\text { happened. }\end{array}$ & $\begin{array}{l}\text { After I have tried to solve } \\
\text { a problem with a certain } \\
\text { course of action, I take } \\
\text { time and compare the } \\
\text { actual outcome to what I } \\
\text { thought should have } \\
\text { happened with others. }\end{array}$ & $\begin{array}{l}\text { After my group and I } \\
\text { have found solutions to } \\
\text { a problem, we take the } \\
\text { time to compare each } \\
\text { alternative. }\end{array}$ & $\begin{array}{l}\text { After my team and I have } \\
\text { collectively found } \\
\text { alternative solutions to a } \\
\text { problem, we take the time } \\
\text { to compare each solution. }\end{array}$ & $\begin{array}{l}\text { After my team and I } \\
\text { collectively find } \\
\text { alternative solutions to } \\
\text { a problem, we compare } \\
\text { each solution. }\end{array}$ \\
\hline $\begin{array}{l}\text { When I have a problem, I } \\
\text { think up as many possible } \\
\text { ways to handle it as I can } \\
\text { until can't come up with } \\
\text { any more ideas. }\end{array}$ & $\begin{array}{l}\text { When I have a problem, I } \\
\text { work with others to think } \\
\text { up as many possible ways } \\
\text { to handle it as I can until I } \\
\text { can't come up with any } \\
\text { more ideas. }\end{array}$ & $\begin{array}{l}\text { When I have a problem, } \\
\text { I work with others to } \\
\text { create many ways to } \\
\text { resolve it until I have } \\
\text { exhausted all } \\
\text { alternative ideas. }\end{array}$ & $\begin{array}{l}\text { When I have a problem, I } \\
\text { work with a team to create } \\
\text { many possible solutions } \\
\text { until we have exhausted } \\
\text { all ideas. }\end{array}$ & $\begin{array}{l}\text { When I have a problem, } \\
\text { I work with a team to } \\
\text { create many possible } \\
\text { solutions until we have } \\
\text { exhausted all the ideas. }\end{array}$ \\
\hline $\begin{array}{l}\text { When confronted with a } \\
\text { problem, I consistently } \\
\text { examine my feelings to } \\
\text { find out what is going on } \\
\text { in a problem situation. }\end{array}$ & $\begin{array}{l}\text { When confronted with a } \\
\text { problem, I consistently } \\
\text { examine my feelings to } \\
\text { find out what is going on } \\
\text { in a problem situation. }\end{array}$ & $\begin{array}{l}\text { When my team and I } \\
\text { are confronted with a } \\
\text { problem, I consistently } \\
\text { examine how I feel } \\
\text { about the problem. }\end{array}$ & $\begin{array}{l}\text { When my team and I are } \\
\text { confronted with a } \\
\text { problem, we examine how } \\
\text { we feel about that } \\
\text { problem. }\end{array}$ & $\begin{array}{l}\text { When my team and I } \\
\text { have a problem, we } \\
\text { examine how we feel } \\
\text { about that problem. }\end{array}$ \\
\hline $\begin{array}{l}\text { When confronted with a } \\
\text { problem, I tend to do the } \\
\text { first thing that I can think } \\
\text { of to solve it. }\end{array}$ & $\begin{array}{l}\text { When confronted with a } \\
\text { problem, I tend to work } \\
\text { with others do the first } \\
\text { thing that I can think of to } \\
\text { solve it. }\end{array}$ & $\begin{array}{l}\text { When confronted with } \\
\text { a problem, I tend to } \\
\text { work with others to } \\
\text { solve it, before } \\
\text { considering the first } \\
\text { solution that comes to } \\
\text { mind. }\end{array}$ & $\begin{array}{l}\text { When confronted with a } \\
\text { problem, I tend to work } \\
\text { with a team to solve it } \\
\text { before considering the first } \\
\text { solution that comes to } \\
\text { mind. }\end{array}$ & $\begin{array}{l}\text { When confronted with } \\
\text { a problem, I work with } \\
\text { a team to solve it before } \\
\text { considering the first } \\
\text { solution that comes to } \\
\text { mind. }\end{array}$ \\
\hline $\begin{array}{l}\text { When deciding on an idea } \\
\text { or possible solution to a } \\
\text { problem, I do not take } \\
\text { time to consider the }\end{array}$ & $\begin{array}{l}\text { When deciding on an idea } \\
\text { or possible solution to a } \\
\text { problem with others, I do } \\
\text { not take time to consider }\end{array}$ & $\begin{array}{l}\text { When I decide on an } \\
\text { idea or a possible } \\
\text { solution to a problem } \\
\text { with a team, I do not }\end{array}$ & $\begin{array}{l}\text { When I decide on a } \\
\text { possible solution to a } \\
\text { problem with a team, I do } \\
\text { not take time to consider }\end{array}$ & TED \\
\hline
\end{tabular}




\begin{tabular}{|c|c|c|c|c|}
\hline $\begin{array}{l}\text { chances of each } \\
\text { alternative being } \\
\text { successful. }\end{array}$ & $\begin{array}{l}\text { the chances of each } \\
\text { alternative being } \\
\text { successful. }\end{array}$ & $\begin{array}{l}\text { take time to consider } \\
\text { the possibility of each } \\
\text { alternative being } \\
\text { successful. }\end{array}$ & $\begin{array}{l}\text { the possibility of } \\
\text { alternative solutions. }\end{array}$ & \\
\hline $\begin{array}{l}\text { When confronted with a } \\
\text { problem, I stop and think } \\
\text { about it before deciding } \\
\text { on the next step. }\end{array}$ & $\begin{array}{l}\text { When confronted with a } \\
\text { problem, I work with } \\
\text { others to stop and think } \\
\text { about it before deciding on } \\
\text { the next step. }\end{array}$ & $\begin{array}{l}\text { When confronted with } \\
\text { a problem, I work with } \\
\text { others to analyze it, } \\
\text { before deciding on the } \\
\text { next step. }\end{array}$ & $\begin{array}{l}\text { When confronted with a } \\
\text { problem, I work with a } \\
\text { team to analyze it, before } \\
\text { deciding on the next step. }\end{array}$ & $\begin{array}{l}\text { When confronted with } \\
\text { a problem, I work with } \\
\text { a team to analyze it } \\
\text { before deciding on the } \\
\text { next step. }\end{array}$ \\
\hline $\begin{array}{l}\text { I generally go to the first } \\
\text { good idea that comes to } \\
\text { my mind. }\end{array}$ & $\begin{array}{l}\text { I generally go to the first } \\
\text { good idea that comes to } \\
\text { my mind. }\end{array}$ & $\begin{array}{l}\text { When working with a } \\
\text { team on solving a } \\
\text { problem, I generally go } \\
\text { to the first good idea } \\
\text { that comes to my mind. }\end{array}$ & $\begin{array}{l}\text { When working with a } \\
\text { team on solving a } \\
\text { problem, we use the first } \\
\text { good idea that comes to } \\
\text { our mind. }\end{array}$ & DELETED \\
\hline $\begin{array}{l}\text { When making a decision, } \\
\text { I weigh the consequences } \\
\text { of each alternative and } \\
\text { compare them against } \\
\text { each other. }\end{array}$ & $\begin{array}{l}\text { When making a decision, I } \\
\text { work with others to weigh } \\
\text { the consequences of each } \\
\text { alternative and compare } \\
\text { them against each other. }\end{array}$ & $\begin{array}{l}\text { When making a } \\
\text { decision, I work with } \\
\text { others to weigh the } \\
\text { consequences of each } \\
\text { alternative and we } \\
\text { compare them against } \\
\text { each other. }\end{array}$ & $\begin{array}{l}\text { When making a decision, I } \\
\text { work with a team to weigh } \\
\text { the consequences of each } \\
\text { alternative and compare } \\
\text { them against each other. }\end{array}$ & $\begin{array}{l}\text { When making a } \\
\text { decision, I work with a } \\
\text { team to weigh the } \\
\text { consequences of each } \\
\text { alternative and compare } \\
\text { them against each } \\
\text { other. }\end{array}$ \\
\hline $\begin{array}{l}\text { I try to predict the overall } \\
\text { result of carrying out a } \\
\text { particular course of } \\
\text { action. }\end{array}$ & $\begin{array}{l}\text { I try to work with others to } \\
\text { predict the overall result of } \\
\text { carrying out a particular } \\
\text { course of action. }\end{array}$ & $\begin{array}{l}\text { I try to work with } \\
\text { others to predict the } \\
\text { overall result of } \\
\text { carrying out a particular } \\
\text { course of action. }\end{array}$ & $\begin{array}{l}\text { I try to work with a team } \\
\text { to predict the overall result } \\
\text { of carrying out a particular } \\
\text { course of action. }\end{array}$ & $\begin{array}{l}\text { I work with a team to } \\
\text { predict the overall } \\
\text { result of implementing } \\
\text { a particular action. }\end{array}$ \\
\hline $\begin{array}{l}\text { When I try to think up } \\
\text { possible solutions to a } \\
\text { problem, I do not come } \\
\text { up with very many } \\
\text { alternatives. }\end{array}$ & $\begin{array}{l}\text { When trying to think up } \\
\text { possible solutions to a } \\
\text { problem, I do not come up } \\
\text { with very many } \\
\text { alternatives when working } \\
\text { with others, }\end{array}$ & $\begin{array}{l}\text { When trying to think up } \\
\text { possible solutions to a } \\
\text { problem, I do not come } \\
\text { up with very many } \\
\text { alternatives in a group } \\
\text { setting. }\end{array}$ & $\begin{array}{l}\text { When trying to think up } \\
\text { possible solutions to a } \\
\text { problem, I do not come up } \\
\text { with alternatives when } \\
\text { working with a team. }\end{array}$ & $\begin{array}{l}\text { When thinking about } \\
\text { possible solutions to a } \\
\text { problem, I do not come } \\
\text { up with alternatives } \\
\text { when working with a } \\
\text { team. }\end{array}$ \\
\hline
\end{tabular}




\begin{tabular}{|c|c|c|c|c|}
\hline $\begin{array}{l}\text { I have a systematic } \\
\text { method for comparing } \\
\text { alternatives and making } \\
\text { decisions. }\end{array}$ & $\begin{array}{l}\text { I have a systematic } \\
\text { method for comparing } \\
\text { alternatives and making } \\
\text { decisions. }\end{array}$ & $\begin{array}{l}\text { When working with } \\
\text { others, I have a } \\
\text { systematic method for } \\
\text { comparing alternatives } \\
\text { and making decisions. }\end{array}$ & $\begin{array}{l}\text { When working with a } \\
\text { team, I have a systematic } \\
\text { method for comparing } \\
\text { alternatives and making } \\
\text { decisions. }\end{array}$ & $\begin{array}{l}\text { When working with a } \\
\text { team, I have a } \\
\text { systematic method for } \\
\text { comparing alternatives } \\
\text { and making decisions. }\end{array}$ \\
\hline $\begin{array}{l}\text { When confronted with a } \\
\text { problem, I do not usually } \\
\text { examine what sort of } \\
\text { external things my } \\
\text { environment may be } \\
\text { contributing to my } \\
\text { problem. }\end{array}$ & $\begin{array}{l}\text { When working with others } \\
\text { and confronted with a } \\
\text { problem, I do not usually } \\
\text { examine what sort of } \\
\text { external things my } \\
\text { environment may be } \\
\text { contributing to my } \\
\text { problem. }\end{array}$ & $\begin{array}{l}\text { When working with a } \\
\text { team/group and } \\
\text { confronted with a } \\
\text { problem, I do not } \\
\text { usually examine what } \\
\text { sort of external things } \\
\text { in my environment may } \\
\text { be contributing to the } \\
\text { problem. }\end{array}$ & $\begin{array}{l}\text { When working with a } \\
\text { team that is confronted } \\
\text { with a problem, I do not } \\
\text { examine external factors in } \\
\text { the environment that may } \\
\text { contribute to the problem. }\end{array}$ & DELETED \\
\hline \multirow[t]{2}{*}{$\begin{array}{l}\text { When I am confused by a } \\
\text { problem, one of the first } \\
\text { things I do is survey the } \\
\text { situation and consider all } \\
\text { the relevant pieces of } \\
\text { information. }\end{array}$} & $\begin{array}{l}\text { When I am confused by a } \\
\text { problem, one of the first } \\
\text { things I do is work with } \\
\text { others to survey the } \\
\text { situation and consider all } \\
\text { the relevant pieces of } \\
\text { information. }\end{array}$ & $\begin{array}{l}\text { When I am confused by } \\
\text { a problem, one of the } \\
\text { first things I do is work } \\
\text { with others to survey } \\
\text { the situation and } \\
\text { consider all the relevant } \\
\text { pieces of information. }\end{array}$ & $\begin{array}{l}\text { When I am confused by a } \\
\text { problem, one of the first } \\
\text { things I do is work with a } \\
\text { team to survey the } \\
\text { situation and consider all } \\
\text { the relevant pieces of } \\
\text { information. }\end{array}$ & $\begin{array}{l}\text { When I am confused by } \\
\text { a problem, I first work } \\
\text { with a team to } \\
\text { understand the situation } \\
\text { and consider all the } \\
\text { relevant information. }\end{array}$ \\
\hline & & & $\begin{array}{l}\text { When I am confronted } \\
\text { with a complex problem, I } \\
\text { do not collaborate with a } \\
\text { team to develop a strategy } \\
\text { to collect information. }\end{array}$ & DELETED \\
\hline
\end{tabular}




\section{Personal Control}

\begin{tabular}{|c|c|c|c|c|}
\hline Original PSI & $\begin{array}{c}\text { Adapted PSI } \\
\text { (no Changes with } \\
\text { Personal Control } \\
\text { Construct) given to } \\
\text { experts } \\
\end{array}$ & Experts Feedback & $\begin{array}{l}\text { Focus Group Cognitive } \\
\text { Interview Feedback }\end{array}$ & Final \\
\hline $\begin{array}{l}\text { When my first efforts to } \\
\text { solve a problem fail, I } \\
\text { become uneasy about my } \\
\text { ability to handle the } \\
\text { situation. }\end{array}$ & $\begin{array}{l}\text { When my first efforts to } \\
\text { solve a problem fail, I } \\
\text { become uneasy about my } \\
\text { ability to handle the } \\
\text { situation. }\end{array}$ & $\begin{array}{l}\text { When my first efforts } \\
\text { to solve a problem fail, } \\
\text { I become uneasy about } \\
\text { my ability to handle the } \\
\text { situation. }\end{array}$ & $\begin{array}{l}\text { When my first efforts to } \\
\text { solve a problem fail, I } \\
\text { pause and reassess the } \\
\text { situation again. }\end{array}$ & $\begin{array}{l}\text { When my first efforts } \\
\text { to solve a problem fail, } \\
\text { I pause and reassess the } \\
\text { situation. }\end{array}$ \\
\hline $\begin{array}{l}\text { Sometimes I do not stop } \\
\text { and take time to deal with } \\
\text { my problems, but just } \\
\text { kind of muddle ahead. }\end{array}$ & $\begin{array}{l}\text { Sometimes I do not stop } \\
\text { and take time to deal with } \\
\text { my problems, but just kind } \\
\text { of muddle ahead. }\end{array}$ & $\begin{array}{l}\text { Sometimes I do not } \\
\text { stop and take time to } \\
\text { deal with my problems. }\end{array}$ & $\begin{array}{l}\text { I stop and take time to deal } \\
\text { with professional } \\
\text { problems within the } \\
\text { organization. }\end{array}$ & $\begin{array}{l}\text { I stop and take time to } \\
\text { deal with professional } \\
\text { problems within the } \\
\text { organization. }\end{array}$ \\
\hline $\begin{array}{l}\text { Even though I work on a } \\
\text { problem, sometimes I feel } \\
\text { like I am groping or } \\
\text { wandering, and am not } \\
\text { getting down to the real } \\
\text { issue. }\end{array}$ & $\begin{array}{l}\text { Even though I work on a } \\
\text { problem, sometimes I feel } \\
\text { like I am groping or } \\
\text { wandering, and am not } \\
\text { getting down to the real } \\
\text { issue. }\end{array}$ & $\begin{array}{l}\text { Even though I work on } \\
\text { a problem, sometimes I } \\
\text { feel like I am not } \\
\text { getting to the real issue. }\end{array}$ & $\begin{array}{l}\text { When I work on a } \\
\text { professional problem in } \\
\text { the organization, I feel like } \\
\text { I am getting to the root of } \\
\text { the problem. }\end{array}$ & $\begin{array}{l}\text { When I work on a } \\
\text { professional problem in } \\
\text { the organization, I am } \\
\text { getting to the root of } \\
\text { the problem. }\end{array}$ \\
\hline $\begin{array}{l}\text { I make snap judgments } \\
\text { and later regret them. }\end{array}$ & $\begin{array}{l}\text { I make snap judgments } \\
\text { and later regret them. }\end{array}$ & $\begin{array}{l}\text { I make snap judgments } \\
\text { and later regret them. }\end{array}$ & $\begin{array}{l}\text { I make snap judgments } \\
\text { about professional } \\
\text { problems and later regret } \\
\text { them. }\end{array}$ & DELETED \\
\hline $\begin{array}{l}\text { Sometimes I get so } \\
\text { charged up emotionally } \\
\text { that I am unable to } \\
\text { consider many ways of }\end{array}$ & $\begin{array}{l}\text { Sometimes I get so } \\
\text { charged up emotionally } \\
\text { that I am unable to } \\
\text { consider many ways of } \\
\text { dealing with my problems. }\end{array}$ & $\begin{array}{l}\text { Sometimes I get so } \\
\text { charged up emotionally } \\
\text { that I am unable to } \\
\text { consider ways of }\end{array}$ & $\begin{array}{l}\text { I get emotional when } \\
\text { faced with professional } \\
\text { problems within the } \\
\text { organization. }\end{array}$ & DELETED \\
\hline
\end{tabular}




\begin{tabular}{|l|l|l|l|l|}
\hline $\begin{array}{l}\text { dealing with my } \\
\text { problems. }\end{array}$ & $\begin{array}{l}\text { dealing with my } \\
\text { problems. }\end{array}$ & $\begin{array}{l}\text { When confronted with } \\
\text { a problem, I am unsure } \\
\text { of whether I can handle } \\
\text { the situation } \\
\text { independently. }\end{array}$ & $\begin{array}{l}\text { When confronted with a } \\
\text { professional problem } \\
\text { within the organization, I } \\
\text { am confident that I can } \\
\text { handle the situation } \\
\text { independently. }\end{array}$ & $\begin{array}{l}\text { When confronted with } \\
\text { a professional problem } \\
\text { within the organization, } \\
\text { I am confident that I } \\
\text { can handle the situation } \\
\text { independently. }\end{array}$ \\
\hline & $\begin{array}{l}\text { Many problems I face } \\
\text { are too complex for me } \\
\text { to solve by myself. }\end{array}$ & $\begin{array}{l}\text { I am able to consider ways } \\
\text { of dealing with my } \\
\text { professional problems } \\
\text { within the organization. }\end{array}$ & $\begin{array}{l}\text { I am able to think ok } \\
\text { different ways of } \\
\text { dealing with my } \\
\text { professional problems } \\
\text { within the organization. }\end{array}$ \\
\hline
\end{tabular}


VITA

\section{SALMA A. HADEED}

$2004-2006$

Bachelor of Science

Hospitality Management

Florida International University

Miami, Florida

$2007-2009$

Master of Science

Hospitality Management

Florida International University

Miami, Florida

$2009-2012$

Purchasing Coordinator

Hilton Trinidad \& Conference Centre

Trinidad \& Tobago

2013- 2015

Graduate Certificate

Conflict Resolution \& Consensus Building

Florida International University

Miami, Florida

2013- 2015

Master of Science

Adult Education \& Human Resource Development

Florida International University

Miami, Florida

$2014-2016$

Graduate Assistant

PantherLIFE

Miami, Florida

$2016-2018$

Operations Assistant

Comparative \& International Education Society

Miami, Florida

$2017-2018$

Doctoral Candidate

Florida International University

Miami, Florida

PUBLICATIONS \& PRESENTATIONS

Henry-Campbell, S. \& Hadeed, S. A. (2016). Managing a diverse workforce in Encyclopedia for Strategic Leadership and Management (IGI Global). 
Hadeed, S. A. \& Henry-Campbell, S. (2016). An analysis of learning styles- generation X and millennials. Proceedings of International Journal of Self -Directed Symposium. Cocoa Beach, FL.

Henry - Campbell, S. \& Hadeed, S. A. (2015). Protocols of transformation: transforming the profile of Caribbean HRD: building global organizations locally. Proceedings of The Human Resource Development Unit 20 ${ }^{\text {th }}$ Anniversary Conference. Kingston, Jamaica.

Hadeed. S. A. \& Henry- Campbell, S. (2015). Transformative learning theory and its relevance to managing group dynamics in a competitive work environment. Proceedings of the Fourteenth Annual South Florida Education and Research Conference. Miami, FL: Barry University.

Giust, A. \& Hadeed, S. A. (2015). Providing Resources to Student Mentors in Postsecondary Programs. Florida Council for Exceptional Children, Orlando, FL.

Hadeed, S. A. \& Giust, A. (2015) Positive Impact of Peer Mentorship in the Project Panther LIFE Program. Proceedings of the Fourteenth Annual South Florida Education and Research Conference Miami, FL.

Hadeed, S. A. (2014). How transformational theory can be used to understand the personal experience of being bullied in the workplace. Proceedings of the Thirteenth Annual South Florida Education and Research Conference. Miami, FL: Florida International University.

Hadeed, S. A. (2009). The Impacts of tourism in Trinidad and Tobago. Unpublished manuscript, Florida International University, Miami, FL. 